University of Louisville ThinkIR: The University of Louisville's Institutional Repository

Electronic Theses and Dissertations

$5-2019$

\title{
Evaluation of the health and exposure histories of a community surrounded by industry and industrial waste : a mixed methods approach.
}

Lindsay Koloff Tompkins

University of Louisville

Follow this and additional works at: https://ir.library.louisville.edu/etd

Part of the Epidemiology Commons

\section{Recommended Citation}

Tompkins, Lindsay Koloff, "Evaluation of the health and exposure histories of a community surrounded by industry and industrial waste : a mixed methods approach." (2019). Electronic Theses and Dissertations. Paper 3192.

https://doi.org/10.18297/etd/3192

This Doctoral Dissertation is brought to you for free and open access by ThinkIR: The University of Louisville's Institutional Repository. It has been accepted for inclusion in Electronic Theses and Dissertations by an authorized administrator of ThinkIR: The University of Louisville's Institutional Repository. This title appears here courtesy of the author, who has retained all other copyrights. For more information, please contact thinkir@louisville.edu. 
EVALUATION OF THE HEALTH AND EXPOSURE HISTORIES OF A COMMUNITY SURROUNDED BY INDUSTRY AND INDUSTRIAL WASTE: A MIXED METHODS APPROACH

By

Lindsay Koloff Tompkins

B.S., University of North Carolina, 2012

M.S., University of Louisville, 2016

\author{
A Dissertation \\ Submitted to the Faculty of the \\ School of Public Health and Information Sciences \\ of the University of Louisville \\ in Partial Fulfillment of the Requirements \\ for the Degree of \\ Doctor of Philosophy in Public Health Sciences \\ Department of Epidemiology and Population Health \\ University of Louisville \\ Louisville, Kentucky
}

May 2019 

EVALUATION OF THE HEALTH AND EXPOSURE HISTORIES OF A COMMUNITY SURROUNDED BY INDUSTRY AND INDUSTRIAL WASTE: A MIXED METHODS APPROACH

\author{
By \\ Lindsay Koloff Tompkins \\ B.S., University of North Carolina, 2012 \\ M.S., University of Louisville, 2016
}

A Dissertation Approved on

March 22, 2019

by the following Dissertation Committee:

Kristina M. Zierold, $\mathrm{PhD}$, MS

Stephanie D. Boone, $\mathrm{PhD}, \mathrm{MPH}$

Richard N. Baumgartner, PhD

Douglas Thoroughman, $\mathrm{PhD}$, MS

Ryan Combs, $\mathrm{PhD}$ 


\section{ACKNOWLEDGMENTS}

I would like to express my deepest gratitude to my mentor, advisor, and committee chair, Dr. Kristina Zierold. Your endless support, guidance, and encouragement throughout my time as a graduate student have had an immense impact on what I have been able to accomplish over the past several years and the researcher that I have become. Your dedication to your students is incredible, and I feel so fortunate to have worked with you. Special thanks to my co-chair, Dr. Stephanie Boone, for your time and reviews of my work, for challenging me to think more critically about my statistical methods, and for sharing your passion for epidemiology, both inside and outside of the classroom. I would also like to thank my dissertation committee members: Drs. Richard Baumgartner, Douglas Thoroughman, and Ryan Combs. Thank you for your guidance throughout this process and for responding to my work with the utmost care and thought. To my colleagues and friends, Chisom Odoh, Jack Pfeiffer, and Clara Sears, I am so appreciative of the time that you volunteered and the support that you provided during this project. Chisom, I cannot thank you enough for the countless hours that you spent interviewing participants, distributing study materials, and holding community meetings with me.

I would like to extend a heartfelt thank you to Drs. Joy Hart and Kandi Walker. Thank you for your endless encouragement and for the countless opportunities that you have given me over the years. I am a better researcher and team player because of the two of you. Thank you to my family, especially my parents, for cheering me on every step of 
the way. A very special thank you to Landon Tompkins. I could not have reached this milestone without your unwavering support, patience, and encouragement. You have been the very best partner throughout this process, and I hope to support you as well as you have supported me as you complete your dissertation.

Finally, I would like to thank the community members for their interest and participation in this project, as well as the funding sources: University of Louisville's Commission on Diversity and Racial Equality and the Graduate Student Council. 


\title{
ABSTRACT \\ EVALUATION OF THE HEALTH AND EXPOSURE HISTORIES OF A COMMUNITY SURROUNDED BY INDUSTRY AND INDUSTRIAL WASTE: A MIXED METHODS APPROACH
}

\author{
Lindsay Koloff Tompkins
}

March 22, 2019

Environmental pollution is not distributed equally across members of society. Low-income individuals are more likely to live near waste sites and other sources of pollution, and, therefore, face greater exposure to environmental health hazards. One such community in Louisville, Kentucky, the Riverside Gardens neighborhood, consists of approximately 300 homes that are surrounded on three sides by industry and industrial waste, including a remediated Environmental Protection Agency Superfund site, a former coal-burning power plant and coal ash storage site, and multiple chemical, rubber, and plastic manufacturing companies. Residents have reported elevated rates of cancer and other chronic diseases and have requested a formal health assessment. This dissertation study is the first documented attempt to collect and evaluate health and exposure histories from Riverside Gardens residents.

This study used a mixed-methods design conducted in two phases. The first phase of the study employed qualitative research methods. Individual interviews were conducted between March and May of 2017 with 15 residents who had resided in the community for at least five years. Inductive thematic analysis was used to assess the 
health and environmental exposure concerns of the community. The interview findings, in addition to the specific health and exposure concerns shared during community meetings, informed the creation of a health and exposure assessment questionnaire that was distributed to community members between July and October of 2018 during the second phase of the study (a cross-sectional epidemiologic study). Participants selfreported medical conditions diagnosed by a physician or other health professional and answered exposure-related questions.

Prevalence estimates of health conditions reported by 83 adult residents were compared to local, state, and national data from representative surveys using prevalence difference tests. Additionally, health history data were categorized and compared among residents with differing levels of an exposure score that was developed using selfreported neighborhood exposures through binary and multinomial logistic regression analyses estimating odds ratios (ORs), adjusted odds ratios (AORs), and $95 \%$ confidence intervals (CIs). Finally, the frequency with which groups of symptoms were experienced was compared between participants who lived closer to and farther from contaminant sources using binary logistic regression analyses.

Prevalence estimates of certain musculoskeletal, respiratory, circulatory, and mental health conditions among Riverside Gardens adults significantly exceeded local, state, and/or national estimates. Comparisons within the community found that those with higher exposure scores were more likely to self-report a diagnosis of a musculoskeletal system or connective tissue disease, before and after adjustment for age (OR: 1.39, 95\% CI: $1.08-1.78$; AOR: $1.32,95 \%$ CI: $1.01-1.72)$. Groups of self-reported symptoms did not significantly differ by participants' home locations. These results, however, are based 
on a small sample of residents and should be interpreted with caution. Additional research is needed to assess the relationship between exposure to environmental contaminants and disease outcomes among Riverside Gardens community members, including children. 


\section{TABLE OF CONTENTS}

PAGE

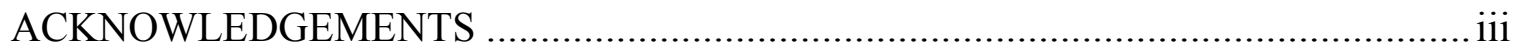

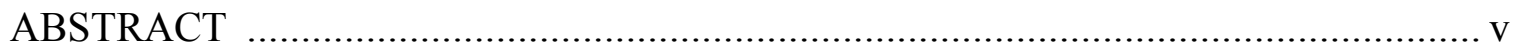

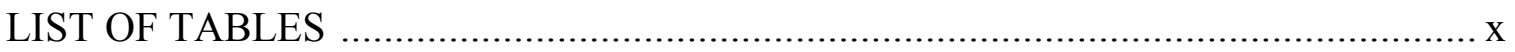

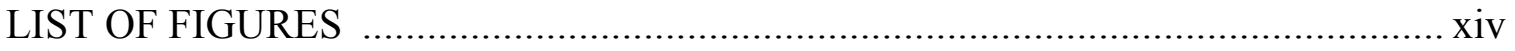

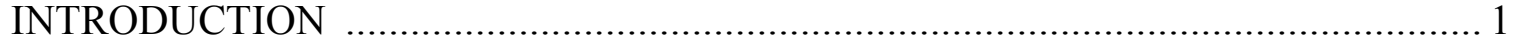

OBJECTIVE, HYPOTHESIS, AND SPECIFIC AIMS .......................................... 3

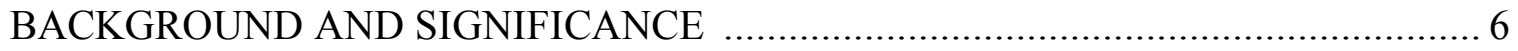

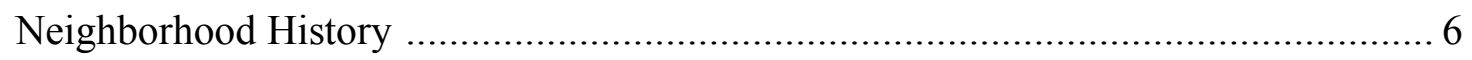

Environmental Concerns of the Community …................................................... 8

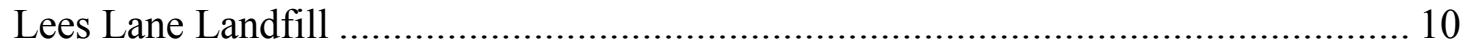

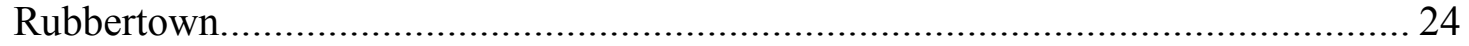

LG\&E's Cane Run Power Plant .......................................................................... 34

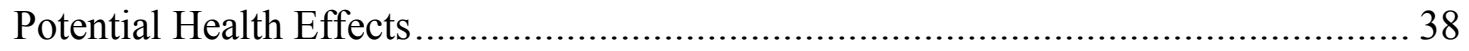

Community Health Investigations .............................................................. 45

Riverside Gardens Cancer Morbidity Review ................................................... 60

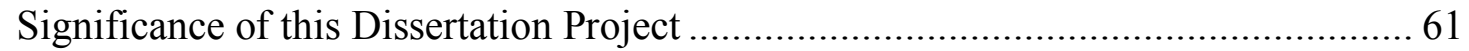

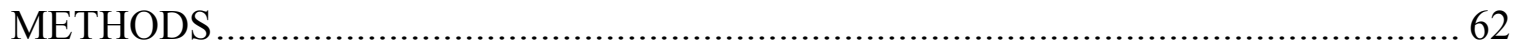

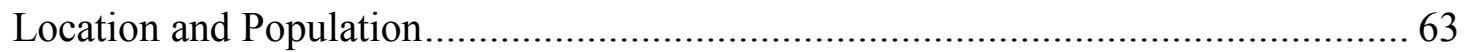

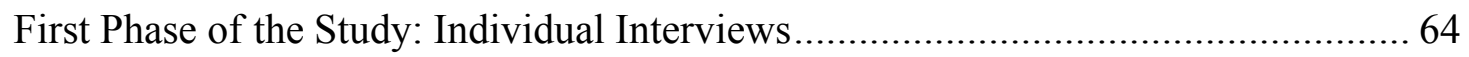

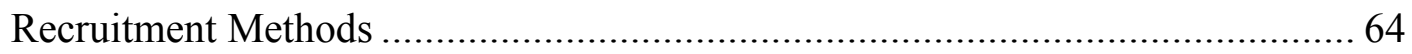

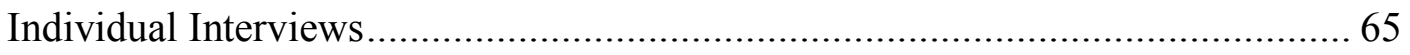

Community Meeting to Discuss Qualitative Findings .................................... 67

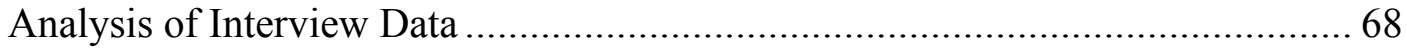


Second Phase of the Study: Health and Exposure Assessment Questionnaire 69

Development of the Health and Exposure Assessment Questionnaire .................. 70

Questionnaire Review and Pretesting............................................................ 78

Recruitment and Dissemination Methods......................................................... 79

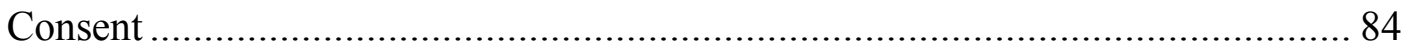

Confidentiality, Privacy, and Use of Contact Information.................................. 85

Questionnaire Collection and Incentives........................................................... 85

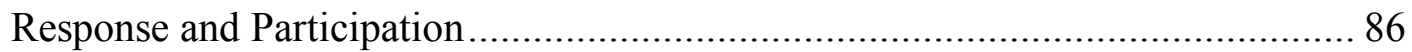

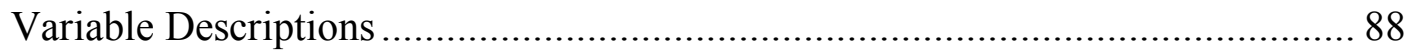

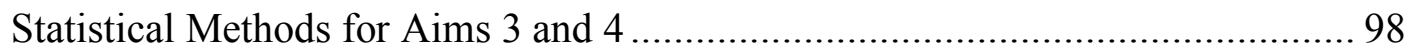

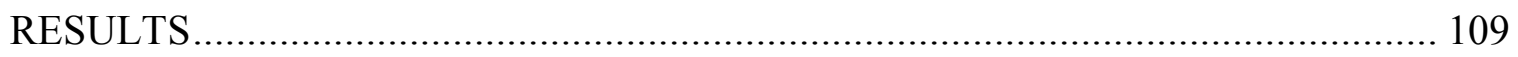

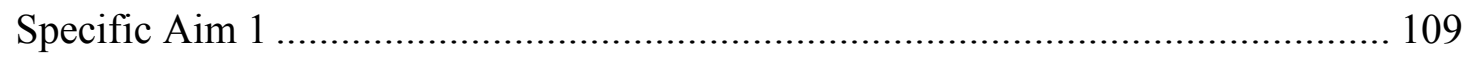

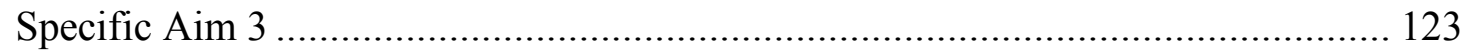

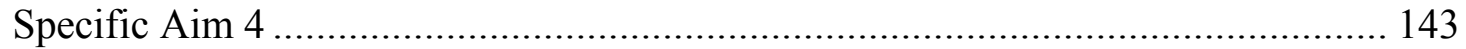

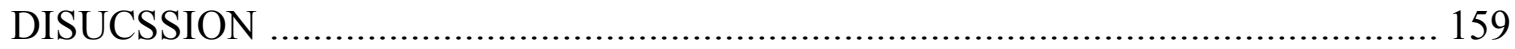

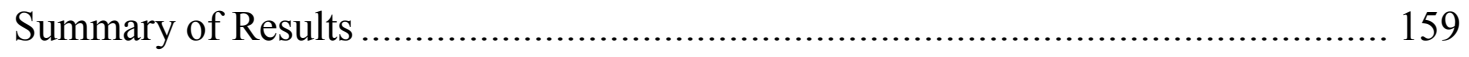

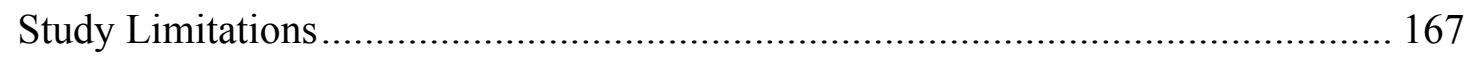

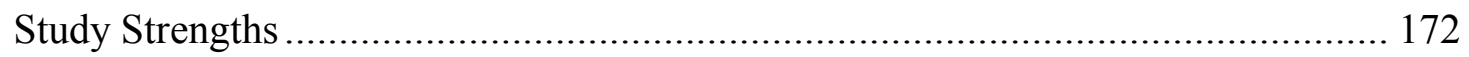

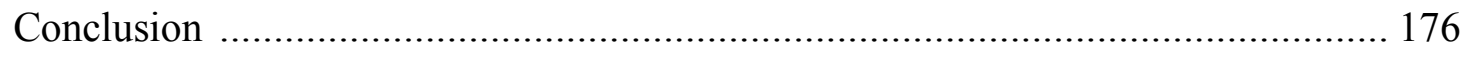

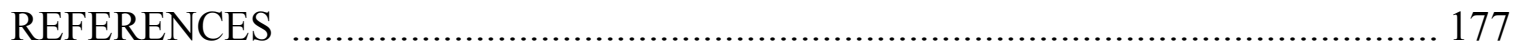

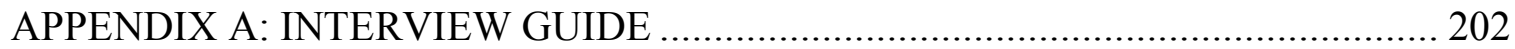

APPENDIX B: HEALTH AND EXPOSURE ASSESSMENT QUESTIONNAIRE ... 207

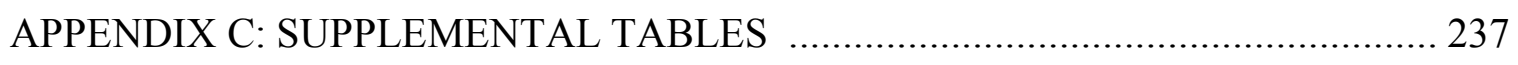

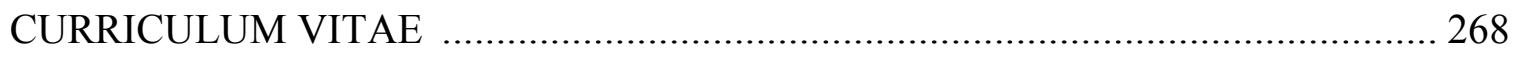




\section{LIST OF TABLES}

TABLE

PAGE

1. Summary of Pollutants Detected During Recent Sampling .............................. 20

2. Chemicals Released On-Site by Hexion Chemical (formerly Momentive and Borden) between 1987 and 2016, Listed Alphabetically .................................. 26

3. Chemicals Released On-Site by Superior Solvents and Chemicals between 1998 and 2016, Listed Alphabetically

4. Chemicals Released On-Site by MPLX Terminals between 1998 and 2016, Listed Alphabetically

5. Chemicals Released On-Site by American Synthetic Rubber Company between 1987 and 2016, Listed Alphabetically

6. Chemicals Released On-Site by Rohm \& Haas between 1987 and 2016, Listed Alphabetically

7. Chemicals Released On-Site by Chemours between 1987 and 2016, Listed Alphabetically

8. Chemicals Released On-Site by LG\&E's Cane Run Plant between 1998 and 2015, Listed Alphabetically 38

9. Participant Demographics by Questionnaire Version

10. Disease Category Prevalence by Questionnaire Version 238

11. Categories of Diagnosed Diseases 103

12. Associations Between Exposure Score Variables 239

13. Symptoms Included in Each Symptom Group 108

14. Participant Demographics 124

15. Crude Prevalence of Disease for Non-Cancer Outcomes 126

16. Crude and Age-Adjusted Prevalence of Circulatory System Diseases in Riverside Gardens, Louisville/Jefferson County, Kentucky, and the United States 
17. Crude and Age-Adjusted Prevalence of Digestive System Diseases in Riverside Gardens and the United States

18. Crude and Age-Adjusted Prevalence of Endocrine, Nutritional, and Metabolic Diseases in Riverside Gardens, Louisville/Jefferson County, Kentucky, and the United States

19. Crude and Age-Adjusted Prevalence of Diseases of the Eye in Riverside Gardens and the United States

20. Crude and Age-Adjusted Prevalence of Diseases of the Genitourinary System in Riverside Gardens, Louisville/Jefferson County, and Kentucky

21. Crude and Age-Adjusted Prevalence of Mental, Behavioral, and Neurodevelopmental Disorders in Riverside Gardens, Louisville/Jefferson County, Kentucky, and the United States

22. Crude and Age-Adjusted Prevalence of Diseases of the Musculoskeletal System and Connective Tissue in Riverside Gardens, Louisville/Jefferson County, Kentucky, and the United States

23. Crude and Age-Adjusted Prevalence of Diseases of the Nervous System in Riverside Gardens and the United States

24. Crude and Age-Adjusted Prevalence of Disease of the Respiratory System in Riverside Gardens, Louisville/Jefferson County, Kentucky, and the United States 136

25. Crude and Age-Adjusted Prevalence of Skin and Subcutaneous Diseases in Riverside Gardens and the United States

26. Significant Differences in Disease Prevalence Estimates between Riverside Gardens and Louisville/Jefferson County, Kentucky, and the United States

27. Crude Prevalence of Reported Cancer Sites

28. Crude and Age-Adjusted Prevalence of Cancer in Riverside Gardens, Louisville/Jefferson County, Kentucky, and the United States

29. Potential Covariates and Exposure Score by Diseases of the Blood and Blood-Forming Organs

30. Potential Covariates and Exposure Score by Cancer Diagnosis 241

31. Potential Covariates and Exposure Score by Circulatory System Disease 144

32. Potential Covariates and Exposure Score by Digestive System Disease 242 
33. Potential Covariates and Exposure Score by Ear and Mastoid Process Disease ... 145

34. Potential Covariates and Exposure Score by Endocrine, Nutritional, and Metabolic Diseases

35. Potential Covariates and Exposure Score by Eye and Adnexa Disease

36. Potential Covariates and Exposure Score by Genitourinary System Disease

37. Potential Covariates and Exposure Score by Mental, Behavioral, and

Neurodevelopmental Disorders

38. Potential Covariates and Exposure Score by Musculoskeletal System and Connective Tissue Diseases

39. Potential Covariates and Exposure Score by Nervous System Diseases 245

40. Potential Covariates and Exposure Score by Respiratory Diseases 246

41. Potential Covariates and Exposure Score by Skin and Subcutaneous Diseases...

42. Exposure Variables and Score by Diseases of the Blood and Blood-Forming Organs

43. Exposure Variables and Score by Cancer Diagnosis 248

44. Exposure Variables and Score by Diseases of the Circulatory System 249

45. Exposure Variables and Score by Diseases of the Digestive System 250

46. Exposure Variables and Score by Diseases of the Ear and Mastoid Process 251

47. Exposure Variables and Score by Endocrine, Nutritional, and Metabolic Diseases 252

48. Exposure Variables and Score by Diseases of the Eye and Adnexa 253

49. Exposure Variables and Score by Diseases of the Genitourinary System 254

50. Exposure Variables and Score by Mental, Behavioral, and Neurodevelopmental Disorders 255

51. Exposure Variables and Score by Diseases of the Musculoskeletal System 256

52. Exposure Variables and Score by Diseases of the Nervous System 257

53. Exposure Variables and Score by Diseases of the Respiratory System 258

54. Exposure Variables and Score by Diseases of the Skin and Subcutaneous

Tissue 259

55. Potential Covariates by Exposure Score

56. Unadjusted Binary Logistic Regression Models Predicting Disease Group Diagnoses.

57. Adjusted Binary Logistic Regression Models Predicting Disease Group 
Diagnoses

58. Potential Covariates and Exposure Score by Number of Chronic Diseases Reported.

59. The Crude and Adjusted Associations between Exposure Score and Number of Chronic Diseases Reported

60. Potential Covariates and Home's Location in Neighborhood by Frequency of Reported Bone and Muscle Symptoms 260

61. Potential Covariates and Home's Location in Neighborhood by Frequency of Reported Eye Symptoms 261

62. Potential Covariates and Home's Location in Neighborhood by Frequency of Reported Gastrointestinal Symptoms

63. Potential Covariates and Home's Location in Neighborhood by Frequency of Reported Mood Symptoms 263

64. Potential Covariates and Home's Location in Neighborhood by Frequency of Reported Neurological Symptoms

65. Potential Covariates and Home's Location in Neighborhood by Frequency of Reported Respiratory Symptoms

66. Potential Covariates and Home's Location in Neighborhood by Frequency of Reported Skin Symptoms 266

67. Potential Covariates by Home's Location in Neighborhood 267

68. Unadjusted Binary Logistic Regression Models Predicting Daily or Weekly Symptom Frequency 


\section{LIST OF FIGURES}

FIGURE

PAGE

1. Proximity of Riverside Gardens to Surrounding Industries and Industrial Waste ..... 9

2. Timeline of the Remediation of Lees Lane Landfill ...................................... 17

3. Search Methods Used to Understand Riverside Gardens Community Members'

Potential Exposures by Site of Interest .................................................... 73

4. Participation in the Health and Exposure Assessment Questionnaire

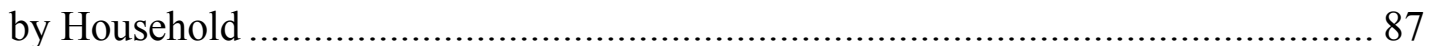

5. Adult Resident Participation in the Health and Exposure Assessment

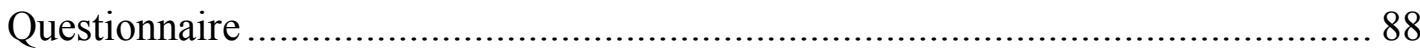




\section{INTRODUCTION}

The Riverside Gardens neighborhood is located in West Louisville, Jefferson County, Kentucky, and consists of twelve blocks and approximately 560 adult residents. ${ }^{1}$ Riverside Gardens began as a resort community along the Ohio River in the 1920s; however, today, it is a subdivision of single-family homes surrounded by industry and industrial waste. To the west, separating Riverside Gardens from the Ohio River, is the Lees Lane Landfill, an unlined, 112-acre remediated Environmental Protection Agency Superfund site. To the north, the neighborhood is bordered by Rubbertown, an industrial area in Louisville where several plants that produce rubber, plastics, and chemicals reside. To the south lies Louisville Gas \& Electric's (LG\&E) Cane Run power plant, which houses a coal ash landfill and surface impoundments.

Riverside Gardens has a large population of lifelong residents who have advocated for the health and well-being of their community for decades. While numerous reports have been made by community members to the media, health department employees, and federal agencies citing concerns of elevated cancer rates and other health conditions in the community, ${ }^{2-5}$ a comprehensive health assessment focusing solely on those residing in the neighborhood had not taken place prior to this study.

This dissertation presents results from a two-part, community-based, mixedmethods epidemiologic study that took place in the Riverside Gardens neighborhood. The first phase of the study employed qualitative research methods 
(individual interviews) with 15 adult community members who had lived in the neighborhood for a minimum of five years. Topics explored during the interviews included the neighborhood's history, participants' perceptions of the community's health, participants' personal health, and participants' exposure histories.

Findings from the individual interviews were used to create a comprehensive health and exposure assessment questionnaire that was used in the second phase of this study (a cross-sectional epidemiologic study). The second phase of the study was both a qualitative and quantitative exploration of the health and exposure histories of 83 adult community members who had lived in the neighborhood for at least one year.

This dissertation study is the first documented attempt to collect health and exposure histories from Riverside Gardens community members. Furthermore, this study sought to determine if there is an excess burden of disease among current adult Riverside Gardens residents by comparing the prevalence of cancer and other chronic diseases among residents to local, state, and national estimates. The relationships between categories of health conditions and differing levels of self-reported neighborhood exposures were also assessed. 


\section{OBJECTIVE, HYPOTHESIS, AND SPECIFIC AIMS}

\section{Overall Objective}

The overall objective of this study is to investigate the self-reported health and exposure histories of adults 18 years and older who currently reside in the Riverside Gardens neighborhood of Jefferson County, Kentucky.

\section{Central Hypothesis}

Adults living in Riverside Gardens will report higher rates of cancer and chronic diseases when compared to local, state, and national rates. Residents of Riverside Gardens who report greater exposure to environmental pollutants will be more likely to report cancer, chronic diseases, and other health effects than residents who report less exposure to environmental pollutants.

This hypothesis was investigated through the following four specific aims:

\section{Specific Aim 1}

To explore community health perceptions, environmental exposure experiences, and health concerns of adults who have lived in Riverside Gardens for five or more years, using qualitative research methods. 


\section{Specific Aim 2}

To create a comprehensive health and exposure assessment questionnaire specifically designed for the Riverside Gardens community utilizing the findings from Aim \#1, the availability of comparison data, and consultation with the Kentucky Department for Public Health.

\section{Specific Aim 3}

To assess and compare the prevalence of self-reported health conditions in Riverside Gardens.

Subaim 3A: To compare self-reported chronic disease prevalence between Riverside Gardens residents and local, state, and national prevalence, as available, using data from representative surveys.

Subaim 3B: To compare self-reported cancer prevalence between Riverside Gardens residents and local, state, and national cancer prevalence using representative survey data.

\section{Specific Aim 4}

To evaluate the relationship between environmental exposure histories and self-reported health conditions among residents of Riverside Gardens.

$\underline{\text { Subaim 4A: }}$ To assess if residents with higher exposure scores are more likely to report histories of disease diagnoses within defined categories (e.g., circulatory system diseases, respiratory system diseases, etc.). 


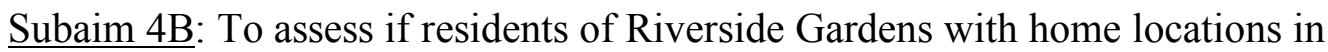
closer proximity to sources of pollution, including the Lees Lane Landfill, Rubbertown, and LG\&E, are more likely to report frequently (i.e., daily or weekly) experiencing groups of symptoms (e.g., respiratory symptoms, neurological symptoms, etc.) while in the neighborhood and in their homes. 


\section{BACKGROUND AND SIGNIFICANCE}

This history of the Riverside Gardens neighborhood began in the 1800s. Between the 1800 s and today, the neighborhood has evolved from an estate to a vacation resort to a subdivision of single-family homes. The land surrounding the neighborhood has also undergone significant development, transitioning from farmland to the site of numerous industrial facilities and a hazardous waste landfill. This section will cover the background of the Riverside Gardens neighborhood and its surrounding areas, as well as the significance of this work.

\section{Neighborhood History}

The land on which the Riverside Gardens neighborhood was built was originally the estate of David Meriwether, a Kentucky politician during the 1800s who was a member of the Kentucky House of Representatives, the Secretary of State of Kentucky, and a United States Senator. ${ }^{6}$ Meriwether's Jefferson County estate, named Hayfield, included a colonial mansion which sat along the Ohio River. ${ }^{6}$ The estate remained in Meriwether's family after his death in 1893, but by 1926 the estate's land had been subdivided and was used in part to build the resort community known as Riverside Gardens. $^{6}$

Developers envisioned Riverside Gardens as a getaway for Louisvillians wishing to escape city life and relax along the Ohio River. ${ }^{7,8}$ Free rides between downtown 
Louisville and Riverside Gardens, about a 9-mile drive, were available on Saturdays and Sundays. ${ }^{8}$ Music and entertainment were often offered to draw guests to the development. ${ }^{8}$ A clubhouse, which was constructed on the development's west side on a beach along the river, served as a dance hall on Saturday nights. ${ }^{7,9}$

About ten years after Riverside Gardens was developed, the Great Ohio River Flood of 1937 covered the neighborhood with 7.2 feet of water. ${ }^{10}$ Between the flood and the rise of Rubbertown, a heavily industrialized area of West Louisville, the area soon lost its appeal as a vacation destination. ${ }^{7}$ As a result, the neighborhood clubhouse closed, and Riverside Gardens transitioned from a resort to a subdivision of single-family homes, which is how it remains today.

\subsection{Riverfront}

The riverfront on which the Hayfield estate's mansion and the Riverside Gardens Clubhouse once resided is part of the 100-year Ohio River floodplain. ${ }^{11}$ This land became home to a sand and gravel quarry in the 1940s after the closure of the clubhouse. ${ }^{7,11}$ It converted to a junkyard briefly before transitioning to a landfill that operated from the late 1940s until $1975 .{ }^{11}$ Since the landfill's closing, the land has been used for recreational activities, such as hunting, fishing, playing, and riding all-terrain vehicles

and motorbikes, though accessing the site is prohibited. ${ }^{11-16}$ In the early 2000s, Riverside Gardens became home to a trailhead for the Louisville Loop, a trail system for walkers, joggers, in-line skaters, and bicyclists. ${ }^{17}$ The trail goes through the center of the neighborhood and continues along the border of the closed landfill site, crossing over the site's southernmost corner. ${ }^{15,18}$ 


\subsection{Today’s Community}

According to 2016 American Community Survey 5-year estimates, current residents of the Riverside Gardens community are largely non-Hispanic White ${ }^{19}$ and English speaking. ${ }^{20}$ Approximately $70 \%$ of the population (about 560 residents $^{1}$ ) is aged 18 years or older, and the median age range among adults is 50 to 54 years. ${ }^{21}$ There are slightly more males (54.1\%) in the area than females (45.9\%). ${ }^{21}$ Most (75.8\%) adult residents aged 25 years and older have at least a high school diploma or GED, and about one-quarter (23.8\%) have completed at least some college. ${ }^{22}$ The median household income for this community and surrounding neighborhoods is $\$ 33,750,{ }^{23}$ compared to Jefferson County's median household income of $\$ 50,099^{24}$ and Kentucky’s median household income of $\$ 44,811 .{ }^{25}$ Material moving, protective service, construction, production, and law enforcement occupations are common among men, while sales, management, and building and grounds cleaning and maintenance occupations are common among women. ${ }^{26}$ The majority $(72.1 \%)$ of the occupied houses in the area are owned. ${ }^{27}$

\section{Environmental Concerns of the Community}

In the 1940s and 1950s, the area surrounding Riverside Gardens began to change as the Ohio River waterfront in West Louisville began to industrialize. Chemical, plastic, and rubber manufacturers took up residence on Riverside Gardens' north side in an area now known as Rubbertown. ${ }^{28-30}$ Around the same time, in 1948, the aforementioned landfill opened along the neighborhood's west side. ${ }^{15}$ Not long after, in 1954, an energy 
company purchased land to the south of Riverside Gardens and built a coal-burning power plant. ${ }^{31}$ Figure 1 shows the proximity of the neighborhood to each of these sites.

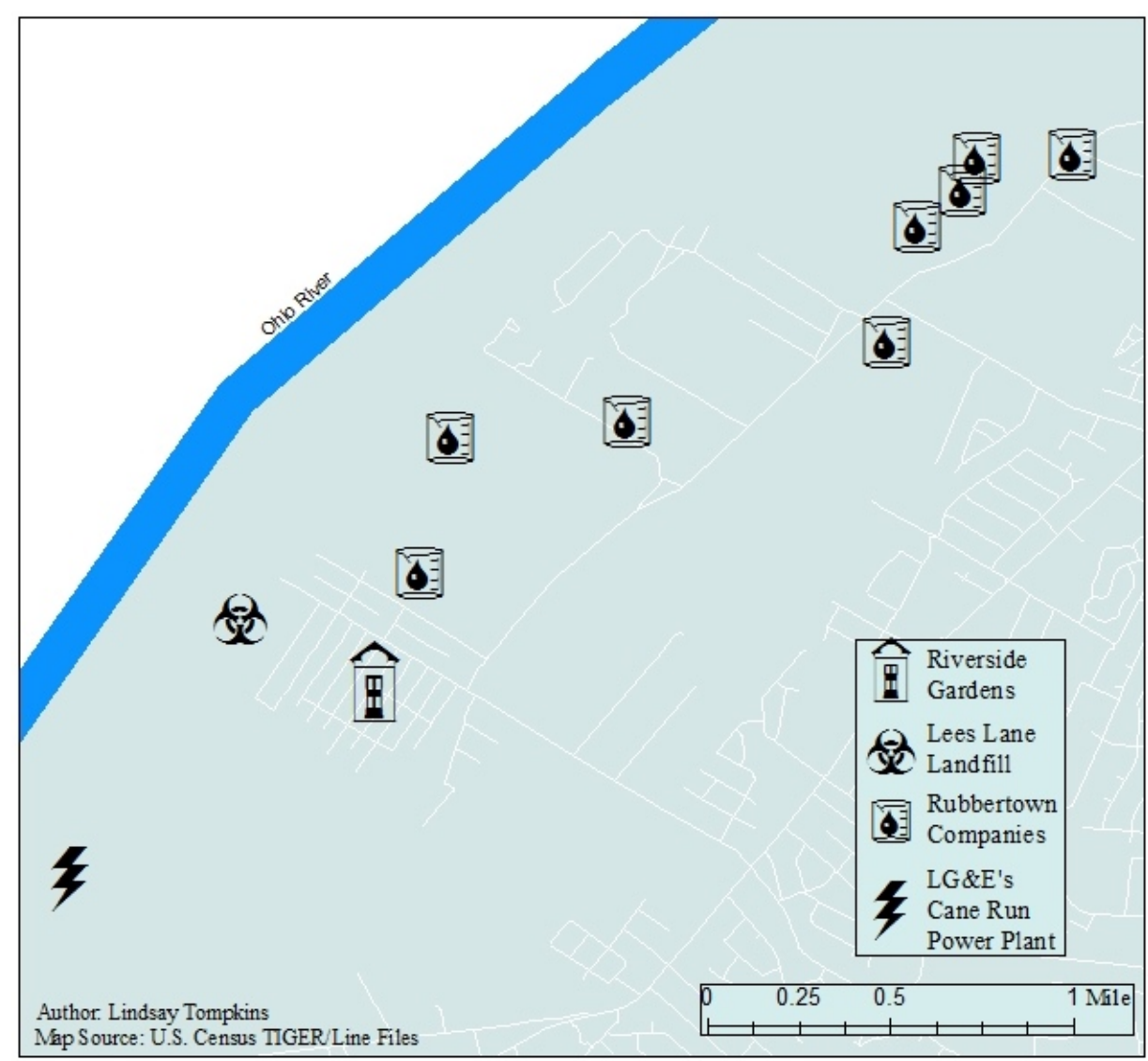

Figure 1. Proximity of Riverside Gardens to Surrounding Industries and Industrial Waste

As the area surrounding Riverside Gardens industrialized, residents became concerned with how the nearby industries and waste sites were impacting their environment and health. Riverside Gardens residents have long expressed concerns about the Lees Lane Landfill, with complaints documented as early as 1971 and as recent as 2018..$^{2,3,16,32-35}$ They reported fears about contamination to the air, water, and soil in the neighborhood due its proximity to the hazardous waste site, as well as the lifelong effects that such exposures could have on their health. ${ }^{33}$ From the Rubbertown plants, residents have been alarmed by numerous chemical releases and explosions ${ }^{36-40}$ and affected by 
strong odors and air pollution. ${ }^{40-45}$ They have expressed concerns regarding the impacts that living near Rubbertown could have on their health. ${ }^{2,39,44}$ Riverside Gardens residents have also expressed concern and frustration over the fugitive coal ash and odors that come from Louisville Gas \& Electric's (LG\&E) Cane Run power plant. ${ }^{46,47}$ Residents have been particularly concerned with coal ash, a byproduct of coal combustion, and its impacts on their health and quality of life. ${ }^{5,48}$

The following four sections will detail the history, development, and environmental and community impacts of the Lees Lane Landfill, Rubbertown, and LG\&E's Cane Run power plant, as well as the potential health effects related to exposure to the environmental pollutants released by these sites.

\section{Lees Lane Landfill}

\subsection{Background}

The Lees Lane Landfill operated between 1948 and $1975 .{ }^{15}$ It sits on 112 acres along the Ohio River, ${ }^{11}$ land which was once home to the Hayfield estate's mansion and the Riverside Gardens Clubhouse. It is unlined and was not designed with gas collection and venting systems, ${ }^{49}$ features of landfills that help to prevent waste from spreading to outside soil and groundwater as well as manage the gases the landfill waste produces. Lying within the 100-year floodplain of the Ohio River, major flooding could cover 25 to 50 percent of the site. ${ }^{11}$

The landfill accepted at least 212,400 tons of domestic, commercial, and industrial waste during its 27 years of operation. ${ }^{11}$ Between 700 and 800 individuals, companies, and other entities were believed to have used the landfill. ${ }^{15,33}$ Approximately 
thirty of these were identified as having used the landfill to dispose of hazardous substances. ${ }^{15}$ Several of those responsible for disposing hazardous waste in the landfill were nearby Rubbertown companies. ${ }^{50,51}$ Waste Management of Kentucky was also noted as a contributor. ${ }^{50,51}$ One portion of the landfill, the southern tract, operated under a permit issued in 1971 by Kentucky under its Solid Waste Program. ${ }^{11}$ The landfill was repeatedly cited with compliance violations, and in 1974, the landfill's permit was not renewed due to these violations. ${ }^{11}$

\subsection{Landfill Closing and Monitoring Response}

In March 1975, the Lees Lane Landfill gained national attention when flash fires occurred in the basements of several Riverside Gardens homes surrounding the landfill. ${ }^{15,33}$ The fires were caused by methane gas that escaped the landfill and ignited when it neared the pilot lights of hot water heaters. ${ }^{15,33}$ In response, the Jefferson County Housing Authority evacuated the residents of seven homes and later purchased these homes due to the presence of explosive levels of methane. ${ }^{33}$ The Kentucky Natural Resources and Environmental Protection Cabinet filed a lawsuit against the owners of the landfill in April 1975, resulting in the landfill's closure that year. ${ }^{15}$

Initial site responses by state and federal agencies included gas and water monitoring. Forty-four gas observation wells were installed in and around the landfill and in Riverside Gardens between 1975 and 1979. ${ }^{15}$ The agency that installed the gas observation wells is unknown. The wells were used to monitor the concentration, pressure, and lateral extent of methane gas migration. ${ }^{15}$ The gas samples that were collected indicated that the decomposition of landfill waste was the source of methane 
and other toxic gases. ${ }^{15}$ In an attempt to remedy the landfill gas issue, the Kentucky Department of Hazardous Materials and Waste Management designed and installed a landfill gas collection system in October $1980 .{ }^{15}$ The landfill gas collection system was placed between the landfill and the Riverside Gardens neighborhood. ${ }^{15}$

In addition to methane gas, other landfill pollutants were of concern. To assess whether residents were exposed to contaminated drinking water, water samples were collected from residential wells in Riverside Gardens in November 1978 by the Kentucky Division of Waste Management's Surveillance and Analysis Division. ${ }^{15}$ While almost the entire neighborhood has been supplied with public water since 1993, some homes relied on private wells for water during the time the landfill operated. ${ }^{14}$ Analysis of these samples indicated that there was no migration of contaminated groundwater from the landfill to residential wells. ${ }^{15}$

While none of the samples collected from residential wells indicated that there was groundwater contamination, eleven groundwater monitoring wells were installed onsite in early 1981 by the Kentucky Natural Resources and Environmental Protection Cabinet. ${ }^{15}$ Five of these were sampled by the U.S. Environmental Protection Agency (EPA) in April 1981. ${ }^{15,52}$ Sample analyses indicated that groundwater was contaminated with elevated concentrations of inorganic contaminants including arsenic, lead, and chromium; however, the EPA noted that these results may have been affected by improper well installation and the presence of sediment in the wells. ${ }^{15}$

In February 1980, approximately 400 drums were discovered on the landfill site approximately 100 feet from the Ohio River bank. ${ }^{33}$ The drums remained on-site until September and October 1981, when a court order mandated that the landfill owners 
remove them. ${ }^{33}$ Contents of the drums were tested, and forty drums were found to contain hazardous materials including benzene, phenolic resins, and heavy metals including lead, chromium, cadmium, copper, and nickel. ${ }^{11,49}$ Drums with hazardous waste were relocated to a hazardous waste disposal facility, while drums with non-hazardous waste and empty drums were buried on-site within the landfill. ${ }^{33}$ Additional drums were found in 1991 after Riverside Gardens residents reported chemical odors coming from the landfill. ${ }^{49}$ These odors were later traced to three leaking, rusted drums on the landfill site. ${ }^{49}$ The drums were removed by the Kentucky Natural Resources and Environmental Protection Cabinet. $^{12}$

\subsection{Lees Lane Landfill Becomes a Superfund Site}

On December 12, 1982, the EPA proposed the Lees Lane Landfill to the Superfund National Priorities List (NPL) based on the site's Hazard Ranking System (HRS) score. ${ }^{15,53}$ The EPA uses the HRS scoring system to assess the relative threat of an actual or potential hazardous substance release at a contaminated site. ${ }^{53}$ At the time that the Lees Lane Landfill was proposed to the NPL, HRS scores were determined by the evaluation of groundwater, surface water, and air migration pathways at sites. ${ }^{53}$ At the Lees Lane Landfill site, the HRS score took into account the methane gas that was being released from the landfill and impacting air quality as well as the high concentrations of inorganic contaminants in the groundwater, including arsenic, lead, and chromium. ${ }^{15}$ The site was given a score of 47.46, which surpassed the EPA's cutoff score of 28.50 and qualified it for placement on the Superfund NPL. ${ }^{14,53}$ 
The Lees Lane Landfill was listed on the NPL on September 8, 1983, denoting it as one of the nation's most contaminated waste sites. ${ }^{15}$ After sites are listed on the NPL, remedial investigation/feasibility studies (RI/FS) are performed. ${ }^{54}$ The purpose of a remedial investigation $(\mathrm{RI})$ is to collect data to "characterize site conditions, determine the nature of the waste, assess risk to human health and the environment, and conduct treatability testing to evaluate the potential performance and cost of the treatment technologies that are being considered." 54 The feasibility study (FS) involves the development, screening, and evaluation of remedial actions. ${ }^{54}$

The RI/FS at the Lees Lane Landfill began on September 27, 1983 and was completed on September 25, 1986. ${ }^{15}$ The RI found very low levels of contaminants in onsite surface water; two "hot spot" areas with high concentrations of lead and chromium in soil along the access road to the landfill; high concentrations of arsenic, barium, cadmium, chromium, iron, lead, and manganese in on-site groundwater; and high concentrations of manganese and iron in off-site wells not located in Riverside Gardens. ${ }^{15}$ Based on the chemical, biological, and toxicological properties of contaminants identified in addition to the frequency with which they were detected during the RI, the critical contaminants selected for further evaluation included arsenic, benzene, chromium, and lead..$^{33}$

In 1985, a public health assessment (PHA) was conducted as part of the RI. ${ }^{15}$ The purpose of the PHA was to identify environmental pathways of concern; this assessment did not involve residents. ${ }^{49}$ The assessment concluded that the elevated chromium levels found in samples taken from on-site groundwater was the site's primary public health concern. ${ }^{15}$ While the PHA did not find evidence of a public health or environmental 
problem off-site, it did identify the need for long-term groundwater and air monitoring, in addition to routine subsurface gas monitoring both on-site and in Riverside Gardens. ${ }^{15}$ The PHA stated that if access to the landfill site could not be controlled, the surface wastes should be removed and contaminated soils should be covered. ${ }^{15}$

Based on the RI data, the EPA determined that the following response actions were needed:

1. Provision of a properly operating gas collection system.

2. Consideration of a future alternate water supply.

3. Cleanup of the surface water areas including removal of exposed drums, capping of "hot spot" soils, and an area containing exposed trash.

4. Bank Protection Controls including installation of riprap and stabilization of the entire bank (29 acres) along the Ohio River.

5. Posting of cautionary signs.

6. Installation of a gate at the landfill's Putman Avenue (street in Riverside Gardens) access point.

7. Operation and maintenance activities including inspection of the gas monitoring wells, quarterly gas and groundwater sampling, and analysis and sampling of air three times per year. Additionally, inspection and maintenance of the gas collection system, capped waste areas, and the riprap along the Ohio River bank.

8. Provisions for the sampling of an additional ground water monitor well to aid in determining alternate concentration limits (ACLs). ${ }^{15}$ 
The implementation of the remedial actions began in March 1987 and concluded in October 1987. ${ }^{15}$ Remedial actions included the identification and covering of soil "hot spots" with clay, covering of exposed waste with topsoil, clearing of vegetation from the landfill's central tract, sowing of grass seed, installation of a rip-rap slope along the Ohio River bank, and installation of gas and water wells for future monitoring. ${ }^{15,49}$

In 1991, the Louisville/Jefferson County Metropolitan Sewer District (MSD) was selected to conduct the site's remedy operation and maintenance until the year 2020. The landfill remained on the NPL until April 25, 1996. ${ }^{15}$ Figure 2 provides a timeline of the site remediation, from the reporting of the flash fires to the site's deletion from the NPL. 


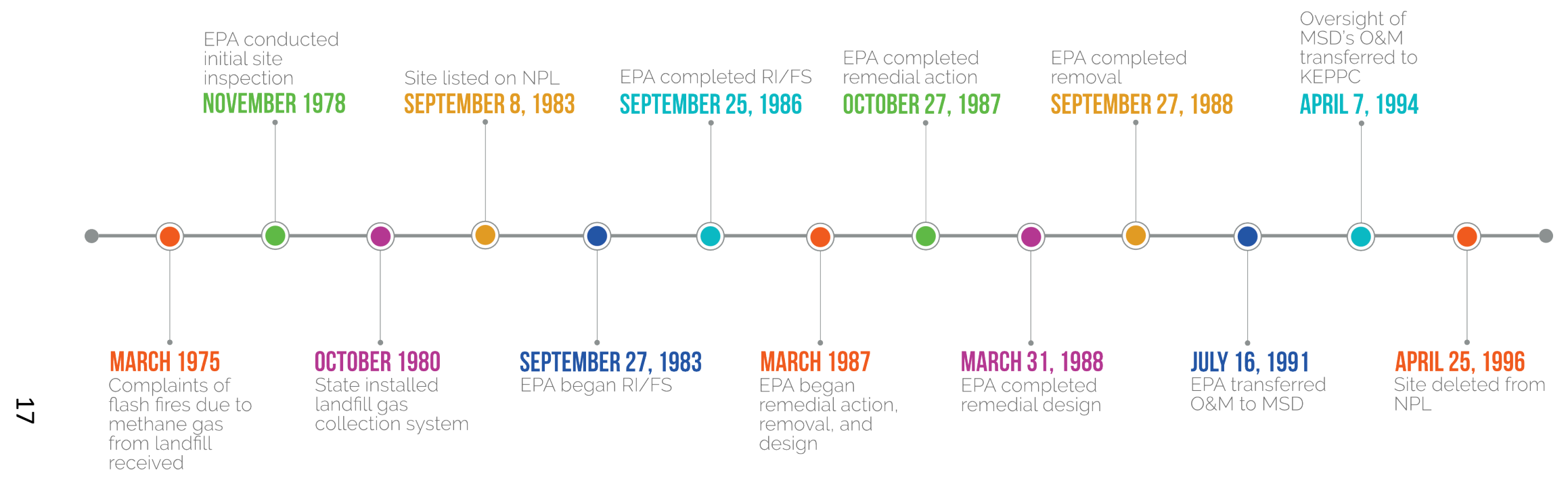

Figure 2. Timeline of the Remediation of Lees Lane Landfill ${ }^{15,49}$ 


\subsection{Recent Sampling and Pollutants Detected}

Even though the landfill was removed from the NPL in 1996, environmental monitoring continues. Results of the sampling conducted between 2011 and 2015 are summarized in Table 1 (see page 20).

In 2011, the EPA collected soil samples from four locations at the landfill site and compared them to the EPA's residential Regional Screening Levels (RSLs). ${ }^{15}$ The EPA developed RSLs for the screening of chemical contaminants at Superfund sites. ${ }^{55}$ RSLs are risk-based concentrations derived using standardized equations that combine exposure information with EPA toxicity data. ${ }^{55}$ RSLs are provided for comparison to levels of chemical contaminants in soil, air, and tap water in residential, occupational, and recreational settings. ${ }^{55}$ When the concentration of a contaminant is between zero and the RSL, no further action is warranted; ${ }^{56}$ the EPA considers these levels to be protective for humans (including sensitive groups) over a lifetime. ${ }^{55}$ Several contaminants that exceeded residential RSLs were detected in soil samples collected from the landfill site in 2011: arsenic, benzo(a)pyrene, benzo(a)anthracene, benzo(b)fluoranthene, $\operatorname{dibenz}(\mathrm{a}, \mathrm{h})$ anthracene, and indeno(1,2,3-cd)pyrene. ${ }^{15}$ All samples had arsenic values that exceeded the RSLs, and three of the four samples were contaminated above RSLs with one of the other compounds. ${ }^{15}$

In 2013, the Kentucky Department for Environmental Protection (KDEP) collected 33 surface and subsurface soil samples from 28 locations on the landfill site..$^{57,58}$ Lead, thallium, iron, and arsenic were found in soil samples that exceeded the residential RSLs. ${ }^{58}$ Chromium currently does not have an RSL, but it was detected in all soil samples analyzed (range: $13-270 \mathrm{mg} / \mathrm{kg}$ ) ${ }^{58}$ Dieldrin, an organochlorine pesticide, and 
polychlorinated biphenyls (PCBs) were detected at levels exceeding the residential RSLs. ${ }^{57}$ Several semi-volatile organic compounds were also detected in the soil samples, including benzo(a)pyrene, benzo(a)anthracene, benzo(b)fluoranthene, $\operatorname{dibenz}(\mathrm{a}, \mathrm{h})$ anthracene, indeno(1,2,3-cd)pyrene, benzo(k)fluoranthene, and di(2ethylhexyl)phthalate, all of which exceeded residential RSLs and some of which exceeded industrial RSLs. ${ }^{58}$

In addition to soil monitoring by KDEP, ambient air monitoring has been conducted. ${ }^{57}$ Seven air monitors were placed along the landfill border (northern and southern tracts) and in the western portion of the Riverside Gardens neighborhood. ${ }^{57}$ These monitors showed high levels of chloroform between 2012 and 2015, exceeding the RSL in September 2013. ${ }^{57}$

In early June 2013, the EPA conducted soil-gas monitoring between the landfill's gas collection system and the Riverside Gardens neighborhood. ${ }^{59}$ These sampling results showed high levels of chloroform, along with six other chemicals of concern: benzene, 1,3-butadiene, carbon tetrachloride, tetrachloroethene, trichloroethylene, and vinyl chloride ${ }^{59}$ The levels of 1,3-butadiene, carbon tetrachloride, chloroform, and tetrachloroethene were found to greatly exceed the screening value, thus warranting further investigation. ${ }^{59}$

Vapor intrusion samples taken from eight homes in the Riverside Gardens neighborhood in 2014 showed high levels of 1,2-dichloroethane, 1,4-dichlorobenzene, 1,3-butadiene, benzene, and chloroform; however, the EPA determined that, based on soil gas measurements also taken from each home's property, the vapor intrusion pathway from soil gas to indoor air was incomplete. ${ }^{57}$ 
Table 1. Summary of Pollutants Detected During Environmental Sampling Conducted between 2011 and 2015

\begin{tabular}{|c|c|c|c|c|c|c|}
\hline Pollutant Detected & $\begin{array}{c}\text { Sample } \\
\text { Type }\end{array}$ & Year & $\begin{array}{l}\text { Detected } \\
\text { Above } \\
\text { Residen- } \\
\text { tial RSL }\end{array}$ & $\begin{array}{l}\text { Detected } \\
\text { Above } \\
\text { Industr- } \\
\text { ial RSL }\end{array}$ & $\begin{array}{c}\text { Exceeded } \\
\text { Screening } \\
\text { Values }\end{array}$ & $\begin{array}{l}\text { Detected } \\
\text { in } \\
\text { Riverside } \\
\text { Gardens } \\
\text { Homes }\end{array}$ \\
\hline 1,2-dichloroethane & $\begin{array}{l}\text { Vapor } \\
\text { intrusion }\end{array}$ & 2014 & & & & Yes \\
\hline 1,3-butadiene & $\begin{array}{l}\text { Soil-gas, } \\
\text { Vapor } \\
\text { intrusion }\end{array}$ & $\begin{array}{l}2013 \\
2014\end{array}$ & & & Yes & Yes \\
\hline 1,4-dichlorobenzene & $\begin{array}{l}\text { Vapor } \\
\text { intrusion }\end{array}$ & 2014 & & & & Yes \\
\hline Arsenic & Soil & $\begin{array}{l}2011 \\
2013\end{array}$ & Yes & & & \\
\hline Benzene & $\begin{array}{l}\text { Soil-gas, } \\
\text { Vapor } \\
\text { intrusion }\end{array}$ & $\begin{array}{l}2013 \\
2014\end{array}$ & & & Yes & Yes \\
\hline Benzo(a)anthracene & Soil & $\begin{array}{l}2011 \\
2013\end{array}$ & Yes & Yes & & \\
\hline Benzo(a)pyrene & Soil & $\begin{array}{l}2011 \\
2013\end{array}$ & Yes & Yes & & \\
\hline Benzo(b)fluoranthene & Soil & $\begin{array}{l}2011 \\
2013\end{array}$ & Yes & Yes & & \\
\hline Benzo(k)fluoranthene & Soil & 2013 & Yes & & & \\
\hline Carbon tetrachloride & Soil-gas & 2013 & & & Yes & \\
\hline Chloroform & $\begin{array}{l}\text { Air, } \\
\text { Soil-gas, } \\
\text { Vapor } \\
\text { intrusion }\end{array}$ & $\begin{array}{l}2013 \\
2013 \\
2014 \\
2015\end{array}$ & Yes & & Yes & Yes \\
\hline Chromium & Soil & 2013 & N/A & N/A & & \\
\hline $\begin{array}{l}\text { Di(2- } \\
\text { ethylhexyl)phthalate }\end{array}$ & Soil & 2013 & Yes & Yes & & \\
\hline Dibenz(a,h)anthracene & Soil & $\begin{array}{l}2011 \\
2013\end{array}$ & Yes & Yes & & \\
\hline Dieldrin & Soil & 2013 & Yes & & & \\
\hline Indeno( $1,2,3 \mathrm{~cd})$ pyrene & Soil & $\begin{array}{l}2011 \\
2013\end{array}$ & Yes & & & \\
\hline Iron & Soil & 2013 & Yes & & & \\
\hline Lead & Soil & 2013 & Yes & Yes & & \\
\hline PCBs & Soil & 2013 & Yes & Yes & & \\
\hline Tetrachloroethene & Soil-gas & 2013 & & & Yes & \\
\hline Thallium & Soil & 2013 & Yes & & & \\
\hline Trichloroethylene & Soil-gas & 2013 & & & Yes & \\
\hline Vinyl chloride & Soil-gas & 2013 & & & Yes & \\
\hline
\end{tabular}




\subsection{Ongoing Assessment and Monitoring}

The EPA is required to conduct site reviews of the landfill at least every five years until hazardous substances, pollutants, or contaminants at the site remain at levels that allow for unlimited use and unrestricted exposure per Section 121(c) of the Comprehensive Environmental Response, Compensation, and Liability Act (CERCLA) and the National Contingency Plan (NCP) 40 CFR Part 300.430(f)(4)(ii). ${ }^{60}$

The fifth five-year review (FYR) report was issued on September 25, 2013. ${ }^{15}$ In this report, the EPA was unable to conclude that the site remedy is protective of human health and the environment. ${ }^{15}$ Technical issues played a role in this determination. During this FYR, the landfill gas collection system did not appear to be functioning properly and data gaps were found concerning site soil and groundwater contamination. ${ }^{15}$ Concerns over the effectiveness and condition of the gas collection systems have been discussed in all previous FYR reports since $1998^{12-15}$ and the EPA's 1993 review of response actions at the site. ${ }^{11}$ In the 2003 and 2008 FYR reports, improvements to the gas collection systems were listed as "main recommendations." ${ }^{13,14}$ In addition to the EPA's landfill gas collection system findings, in 2010, the Smith Management Group (SMG) conducted a visual assessment of the overall condition of the landfill gas collection system's blower equipment, headers, and well moisture traps per MSD's request. ${ }^{15}$ The inspection concluded that "based on the 29-year age of the gas collection system, observations from the 2004 assessment by SCS Engineers, and results of the current assessment, SMG concludes that the current system is inoperable and has exceeded the useful life of the system." 15 
The sixth FYR report was issued on August 30, 2018. ${ }^{32}$ In this report, the EPA determined that the landfill site was "short-term protective" to human health and the environment. ${ }^{32}$ The EPA stated that "the remedy at the Site currently protects human health and the environment because there are currently no completed exposure pathways," ${ }^{32}$ meaning that the EPA did not determine that there is currently a way in which a person could come into contact with site-related contaminants. ${ }^{61}$ However, the EPA indicated that in order for the remedy to be protective in the long term, several actions need to be taken. These actions include implementing groundwater and land use controls on-site, identifying the source of volatile organic compounds (VOCs) that were detected in soil-gas samples in 2013, and monitoring soil vapor levels migrating from the landfill. ${ }^{32}$ Another FYR report is required in five years (2023).

According to the EPA's 1993 review of the site, "as long as there is presence of waste material buried in the Lees Lane Landfill, there is always a possibility that an exposure pathway could develop." ${ }^{\prime 1}$ Because waste materials remain on-site and the landfill is only partially capped, ${ }^{32}$ it is still possible that materials could surface and that individuals could come in contact with contaminants from the site.

\subsection{Lees Lane Landfill's Impacts on the Riverside Gardens Community}

The Riverside Gardens community was deeply impacted by the creation and operation of the Lees Lane Landfill, and community members expressed their frustrations on numerous occasions. One of the first documented examples of legal action taken as a result of the landfill's impact on the community occurred in 1970, when residents filed a lawsuit after landfill operators began using the northern tract of the landfill for 
dumping. ${ }^{35}$ Residents argued that the land on which the northern tract sat was zoned for river terminal activities and could not be used for dumping. ${ }^{35}$ The Jefferson Circuit Court sided with the residents and issued an injunction against dumping in the northern tract. ${ }^{35}$ When illegal dumping in this tract began once more, Riverside Gardens residents sought the help of the Louisville and Jefferson County Planning Commission to cease dumping in the tract. ${ }^{35}$

The community also filed complaints to their local and federal government concerning the landfill operation's excessive noise, vibrations, dust, and odor, as well as the poor maintenance of the landfill site and its surrounding area. ${ }^{16,34}$ Additionally, residents reported on numerous occasions that chemical liquids were being illegally dumped into the landfill and that dumping was occurring at all hours of the night, well after normal hours of operation. ${ }^{16,34,62}$ These reports were largely ignored at the time but were eventually corroborated by several former landfill employees when landfill operations were investigated in $1975 .{ }^{62}$ These complaints led the Louisville and Jefferson County Planning Commission to file a lawsuit in 1971 to prevent landfill operations from continuing due to the operator's "clear and conscious disregard of zoning regulations;",34 however, landfill operations were allowed to continue.

After the landfill closed, its presence continued to be a problem for Riverside Gardens residents. For example, illegal dumping remained an issue well after the landfill's closure. ${ }^{49,63}$ Five years after the landfill had closed, there were reports that trash was brought into the neighborhood and left on the empty lots near a former landfill access road, where the homes with explosive levels of methane gas once stood. ${ }^{63}$ Then in 
1991, more than 15 years after the landfill had closed, three leaking, rusted drums that contained hazardous waste were found near the same location. ${ }^{64,65}$

Community members were also concerned about the length of time that it took to clean up the landfill site. ${ }^{66}$ Banks would not lend money to prospective buyers during this time period and, therefore, residents were unable to sell their homes ${ }^{67}$ Additionally, the neighborhood was ineligible for federal community development funds during the cleanup period, even though it had been in line to receive funds for a $\$ 250,000$ drainage project. ${ }^{67}$ Furthermore, it took more than five years for a landfill gas collection system to be installed after flash fires occurred in residents' homes due to explosive levels of methane gas coming from the landfill. ${ }^{67}$ The delay was in great part due to the opinion that the residents were not in 'imminent danger. ${ }^{67}$ Residents lived in fear that another explosion would occur due to the high levels of methane gas coming from the landfill during the years before the landfill gas collection system was installed. ${ }^{67}$

Many community members continue to voice concerns about the landfill site, including its contents, the remediation plant that was selected, and the site's impacts on human health, to journalists and state and federal officials. ${ }^{2,3,32}$

\section{Rubbertown}

\subsection{Background}

To the north of Riverside Gardens sits Rubbertown, a heavily industrialized portion of West Louisville made up of chemical, rubber, and plastic manufacturing plants. Petrochemical companies were the first to industrialize this portion of Louisville. ${ }^{28}$ The Standard Oil of Kentucky Refinery opened in 1918, followed by Aetna 
Oil and Louisville Refining. ${ }^{28}$ It was at the start of World War II, when rubber was in high demand, that rubber manufacturing became popular in this portion of West Louisville, giving Rubbertown its name. ${ }^{29}$

National Carbide was the first rubber manufacturing plant to be built in this area in $1941 .{ }^{29}$ National Carbide produced acetylene gas, which another nearby plant, E.I. du Pont de Nemours \& Co. (DuPont), ${ }^{29}$ used to produce neoprene, a synthetic rubber. ${ }^{28}$ National Carbide also pumped its output to BF Goodrich, which was constructed later in 1941, and they produced a synthetic rubber known as koroseal. ${ }^{29}$ In 1943 , the federal government constructed a new plant to make a styrene-butadiene rubber. ${ }^{30}$ That plant is known today as the American Synthetic Rubber Company. Over time, chemical and plastic manufacturing plants moved into the area and expanded Rubbertown's boundaries. Many of the companies in Rubbertown have undergone name changes due to company mergers and acquisitions.

\subsection{Hexion (currently operating)}

Hexion, the chemical company closest to Riverside Gardens which sits directly to the north of the neighborhood, was previously known as Momentive Performance Materials. Before that, it was Borden Chemical. Borden opened its Rubbertown location in $1979 .{ }^{68}$ The plant produced formaldehyde, urea-forming formaldehyde resins, phenolic resins, and adhesives. ${ }^{68}$ Today, the plant continues to operate as a plastic material and resin manufacturer as part of the Hexion company. ${ }^{69}$

Methanol, toluene, formaldehyde, and phenol were the predominate chemicals disposed of on-site from 1987 until 1995 at which time the plant ceased its disposal of 
toluene. ${ }^{70}$ Methanol, formaldehyde, and phenol remain the predominate chemicals released on-site today. ${ }^{70}$ They were joined by zinc compounds in $2007 .{ }^{70}$ All chemicals released on-site between 1987 (first year for which data are available) and 2016 (most recent data available) that were reported to the EPA's Toxics Release Inventory (TRI) program are listed in Table 2. The EPA's TRI program tracks how certain toxic chemicals are managed by U.S. industrial facilities. ${ }^{71}$ Facilities must report annually how much of each TRI tracked chemical is released (in pounds) into the environment or managed via recycling, energy recovery, and treatment. ${ }^{71}$ Currently, there are more than 650 chemicals covered by the TRI Program. ${ }^{71}$

Table 2. Chemicals Released On-Site by Hexion Chemical (formerly Momentive and Borden) between 1987 and 2016, Listed Alphabetically ${ }^{70}$

\begin{tabular}{|c|c|c|c|}
\hline $\begin{array}{l}4,4^{\prime}- \\
\text { isopropylidenediphenol }\end{array}$ & Diisocyanates & N-Butyl Alcohol & $\begin{array}{l}\text { Sodium } \\
\text { Hydroxide }\end{array}$ \\
\hline Ammonia & Ethylbenzene & $\begin{array}{l}\text { N-Methyl-2- } \\
\text { Pyrrolidone }\end{array}$ & Styrene \\
\hline Barium & Ethylene Glycol & Naphthalene & Sulfuric Acid \\
\hline Barium Compounds & Formaldehyde & O-Cresol & Toluene \\
\hline Biphenyl & M-Cresol & P-Cresol & Triethylamine \\
\hline Certain Glycol Ethers & Melamine & Phenol & Xylene \\
\hline Cresol & Methanol & Phosphoric Acid & Zinc \\
\hline Dicyclopentadiene & $\begin{array}{l}\text { Methyl Ethyl } \\
\text { Ketone }\end{array}$ & Propionaldehyde & Zinc Compounds \\
\hline
\end{tabular}

\subsection{Atkemix Ten (closed)}

Atkemix Ten Inc. and its affiliated company, ICI Americas Inc., own the site of the chlorinated solvents manufacturing plant formerly operated by Stauffer Chemical Company. The site was acquired by Atkemix Ten/ICI Americas in 1987 as a result of the divestiture of Stauffer. The Stauffer plant was constructed in 1953 and operated until the summer of $1983 .{ }^{72}$ The original facility produced anhydrous hydrogen chloride, carbon tetrachloride, muriatic acid, and perchloroethylene. ${ }^{72}$ Additional construction in 1955 
resulted in a facility that produced anhydrous hydrogen chloride, carbon tetrachloride, chloroform, methylene chloride, and muriatic acid. ${ }^{72}$ A final facility was constructed in 1961 for the sale and recycling of methyl chloride. ${ }^{72}$ The original facility closed in 1981 , while the other two facilities were closed in $1983 .{ }^{72}$

The Stauffer plant had many waste disposal methods during its 30 years of operation. Wastewater was treated and then discharged into the Ohio River. ${ }^{72}$ The plant also maintained several waste disposal units on-site. ${ }^{72}$ These included the north and south landfills, two copper disposal ponds, and two evaporation ponds. The north and south landfills were primarily used to dispose of hexachlorinated waste products from the production of perchloroethylene, but they also were used to store alumina, coal cinders, coal fly ash, lime, and water solids. ${ }^{72}$ These landfills were located downgradient of the flood control levee along the Ohio River and were within the 100 -year floodplain. ${ }^{72}$ The landfills accepted waste between 1953 and 1975 and were closed in $1982 .{ }^{72}$ Closure plans were approved by the Kentucky Division of Waste Management. ${ }^{72}$ Materials were not removed from the landfill during closure. ${ }^{72}$ The copper disposal ponds were used to dispose of copper chloride between 1956 and 1976 and were closed in $1979 .{ }^{72}$

The first evaporation pond was constructed in 1976 and was used for the disposal and dewatering of lime-based solids from the water treating system as well as the settling basin solids from the KPDES system. ${ }^{72}$ The pond was lined. ${ }^{72}$ It accepted waste until November 1980 and was closed in $1983 .{ }^{72}$ The pond's closure plan was approved by the Kentucky Division of Waste Management. ${ }^{72}$ The second evaporation pond was constructed in 1980, shortly before Stauffer ceased operations at the plant, and sat on one acre. ${ }^{72}$ This pond was also lined, and a leachate collection system was installed between 
the two liners. ${ }^{72}$ The pond was used to store slurries that often included the following: calcium carbonate, carbon, carbon tetrachloride, chlorinated hydrocarbons, coal fly ash, iron hydroxide, iron oxide, lime, and magnesium carbonate. ${ }^{72}$ This pond was the only onsite waste disposal unit regulated under the Resource Conservation and Recovery Act (RCRA). ${ }^{72}$ It was closed in 1986, and the pond's closure plan was approved by the Kentucky Division of Waste Management. ${ }^{72}$ Wells were installed near the landfills, copper ponds, and the second evaporation pond to monitor the groundwater. ${ }^{72}$ Postclosure monitoring was not part of the first evaporation pond's closure plan. ${ }^{72}$

Limited documentation concerning spills and releases is available. One documented event involved the entire contents of a 15,000-gallon tank containing chloroform, methylene chloride, carbon tetrachloride, and miscellaneous solvents being spilled. ${ }^{72}$ The area surrounding the tank was not surfaced, but it is unknown how much of the spilled chemicals seeped into the ground. ${ }^{72}$

The site has extensive soil and groundwater contamination and is listed as a nonNPL Superfund site. It was transferred to the RCRA Corrective Action Program in $1991 .{ }^{72}$ The site is considered to be a large quantity generator, ${ }^{73}$ meaning that it generates at least 1,000 kilograms of hazardous waste per month or at least one kilogram of acutely hazardous waste per month. ${ }^{74}$ Soil and groundwater remediation efforts have been underway since $1997 .{ }^{75}$ Waste products of concern include carbon tetrachloride, chloroform, hexachlorobutadiene, hexachloroethane, tetrachloroethylene, trichlorethylene, heavy ends or distillation residues from the production of carbon tetrachloride, and corrosive waste. ${ }^{76-83}$ 


\subsection{Superior Solvents and Chemicals (currently operating)}

Superior Solvents and Chemicals, owned by Superior Oil Company, is a chemical wholesaler located approximately one mile north of Riverside Gardens. ${ }^{84}$ Superior Solvents began reporting to the EPA's TRI program in $1998 .{ }^{85}$ All of Superior Solvents' reported on-site releases have occurred via air. ${ }^{85}$ From 1998 until 2016, the most common chemical released was toluene, followed by methanol, methyl ethyl ketone, xylene, certain glycol ethers, and n-Hexane. ${ }^{85}$ In total, Superior Solvents has released 51,181.80 pounds of these chemicals on-site ${ }^{85}$ All chemicals released on-site between 1998 and 2016 (most recent data available) that were reported to the EPA's TRI program are listed in Table 3.

Table 3. Chemicals Released On-Site by Superior Solvents and Chemicals between 1998 and 2016, Listed Alphabetically ${ }^{85}$

\begin{tabular}{|l|l|l|}
\hline Certain Glycol Ethers & Methyl Ethyl Ketone & Toluene \\
\hline Methanol & N-Hexane & Xylene \\
\hline
\end{tabular}

\subsection{Marathon Petroleum Company (currently operating)}

MPLX Terminals is owned by the Marathon Petroleum Corporation. ${ }^{86}$ All of MPLX Terminals' on-site releases have been made via air and water. ${ }^{87}$ Most (98.94\%) of the on-site releases have been made via air. ${ }^{87}$ Xylene and toluene releases have accounted for approximately half of the company's reported on-site releases during the 19 years it has reported to the EPA's TRI. ${ }^{87}$ Other commonly released chemicals include methyl tert-butyl ether, benzene, and n-Hexane ${ }^{87}$ All chemicals released on-site between 1998 and 2016 (most recent data available) that were reported to the EPA's TRI program are listed in Table 4. 
Table 4. Chemicals Released On-Site by MPLX Terminals between 1998 and 2016, Listed Alphabetically ${ }^{87}$

\begin{tabular}{|l|l|l|l|}
\hline $\begin{array}{l}1,2,4- \\
\text { Trimethylbenzene }\end{array}$ & Cyclohexane & $\begin{array}{l}\text { Methyl Tert-Butyl } \\
\text { Ether }\end{array}$ & Toluene \\
\hline Benzene & Ethylbenzene & N-Hexane & Xylene \\
\hline Cumene & Lead & Naphthalene & \\
\hline
\end{tabular}

\subsection{American Synthetic Rubber Company (currently operating)}

The American Synthetic Rubber Company started in 1943 as the governmentowned National Synthetic Rubber Corporation in response to the rubber production demands of World War II. ${ }^{30}$ In 1954, the plant was sold to private operators and took on its current name, the American Synthetic Rubber Corporation. ${ }^{30}$ The company continues to focus on the production of rubber today.

Between 1987 and 2016, American Synthetic released 53,214,752.51 pounds of chemicals on-site via air, water, and land. ${ }^{88}$ The majority $(99.97 \%)$ of these releases were via air. ${ }^{88}$ The most common chemicals released in order of volume were toluene, 1,3Butadiene, cyclohexane, and styrene. ${ }^{88}$ All chemicals released on-site between 1987 (first year for which data are available) and 2016 (most recent data available) that were reported to the EPA's TRI program are listed in Table 5.

Table 5. Chemicals Released On-Site by American Synthetic Rubber Company between 1987 and 2016, Listed Alphabetically ${ }^{88}$

\begin{tabular}{|l|l|l|l|}
\hline 1,3-Butadiene & $\begin{array}{l}\text { Cyclohexane } \\
\text { Acrylic Acid }\end{array}$ & $\begin{array}{l}\text { Mercury } \\
\text { Hercury Compounds }\end{array}$ & $\begin{array}{l}\text { Sulfuric Acid } \\
\text { Titanium } \\
\text { Tetrachloride }\end{array}$ \\
\hline Acrylonitrile & Hydrogen Fluoride & Sodium Hydroxide & Toluene \\
\hline Ammonia & Lead Compounds & Styrene & \\
\hline
\end{tabular}




\subsection{Arkema (currently operating)}

Arkema, formerly known as Atofina, is a plastics manufacturing company in Rubbertown. ${ }^{89}$ The plant makes an acrylic resin used to make Plexiglas. ${ }^{90}$ All of Arkema's on-site releases have been via air. ${ }^{91}$ The plant releases three chemicals, listed in order of volume beginning with the highest: methyl methacrylate, ethyl acrylate, and dichloromethane. ${ }^{91}$ Arkema has reported releases to EPA's TRI since $1998 .{ }^{91}$

\subsection{Rohm \& Haas (currently operating)}

Rohm \& Haas is a plastics material and resin manufacturing plant owned by Dow Chemical Company. ${ }^{92}$ Rohm \& Haas has reported on-site releases via air, water, and soil, though most releases (94.4\%) were via air. ${ }^{93}$ The most commonly released chemicals via air, listed in order of volume beginning with the highest, include: toluene, methyl methacrylate, ethyl acrylate, tert-butyl alcohol, styrene, and 1,3-butadiene. ${ }^{93}$ All chemicals released on-site between 1987 (first year for which data are available) and 2016 (most recent data available) that were reported to the EPA's TRI program are listed in Table 6.

Table 6. Chemicals Released On-Site by Rohm \& Haas between 1987 and 2016, Listed Alphabetically ${ }^{93}$

\begin{tabular}{|l|l|l|l|l|}
\hline 1,3-Butadiene & Benzoyl Peroxide & Ethylbenzene & $\begin{array}{l}\text { Methyl Ethyl } \\
\text { Ketone }\end{array}$ & Toluene \\
\hline Acetone & Butyl Acrylate & Ethylene Glycol & $\begin{array}{l}\text { Methyl } \\
\text { Methacrylate }\end{array}$ & Xylene \\
\hline Acetophenone & $\begin{array}{l}\text { Certain Glycol } \\
\text { Ethers }\end{array}$ & Formaldehyde & N-Butyl Alcohol & $\begin{array}{l}\text { Zinc } \\
\text { Compounds }\end{array}$ \\
\hline Acrylic Acid & $\begin{array}{l}\text { Cumene } \\
\text { Hydroperoxide }\end{array}$ & $\begin{array}{l}\text { Hydrochloric } \\
\text { Acid }\end{array}$ & Phosphoric Acid & \\
\hline Acrylonitrile & $\begin{array}{l}\text { Di(2-Ethylhexyl) } \\
\text { Phthalate }\end{array}$ & Hydroquinone & Styrene & \\
\hline Ammonia & Dimethyl Phthalate & Methanol & Sulfuric Acid & \\
\hline $\begin{array}{l}\text { Ammonium } \\
\text { Nitrate }\end{array}$ & Ethyl Acrylate & Methyl Acrylate & $\begin{array}{l}\text { Tert-Butyl } \\
\text { Alcohol }\end{array}$ & \\
\hline & & & & \\
\hline
\end{tabular}




\subsection{Chemours (currently operating)}

Chemours, a spinoff of E.I. DuPont De Nemours \& Company (DuPont), is a chemical manufacturing company. ${ }^{94}$ The Louisville plant has reported on-site air, water, and land releases, but most $(99.98 \%)$ of the releases were made via air. ${ }^{95}$ Chlorodifluoromethane accounts for the majority of Chemours' chemical releases, followed by chloroprene and hydrochloric acid. ${ }^{95}$ All chemicals released on-site between 1987 (first year for which data are available) and 2016 (most recent data available) that were reported to the EPA's TRI program are listed in Table 7.

Table 7. Chemicals Released On-Site by Chemours between 1987 and 2016, Listed Alphabetically ${ }^{95}$

\begin{tabular}{|c|c|c|c|}
\hline $\begin{array}{l}\text { 2,2-Dichloro- } \\
1,1,1- \\
\text { Trifluoroethane }\end{array}$ & Chlorine & Dichlorodifluoromethane & Hydrochloric Acid \\
\hline 2-Ethoxyethanol & Chlorodifluoromethane & Dichlorofluoromethane & Hydrogen Fluoride \\
\hline Ammonia & Chloroform & Dichloromethane & Tetrachloroethylene \\
\hline $\begin{array}{l}\text { Antimony } \\
\text { Compounds }\end{array}$ & Chloroprene & Dichlorotetrafluoroethane & Toluene \\
\hline Boron Trifluoride & $\begin{array}{l}\text { Chromium } \\
\text { Compounds }\end{array}$ & Diethanolamine & Vinyl Fluoride \\
\hline
\end{tabular}

\subsection{Rubbertown's Impacts on the Riverside Gardens Community}

Riverside Gardens residents have been deeply impacted by the development of Rubbertown. The first example of Rubbertown's impacts on the community involves the community's rezoning. In order for Rubbertown to expand, Riverside Gardens was rezoned for industry (M-3 Industrial Zoning) in 1964. ${ }^{96,97}$ The neighborhood's industrial rezoning prevented Riverside Gardens residents from making improvements to their homes, such as adding on garages, and from building new houses. ${ }^{96}$ The industrial 
rezoning also allowed salvage operations and junkyards to move into the neighborhood. ${ }^{96}$ Residents petitioned their local government to change the neighborhood's zoning from industrial to residential for years, and they finally succeeded in $1971 .{ }^{96,98}$

Living near Rubbertown has also posed many safety concerns over the past 50 years. Explosions occurred at the DuPont plant in 1965 and again in $1969 .{ }^{99}$ The Stauffer plant experienced a major explosion in 1966, ${ }^{72}$ and the former Borden plant (now Hexion) experienced a tank blast in $1985 .{ }^{99}$ More recently in September 2018, a fire started at the nearby American Synthetic Rubber Company plant. ${ }^{38}$ Numerous chemical releases from Rubbertown plants have also occurred, ${ }^{36}$ the most recent in February 2017, when a green substance was released from Hexion into a creek that runs through Riverside Gardens. ${ }^{37}$ It is not uncommon for Rubbertown companies to withhold information from community members after releases, explosions, or fires occur, which has frequently caused community members to worry about their health and safety. ${ }^{36,38,39}$ Additionally, strong odors, allegedly emitting from Rubbertown plants, have been reported by nearby residents. ${ }^{41,42}$ Air pollution is another major concern in the area and has been for decades, with documented reports from as early as the $1940 \mathrm{~s} .{ }^{43-45,100} \mathrm{~A}$ recent example of the air pollution problems in the area involves Hexion Specialty Chemicals, Inc., the chemical company that borders Riverside Gardens to the north. Hexion faced a fine of \$258,750 in March 2018 after the Louisville Metro Air Pollution Control District determined that the company had nearly 100 excess emission events between February 2015 and January 2018. ${ }^{101}$ Fourteen of the events occurred between February 2015 and April 2016, and then 85 more took place between April 2016 and January 2018. ${ }^{101}$ This fine comes more than a decade after residents of Riverside Gardens 
filed a lawsuit against Hexion alleging damages related to air emissions, releases, and odors coming from the company's Rubbertown plant. ${ }^{40}$ The lawsuit was settled out of court.

\section{LG\&E's Cane Run Power Plant}

\subsection{Background}

In addition to the Lees Lane Landfill and Rubbertown, Riverside Gardens is surrounded by coal ash, a byproduct of coal combustion. LG\&E's Cane Run power plant is located to the south of the Riverside Gardens neighborhood. The plant began operating in November $1954^{31}$ and operated as a coal-burning plant until June 2015, at which time it transitioned to natural gas. ${ }^{31,102}$

A coal ash landfill occupying 110 acres $^{103}$ with an elevation of 560 feet resides on the property. ${ }^{104}$ This coal ash landfill opened in $1982 .{ }^{103}$ Before that, the site of the coal ash landfill was used as a coal ash pond. ${ }^{104}$ The landfill became inactive in 2015 after the plant converted to natural gas ${ }^{105}$ and has been capped. ${ }^{106}$

From 1972 until August 31, 2017, ${ }^{107}$ the plant contained another large coal ash pond with a surface area of approximately 40 acres. ${ }^{104}$ This large pond was previously given a high hazard rating by the EPA, meaning that failure of the structure "would probably result in loss of human life." ${ }^{108,109}$ At one time, the plant also had several small ponds, at least one of which potentially stored coal ash. ${ }^{104}$ It is unknown if these ponds have been closed. 


\subsection{Coal Ash}

The properties of coal ash are dependent on several factors, including the composition of the coal burned, burning conditions, and climate. ${ }^{110}$ Despite the potential differences in makeup, coal ash frequently contains heavy metals, radioactive elements, and polycyclic aromatic hydrocarbons (PAHs). ${ }^{111-115}$ There are several types of coal ash, including bottom ash, boiler slag, synthetic gypsum, and fly ash; the most common of these is fly ash. ${ }^{116}$ Fly ash is made up of small, spherical particles with diameters predominately $\leq 10 \mu \mathrm{m}\left(\mathrm{PM}_{10}\right) .{ }^{113,117}$ The particles often appear as tan or gray in color and are of fine to medium silt-size depending on the parent coal. ${ }^{111,112}$

Fly ash particles are formed during coal combustion. When coal is burned for energy production, fine liquid droplets are released and carried away by flue gases. ${ }^{111}$ As these droplets rise through the smokestack, they undergo rapid solidification and form small, glassy, perfectly spherical particles known as fly ash. ${ }^{111}$ Fly ash particles collect in air pollution control devices and, after their removal, are transported in trucks to ash ponds and landfills for storage. Some coal ash is recycled and used in products such as cement and concrete, but most ash is stored on site.

Fly ash particles can be emitted into the air during the loading, unloading, and transportation processes involved in their relocation to ash ponds and landfills. Wind conditions can influence the number of fly ash particles that are made airborne. Once these particles are made airborne, they may be able to travel distances of up to hundreds of kilometers before settling. ${ }^{118}$ These migrating particles are referred to as fugitive dust. Once the fly ash particles reach their storage site, fugitive dust is still a concern. Features of the ash landfills and ponds as well as their maintenance can affect fugitive dust 
emissions. For example, dry, uncovered landfills are more prone to emit fugitive dust than wet, covered landfills. Likewise, ash ponds that lack adequate water are more likely to emit fugitive dust than those with a proper water to coal ash ratio. In an attempt to prevent fugitive dust emissions, the EPA now mandates that coal ash landfill and pond operators develop fugitive dust plans, which include the use of covers for trucks transporting ash to ponds and landfills, wind barriers around storage sites, and water spray systems. ${ }^{119}$

\subsection{Community Coal Ash Complaints}

Residents have expressed their concerns about coal ash for years. In 2012, Riverside Gardens community members participated in focus groups along with community members from other neighborhoods that border the Cane Run plant. ${ }^{48}$ Focus groups revealed that residents were worried about their health and their children's health, highlighting conditions such as ADHD and asthma. In addition to health concerns, residents mentioned the smell of the plant's ponds as well as dirty houses and cars when discussing how coal ash storage at the nearby plant impacted their lives. Residents also expressed that dirtiness caused by fugitive ash escaping from the landfill impacted their quality of life.

Riverside Gardens residents have filed complaints with the Louisville Metro Air Pollution Control District (APCD) concerning fugitive coal ash and odors coming from the Cane Run plant. LG\&E received numerous fines related to fugitive coal ash dust, strong odors, and other violations between August 2011 and July 2014 alone. ${ }^{46,47}$ In March 2011, Riverside Gardens residents filed a lawsuit against LG\&E alleging that the 
Cane Run coal-powered plant and its coal ash landfill had polluted their neighborhood for years with an assortment of toxins. ${ }^{120}$ The lawsuit was settled out of court.

\subsection{Fly Ash Exposure and Human Health}

Humans may be exposed to coal ash through inhalation, skin absorption, and oral ingestion. The small size and shape of fly ash particles makes them particularly hazardous to human health when inhaled. Particles of this size are able to penetrate deeply into the lungs and make their way into the bloodstream. ${ }^{13,121}$ As particle size decreases, surface area and pollutant concentration increase. ${ }^{117,122}$ Spencer and Drake (1987) found that the concentration of metals in fly ash can be two times higher than concentrations found in coal.

Despite the potential for fly ash-sized particles to bypass the human body's natural barriers, the effects of chronic coal ash exposure have not been well-studied. The studies that have explored this area are limited to animals, occupational exposures, effects of prenatal exposure, human cells, or are specific to PAHs. Although the health effects of exposure to coal ash have not been well-investigated, numerous studies have assessed the effects of exposure to many of coal ash's components, including metals, as well as to airborne particulate matter in general. Health effects related to metals and particulate matter will be discussed in the next section. 


\subsection{On-Site Releases of Toxic Chemicals Reported to EPA's TRI Program}

In addition to coal ash, Riverside Gardens residents are also potentially exposed to other chemicals released by LG\&E's Cane Run plant. Between 1998 and 2015, LG\&E's Cane Run plant reported on-site releases of toxic chemicals to air, land, and water to the EPA's TRI program. ${ }^{123}$ Slightly more than half (53.3\%) of these releases were made via air, followed by land releases $(46.4 \%)$ and water releases $(0.3 \%){ }^{123}$ Metals were often released to land while sulfuric acid, hydrochloric acid, and hydrogen fluoride were frequently released via air. ${ }^{123}$ All chemicals released on-site between 1998 (first year for which data were reported to TRI) and 2015 (last year for which data were reported to TRI) that were reported to the EPA's TRI program are listed in Table 8.

Table 8. Chemicals Released On-Site by LG\&E's Cane Run Plant between 1998 and 2015, Listed Alphabetically ${ }^{123}$

\begin{tabular}{|c|c|c|c|}
\hline Arsenic Compounds & $\begin{array}{l}\text { Dioxin and Dioxin- } \\
\text { Like Compounds }\end{array}$ & $\begin{array}{l}\text { Mercury } \\
\text { Compounds }\end{array}$ & $\begin{array}{l}\text { Vanadium } \\
\text { Compounds }\end{array}$ \\
\hline Barium Compounds & Hydrochloric Acid & N-Hexane & Zinc Compounds \\
\hline Chromium Compounds & Hydrogen Fluoride & Nickel Compounds & \\
\hline Cobalt Compounds & Lead Compounds & $\begin{array}{l}\text { Polycyclic Aromatic } \\
\text { Compounds }\end{array}$ & \\
\hline Copper Compounds & $\begin{array}{l}\text { Manganese } \\
\text { Compounds }\end{array}$ & Sulfuric Acid & \\
\hline
\end{tabular}

\section{Potential Health Effects}

Residents of Riverside Gardens are potentially exposed, or may have been exposed in the past, to numerous types of environmental pollution from the Lees Lane Landfill, Rubbertown companies, and LG\&E's Cane Run power plant. In some cases, the same substances are released from or have been detected at multiple sites. For example, lead has been detected in groundwater and soil samples collected from the Lees Lane Landfill site ${ }^{15,57}$ and has been released from LG\&E and two Rubbertown 
companies. ${ }^{87,88,123}$ Many of the substances that have been released or detected are associated with health effects. Exposure to these substances may occur through ingestion (e.g., through contaminated groundwater, soil, or food grown in the neighborhood), inhalation, or dermal absorption.

\subsection{Cancer}

One potential category of health outcome that has been linked to some of these contaminants is cancer. For example, arsenic, ${ }^{124}$ benzene, ${ }^{125}$ cadmium, ${ }^{124}$ chromium (VI), ${ }^{124}$ 1,3-butadiene, ${ }^{125}$ benzo(a)pyrene, ${ }^{125} \mathrm{PCBs},{ }^{126}$ trichloroethylene (TCE), ${ }^{127}$ and vinyl chloride ${ }^{125}$ have all been detected in or around the Lees Lane Landfill site (including residents' homes), are released by nearby Rubbertown companies, and/or are common components of coal ash. All of these are also classified as Group 1 carcinogens by the International Agency for Research on Cancer (IARC), indicating that there is sufficient evidence that each of these is carcinogenic to humans. Additionally, IARC has classified particulate matter as a Group 1 carcinogen. ${ }^{128}$ Exposure to arsenic, ${ }^{124}$ PCBs, ${ }^{129}$ TCE, ${ }^{127}$ and vinyl chloride ${ }^{125}$ has been associated with liver cancer. Exposure to PCBs is associated with cancer of the biliary tract. ${ }^{129} \mathrm{TCE},{ }^{127}$ cadmium, ${ }^{124}$ and particulate matter ${ }^{128}$ are associated with kidney cancer, while arsenic exposure has been linked to bladder cancer. ${ }^{124}$ Some cancers of the blood have been observed after long-term exposure to vinyl chloride and inhalation of 1,3-butadiene, ${ }^{125,129}$ and exposure to benzene can lead to acute myelogenous leukemia. ${ }^{125} \mathrm{TCE}^{127}$ and 1,3-butadiene ${ }^{125}$ exposures are associated with cancer of the lymphatic system. Exposure to arsenic, ${ }^{124}$ chromium (VI), ${ }^{124}$ and particulate matter ${ }^{128}$ has been associated with lung cancer. Additionally, 
arsenic exposure has been linked to skin cancer. ${ }^{124}$ Positive associations have also been found between cadmium exposure and prostate cancer. ${ }^{124}$ While this section has focused on substances that are widely accepted to be carcinogenic to humans, there are at least 19 other chemicals that have been released or detected in the Riverside Gardens area that are possible or probable carcinogens. ${ }^{127,130-142}$

\subsection{Respiratory Effects}

Aside from cancer, studies have shown that many of the substances that are found in coal fly ash, are released from Rubbertown plants, and have been identified in or near the landfill site as well as in Riverside Gardens homes can lead to a variety of other acute and chronic health outcomes. Numerous respiratory outcomes are related to the substances that have been released or detected in the Riverside Gardens area. For example, respiratory outcomes such as shortness of breath, cough, wheeze, and asthma can result from chromium (VI) exposure, ${ }^{143}$ which has been detected at the Lees Lane Landfill and is released by a nearby Rubbertown company. Breathing difficulties can also result from exposure to other contaminants released from Rubbertown, as well as from exposure to coal fly ash and particulate matter. ${ }^{134,144-147}$ Nose and mouth dryness, nose ulcers, runny nose, and nose, throat, and lung irritation are all outcomes related to the exposure of several landfill site and Rubbertown contaminants. ${ }^{143,148-155}$ Additionally, exposure to airborne particulate matter has been linked to respiratory conditions such as chronic obstructive pulmonary disease. ${ }^{156}$ 


\subsection{Cardiovascular Effects}

Cardiovascular effects including changes in heart rhythm, heart rate, blood pressure, blood flow, and blood vessels have been observed after exposure to several of the chemicals found on the landfill site and in Riverside Gardens homes. ${ }^{138,148,150,157-161}$ Exposures to metal pollutants such as arsenic, lead, and possibly cadmium, all of which have been identified at the Lees Lane Landfill and may be found in coal ash, are associated with cardiovascular disease, coronary heart disease, stroke, and hypertension. ${ }^{162}$ Additionally, exposure to airborne particulate matter has been associated with cardiovascular morbidity and mortality in adults. ${ }^{163}$

\subsection{Hematological Effects}

Arsenic, ${ }^{151}$ benzene, ${ }^{150}$ and lead ${ }^{138}$ may cause an interruption in normal blood cell production. Exposure to naphthalene, which is released by the chemical company that borders Riverside Gardens to the north, can damage and destroy red blood cells, which can lead to hemolytic anemia. ${ }^{164}$

\subsection{Renal and Hepatic Effects}

The kidneys and liver are negatively impacted by exposure to many of the substances found on or near the landfill, are commonly present in coal ash, and/or are released from Rubbertown companies. ${ }^{132,133,138,158-160,165}$ Exposures to metal pollutants such as arsenic, lead, and cadmium, all of which have been identified at the Lees Lane Landfill and may be found in coal ash, are associated with kidney disease. ${ }^{162}$ 


\subsection{Gastrointestinal Effects}

An assortment of gastrointestinal effects may occur after exposure to many of the chemicals found in and around Riverside Gardens. Such effects include nausea, vomiting, loss of appetite, stomach discomfort, inflammation, reflux, ulcers, and diarrhea. ${ }^{145,152,157,158,164-166}$ Gastrointestinal disturbances and abdominal cramps may result from the ingestion of barium, ${ }^{157}$ and the ingestion of barium, cadmium, and thallium can all cause diarrhea. ${ }^{157,158,165}$ High concentrations of barium and cadmium were detected in samples of groundwater from the Lees Lane Landfill site, and a higher than expected level of thallium was detected in on-site soil samples.

\subsection{Neurological Effects}

A variety of central nervous system (CNS) effects have resulted from exposure to contaminants found at the landfill site, in Riverside Gardens homes, in coal ash, and that are released by Rubbertown companies. Such effects include narcosis, headache, drowsiness, dizziness, confusion, and unconsciousness. ${ }^{132,134,150,151,157,158,160,161,167-170}$ The feeling of pins and needles in the hands and feet, numbness around the face and in fingers and toes, tremors, and paralysis are also possible outcomes. ${ }^{134,150,151,157,158,166,171}$ Changes in behavior and mood have been observed. ${ }^{167,172}$ Incoordination, experiencing the feeling of being intoxicated, impaired judgement, slowed reaction time, vision changes, visual disturbances, and problems with attention have also been noted..$^{132,134,167,173}$ Finally, exposure to airborne particulate matter has been linked to sleep disturbances. ${ }^{174}$ 


\subsection{Developmental Effects}

Lead, arsenic, manganese, mercury, chromium (VI), and cadmium are known neurotoxins. ${ }^{138,143,165,166,172,175}$ All of these metals are released into the environment by companies surrounding Riverside Gardens or have been detected at the Lees Lane Landfill. Exposure to neurotoxins can result in developmental delays, cognitive deficits, and changes in behavior, along with other neurobehavioral impacts. ${ }^{147,175}$

\subsection{Skin and Eye Effects}

Skin and eye irritation are commonly reported after exposure to numerous chemicals that are released by Rubbertown companies and that have been detected in samples taken from the Lees Lane Landfill and Riverside Gardens

homes. ${ }^{130,131,144,149,169,170}$ Exposure to arsenic can lead to a variety of skin problems, including the darkening of the skin, redness and swelling, and the development of small corns and warts on the torso, palms of hands, and soles of feet. ${ }^{151}$ Rashes, acne, skin sores, temporary hair loss, and scleroderma have also been reported after exposure to multiple landfill site contaminants. ${ }^{158,159,176}$

\subsection{Reproductive Effects}

Lead $^{138}$ and manganese ${ }^{172}$ exposure may impact reproduction, and lead exposure may result in miscarriage or damage to the organs responsible for sperm production. ${ }^{138}$ Exposure to benzo(a)pyrene, which was detected in soil samples collected on and off the Lees Lane Landfill site, may be toxic to both male and female reproductive systems. ${ }^{177}$ 
TCE exposure in the workplace has been linked to decreases in reproductive hormone levels and sperm quality in men. ${ }^{159}$

\subsection{Health Outcomes in Communities Near Hazardous Waste Sites and Other Industrially-Contaminated Areas}

Past studies evaluating the human health outcomes associated with exposure to hazardous waste sites and other industrially-contaminated areas have documented a wide range of health problems. Examples of frequently documented categories of health problems include irritation of the eyes and skin, ${ }^{178-187}$ respiratory symptoms and disorders, ${ }^{178,180,183,185,186,188}$ gastrointestinal problems and disorders, ${ }^{180-182,184,186-188}$ fatigue, ${ }^{179-181,188}$ chest pain, ${ }^{178,179,184,188}$ heartbeat irregularities, ${ }^{179,186,188}$ psychological symptoms, ${ }^{179,180,182-184,187}$ learning difficulties, ${ }^{179,187}$ and headaches. ${ }^{184,188}$ Less frequently reported health problems include chronic sinusitis, ${ }^{186}$ dizziness, ${ }^{179}$ numbness in fingers/toes, ${ }^{179}$ sleeping difficulties, ${ }^{179}$ peculiar odor/taste, ${ }^{179}$ poor concentration, ${ }^{180}$ sore throat, ${ }^{180}$ allergies, ${ }^{182}$ anemia, ${ }^{188}$ other blood problems, ${ }^{188}$ bruising and bleeding, ${ }^{188}$ incontinence, ${ }^{187}$ endometriosis, ${ }^{189}$ thyroid gland disorders, ${ }^{189}$ miscarriages, ${ }^{184}$ and poor general health. ${ }^{184}$ Additionally, in a systematic literature review of 41 papers, maternal residential proximity to industrially polluted sites was associated with adverse reproductive outcomes in all studies, though not all were statistically significant. ${ }^{190}$ Low birth weight was associated with maternal residential proximity to industrially polluted sites in all but two of these studies. ${ }^{190}$ Another systematic review on the health status of communities living near hazardous waste sites found associations with liver, bladder, breast, and testicular cancer, as well as non-Hodgkin lymphoma. ${ }^{191}$ 


\section{Community Health Investigations}

Urgent community requests for the investigation of health and exposure concerns similar to those expressed by Riverside Gardens residents are not unprecedented. There are numerous examples of how such persistent calls for action have resulted in formal health investigations that have sought to answer a community's health questions related to an environmental exposure. Examples of such investigations include those that took place in the Love Canal neighborhood of New York; Toms River in Toms River Township (formerly Dover Township), New Jersey; and recently, Pompton Lakes, New Jersey.

\subsection{Love Canal, New York}

Love Canal is one of the most well-known environmental disasters in U.S. history. Love Canal's story began in 1894 when William T. Love began digging a trench in Niagara Falls, New York in an attempt to connect the upper and lower Niagara Rivers. ${ }^{192}$ Soon after digging began, the partially-dug canal was abandoned. ${ }^{192}$ In 1942 , Hooker Chemical, a nearby chemical company, began using the canal for the disposal of chemical waste. ${ }^{192}$ Between 1942 and 1953, Hooker Chemical disposed approximately 21,800 tons of at least 200 different chemicals. ${ }^{192}$ In 1953, the landfill site was sold to the Niagara Falls Board of Education, and an elementary school was built on the landfill site the following year. ${ }^{192}$

Between the mid-1950s and early 1970s, homes were built near the landfill site, including many homes with backyards that bordered the site. ${ }^{192}$ In 1976 , reports that landfill materials were seeping into basements of homes were made by community 
members whose property bordered the landfill. ${ }^{192,193}$ Chemical odors and the surfacing of contaminated waste in residents' backyards were also reported. ${ }^{192}$ Community members became concerned about the potential health effects of the waste products they were being exposed to and took it upon themselves to begin tallying illnesses in the neighborhood. ${ }^{194}$ The community became concerned with the number of reports of miscarriages, birth defects, and illnesses that were reported during the survey. ${ }^{194}$ Community complaints to state and federal officials and media coverage began to grow. ${ }^{193,194}$ As a result, the New York State Health Department's Division of Laboratories and Research began environmental sampling in homes near the landfill site in March 1978. ${ }^{192}$ Air sampling was the initial focus, and numerous volatile organic compounds were found in the air in basements and living spaces of homes bordering the landfill. ${ }^{192}$ The New York State Health Commissioner declared the landfill site "a threat to human health and welfare" in April 1978, and a fence was erected to restrict access to the site. ${ }^{192}$ Beginning in the spring of 1978 , field interviews were conducted by the state health department's Bureau of Environmental Epidemiology and Occupational Health. ${ }^{192}$ Field interviews were conducted with Love Canal residents, their physicians, and control populations. ${ }^{192}$ A 22-page questionnaire focusing on participants' health and exposure histories was administered. ${ }^{192}$ Blood samples were also collected from some participants. ${ }^{192}$

In August 1978, state officials began relocation efforts to permanently evacuate residents who lived closest to the landfill. ${ }^{192}$ Many Love Canal residents whose homes were not within the relocation area became concerned about the potential effects that living near the site was having on their health. After the initial relocation occurred, Lois 
Gibbs, a homeowner and community activist who lived outside the initial relocation zone, became president of the Love Canal Homeowners Association. ${ }^{194}$ Gibbs and other community members fought state and federal officials to expand the relocation area, arguing that environmental testing in their area found levels of chemicals that could be harmful to human health. ${ }^{194}$ Gibbs also began working with Beverly Paigen, a cancer researcher of Roswell Memorial Institute, and together they developed a hypothesis that chemicals were migrating farther from the landfill than previously thought through swales, natural depressions created by old streambeds and ponds that had been filled in during the neighborhood's development. ${ }^{194}$ Gibbs and Paigen then reviewed illness rates among people living along swales and found higher illness rates in those areas. ${ }^{194}$ Their hypothesis was controversial at the time but was later supported by studies carried out by the New York State Department of Health. ${ }^{194}$

In May of 1980, the results of an EPA pilot study on genetic damage among Love Canal residents were leaked. ${ }^{194}$ Media coverage of Love Canal peaked as angry residents demanded immediate action. ${ }^{194}$ In May of 1980, President Jimmy Carter declared Love Canal a national emergency, which allowed for the relocation of the remaining residents. ${ }^{193}$

7.1.1 Health Investigations of Love Canal Residents. Questions concerning how Love Canal's landfill may have affected the health of community members are still being answered today. Early investigations suggested that there may have been an increased prevalence of asthma and seizure disorders, frequency of chromosomal aberrations, incidence of respiratory cancer, and risk of abnormal liver tests among Love Canal residents; ${ }^{187,192,195}$ however, subsequent studies had contradictory findings. ${ }^{187,192,195,196}$ 
Among Love Canal births, increased risks of low birth weights, congenital malformations, and other adverse reproductive events were observed. ${ }^{195,197,198}$ In 1996, the New York State Department of Health, with input from former Love Canal residents and an Expert Advisory Committee, initiated the Love Canal Follow-Up Health Study. The study's purpose is to explore health outcomes among residents who participated in health interviews between 1978 and 1982 and their children. The follow-up study is focused on four topics: birth outcomes, death rates and causes, cancer incidence, and the measurement and evaluation of some Love Canal chemicals in the stored blood serum samples of a subgroup of the residents. ${ }^{195}$ Former Love Canal community members have been included in decisions related to the study, including the study's focus and design. ${ }^{195}$

Initial findings related to birth outcomes include an increased risk of preterm birth among children born at Love Canal, greater than expected frequencies of congenital malformations among males, lower ratio of male to female births among children conceived at Love Canal, and an increased risk for low birth weight infants among mothers who lived closest to the canal as children. ${ }^{199}$ The study assessing death rates and causes found an increased mortality ratio for acute myocardial infarction when comparing the Love Canal cohort to New York State. ${ }^{200}$ Additionally, a greater than expected incidence of bladder and kidney cancer was observed when comparing cancer incidence in former Love Canal residents to New York State residents, though the differences were not statistically significant. ${ }^{201}$ The Love Canal cohort is still relatively young and the mortality and cancer incidence findings may change as the community ages. For this reason, the cohort continues to be followed. 


\subsection{Toms River, New Jersey}

In 1995, a member of the Toms River Township (formerly Dover Township), New Jersey community and a nurse from a nearby pediatric cancer center both contacted the Agency for Toxic Substances and Disease Registry (ATSDR) and expressed concerns about the incidence of childhood cancer in the Toms River area. ${ }^{202}$ Prior to being contacted by these individuals, ATSDR had been working with officials from the New Jersey Department of Health and Senior Services (NJDHSS) to identify public health threats from two EPA NPL sites in the Toms River area. ${ }^{202}$ The two NPL sites were the Ciba-Geigy Corporation site and the Reich Farm property. ${ }^{202}$ A municipal landfill in the area that had previously received industrial wastes was also investigated. ${ }^{202}$

7.2.1 Ciba-Geigy. The Ciba-Geigy Corporation site was home to a chemical manufacturing plant from 1952 until $1996 .{ }^{203}$ The site was surrounded by the Toms River, an outdoor recreational area, multiple residential areas, an elementary school, and commercial properties. ${ }^{203}$ Beneath the site lie several aquifers, some of which discharge into the Toms River. ${ }^{203}$ The aquifers that lie beneath the Ciba-Geigy site are a major source of potable and irrigation water in the Toms River area. ${ }^{203}$

The company's manufacturing processes generated liquid and solid waste products that were disposed of in approximately 20 on-site areas, several of which were unlined. ${ }^{203}$ Contaminants such as VOCs, semivolatile organic chemicals, polycyclic aromatic hydrocarbons, and heavy metals (including arsenic, cadmium, chromium, mercury, and lead) have been identified on-site. ${ }^{203}$ Additionally, from 1952 through 1966, treated process wastewater was discharged directly to the Toms River. ${ }^{203}$ Groundwater near the site was found to be contaminated with a variety of VOCs, metals (including 
lead and mercury), and possibly other chemicals. ${ }^{203}$ Community water system supply wells near the site were found to be contaminated with dyes, nitrobenzene, and possibly other compounds during the mid-1960s, and private residential wells used for irrigation near the site were found to be contaminated with VOCs in the mid-1980s. ${ }^{203}$

The community surrounding the Ciba-Geigy site had expressed concerns and filed complaints about environmental contamination at the site throughout its period of operation. ${ }^{203}$ Many of the complaints received regarded odors, stack emissions, and contamination of surface waters of the Toms River. ${ }^{203}$

The Ciba-Geigy site was listed as an NPL Superfund site in $1983 .{ }^{204}$ The remedy that was selected to restore groundwater utilized a combination of removal and bioremediation techniques. ${ }^{204}$ Contaminated groundwater beneath the site was pumped out, treated, and returned to the aquifer. ${ }^{204}$ Additionally, contaminated irrigation wells were sealed off and wastewater treatment plants were modified to treat contaminated groundwater. ${ }^{204}$ The remedy selected for on-site contamination included on-site ex-situ bioremediation, removal and off-site disposal of about 35,000 drums and 5,000 cubic yards of soil, and the installation of caps and slurry walls on-site. ${ }^{204}$

7.2.2 Reich Farm. The Reich Farm property is just northeast of the Ciba-Geigy site in Toms River Township. Reich Farm operated as a poultry farm, and in 1971, the farm's owners agreed to allow an independent waste hauler to lease a portion of their farm for the temporary storage of 55-gallon drums. ${ }^{205,206}$ In December 1971, the Reich Farm property owners noticed odors emitting from the drum storage area. ${ }^{205}$ They discovered about 4,500 drums containing wastes and 450 empty drums that had been left on the property. ${ }^{206}$ The drums contained organic solvents and residues from the 
manufacturing of organic chemicals, plastics, and resins. ${ }^{206}$ The majority of the drums had Union Carbide Corporation markings on them. ${ }^{206}$ In addition to the drums, trenches in which wastes may have been dumped were discovered. ${ }^{206}$ Consequently, the Reich Farm property owners and Toms River Township filed complaints to the New Jersey Superior Court against the waste hauler and Union Carbide. ${ }^{206}$ The court ordered dumping to cease and the removal of all waste and drums from the property. ${ }^{206}$ In 1972 and 1974, Union Carbide removed drums and over 1,000 cubic yards of contaminated soil and trenched wastes from the site. ${ }^{206}$

In 1974, community members living near the site became concerned about the unusual odor and taste of their well water. ${ }^{206}$ The well water was tested and petrochemical contaminants, such as toluene and phenol, were detected. ${ }^{206}$ As a result of extensive testing to nearby well water, 148 private wells were closed and groundwater use near the Reich Farm property was restricted. ${ }^{206}$ The cause of the well water contamination was determined to be residual waste that had leaked from the drums stored on the Reich Farm property. ${ }^{207}$ The waste had contaminated the soil and underlying groundwater with organic chemicals. ${ }^{207}$

The Reich Farm property was listed as an NPL Superfund site in 1983. ${ }^{207}$ Contaminants of concern at the site were 1,1,1,-trichloroethane (TCA), TCE, and tetrachloroethylene (PCE). ${ }^{207}$ The site's remedy called for additional groundwater and soil sampling; the excavation and treatment of contaminated soil; and the installation and operation of a groundwater pumping, treatment, and reinjection system. ${ }^{207}$

\subsubsection{Dover Township Municipal Landfill. The Dover Township Municipal} Landfill is located northeast of the Reich Farm property. It accepted municipal, industrial, 
and other waste from 1956 to $1981 .^{208}$ Similar to Reich Farm, the landfill received drums of waste products from Union Carbide Corporation's Bound Brook facility in 1971. ${ }^{209}$ The majority of the land that surrounds the landfill is used for residential purposes. ${ }^{209}$ In 1981, community members from the residential areas surrounding the landfill expressed concerns regarding the taste and odor of water coming from private wells. ${ }^{209}$ In 1982 , groundwater from the landfill's on-site monitoring wells was found to contain lead, arsenic, and volatile organic compounds. ${ }^{209}$ Private wells were tested in 1982 and volatile organic compounds were detected. ${ }^{209}$ Additional private well sampling occurred between 1987 and 1989, and VOCs and lead were detected. ${ }^{209}$ In response, community members using private well water were connected to a community water supply and their private wells were capped. ${ }^{209}$

7.2.4 Initial Childhood Cancer Incidence Investigation. In 1995, in response to the community's concerns about childhood cancer in the Toms River area, the ATSDR asked NJDHSS to investigate cancer incidence using New Jersey State Cancer Registry data. ${ }^{210}$ Toms River and Ocean County, the county in which Toms River resides, were found to have an excess of childhood brain and central nervous system cancer between 1979 and 1991 when compared to state data. ${ }^{211}$

\subsubsection{Toms River Citizens Action Committee on Childhood Cancer Cluster}

(CACCCC). In response to the childhood cancer incidence investigation, concerned community members formed the Toms River Citizens Action Committee on Childhood Cancer Cluster (CACCCC). ${ }^{210}$ The community was particularly concerned about the role that exposures to environmental contaminants may have played in the area's elevated childhood cancer incidence. ${ }^{210}$ Community members specifically cited the Ciba-Geigy 
and Reich Farm Superfund sites as areas of concern. ${ }^{210}$ The CACCCC went on to play an important role in the investigation of childhood cancer incidence in the Toms River area, serving as a liaison between NJDHSS/ATSDR and the community. ${ }^{210}$ Meetings were also held to inform community members of activities, progress, and findings related to the health investigation. ${ }^{202}$ The meetings were held monthly and occurred throughout the duration of the $5 \frac{1}{2}$ year investigation. ${ }^{202}$

7.2.6 Further Evaluation of Childhood Cancer Incidence. In response to the community's concerns about the elevated childhood cancer incidence in the Toms River area, the NJDHSS and ATSDR first expanded their investigation of childhood cancer incidence through $1995 .{ }^{211}$ Overall childhood cancer incidence was statistically elevated in Dover Township between 1979 and 1995 when compared to state data (standardized incidence ratio [SIR]: $1.3,95 \%$ confidence interval [CI]: 1.1-1.7). ${ }^{209,212}$ This was not true of any other municipality in Ocean County, the county in which Dover Township resides. ${ }^{209}$ The incidence of leukemia was also elevated in Dover Township (SIR not reported). ${ }^{209}$ In the Toms River section of Dover Township, the incidence of overall childhood cancer (SIR: 1.7, 95\% CI: 1.1-2.5), ${ }^{212}$ leukemia (SIR not reported), and brain and central nervous system cancer (SIR not reported) were all elevated. ${ }^{209}$ The excess incidence in leukemia and brain and central nervous system cancer was found primarily among female children under the age of five. ${ }^{209}$

Due to these findings and the concerns expressed by community members of a possible link between environmental factors and elevated childhood cancer incidence, two case-control studies were designed to explore childhood cancer in Dover Township. ${ }^{208}$ The first case-control study employed interviews conducted with parents of 
children who had $(\mathrm{n}=40)$ or had not $(\mathrm{n}=159)$ been diagnosed with certain types of cancer (leukemia, brain, central nervous system, or sympathetic nervous system) between 1979 and $1996 .{ }^{208}$ The interview included questions about the family's medical history, mother's pregnancy history, mother's and child's residence histories, parents' occupations, mother's and child's illnesses, medication use, medical procedures, diet, tap water use, and potential exposures to certain chemicals and biological agents. ${ }^{208}$

The second case-control study looked at birth records of children born in Dover Township between 1964 and 1996 who had been diagnosed with any type of cancer between 1979 and $1996(n=48) .{ }^{208}$ Each case was compared to ten controls who were born in Dover Township in the same year as the case $(n=480) .{ }^{208}$ Pregnancy and birth characteristic data, as well as the mother's residence at the time of the child's birth, were extracted from birth certificates and compared between cases and controls. ${ }^{208}$

In both of the case-control studies, environmental exposures were also considered. ${ }^{212}$ Prior water sampling and identification of the child's water source based on questionnaire responses were used to estimate exposure to groundwater contamination. ${ }^{212}$ Exposure to air pollution was estimated using computer model simulations that took emissions data from the Ciba-Geigy facility and a nearby nuclear generating station and estimated point source air pollution. ${ }^{212}$ Residential proximity to the Ciba-Geigy Superfund site and pipeline, the Reich Farm Superfund site, the Dover Township Municipal Landfill, and other areas of concern were also considered. ${ }^{212}$

The main findings from the case-control studies included: (1) statistically significant associations between prenatal exposure to water from a particular well field between 1982 and 1996 and leukemia in female children of all ages, and (2) elevated 
odds ratios and an apparent dose-response effect between prenatal exposure to CibaGeigy ambient air and leukemia in female children diagnosed before age five in both case-control study populations. ${ }^{212}$

\subsection{Pompton Lakes, New Jersey}

Between 1902 and 1994, E.I. DuPont De Nemours \& Company operated an explosive manufacturing plant in northern Pompton Lakes, New Jersey. ${ }^{213}$ The land surrounding the plant is largely residential and commercial. ${ }^{213}$ Over its decades of operation, the plant's waste management practices led to the contamination of the soils, sediments, and groundwater both on and off the site. ${ }^{214}$ Contaminants of concern in soils and sediments include heavy metals, such as lead and mercury. ${ }^{214}$ Chlorinated solvents, such as TCE and PCE, contaminate the groundwater. ${ }^{214}$

In the 1980s, DuPont began testing private wells of residences bordering the property, and chlorinated solvents and heavy metals were detected in water samples. ${ }^{215}$ By the end of the 1980s, all homes bordering the site were connected to the municipal water supply. ${ }^{215}$ DuPont installed a groundwater treatment system along the site's southeast boundary in 1998 in order to treat the contaminated water and prevent further contamination from leaving the site. ${ }^{215}$

Since chlorinated solvents were present in the off-site groundwater, vapor intrusion became a concern. ${ }^{214}$ In 2008, the indoor air of more than 300 residences near the DuPont site was tested to assess for vapor intrusion. ${ }^{214}$ For homes above the groundwater contamination plume, the New Jersey Department of Health (NJDOH) and ATSDR recommended the installation of migration systems. ${ }^{214}$ 
7.3.1 Community Concerns. Pompton Lakes community members began to express concerns about numerous health and environmental issues to NJDOH and ATSDR. ${ }^{214}$ In 2009, the Mayor of Pompton Lakes and community members requested an investigation into cancer incidence among residents living above the contaminated groundwater plume. ${ }^{214}$ In response, the NJDOH and ATSDR completed an investigation. ${ }^{214} \mathrm{~A}$ community advisory group (CAG) for health was also formed to allow community representatives to express concerns, ask questions, and advise the NJDOH and ATSDR on the community's priorities for health investigation. ${ }^{214}$

7.3.2 Investigation of Cancer Incidence. New Jersey State Cancer Registry data were used to compare cancer incidence between the Pompton Lakes population (specifically those with homes above the groundwater contamination plume) and the state from 1979 to $2006 .{ }^{215}$ Standardized incidence ratios (SIRs) were used for comparison. ${ }^{215}$ The incidence of kidney cancer among females was significantly greater than expected when compared to state rates (SIR: 3.15, 95\% CI: 1.26, 6.49); however, after adjustment for age, there was no longer a statistically significant difference between the two populations, but the SIR remained elevated (SIR: $3.27,95 \%$ CI: 0.88, 8.38). ${ }^{215}$ Overall cancer incidence among females was slightly higher than expected after adjustment for age, but not significantly so (SIR: $1.27,95 \%$ CI: $0.99,1.60) .{ }^{215}$ The only significant elevation in Pompton Lakes men was found for non-Hodgkin lymphoma after age adjustment (SIR: 2.67, 95\% CI: 1.07, 5.50). ${ }^{215}$

7.3.3 Community Health Profile. After the initial investigation into cancer incidence in the Pompton Lakes groundwater contamination plume area, community members continued to express concerns that the community was experiencing a 
disproportionate number of health problems. ${ }^{216}$ Members of the Health CAG took these concerns to NJDOH and ATSDR, and in response, a Community Health Profile and Household Health Survey were developed. ${ }^{216}$ The Community Health Profile utilized existing public health and demographic datasets to compare the health experiences of Pompton Lakes residents to residents of other areas. ${ }^{214}$ Birth records, death records, hospitalization and emergency department records, the New Jersey State Cancer Registry, birth defects registry, childhood lead exposure data, and census information were all used as part of the Community Health Profile. ${ }^{214}$ Key findings included (1) higher mortality rates than expected among those 80 years of age and older, including all-cause mortality and mortality due to heart disease and malignant neoplasms, (2) elevated cancer incidence among Pompton Lakes females compared to state rates between 1990 and 2008, and (3) a higher proportion of emergency department visits due to migraine headaches among Pompton Lakes females when compared to state rates. ${ }^{214}$

\subsubsection{Household Health Survey. The Household Health Survey gathered} information on chronic health conditions experienced by the current and former residents of houses located above the groundwater contamination plume. ${ }^{216}$ The survey was conducted in 2012 and $38.5 \%$ of households responded. ${ }^{216,217}$ Rates of the reported health conditions were compared with national rates from the National Health Interview Survey or state rates from the Behavioral Risk Factor Surveillance System in $2010 .^{216}$ The Household Health Survey found that the percentages of kidney disease, chronic bronchitis, and any type of cancer were elevated among adults surveyed; however, these differences were not statistically significant. ${ }^{217}$ Elevated, yet non-significant, differences 
in asthma diagnoses among children were also observed when compared to national statistics. $^{217}$

7.3.5 Next Steps. The NJDOH and ATSDR reported plans to disseminate the findings of the Community Health Profile and the Household Health Survey to both the Health CAG and Pompton Lakes community. ${ }^{214}$ NJDOH and ATSDR stated that they would continue working with the Health CAG to address the community's questions and concerns. ${ }^{214}$ While steps have been taken to answer the community's health questions, many of the community's environmental concerns remain unaddressed. The community has pushed for years to secure a spot for the Pompton Lakes DuPont site on the NPL Superfund list. ${ }^{218,219}$ At one point, the community group Citizens for a Clean Pompton Lake had gathered 9,650 signatures asking the EPA and elected officials to consider the site for the list, ${ }^{219}$ but the state has so far refused to nominate it. ${ }^{218}$ When asked why, the acting commissioner of the New Jersey Department of Environmental Protection said that there was "no need to involve Superfund - there's a polluter who is paying for cleanup" and that "going through the Superfund process would slow things down."220

\subsection{Summary of Selected Community Health Investigations}

The health investigations that took place at Love Canal, Toms River, and Pompton Lakes provide different examples of how communities and state and federal agencies can work together to investigate and address the health and exposure concerns of a community. The investigations took place over different time periods, and great differences in how community members worked with state and federal agencies during these health investigations can be observed. For example, though some of the Love Canal 
residents worked with independent researchers who were investigating health concerns in their area, there was a great deal of mistrust surrounding state and federal agencies during the early years of the Love Canal investigation early years. A much more collaborative approach was taken with former Love Canal residents during the design of the Love Canal Follow-Up Health Study. While the Toms River CACCCC served as a liaison between state and federal agencies and the community, it was not as collaborative of a relationship as the one between the Pompton Lakes Health CAG and state and federal agencies.

These examples also highlight the different methods that have been employed to answer community members' health questions. Survey research methods were used to collect self-reported health outcomes in the Love Canal and Pompton Lakes communities. This information was later used to make comparisons involving disease prevalence within the community (among those with different exposure levels) and to populations outside of the community.

Existing data sources such as state cancer registries, birth records, and death records have also been utilized. In the Toms River and investigation, existing data sources were used to evaluate the community's cancer concerns first before moving on to more rigorous epidemiologic methods (i.e., two case-control studies that were developed to explore the differences in environmental exposures between the cases and controls). During the Pompton Lakes investigation, existing data sources were assessed first, and then state and national data were used as a comparison group for data collected (using survey research methods) from current and former residents concerning their selfreported health outcomes. In the case of Love Canal, existing data sources (i.e., state 
cancer registry, vital statistics, and state congenital malformations registry) are being utilized to follow a cohort of former Love Canal residents as part of the Love Canal Follow-Up Health Study.

\section{Riverside Gardens Cancer Morbidity Review}

For years, residents of Riverside Gardens expressed concerns regarding the health of the community to local and state officials, the media, and the EPA. In August 2011, the ATSDR contacted the Kentucky Department for Public Health (KDPH) regarding the Riverside Gardens community's health concerns. ${ }^{15}$ ATSDR asked KDPH to review cancer morbidity rates near the Lees Lane Landfill. ${ }^{15}$ In response, KDPH assessed cancer morbidity between 1999 and 2008 in the 40216 zip code, the zip code to which the Riverside Gardens community belongs. ${ }^{15}$ The ratio of the observed to expected cancer cases in the 40216 zip code was 1.43 (confidence interval not reported). ${ }^{15}$ The Centers for Disease Control and Prevention (CDC) guidelines were used in order to determine if a formal health investigation would take place. ${ }^{15}$ These guidelines recommend that observed to expected cancer ratios should be 2 or 3 before considering an environmental investigation. ${ }^{15}$ Using these guidelines, it was determined that the criteria for a further health investigation had not been met. ${ }^{15}$

While Riverside Gardens is part of the 40216 zip code, the neighborhood only accounts for a small portion of the zip code's population. For example, 2012-2016 American Community Survey 5-Year Estimates estimate that the population size of the 40216 zip code is $42,371 .{ }^{1}$ The block group to which Riverside Gardens belongs (Block Group 2, Census Tract 127.02) has an estimated population of $1,086,{ }^{1}$ and Riverside 
Gardens itself has an estimated population of about $800 .{ }^{1}$ Statistics calculated on the zip code level may not be representative of the Riverside Gardens neighborhood. Thus, cancer morbidity on the zip code level may differ from the cancer morbidity on the neighborhood level. However, it should also be noted that an evaluation of cancer morbidity using a population of 800 would likely yield unstable estimates.

\section{Significance of this Dissertation Project}

Like the investigations conducted in Love Canal, Toms River, and Pompton Lakes, this study is an important next step in understanding the health and environmental exposures of Riverside Gardens residents. This project is the first to collect self-reported health and exposure history data from residents. The study and its findings are extremely significant to the community, as they will help to answer community questions regarding the health of residents and explore if health conditions in the neighborhood exceed local, state, and national estimates.

Furthermore, this project aimed to assist the Kentucky Department for Public Health (KDPH) in responding to questions regarding the health of the community and to help strengthen the community bond between the University of Louisville and residents of Riverside Gardens, as the University attempts to conduct research that is communitybased and helpful to its surrounding population. 


\section{METHODS}

In the summer of 2015, KDPH contacted University of Louisville faculty member, Kristina Zierold, $\mathrm{PhD}$, about conducting a health study in the Riverside Gardens neighborhood of Jefferson County, Kentucky. Over the years, several residents had contacted the health department with concerns of elevated rates of cancer and other health conditions in their community, and KDPH wanted to partner with Dr. Zierold to assess the health of the community. Dr. Zierold discussed the idea of conducting a health study in Riverside Gardens with me in the summer of 2015. After securing graduate student research funding from the University of Louisville's Commission on Diversity and Racial Equality in the spring of 2016, I began working on this project as an independent study under Dr. Zierold in the summer of 2016. Additional funding for this project was awarded by the University of Louisville's Graduate Student Research Fund in the spring of 2017. The independent study project led to this dissertation study.

This dissertation will present results from a two-part, community-based, mixedmethods study taking place in the Riverside Gardens neighborhood. The first phase of the study employed qualitative research methods (individual interviews) with adult community members who had lived in the neighborhood for a minimum of five years. Topics explored during the interviews included the neighborhood's history, participants' perceptions of the community's health, participants' personal health, and participants' exposure histories. 
Findings from the individual interviews were used to create a comprehensive health and exposure assessment questionnaire that was used in the second phase of this study (a cross-sectional epidemiologic study). The second phase of the study was both a qualitative and quantitative exploration of the health and exposure histories of adult community members who had lived in the neighborhood for at least one year.

The first phase of the study involving the individual interviews was approved by the University of Louisville's Institutional Review Board in Fall 2016 (IRB Number: 16.0843). The health and exposure assessment survey, the second part of the study, received IRB approval in early Summer 2018 (IRB Number: 18.0022).

\section{Location and Population}

Participants for both the individual interviews and the health and exposure assessment survey were recruited from the Riverside Gardens neighborhood located in Jefferson County, Kentucky (40216). Eligibility criteria for individual interviews included residence in Riverside Gardens at the time of the interview and for at least five years prior, and a minimum age of 18 years. Eligibility criteria for the health and exposure assessment survey were similar to those used for the individual interviews, however, instead of requiring that participants live in the neighborhood for five years, participants were only required to have lived in Riverside Gardens for at least one year. Non-English speaking adults and adults with diagnosed cognitive illnesses (e.g. dementia) were excluded from participating in both phases of the study. 


\section{First Phase of the Study: Individual Interviews}

\subsection{Recruitment Methods}

Recruitment for the individual interview phase of the study began during a community meeting that was held to introduce the study in February 2017. The community meeting was advertised via flyers distributed at least three times to every home in the Riverside Gardens neighborhood. Flyers were also delivered to churches located in the neighborhood and were placed on neighborhood telephone poles. If a resident was outside the home when flyers were being distributed, a member of the study team stopped and talked with the resident about the study and left a flyer with the resident. If a resident was not outside the home, a flyer was left outside, most often on resident's front door. If homes could not be approached due to fencing that spanned the perimeter of the property or safety concerns (e.g., the presence of large dogs), flyers were left on fence gates or in newspaper slots under mailboxes. The flyers were printed on goldenrod-colored paper to attract the attention of residents and listed the date, time, and location of the community meeting; a brief description of the study; and the study team's contact information. Distribution began one month in advance and ended two days before the meeting.

Only Riverside Gardens residents were invited to attend the community meeting. The meeting was held in a private room of a long-standing, locally-owned restaurant located near the neighborhood. All attendants were asked to sign in as they entered the meeting room. The sign-in sheet included sections for the meeting attendants' names, phone numbers, and home addresses. To ensure that attendants lived in Riverside 
Gardens, the study team used a neighborhood street name list to verify that attendants' street addresses were within the neighborhood. This meeting was attended by four University of Louisville study team members, two KDPH employees, and 36 adult residents. Dinner was provided.

The purpose of the meeting was to inform community members of the study and discuss the opportunity to participate in individual interviews. A short presentation about the project was given at the beginning of the meeting, followed by a discussion about the neighborhood and the concerns of residents, including health concerns. Residents' questions were answered and discussion was allowed.

At the end of the meeting, an individual interview sign-up sheet was distributed. Adult meeting attendants who had lived in the neighborhood for at least 5 years and wished to be interviewed were asked to provide their names, addresses, and phone numbers. A total of 26 adult attendees signed up to participate in interviews. An additional community member contacted the study team after the meeting and asked to participate. Those interested in being interviewed were later contacted and, if they still wished to be interviewed, appointments were scheduled for dates, times, and locations that were convenient for the participants.

\subsection{Individual Interviews}

Individual interviews were selected for use instead of focus groups for this phase of the study due to the sensitive nature of the personal and family health questions that were planned. Interviews were conducted with 15 residents between March 2017 and May 2017. The other 12 community members who signed up to participate in individual 
interviews either could not be reached using the contact information that they provided $(n=5)$, decided they no longer wanted to be interviewed $(n=3)$, reported that they signed up accidentally $(\mathrm{n}=2)$, or were scheduled but never confirmed their interview times $(\mathrm{n}=2)$. All participants chose to be interviewed in their homes.

Each participant was assigned a participant identification number to maintain confidentiality. This identification number was used throughout data collection and analysis. The link between the participants' names and their identification numbers was stored in a locked filing cabinet in the principal investigator's locked office. The participants provided written informed consent prior to the start of the interviews.

Interviews were recorded using an Olympus DS-5000 digital voice recorder. The participant's identification number was spoken into the recorder at the beginning of the recording. Participants' names were not used during the interviews. Two study team members were present during each interview. One team member interviewed the participant while the other took notes concerning the participant's responses. The same team member, the author of this dissertation, interviewed all of the participants.

The interviews were semi-structured in format. The interview guide contained twenty-two open-ended questions concerning the participants' demographic information, knowledge of the neighborhood's history, perceptions of the community's health, health histories, and exposure histories (see Appendix A). It was constructed by the study team for the purpose of this project and was reviewed by two former community leaders.

Interviews ranged from 20 minutes to 1 hour and 32 minutes in length. Each interview was transcribed verbatim. Notes from the interviews were consulted if questions arose during the transcription process. 


\subsection{Community Meeting to Discuss Qualitative Findings and Collect Additional Data}

A second community meeting was held in October 2017 to discuss the results of the individual interviews and ask for additional information on the health and exposure histories of the community. As with the first meeting, the second meeting was advertised via flyers distributed at least twice to every home in the Riverside Gardens neighborhood. Flyer distribution began one month in advance and ended four days before the meeting. Additionally, the phone numbers that meeting attendants provided at the first community meeting were used to notify them of the second meeting.

This second community meeting was held in the same private room of the nearby restaurant that was used for the first community meeting. Once again, only members of the Riverside Gardens community were invited to attend this meeting. The same sign-in procedure and residency verification used during the first community meeting was employed; however, this time attendants were also asked to provide email addresses when signing in. This meeting was attended by three University of Louisville study team members and 41 adult Riverside Gardens residents. Dinner was provided.

During the meeting, a short presentation was made where community members were shown the health conditions that were most frequently reported during the individual interviews and were asked if they had more to add. Discussion ensued. Additionally, attendants were asked to expand upon what they reported experiencing in the neighborhood that made them feel like they were being exposed to pollution (e.g., what words would they use to describe what they saw, felt, and smelled). Notes were taken by the study team as community members shared their experiences. The 
information provided was used to clarify points that community members had made during individual interviews in order to refine questions that were being considered for addition to the health and exposure questionnaire.

\subsection{Analysis of the Interview Data}

Interview transcripts were analyzed using inductive thematic analysis. ${ }^{221-223}$ Each interview transcript was read carefully by three study team members and segments related to the research questions were highlighted and coded. These coded segments were examined again, and similarities in codes across participants were grouped together into categories. Categories were given working titles based on their content. As the review process progressed, categories were merged, and key themes arose. Each of the three members of the study team worked through this process independently. Later, the team met and discussed the themes that emerged across participants. Any differences in interpretation between study team members were resolved through discussion.

In conjunction with paper and pencil methods, this analysis was also carried out using ATLAS.ti version 8.1 software. Questions were analyzed one at a time. All participants' responses to one question were read multiple times in order to become familiar with the data. Segments related to the research question were highlighted and coded. These coded segments were examined again, and similarities in codes across participants were grouped together into categories. Categories were given working titles based on their content. As the review process progressed, categories were merged and split. After a coding structure was developed, codes were grouped in meaningful patterns that related to the research question and key themes emerged. Final checks were made to 
assess the fit of each theme by looking back on the individual data segments supporting the theme. Themes were also compared to one another to assess if they should be collapsed or expanded upon. After themes were finalized, they were named. The analysis performed using ATLAS.ti supported the themes that emerged from the paper and pencil analysis. Themes and supporting excerpts from answers to open-ended questions are reported.

\section{Second Phase of the Study: Health and Exposure Assessment}

The second phase of the study involved the development and distribution of a health and exposure assessment questionnaire. Questionnaire development was guided by the findings of the individual interviews and information shared during community meetings; it was also influenced by the known health effects of the substances found in or around the Lees Lane Landfill, those released by industries in Rubbertown, and elements typically found in coal fly ash. The next subsection details the efforts taken to understand the potential environmental exposures of concern in Riverside Gardens.

After the potential exposures of concern were identified, the health effects related to such exposures were searched and added to the list of health concerns shared during interviews and community meetings to determine the health questions that would be included on the questionnaire. These health questions, along with demographic and lifestyle questions, were worded similarly to questionnaire items from representative surveys when possible to aid in the comparison between datasets. Finally, environmental exposure questions were developed using information shared during individual interviews and community meetings. 


\subsection{Development of the Health and Exposure Assessment Questionnaire}

3.1.1 Understanding Potential Exposures. In order to understand which substances Riverside Gardens community members may currently be exposed to or may have been exposed to in the past, several in-depth searches were conducted. Methods used to obtain these data included searching the EPA's Superfund Records Collection ${ }^{224}$ and the EPA's TRI Program (2016) ${ }^{225}$; filing Freedom of Information Act (FOIA) requests; calling and emailing site and project managers; and obtaining copies of the EPA's Hazardous Waste Biennial Reports 226 and LG\&E’s Cane Run Coal Combustion Residuals (CCR) Rule compliance documents. ${ }^{227}$ These methods are described below and later summarized in Figure 3.

Documents pertaining to the Lees Lane Landfill were obtained in a variety of ways. A thorough online search of the Lees Lane Landfill yielded the 2018, ${ }^{32} 2013,{ }^{15}$ $2008,{ }^{14}$ and $2003^{13}$ EPA five-year review (FYR) reports in the EPA's Superfund Records Collections. ${ }^{224}$ Briefly, FYRs are required when hazardous substances on Superfund sites remain above levels that "permit unrestricted use and unlimited exposure." 60 The implementation and performance of a site's remedy are evaluated during these reviews and a decision is made on whether the remedy remains protective of human health and the environment. The published reports provide summaries of the site's history, provide information on any site activities that have occurred since the last review, describe the remedy evaluation process, and present findings from the remedy evaluation. While the three most recent FYR reports were available online, the first two FYR reports could not be located. To obtain the 1998 and 1993 five-year review documents, the site's Remedial 
Project Manager (RPM) was contacted. Those documents were provided after a phone conversation about the site with RPM.

To further explore the potential pollutants from Lees Lane Landfill, requests for the results of the 2014 vapor intrusion sampling that took place in residents' homes were sent to the site's RPM, the site's National 508 Coordinator, and via a FOIA request submitted to the EPA. Summary documents of these tests were provided by the RPM. Additionally, the EPA provided a disc with digital copies of the letters that were mailed to residents explaining their vapor intrusion test results. The residents' names and addresses were removed from these documents.

Many of the on-site samples from the Lees Lane Landfill were collected by the Kentucky Department for Environmental Protection (KDEP). For this reason, an open records request was submitted to KDEP for the groundwater, soil, and soil gas sampling results conducted at the landfill. A variety of site-related documents were provided; however, KDEP was unable to provide soil gas results as this test was conducted by the EPA. A document containing the soil gas results was later discovered using an ATSDR publication database. ${ }^{59}$ Documents related to KDEP's, specifically the Kentucky Division of Waste Management's, 2013 soil sampling were retrieved through the Kentucky Energy and Environment Cabinet's blog, ${ }^{58}$ which is operated by the Cabinet in order to provide environmental information to Kentucky residents.

To learn more about on-site releases from Rubbertown plants, plants within the 40216 zip code, all of which were within 2.5 miles of Riverside Gardens, were searched using the EPA's TRI. The chemicals that were released on-site, either via air, water, or land, for each plant near Riverside Gardens were documented and later used in the 
development of the health and exposure assessment questionnaire. One plant, Atkemix Ten, released reportable chemicals on-site, but ceased operations prior to the development of the TRI system. ${ }^{72,228}$ As of 2018 , the Atkemix Ten site is still undergoing remediation, and the EPA's Hazardous Waste Report releases Biennial Reports detailing the management and minimization of the hazardous waste on-site. ${ }^{76-83}$ These Biennial Reports coupled with the Remedial Site Assessment Decision, ${ }^{72}$ obtained after contacting an EPA Resource Conservation and Recovery Act (RCRA) Environmental Protection Specialist, detail the substances that are present on-site and their storage conditions. Overall, these methods determined that there were 87 chemicals from the EPA's TRI Program and the Atkemix Ten reports that residents of Riverside Gardens may currently be exposed to or have been exposed to in the past.

The EPA's TRI Program was also searched to explore on-site releases made by LG\&E's Cane Run plant during the time it operated as a coal-burning power plant. Details concerning the coal ash pond and coal ash landfill at LG\&E's Cane Run plant were obtained through documents downloaded from the Coal Combustion Residuals (CCR) Rule Compliance section of LG\&E's website. ${ }^{105,229-232}$

Finally, to obtain information regarding when Riverside Gardens transitioned from well water to public water, a FOIA request was mailed to the Louisville Water Company. The request asked for the dates of initial public water access for houses on the eighteen streets that are entirely or partially within the Riverside Gardens boundary. The legal team at the Louisville Water Company responded to the request, but stated definitive records detailing when the neighborhood gained access to public water were not available and that attempts to generate even an estimate would take an unreasonable 
amount of time. While water company records were not available, searches of archived newspaper articles and EPA FYR documents indicate that public water access was not available to Riverside Gardens residents in $1970,{ }^{233}$ and that by 1993 , only a small number of homes used well water. ${ }^{14}$

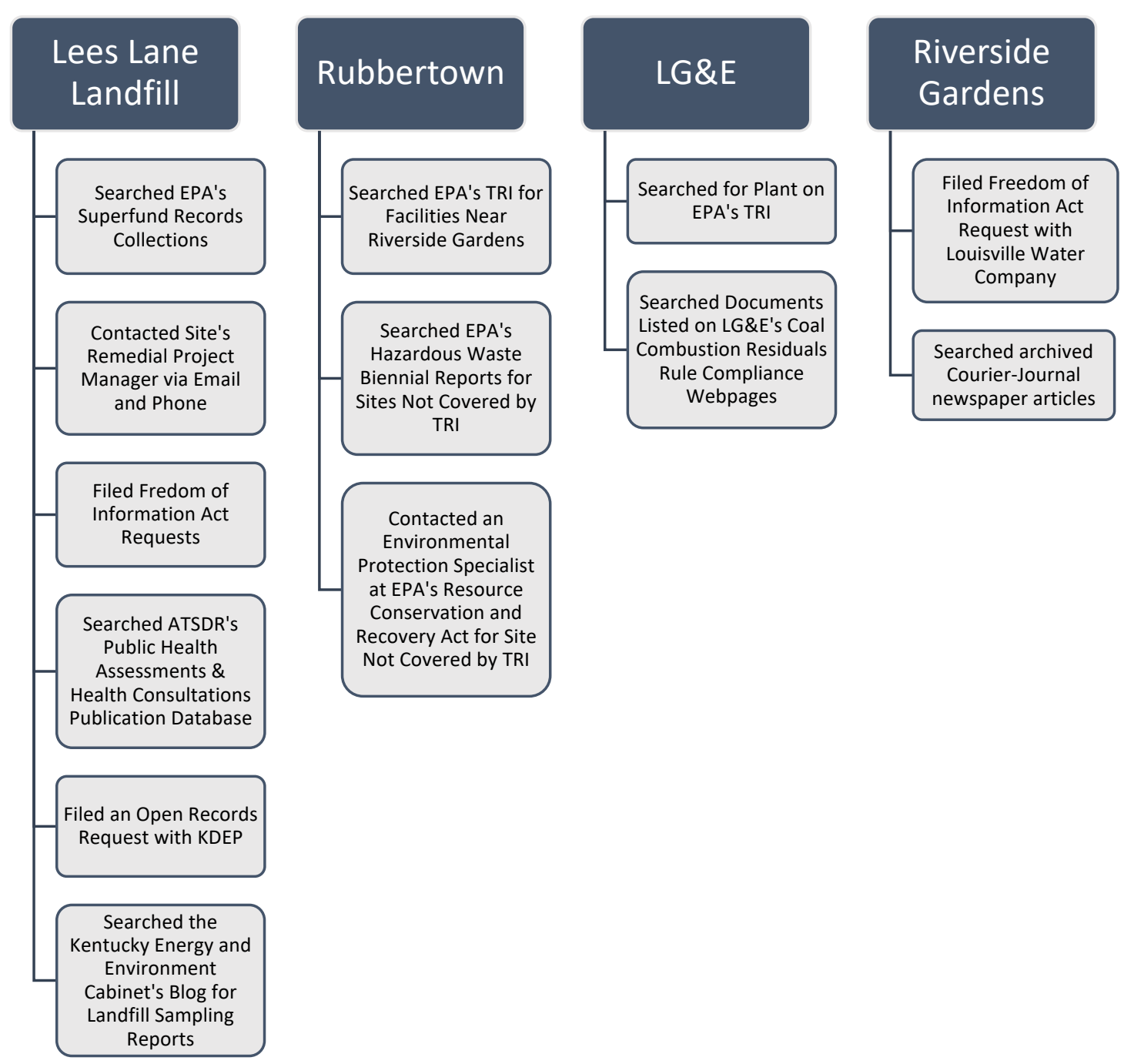

Figure 3. Search Methods Used to Understand Riverside Gardens Community Members' Potential Exposures by Site of Interest

\subsubsection{Health Conditions Included on Questionnaire. After determining}

contaminants of concern, the potential health effects related to exposures to these

contaminants were compiled. These health effects are presented in Background and 
Significance Section 6. The health conditions and symptoms expressed during interviews and community meetings were combined with the health effects related to exposure to Lees Lane Landfill, Rubbertown, and LG\&E contaminants for inclusion in the health and exposure questionnaire's Diagnosed Medical Conditions and Symptoms Experienced at Home and in Neighborhood subsections.

In order to narrow the number of cancer sites included in the Cancer History subsection of the questionnaire, data from the Kentucky Cancer Registry (KCR) were consulted. ${ }^{234}$ Age-adjusted incidence rates for all cancer sites were reviewed at both the state and county level. These incidence rates were based on data released on November 2017 and provided estimates from 1995-2015 as available. The 25 cancer sites with the highest incidence were included in the Cancer History subsection of the questionnaire. These top 25 cancer sites with the highest incidence were the same on both the state and county level. This list was then compared with the list of cancer types reported during the individual interviews and follow-up community meeting. Two cancer types (bone cancer and throat cancer) mentioned by community members were not included in the list compiled using KCR data. These two were added to the list, resulting in a total of 27 cancer types listed in the Cancer History subsection. Additional space for participants to specify cancer types not mentioned in the list was also provided.

3.1.3 Phrasing of Health Questions. To aid in future comparisons between data collected in this study and representative survey datasets, health items included in the Diagnosed Medical Conditions subsection of the health and exposure assessment questionnaire were edited to match the phrasing of questions and answer choices used in representative surveys. For all non-cancer health conditions, participants were asked, 
"Has a doctor, nurse, or other health professional ever told you that you have any of the following medical conditions?" This question was modified from BRFSS 2016 ("Have you ever been told by a doctor, nurse, or other health professional that you have _?"), ${ }^{235}$ NHANES 2015-2016 ("Has a doctor or other health professional ever told you that you have _?"), ${ }^{236}$ and NHIS 2016 ("Have you ever been told by a doctor or other health professional that you had_?"). ${ }^{237}$

One example of how an answer choice in the Diagnosed Medical Conditions subsection of the questionnaire was edited to match a representative survey answer choice involves the condition depression. The answer choice "depression" was changed to "depressive disorder (including depression, major depression, dysthymia, or minor depression)" based on how the depression question was framed on the 2016 Behavioral Risk Factor Surveillance System (BRFSS). ${ }^{235}$ Other answer choices in this section were edited to match the National Health and Nutrition Examination Survey (NHANES; 20152016), ${ }^{236}$ the National Health Interview Survey (NHIS; 2016), ${ }^{237}$ the Behavioral Risk Factor Surveillance System (BRFSS; 2016), ${ }^{235}$ the National Survey on Drug Use and Health (NSDUH; 2016), ${ }^{238}$ the Health and Retirement Study (HRS; 2016), ${ }^{239}$ the National Survey of Family Growth (NSFG; 2013-2015), ${ }^{240}$ the National Comorbidity Study Replication Survey (NCS-R; 2001-2002), ${ }^{241}$ and the Sleep Health Index (2017). ${ }^{242}$

3.1.4 Availability of Comparison Data for Health Conditions. When the questionnaire was created, comparison data were available for the prevalence of 49 of the $70(70.0 \%)$ health conditions in the Diagnosed Medical Conditions section and all of the questions included in the Cancer History section. These comparison data were identified by searching questionnaires used in representative surveys at the local, state, and national 
level. Such surveys included the National Health and Nutrition Examination Survey (NHANES; 2015-2016), ${ }^{236}$ the National Health Interview Survey (NHIS; 2016), ${ }^{237}$ the Behavioral Risk Factor Surveillance System (BRFSS; 2016), ${ }^{235}$ the National Survey on Drug Use and Health (NSDUH; 2016), ${ }^{238}$ the Health and Retirement Study (HRS; 2016), ${ }^{239}$ the National Survey of Family Growth (NSFG; 2013-2015), ${ }^{240}$ the National Comorbidity Study - Replication Survey (NCS-R; 2001-2002), ${ }^{241}$ and the Sleep Health Index (2017). ${ }^{242}$

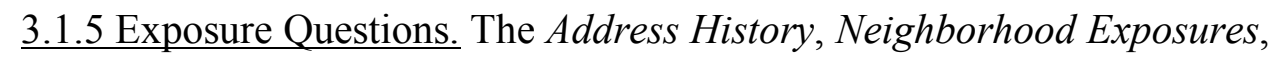
Outdoor Activities In and Around Neighborhood, and Childhood in Riverside Gardens sections of the questionnaire were created for use in this study based on information collected during the individual interviews and community meetings. These sections collected information on how participants may have come into contact with contaminants from the surrounding industries and industrial waste facilities. The Address History section collected information on the lengths of time, periods of life, and timeframes that participants had lived in the neighborhood. Questions regarding participants' perceptions of environmental exposures and the industries and industrial waste facilities that surround the neighborhood were also asked in the Neighborhood Exposures and Childhood in Riverside Gardens sections.

3.1.6 Sources of Other Questionnaire Items. Questionnaire items from the Demographic Information, Employment History, and Tobacco and Alcohol Use sections of the questionnaire came from the following sources:

- Demographic questions were modified or taken from BRFSS 2016, ${ }^{235}$ NHANES 2015-2016, ${ }^{236}$ and NHIS $2016 .^{237}$ 
- Questions related to occupational exposures in the Employment History section were adapted from ATSDR's Exposure History Form. ${ }^{243}$

- Questions related to tobacco and alcohol use were taken or adapted from BRFSS 2016, ${ }^{235}$ NHANES 2015-2016, ${ }^{236}$ and NHIS 2016. ${ }^{237}$

\subsubsection{Questionnaire Contents. The full version of the self-administered} questionnaire consisted of four sections that included items concerning participants': 1) demographic information; 2) personal health histories, including self-reported medical conditions (including cancer) diagnosed by a physician, nurse, or other healthcare provider, undiagnosed medical conditions, symptoms experienced when at home or in the neighborhood, and medication use; 3) environmental exposure histories, including occupational exposures, address histories, neighborhood exposures, outdoor activities, and childhood exposures; and 4) tobacco and alcohol use histories. Many of the questions were in multiple choice formats or asked participants to fill in tables concerning their medical conditions and, if applicable, the year they were diagnosed. There were also several open-ended questions that allowed participants to provide additional information that may not have been covered by the multiple-choice questions. The questionnaire took participants approximately 30 minutes to complete. A copy of the questionnaire is provided in Appendix B.

A shortened version of the questionnaire was created in September 2018 in response to participant feedback. Many community members were concerned about the size of the questionnaire packet. While most participants who completed the full version of the questionnaire found that the questionnaire took 30 minutes or less to complete, the study team was concerned that the visual appearance of the questionnaire's length may 
prevent community members from participating. This was based on comments that were made by many community members upon receiving the questionnaire. As a result, a shorter version of the questionnaire that only included the health sections was created. Sections concerning exposure questions were put into a separate optional packet. Participants who had not yet completed their questionnaires and participants who were enrolled after the short version of the questionnaire was approved were given a choice to complete the short or full version of the questionnaire. However, because the short version of the questionnaire does not contain many of the exposure history questions, the results of this dissertation focus on those who completed the full version of the questionnaire.

\subsection{Questionnaire Review and Pretesting}

The draft health and exposure assessment questionnaire was reviewed by a team of epidemiologists at KDPH in December 2017. The questionnaire was also reviewed by a team of professors at the University of Louisville School of Public Health and Information Sciences in April 2018. After each review, the questionnaire was edited based on the suggestions provided.

The questionnaire was also pretested with a small number of community members before it was widely distributed to community members. To obtain the participants for pre-testing, community members who participated in individual interviews or attended past community meetings were contacted and asked if they would be interested in reviewing the draft questionnaire. Questionnaires were mailed to interested community members in advance so that they could review them prior to gathering for a focus group 
discussion. The target sample size for the focus group discussion was 5-7 participants. Six residents took part in the focus group discussion. Discussion topics included question clarity, the presentation of health questions (e.g., are more examples needed), participants' understanding of the skip patterns, and other feedback participants had. The focus group discussion took place at a nearby restaurant and lasted for two hours. Dinner was provided to those who participated. The questionnaire was revised based on the feedback provided during the focus group.

\subsection{Recruitment and Dissemination Methods}

Recruitment for the health and exposure assessment survey took place between July and October of 2018. Several methods were utilized to recruit participants for the survey. "Shoe-leather" methods similar to those used in the qualitative portion of the study were employed. At times, community members took part in the shoe-leather recruitment, accompanying study team members to homes. Flyers were distributed door to door to every home in the neighborhood, and homes were approached in an attempt to make contact with residents. Additional community meetings and other study events were held, and letters and flyers were mailed to community members.

\subsubsection{Planned Community Meeting \& Questionnaire Distribution and Collection}

Days at Neighborhood Church. The first attempt to distribute the health and exposure questionnaires occurred on planned community distribution and collection days. In order to announce the days, flyers were distributed as described in Methods Section 2, Subsection 2.1 during the first month of recruitment. Flyers were distributed to every home in the community at least three times. Additionally, participants from the individual 
interviews or community members who attended past community meetings were contacted using the phone numbers they provided to explain the upcoming distribution and collections days.

Five community distribution and collection days were arranged and held at a church identified as a common meeting location in the neighborhood. The events took place every Tuesday evening from 6:00-8:00 PM and Saturday morning from 10:00 AMnoon between Tuesday, July $17^{\text {th }}$ and Tuesday, July $31^{\text {st }}, 2018$.

The first distribution and collection day began with a community meeting that allowed residents to learn more about the study. The meeting sign-in and verification of residency processes were previously described in Methods Section 2, Subsection 2.1. This meeting was attended by two University of Louisville study team members and ten adult community members. Refreshments were provided. At the end of the meeting, community members who wished to participate were consented using the process described in Methods Section 3.4. Participants then received study materials and a flyer with the dates and times of upcoming questionnaire distribution and collection days at the church when participants could return their completed questionnaires. Participants had the option of staying and completing their questionnaire at the church or taking them home to complete. The additional four distribution and collection days that were held at the church in July gave community members the opportunity to drop in and learn more about the study, enroll in the study, complete questionnaires, and return completed questionnaires.

3.3.2 Door-to-Door Recruitment. After the community events at the church, during the subsequent recruitment months (August-October 2018), the study team and 
community volunteers went door-to-door to speak with residents about the study. The study team and community volunteers attempted to approach every home in the neighborhood. If the team was able to make contact with a resident, the study team described the study, assessed the resident's eligibility to participate, and asked the resident if they were interested in participating. When community volunteers were present, they often introduced themselves (if they did not know the resident) and shared their experience with participating in the study (e.g., time it took to complete the questionnaire and ease of completing and returning the questionnaire). If the resident was interested in participating, they were consented using the process described in Methods Section 3.4 and received a questionnaire to complete over the course of a week.

If there was no response when a residence was approached, a flyer advertising the study was left at the home. Homes that were completely gated or deemed unsafe (e.g., properties with large dogs between the home and the front door) were not approached. In these cases, flyers were left in the newspaper slot below the mailbox or in the fence gate.

During the door-to-door recruitment, a log of attempts to reach residents was maintained. Each home in the neighborhood was approached at least three times. Homes were approached at least once during a weekday, once during a weeknight, and once on the weekend in an attempt to connect with residents. Questionnaires were handed out door-to-door on 35 separate days between August 2018 and October 2018. Questionnaires were not handed out door-to-door on days that it was raining.

\subsubsection{Mailings. Two mailings were used to advertise the study and recruit} participants. The first mailing occurred in August 2018 and was sent to all residents in the neighborhood who had not yet completed and returned a questionnaire. This mailing 
included a letter that briefly described the study; advertised the date, time, and location of an upcoming study collection and distribution day that would be held at a local restaurant; and provided the study team's contact information. A flyer advertising the distribution and collection day held at a local restaurant was also included.

The second mailing occurred in October 2018 and was sent to residents in the neighborhood who had not yet completed a questionnaire. Residents who were documented as not being eligible to participate in the study (based on the study team's door-to-door encounters with them) were not included in the mailing. The mailing included a letter that briefly described the study, advertised the addition of a short version of the questionnaire, and provided the study team's contact information. All letters were addressed to the "Riverside Gardens and Huff Lane Community Member" unless the name of the resident was known due to their participation in earlier portions of the study.

\subsubsection{Questionnaire Distribution Event at Local Restaurant. A questionnaire}

distribution event was held in a private room of the same restaurant that was used for recruitment in the interview portion of the study. The event took place in August 2018. It was advertised in multiple ways. First, flyers advertising the event were distributed to every home in the neighborhood at least twice using the process described in Methods Section 2, Subsection 2.1. Second, the event was advertised using a mailing (the first mailing described above). Third, community members who had participated in past community meetings or in individual interviews were contacted using the phone numbers they had provided. Finally, study participants (including those who had not yet completed or returned their questionnaires) were contacted using the contact information they had provided. 
Only Riverside Gardens residents were invited to attend the August 2018 event. The meeting sign-in and verification of residency processes were previously described in Methods Section 2, Subsection 2.1. This event was attended by two University of Louisville study team members and 30 Riverside Gardens residents. Dinner was provided.

The purpose of the event was to give community members the chance to ask questions about the study, obtain questionnaires, complete questionnaires, and return completed questionnaires. The study team was also available to provide assistance to participants who needed help completing their questionnaires. Out of the 30 residents who attended, 11 had not previously obtained or completed questionnaires. Two residents received assistance in completing their questionnaires from study team members during the event.

3.3.5 Community Events. Several events that were held by the community were also attended by the study team in order to recruit participants for the study. The study team was invited by the community to attend three community events between July 2018 and October 2018. These events included the community church's annual Summer Festival (July 2018), annual Fall Festival (October 2018), and a community meeting (October 2018). During the Summer and Fall Festivals, a table was set up during the event. Study team members were present to talk to residents about the study, hand out flyers advertising the study, and distribute and collect questionnaires. Refreshments were available to those who stopped by the table. The study team was also invited to attend a meeting hosted by the community to introduce the study. While attending these events did not lead to new participant enrollment, it did allow the study team to connect with 
community members who had already participated in the study, document the ineligibility status of several community members, and demonstrate the study team's commitment to the project and to the community.

\subsection{Consent}

If eligible residents chose to participate in the study, they were first given a preamble (unsigned consent document). The preamble contained information about the background and purpose of the study, the self-administered questionnaire's contents, potential risks and benefits, a gift basket raffle, and confidentiality. The preamble informed individuals that their participation was voluntary, and that they could choose not to take part in the study or to discontinue participation at any time. Several phone numbers were provided for any questions, concerns, or complaints that participants may have had. These numbers included that of the PI, the Co-Investigators, the Human Subjects Protection Program Office at the University of Louisville, and the Compliance Hotline that is provided by a third-party vendor and allows for confidential reporting. Residents were asked to read through the preamble on their own.

Qualified residents were then asked to complete a Demographic and Contact Information Form, which included questions concerning their name, gender, date of birth, address, phone number, email address, and preferred method of contact. By returning the form to the study team, prior to receiving the study questionnaire, individuals agreed to participate. 


\subsection{Confidentiality, Privacy, and Use of Contact Information}

Each participant was assigned an identification number to maintain privacy. The questionnaire given to the participants had their participant identification number listed, but did not ask for their name, gender, or date of birth. Thus, the demographic and contact information form served as the link between the participants' names and their completed questionnaires. Participants living in the same household were given the same identification number followed by a letter so that they could more easily identify which questionnaire belonged to which household member.

Study team members explained to participants that this identification number was used in place of their names during data entry and data analysis. The study team also stated that any future presentation of study findings would not include participants' names. The link between the participant identification numbers and participants' names (the demographic and contact information form) was kept in a locked document box and on a locked computer. Only study team members had access to these documents.

\subsubsection{Use of Contact Information. The contact information provided by} participants was used to contact participants concerning the collection of completed questionnaires and will be utilized to invite participants to a community meeting to discuss the results of the study in Spring 2019.

\subsection{Questionnaire Collection and Incentives}

If participants did not complete questionnaires during the questionnaire distribution and collection days held at the community church or at community events, they were contacted one week later so that a questionnaire pick-up time could be 
scheduled. If the participant had not completed the questionnaire or was unreachable after one week, they were contacted again the next week. A log of attempts to reach the participants was kept and different methods of contact were attempted. The study team also tried to reach participants at home if they were unreachable using the contact information they had provided. Questionnaire collection appointments were scheduled on 29 days between August 2018 and November 2018.

When participants returned their completed questionnaires, they were given a raffle ticket. At the end of the study, several gift baskets will be raffled off as a way to thank participants for their time and effort involved in participating in this study. The gift basket raffle will take place during a community meeting that will be held to discuss study findings in Spring 2019.

\subsection{Response and Participation}

Based on foot recruiting efforts and mailings, 293 homes in Riverside Gardens were determined to be occupied and 44 were vacant between July and October of 2018. The study team was unable to make contact with residents at about one-third of occupied homes (34.1\%) despite leaving numerous flyers advertising the study, knocking on doors on at least three occasions (at least once on a weekday, weeknight, and weekend; if able to access), mailing letters to their homes twice, and attending community events. Of the $65.9 \%$ of occupied homes that the study team was able to make contact with, the residents of $17.1 \%$ were not qualified (11.3\% of total occupied homes), mostly because they had resided in the neighborhood for less than one year, but occasionally because of diagnosed cognitive illnesses that excluded them from participating. Residents of another 
$10.8 \%$ of occupied homes that the study team was able to reach refused to participate in the study. The majority of occupied homes that the study team made contact with (72.0\%) had at least one resident who agreed to participate in the study, but questionnaires were not returned from residents of about one-quarter of these, despite numerous and diverse follow-up attempts. Participation by household is summarized below in Figure 4.

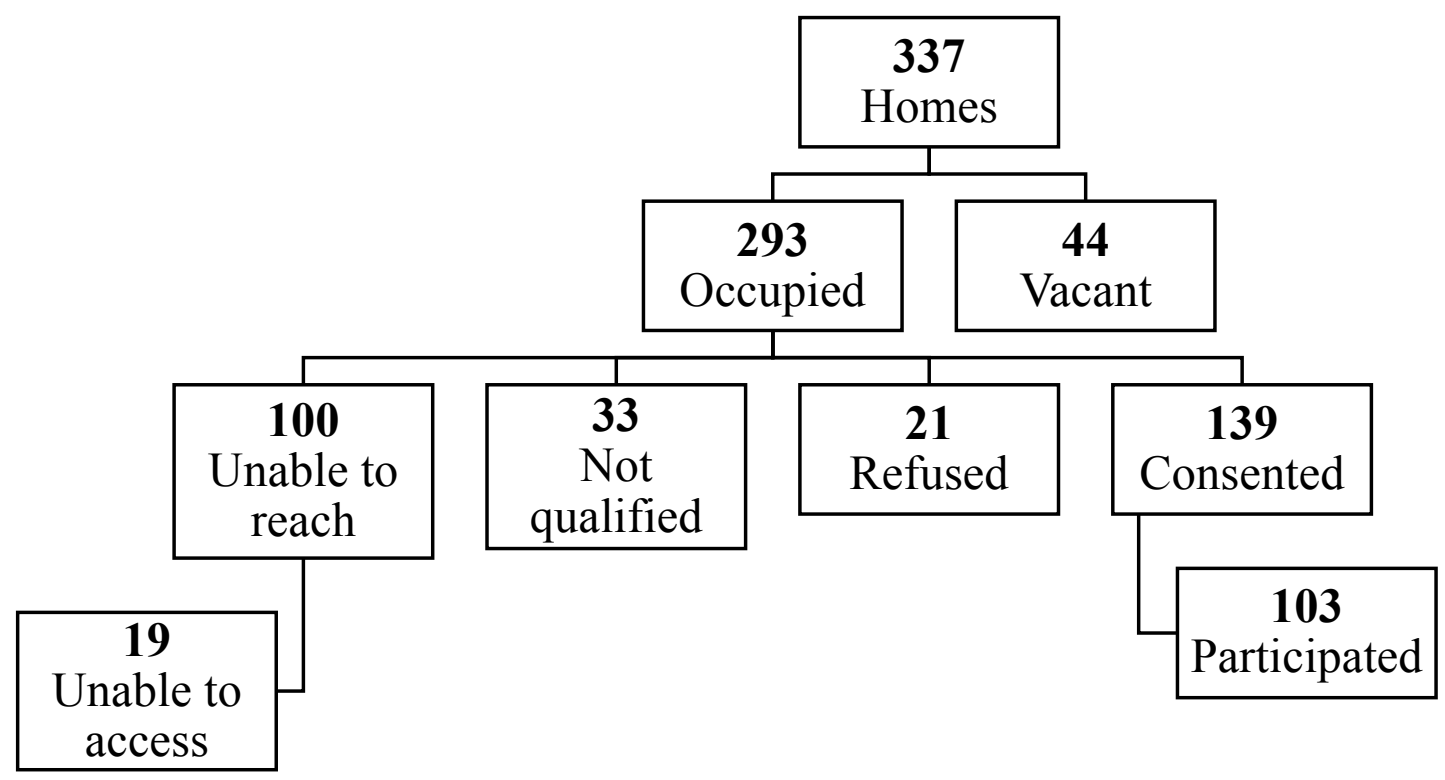

Figure 4. Participation in the Health and Exposure Assessment Questionnaire by Household

A total of 208 eligible adult community members were consented to participate in the study. Of those, $63.0 \%(n=131)$ completed and returned the full or short version of the questionnaire. More than half of those $(63.4 \%, \mathrm{n}=83)$ completed the full version and $36.6 \%(\mathrm{n}=48)$ completed the short version. Based on ACS 2016 data, an estimated 560 
adults live in Riverside Gardens. ${ }^{1}$ Using this estimate, $23.4 \%$ of the adult population in Riverside Gardens completed and returned one of the versions of the questionnaire; $14.8 \%$ completed and returned the full version and $8.6 \%$ completed and returned the short version. Participation estimates based on ACS data underestimate the true participation rates of eligible adult community members, however, as they do not take eligibility requirements into consideration. Adult resident participation is summarized below in Figure 5.

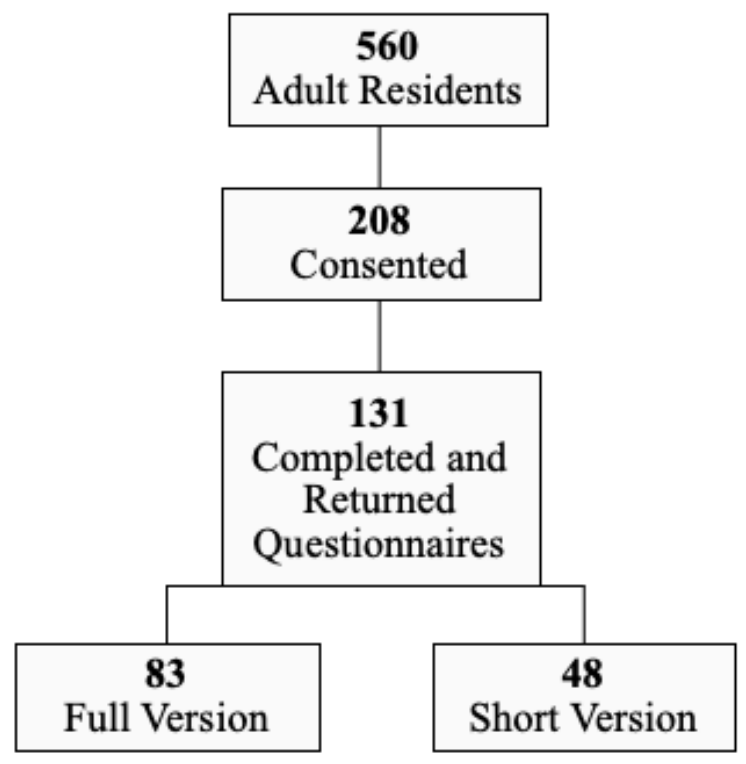

Figure 5. Adult Resident Participation in the Health and Exposure Assessment Questionnaire

\subsection{Variable Descriptions}

This section defines the demographic variables, potential covariates, exposure variables, and outcome variables obtained from the health and exposure assessment questionnaire that were used for statistical analysis in Specific Aims 3 and 4. 
3.8.1 Demographic Variables. The following demographic variables were reported and/or used for statistical analysis in Specific Aims 3 and 4:

- Gender was self-reported by the participants in response to an open-ended question.

- Age (in years) was calculated using the date of birth provided and the date the participant received the questionnaire.

- Race and ethnicity were obtained based on responses to the following question: "What is your racial and ethnic background? Check all that apply." This question was modified from BRFSS $2016^{235}$ and response choices included: White/Caucasian, Black/African American, Hispanic/Latino, Asian, American Indian or Alaskan Native, Native Hawaiian or Other Pacific Islander, and Other. If "other” was selected, participants were asked to specify their race/ethnicity. If participants responded with more than one race, they were categorized as biracial; otherwise, they were categorized using the single race that they reported.

- Highest level of education was obtained using answers to the question, "What is your highest level of education?" This question was modified from BRFSS 2016. ${ }^{235}$ Participants were given 12 response options starting with "Never Attended School/Kindergarten Only" and ending with "Completed Graduate School."

- Annual household income was obtained using the response to the question, "What is your annual household income before taxes? Please include income from sources such as wages, salaries, Social Security or 
retirement benefits, help from relatives, and so forth.” This question was modified from NHANES 2015-2016. ${ }^{236}$ This was a multiple-choice response option in $\$ 5,000$ increments starting at $\$ 1-\$ 4,999$ and ending at $\$ 50,000$ and over. "I don't know" and "Decline to say" were also response options.

- Health care coverage was determined using the response to the following question, "Do you have any kind of health care coverage, including health insurance; prepaid plans such as HMOs; government plans such as Medicare, Medicaid, or Indian Health Service; or military health care such as TRICARE or Veterans Affairs health benefits?" This question was slightly adapted from BRFSS $2016^{235}$ and NHANES 2015-2016..$^{236}$ Response options were "yes," "no," and "I don’t know."

- Participants were asked, "In general, how would you rate your health?" Response options were "excellent," "very good," "good," "fair," and “poor.” This question was slightly adapted from BRFSS 2016. ${ }^{235}$

- The number of homes that participants reported living in within the Riverside Gardens neighborhood was calculated using responses to the Address History section of the questionnaire. Home addresses that participants reported were within the neighborhood were verified using neighborhood street address lists. The number of different homes in the neighborhood was summed for all participants.

3.8.2 Body Mass Index (BMI). BMI was calculated by dividing the participant's self-reported weight in pounds by their self-reported height in inches squared multiplied 
by 703 . One participant did not respond with their weight and another did not respond with their height or weight; thus, BMI is missing for two participants. BMI was categorized into the following groups using World Health Organization cut-points:

normal $(\mathrm{BMI} \leq 24.9)$, overweight $(25.0 \leq \mathrm{BMI} \leq 29.9)$, and obese $(\mathrm{BMI} \geq 30.0)$. Only one participant had a BMI under $18.5(\mathrm{BMI}=18.1)$; therefore, a separate underweight category was not formed.

3.8.3 Personal Tobacco Use. Personal tobacco use was assessed using information collected on multiple tobacco products: cigarettes, cigars, smokeless tobacco, and electronic cigarettes. All tobacco use questions were taken or modified from BRFSS 2016, ${ }^{235}$ NHANES 2015-2016, ${ }^{236}$ and NHIS $2016 .{ }^{237}$ To assess the use of cigarettes, participants were first asked, "Have you smoked at least 100 cigarettes (approximately 5 packs) in your entire life?" All participants who responded to the tobacco use questions responded "yes" or "no" to this question. If participants responded "no," they were categorized as a never cigarette smoker. If participants responded "yes," they were asked, "During the last 30 days, on how many days did you smoke cigarettes?" If participants responded 0 days, they were categorized as a former cigarette smoker. If participants responded with 1-30 days, they were categorized as current cigarette smokers.

The same categorization strategy was used for cigars, smokeless tobacco, and electronic cigarettes, except that the initial question concerning the use of these products asked, "Have you ever (smoked a cigar, cigarillo, or little filtered cigar / used smokeless tobacco / used an electronic cigarette) even one time?" If participants answered "no" they were categorized as a never user of the respective product. If they answered "yes" or "I don't know," they were asked how often they had used the product in the last 30 days. If 
participants responded 0 days, they were categorized as former users of the product. If participants responded with 1-30 days, they were categorized as current users of the product.

If a participant was categorized as a never user of all tobacco products (cigarettes, cigars, smokeless tobacco, and electronic cigarettes), their personal tobacco use status was "never user." If a participant reported using any tobacco product in the past, but not within the past 30 days, their personal tobacco use status was "former user." Finally, if a participant reported using any tobacco product within the past 30 days, their personal tobacco use status was "current user." Information on tobacco use was missing for one participant.

\subsubsection{Occupational Exposure. Occupational exposure histories were assessed} using the following questions adapted from ATSDR 243 : "Have you ever held a job where you handled, worked around, or were otherwise exposed to any of the following: chemicals, metals, hazardous waste, dust or fibers, fumes (such as welding fumes), radiation, or biologic agents." For each of the exposure categories (e.g., chemicals, metals, etc.), the answer choices were "yes", "no", and "I don’t know." A dichotomous variable was created to assess occupational exposure to any of these exposure types. If participants responded "yes" to any of these questions, they were classified as having been occupationally exposed. If participants responded "no" to all occupational exposure types, they were classified as not having been occupationally exposed to any of these agents. Any participant who responded "I don't know" to one or more of the occupational exposure categories also responded "yes" to at least one of the other included questions; thus, these participants were classified as having been occupationally exposed and an "I 
don't know" category for the new combined occupational exposure variable was not needed. Occupational exposure histories were missing for 6 participants.

3.8.5 Neighborhood Exposure Variables. Several exposure variables were created using responses to questionnaire items. Each variable is described in this subsection.

Proportion of Life in Neighborhood. Participants' address histories and ages were used to create a proportion of life in neighborhood variable. Address histories were used to create a continuous variable that represented the cumulative time participants had lived in the neighborhood (in years). This variable was then divided by the participant's age (in years) and multiplied by $100 \%$ to produce the proportion of the participant's life that was spent in Riverside Gardens. The proportion of life variable was then dichotomized into greater than or equal to $50.0 \%$ of life and less than $50.0 \%$ of life, which was approximately the median of the proportion of life variable. The proportion of life variable was coded so that greater than or equal to $50.0 \%$ of life equaled 1 and less than $50.0 \%$ of life equaled 0.

Lived in Neighborhood During Childhood. Responses to the question, "Did you live in Riverside Gardens or the Huff Lane area when you were under the age of 18?" from the Childhood in Riverside Gardens section of the questionnaire were used to determine if participants lived in the neighborhood during childhood. Response choices included “yes", "no”, and “I don’t know." All participants responded "yes” or "no". This variable was coded so that "yes" equaled 1 and "no" equaled 0.

Home's Location in Neighborhood. The Riverside Gardens neighborhood was divided into 2 zones: homes in the neighborhood that border Rubbertown, the Lees Lane Landfill, and/or LG\&E (exterior locations), and homes in the interior of the 
neighborhood. A 0.1-mile buffer was created in OpenStreetMap ${ }^{244}$ to separate the neighborhood into zones. Homes within 0.1 miles of the edge of the neighborhood on the sides that border the neighborhood from Rubbertown, the Lees Lane Landfill, and LG\&E were classified as "exterior zones." Homes that were not within 0.1 miles of the edge of the neighborhood that borders either Rubbertown, the Lees Lane Landfill, or LG\&E were classified as "interior zones." A new dichotomous variable for neighborhood zone was created where interior zones were assigned a 0 and exterior zones were assigned a 1.

\section{Consumed Plants Grown/Animals Captured in Neighborhood. A}

dichotomous variable indicating if participants reported eating plants grown in the neighborhood or animals captured in the neighborhood was created using responses to six different questions from the Outdoor Activities In and Around Neighborhood section of the questionnaire. First, participants were asked if they gardened, hunted, or fished in the Riverside Gardens/Huff Lane area. If they reported that they had gardened, hunted, or fished, they were asked if they ate what they grew or caught. If participants responded that they ate what they grew or caught for at least one of these items, their score for the new dichotomous variable equaled 1. If participants responded that they did not eat what they grew or caught (or if they did not garden, hunt, or fish in the neighborhood), their score for the new dichotomous variable equaled 0 .

Used Well Water in Neighborhood. Participants were asked, "During the time you have lived in Riverside Gardens, have you ever used well water?" in the Neighborhood Exposures section of the questionnaire. Response choices included "yes", “no", and "I don't know." Seven participants were unsure if they had ever used well water. In these cases, the year that participants first moved to Riverside Gardens (based 
on their Address History responses) was used to assess if participants were likely to have used well water. City water was not brought to any part of the neighborhood until after $1970,{ }^{233}$ and by 1993 , only a small number of homes were reported to use well water. ${ }^{14}$ Using this information and the date that participants first moved to Riverside Gardens, 4 of the 7 participants who were unsure if they had used well water in the neighborhood were determined to have used well water (all moved in before 1969). Two of the remaining 3 participants moved into the neighborhood in the 2000s. These participants were unlikely to have used well water and, thus, were marked as not having used well water. One participant who was unsure if they had used well water moved into the neighborhood in the late 1980s. Since most homes had city water by 1993 , this participant was marked as not having used well water. The original well water variable was recoded, and participants who reported/were determined to have used well water were assigned a 1 and those who did not use well water/were determined unlikely to have used well water were assigned a 0 .

Participated in Activities In or Around the Landfill Site. Participants were asked, "Which of the following outdoor activities do you or have you ever participated in in the Riverside Gardens/Huff Lane area?" in the Outdoor Activities In and Around the Landfill section of the questionnaire. For each category (e.g., running, walking, bicycling, etc.), participants were asked to indicate where they participated in these activities. Additionally, participants were specifically asked, "Have you visited and/or participated in activities on or near the site of the closed Lees Lane Landfill? Describe the visits and/or activities using the space below" and "Did you ever go in or near the landfill when it was open (1948-1975). Describe what you did in or near the landfill using the space 
below." A new dichotomous variable was created, and if participants indicated that they participated in activities on the landfill site or around the landfill (e.g., on the bike path or floodwall that border the landfill) in responses to any of these three questions, participants were determined to have participated in activities on or around the landfill site and were assigned a 1. If participants did not indicate that they had participated in activities in or around the landfill site, they were assigned a 0 . Details concerning the nature of the activities on or around the landfill were not considered when creating this variable.

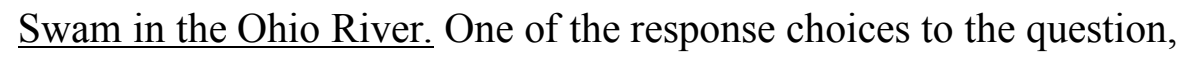
"Which of the following outdoor activities do you or have you ever participated in in the Riverside Gardens/Huff Lane area?" in the Outdoor Activities In and Around Neighborhood section of the questionnaire was "swimming." If participants responded that they swam, they were asked, "Where did you swim?" A new dichotomous variable was created, and if participants listed the Ohio River as a swimming location, they were given a 1 . If participants did not report swimming in the Ohio River, they were given a 0 . Time Spent Outdoors. The average amount of time that participants spend outdoors in the neighborhood in hours per week was obtained using responses to the question from the Outdoor Activities In and Around Neighborhood section of the questionnaire, “About how many hours per week do you spend outdoors in your neighborhood?" This variable was split at its median to create a new dichotomous variable ( $<20$ hours per week, $0 ; \geq 20$ hours per week, 1). Fifteen participants did not respond to this question. 
3.8.6 Diagnosed Medical Conditions. Medical condition diagnoses that were reported by participants were obtained from responses to three questions in the Personal Health History section of the questionnaire. First, participants were asked, "Has a doctor, nurse, or other health professional ever told you that you have any of the following medical conditions?" There were 70 conditions listed and participants could select all that applied.

Next, participants were asked, "Has a doctor, nurse, or other health professional ever told you that you have any of the following types of cancer? If your cancer spread to other locations, check only where your cancer originated.” There were 27 cancer types listed and participants could select all that applied. There were also spaces provided so that participants could report other cancer diagnoses that were not included in the list.

Finally, participants were asked, "Has a doctor, nurse, or other health professional ever told you that you have any medical conditions that were not listed in the previous sections?" The answer choices were "yes," "no," and "I don't know." If participants selected "yes," they were asked to report the medical condition.

Any of the responses described were considered as self-reported diagnosed medical conditions during analyses.

\subsubsection{Symptoms Experienced at Home and in the Neighborhood. Within the} Personal Health History section of the questionnaire, participants were asked, "During the time you have lived in Riverside Gardens or the Huff Lane area, have you experienced any of the following symptoms? If so, how frequently do you experience them and when did they begin?" If participants reported a symptom, they were asked to 
report if they experienced the symptom daily, weekly, monthly, seasonally, or other. If they selected "other" they were asked to specify the frequency.

\subsection{Statistical Methods for Specific Aims 3 and 4}

Specific Aims 3 and 4 utilized data collected by the health and exposure assessment questionnaire in order to: 1) compare the prevalence estimates of disease between Riverside Gardens and local, state, and national estimates, and 2) explore differences in health conditions by environmental exposure status. Data from the 83 participants who completed the full version of the health and exposure assessment questionnaire were included in these analyses. The 48 participants who completed the short version of the questionnaire were not included because many of the environmental exposure questions were omitted from the short version of the questionnaire, resulting in missing data. Demographic characteristics and disease category prevalence by questionnaire version are reported in Tables 9 and 10 in Appendix C.

\section{Specific Aim 3: To assess and compare the prevalence of self-reported health conditions in Riverside Gardens.}

Prevalence estimates were calculated using responses to the Personal Health History section of the health and exposure assessment questionnaire. Any health conditions that were self-reported to have been diagnosed by a doctor, nurse, or other health professional were assessed. Thirty-eight of the 65 non-cancer chronic diseases reported by Riverside Gardens residents were available for comparison to local, state, and/or national prevalence data. Prevalence estimate comparisons for cancer were 
available at the local, state, and national level for all-site cancer, both including and excluding skin cancer. Due to the low counts of individual cancer sites reported by the Riverside Gardens community health and exposure assessment participants, comparisons involving individual cancer sites were not performed. For comparisons to local and state prevalence, BRFSS data for the Louisville/Jefferson County, KY-IN Metropolitan Statistical Area (MMSA; 2017) and state-level data for Kentucky (2017) were used as available. For comparisons to national data, nationally-representative surveys including NHANES (2013-2014, 2015-2016), NHIS (2017), and NCS-R (2001-2002) were used as available.

\subsubsection{Combining Variables for Analysis. At times, BRFSS, NHANES, and NHIS} questionnaire items asked about multiple diseases at once. For example, BRFSS asked if respondents had ever been told by a doctor or other health professional that they had angina or coronary heart disease, while NHANES, NHIS and the Riverside Gardens health assessment questionnaire asked about angina and coronary heart disease in separate questions. In such cases, diseases were compared both individually (if possible) and merged to produce a new variable (e.g., angina and/or coronary heart disease) in order to be comparable to other datasets. Details about the wording of questionnaire items and possible variable mergers are provided in the table footnotes.

\subsubsection{Generation of Prevalence Estimates. Crude and age-adjusted prevalence} estimates for BRFSS, NHANES, NHIS, and NCS-R were calculated using SURVEY procedures in SAS version 9.4 (Cary, N.C.). SAS SURVEY procedures allow the analyst to take complex sampling designs into account when producing estimates, variances, and confidence intervals (CIs). Weight, strata, and cluster variables were included as 
appropriate when analyzing data from each survey. PROC SURVEYFREQ was used to produce crude prevalence estimates, variances, and CIs, and PROC SURVEYREG was used to produce age-adjusted prevalence estimates, variances, and CIs.

Prevalence estimates, variances, standard errors, and CIs for Riverside Gardens data were also produced using SAS; however, SAS SURVEY procedures were not used as a complex sampling design was not employed.

3.9.3 Age Adjustment. To allow for the comparison of prevalence estimates between survey populations with differing age structures, prevalence estimates from all surveys were age-adjusted. Age adjustments were made using direct methods and the 2000 projected U.S. population using the CDC National Center for Health Statistics guidelines. ${ }^{245}$ In all but one case, the following three adjustment categories were used: 18-44 years (standardized proportion: 0.5305$), 45-64$ years (standardized proportion: 0.2992 ), and $\geq 65$ years (standardized proportion: 0.1703 ). NHANES data on the prevalence of osteoporosis were limited to those 40 years of age and older; therefore, the following age adjustment categories were used for both Riverside Gardens and NHANES data in this case: 40-49 (standardized proportion: 0.3578), 50-64 (standardized proportion: 0.3485 ), and $\geq 65$ years (standardized proportion: 0.2937 ).

3.9.4 Statistical Analysis for Aim 3. Descriptive statistics were used to examine characteristics of the Riverside Gardens population. Crude prevalence estimates are provided for all diagnosed diseases reported by Riverside Gardens residents. When comparison data were available, crude and age-adjusted prevalence estimates for Riverside Gardens data and comparison data were reported. 
Noted in tables with crude and age-adjusted prevalence estimates are thresholds of the relative standard errors (RSE) of prevalence estimates for Riverside Gardens data. The RSE is a measure of statistical reliability and is often used when analyzing survey data. ${ }^{246}$ It is reported as a percentage and is calculated by dividing the standard error by the estimate and multiplying it by 100 . Estimates with a relative standard error of more than $30 \%$ are identified with superscripts in results tables. The table footnote details if the RSEs are more than $30 \%$ but less than or equal to $50 \%$ or greater than $50 \%$. RSEs greater than $30 \%$ but less than or equal to $50 \%$ are considered statistically unstable, and the corresponding estimates should be interpreted with caution. RSEs greater than $50 \%$ are considered unreliable.

In order to determine if the prevalence of chronic diseases significantly differed between the Riverside Gardens participants and local, state, and national prevalence, prevalence difference tests were used. The prevalence estimate from the comparison group was subtracted from the prevalence estimate in Riverside Gardens to produce the prevalence difference. The variance of the prevalence difference equals the sum of the variance of each prevalence estimate. A 95\% CI for the difference was then produced using the summed variance $(95 \%$ CI for Prevalence Difference $=$ Prevalence Difference $+/-1.96 *$ sqrt(variance $1+$ variance2). Note that because the difference in prevalence estimates can be negative, prevalence differences and their CIs can also be negative.

If the $95 \% \mathrm{CI}$ of the prevalence difference included 0 (the null), the prevalence estimates were determined to not significantly differ at alpha $=0.05$. Prevalence differences that were found to be statistically significant are reported along with their $95 \%$ CIs. 


\section{Specific Aim 4: To evaluate the relationship between environmental exposure}

\section{histories and self-reported health conditions among residents of Riverside Gardens.}

\section{Subaim $4 A$}

In order to evaluate the relationship between participants' environmental exposure histories and self-reported diagnosed health conditions, the following were created for use in Subaim 4A's logistic regression models: disease categories, a categorical variable for the total number of diseases reported, and an exposure score. The processes for categorizing diseases and creating the exposure score are detailed in the next sections.

\subsubsection{Disease Categories. Due to the vast number of diseases reported by}

participants and the low frequencies with which many of the individual disease diagnoses were reported, diseases and symptoms were grouped into categories for use in regression analyses. The International Classification of Diseases, Tenth Revision, Clinical Modification (ICD-10-CM) ${ }^{247}$ was used to categorize diseases. Table 11 lists the thirteen categories and the diseases included in each. A dichotomous variable indicating whether participants were diagnosed with one or more diseases in each category was created for use in binary logistic regression models ( $1=$ diagnosed with a disease in the category; $0=$ not diagnosed with a disease in the category, referent group). 
Table 11. Categories of Diagnosed Diseases

Disease Category ${ }^{1}$

Diagnosed Diseases Included

\begin{tabular}{|c|c|}
\hline $\begin{array}{l}\text { Blood and Blood-Forming } \\
\text { Organs }\end{array}$ & anemia, leukopenia \\
\hline Cancer (Neoplasms) & $\begin{array}{l}\text { cancer of the: bladder, breast, cervix, colon and } \\
\text { rectum, lung, ovary, prostate, skin (melanoma and } \\
\text { non-melanoma), thyroid, uterus }\end{array}$ \\
\hline Circulatory System & $\begin{array}{l}\text { aneurysm, angina/angina pectoris, bradycardia, } \\
\text { cardiac arrhythmia, congestive heart failure, } \\
\text { coronary heart disease/coronary artery disease, } \\
\text { myocardial infarction, hypertension, Raynaud's } \\
\text { Phenomenon, stroke, tachycardia }\end{array}$ \\
\hline Digestive System & $\begin{array}{l}\text { Crohn's disease, gallbladder disease, } \\
\text { gastroesophageal reflux disease, liver disease, } \\
\text { ulcerative colitis, ulcers (stomach, duodenal, or } \\
\text { peptic) }\end{array}$ \\
\hline Ear and Mastoid Process & hearing loss, vertigo \\
\hline $\begin{array}{l}\text { Endocrine, Nutritional, and } \\
\text { Metabolic Diseases }\end{array}$ & $\begin{array}{l}\text { adrenal gland disorder, hypercholesterolemia, } \\
\text { thyroid disorder, type } 1 \text { diabetes, type } 2 \text { diabetes }\end{array}$ \\
\hline Eye and Adnexa & $\begin{array}{l}\text { cataracts, glaucoma, macular degeneration, retinal } \\
\text { disorder }\end{array}$ \\
\hline Genitourinary System & endometriosis, infertility, kidney disease \\
\hline $\begin{array}{l}\text { Mental, Behavioral, and } \\
\text { Neurodevelopmental } \\
\text { Disorders }\end{array}$ & $\begin{array}{l}\text { anxiety disorder, attention-deficit/hyperactivity } \\
\text { disorder or attention-deficit disorder, bipolar } \\
\text { disorder, depressive disorder, obsessive-compulsive } \\
\text { disorder, panic disorder, schizophrenia }\end{array}$ \\
\hline $\begin{array}{l}\text { Musculoskeletal System and } \\
\text { Connective Tissue }\end{array}$ & $\begin{array}{l}\text { arthritis (not rheumatoid), bulging disc, degenerative } \\
\text { disc disease, fibromyalgia, gout, herniated disc, } \\
\text { osteoarthritis, osteopenia, osteoporosis, rheumatoid } \\
\text { arthritis, scoliosis }\end{array}$ \\
\hline Nervous System & $\begin{array}{l}\text { benign essential tremors, epilepsy/seizure disorder, } \\
\text { migraines, narcolepsy, peripheral } \\
\text { neuropathy/neuritis, reflex sympathetic dystrophy } \\
\text { syndrome, sleep disorder }\end{array}$ \\
\hline Respiratory System & $\begin{array}{l}\text { asthma, chronic bronchitis, chronic obstructive } \\
\text { pulmonary disease, emphysema }\end{array}$ \\
\hline $\begin{array}{l}\text { Skin and Subcutaneous } \\
\text { Tissue }\end{array}$ & lupus, psoriasis, psoriatic arthritis \\
\hline
\end{tabular}

${ }^{1}$ Diseases were categorized using ICD-10-CM.

Participants may be represented in more than one disease category.

3.9.6 Number of Diseases Reported. In addition to disease categories, a

categorical variable representing the number of chronic diseases reported by participants 
was created for use in multinomial logistic regression models. The number of chronic diseases reported by each participant was summed and its distribution was assessed. The distribution was then split into tertiles of approximately equal frequencies: 0-2 (32.5\%), 3-7 (34.9\%), and $\geq 8$ diseases reported (32.5\%).

3.9.7 Exposure Score. An exposure score was created using the following seven dichotomous exposure variables: proportion of life in neighborhood, lived in the neighborhood during childhood, home's location in neighborhood, consumed plants grown/animals captured in neighborhood, used well water in neighborhood, participated in activities in or around the landfill site, and swam in the Ohio River variables. Participants were awarded 1 point towards the exposure score for each of the following: living in the neighborhood for $50.0 \%$ or more of life, living in an exterior neighborhood zone, reporting that they had eaten plants grown or animals captured in the neighborhood, reporting that they had used well water in the neighborhood, reporting that they participated in activities on or around the landfill site, and reporting that they swam in the Ohio River. The points were summed to create the exposure score. The minimum possible value of the score was 0 and the maximum was 7 . The exposure score variable was used in its continuous form in regression analyses. Associations between exposure score variables can be found in Table 12 located in Appendix C.

\subsubsection{Demographic Characteristics and Potential Covariates. Demographic}

characteristics and potential covariates considered for inclusion in the logistic regression models included gender (male-referent group/female), age (in years), race (white-referent group/other race), BMI (normal-referent group/overweight/obese), personal tobacco use 
history (never user-referent group/former user/never user), and occupational exposure histories (no history-referent group/history).

Demographic characteristics and potential covariates were stratified by each of the disease groups, the categorical variable representing the number of diseases reported, and the exposure score. This information is presented in tables and statistical differences in the distribution of demographic characteristics and potential covariates by disease groups and by the exposure score were calculated. For comparisons involving all categorical variables, Chi-square $P$ values were calculated when the expected cell count was greater than five and Fisher's Exact $P$ values were calculated when the expected cell count was less than or equal to five. For comparisons of a non-normally distributed continuous variable across two groups, Wilcoxon Rank-Sum tests were used, and for comparisons across three groups, Kruskal-Wallis tests were used. Spearman correlation coefficients and $P$ values were calculated and reported when assessing the correlation of two non-normally distributed continuous variables. Differences were considered statistically significant when $P<.05$.

3.9.9 Modeling Procedure. Binary logistic regression was conducted to evaluate the association between the exposure score and each of the disease categories. For each of the disease category models, the first step in the model building procedure involved the assessment of the relationship between potential covariates and both the disease group and the exposure score using univariate analyses. Univariate analyses with potential covariates that resulted in a liberal $P$ value $(P \leq .20)$ were considered for inclusion in the adjusted multivariable logistic regression model. Covariates were removed from the model, starting with the covariate with the highest $P$ value, using the backward stepwise 
technique described in Hosmer \& Lemeshow (2000) and Jewell (2003). ${ }^{248,249}$ Covariates remained in the model if they were significant in the model at $P<.10$ or if they improved the fit of the model (determined using the likelihood ratio test). Covariates that were removed during the backward stepwise technique were assessed for confounding effects upon their removal from the model. Removed covariates that resulted in at least a $10 \%$ change in the odds ratio (OR) were added back to the model. At the end of the backward stepwise procedure, potential covariates that were excluded during the univariate analysis step were introduced to the model one at a time and considered for inclusion based on their significance in the model and improved model fit. Final models were assessed using goodness-of-fit tests.

In addition to binary logistic regression, multinomial logistic regression was conducted to evaluate the association between the exposure score and the number of chronic diseases reported by participants. This statistical technique is an extension of logistic regression where the dependent variable has more than 2 categories, also known as a polytomous response. For this study, this method was based on a dependent variable with 3 disease frequency categories: $0-2,3-7$, and $\geq 8$ diseases reported. Using the maximum likelihood estimation, the probability of reporting 3-7 and $\geq 8$ diseases was compared to the probability of reporting 0-2 diseases, creating several binary logistic regression models. ${ }^{248}$ The same modeling procedure previously described for binary logistic regression was used.

The following results are reported for all unadjusted and final adjusted regression models: ORs, 95\% CIs, and $P$ values. All statistical analyses were conducted using SAS version 9.4 (Cary, N.C.). 


\section{Subaim $4 B$}

In order to evaluate the relationship between participants' home locations and self-reported frequency of symptoms reported at home and in the neighborhood, symptom groups were created for use in Subaim 4B's logistic regression models. The process for categorizing symptoms is detailed in the next section.

3.9.10 Symptom Groups. As with individual diseases, the number of symptoms reported by participants and the low frequencies with which many of the individual symptoms were reported necessitated the merger of individual symptoms into symptom groups. Symptoms that residents reported experiencing while in the neighborhood or at home were categorized as described in Table 13. A dichotomous variable was created for each symptom group. Participants who reported experiencing at least one symptom in any one of these categories daily or weekly were categorized as frequently experiencing symptoms from the related symptom group, while participants who reported experiencing symptoms monthly or less (including those who did not report experiencing the symptoms) were categorized as infrequently experiencing symptoms. A dichotomous variable indicating the frequency of experiencing each symptom group (daily or weekly/monthly or less) was created. Experiencing the symptom monthly or less was used as the referent group in regression analyses. 
Table 13. Symptoms Included in Each Symptom Group

\begin{tabular}{|c|c|}
\hline Symptom Group & Symptoms Included \\
\hline Bone and Muscle Symptoms & $\begin{array}{l}\text { back pain, lack of muscle coordination, } \\
\text { muscle cramps, muscle weakness }\end{array}$ \\
\hline Eye Symptoms & blurred vision, eye burning, eye watering \\
\hline Gastrointestinal Symptoms & diarrhea, heartburn, nausea, stomach discomfort \\
\hline Mood Symptoms & anxiety, depression \\
\hline Neurological Symptoms & $\begin{array}{l}\text { confusion, dizziness, drowsiness, feeling of "pins and } \\
\text { needles" on hands or feet, headaches, memory loss, } \\
\text { numbness in hands or feet, rapid heart rate at rest, } \\
\text { tired or fatigued, tremors, trouble concentrating, } \\
\text { trouble with balance }\end{array}$ \\
\hline Respiratory Symptoms & $\begin{array}{l}\text { cough, shortness of breath, sinus problems, } \\
\text { sore throat, wheezing }\end{array}$ \\
\hline Skin Symptoms & $\begin{array}{l}\text { boils; corns or warts on hands, feet, chest, back, or } \\
\text { abdomen; darkening of skin; rashes; skin dryness; } \\
\text { skin itchiness; skin ulcers }\end{array}$ \\
\hline
\end{tabular}

Participants may be represented in more than one symptom group.

\subsubsection{Demographic Characteristics and Potential Covariates. Demographic}

characteristics and potential covariates considered for inclusion in the logistic regression

models included gender (male-referent group/female), age (in years), race (white-referent group/other race), BMI (normal-referent group/overweight/obese), personal tobacco use history (never user-referent group/former user/never user), occupational exposure histories (no-referent group/yes), and time spent outdoors in the neighborhood $(<20$ hours per week-referent group/ $\geq 20$ hours per week).

Demographic characteristics and potential covariates were stratified by each of the symptom groups and the home location variable. This information is presented in tables. Statistical differences in the distributions presented in tables and the binary logistic regression modeling procedure used in Subaim 4B are the same as those previously described for Subaim 4A. Interior home location was used as the referent group in logistic regression analyses. 


\section{RESULTS}

\section{Results for Specific Aim 1: To explore community health perceptions, environmental exposure experiences, and health concerns of adults who have lived in Riverside Gardens for five or more years, using qualitative research methods.}

This section covers the results of the qualitative portion of this research project, including individual interviews with 15 participants between the months of March and May in 2017. Main themes regarding the community's history and transformation, environmental exposure experiences, and health and well-being were assessed from the interview transcripts and are presented here.

\subsection{Participants}

Of the 15 interview participants, $73.3 \%(n=11)$ were male and $26.7 \%(n=4)$ were female. Participants ranged in age from 24 to 69 years (median 59, interquartile range (IQR) 10). Males were significantly older than females (median age for males: 60 years, median age for females: 48 years; $P=.02$ ). Two of the participants lived in the same house. The majority $(73.3 \%, \mathrm{n}=11)$ of participants had lived in the neighborhood for over 20 years. Almost half $(46.7 \%, \mathrm{n}=7)$ lived in the neighborhood during childhood; all participants who lived in the neighborhood during childhood moved away as adults for a period of time, but later returned. 


\subsection{Community History and Transformation}

The majority $(86.7 \%, n=13)$ of participants were knowledgeable about the community's history and two-thirds recited facts about the neighborhood's beginnings as a resort community. Some of those who had grown up in the neighborhood, particularly those who were children during the 1950s and 1960s, were able to expand upon the ways in which the community itself has changed over time, fondly recalling that the neighborhood was once "family-oriented." They described the community as one that was full of children and reported that large groups of children from across the neighborhood could be frequently found playing outdoors. The community was also described as being close-knit during this time period, a place where everyone knew their neighbors. In contrast, when discussing the neighborhood today, all of the participants described ways in which community members were isolated. Some reported only associating with their immediate neighbors, while others commented that they "keep to [themselves] and like for [others] to do the same."

Many participants cited changes in homeownership as a reason for the isolation that exists within the community today. Participants shared that the community used to be full of homeowners who were often lifelong residents. However, participants explained that in recent years, as older, lifelong community members passed away, their houses were not put up for sale; instead, these houses either remained vacant or became rental properties. One 51-year-old female participant stated that renters only remained in rental properties for a year or less, and some participants felt that the renters have not been as involved in the community, both of which have contributed to the lack of connection among neighbors. 
Interview participants also felt that increases in the number of vacant homes and rental properties led to changes in the neighborhood's physical appearance. The increase in vacant homes and rental properties in the neighborhood was described by one 53-yearold male participant as a "downward spiral." Many participants noted that the rental houses and vacant properties are not well-maintained. Numerous houses in the neighborhood were described as "run down," and some participants expressed frustration that community members no longer "took pride" in their homes. Many of the long-term residents reported that they were negatively affected by these changes in the neighborhood. One 59-year-old male participant who grew up in the neighborhood summarized what several shared by saying, "I'd give anything if [other community members] could take a little more pride and clean some of these places up around here. It's depressing."

Furthermore, property devaluation is a theme that emerged and is closely related to the decline in homeownership. More than half $(53.3 \%, n=8)$ of participants expressed that they were unable to get fair market value for their properties, and one male participant stated that he owed more money on his home than it was worth. All eight participants cited the neighborhood's proximity to the landfill or nearby industries as reasons for property devaluation in the neighborhood. One 58-year-old male participant who has lived in the neighborhood for over 30 years explained, "Nobody wants [houses] down here. They've all seen our lawsuits [against nearby industries]. They've heard about it...The investment is nothing anymore." Another male participant (age 62) shared, "You can't get your money. This place is circled. It's red. It's a hazard. And it's 'cause of 
these chemical factories." Several participants reported feeling "stuck" with their homes for this reason.

In addition to highlighting changes in the neighborhood's sense of community, prevalence of homeownership, and property values, participants provided information concerning the histories of the neighboring landfill and surrounding industries.

Participants were well informed about the industries and industrial waste facilities that surrounded the neighborhood. Several participants recalled details about the landfill, including its construction, operation, and closing, as well as the EPA's subsequent involvement. Many participants also discussed the neighboring power plant's conversion from using coal to natural gas. Finally, when discussing neighboring chemical, plastic, and rubber manufacturers, participants often noted frequent ownership and company name changes, as well as histories of the plants' operations, including explosions and waste releases.

\subsection{Environmental Exposure Experiences}

All of the participants highlighted the ways in which living near the landfill and industries impacted their lives. Each participant shared examples of why they felt that they were exposed to environmental pollution, particularly air pollution and water pollution, in their neighborhood and described what they saw, smelled, and heard that made them feel that way.

Participants noted that exposures have changed over time and that the closing of the landfill and the power plant's conversion from using coal to natural gas have improved the neighborhood's environment; however, even with these changes, 
participants felt that the neighborhood continued to be exposed to pollution from these sources and the other nearby industries (i.e. the neighboring chemical, plastic, and rubber manufacturers). Additionally, participants who grew up in the neighborhood discussed unique exposure experiences during childhood.

Common themes related to the impact of the surrounding industries and industrial waste sites on the community included soot and chemical films on houses and property, unpleasant odors, water contamination, and loud noises.

\subsubsection{Air Pollution. All participants cited air pollution as one of the} neighborhood's environmental concerns. When asked to expand upon why they felt that air pollution was a problem, participants frequently discussed seeing substances that had deposited onto their houses and property and smelling unpleasant odors.

Almost three-quarters $(73.3 \%, \mathrm{n}=11)$ of participants discussed problems with soot that had settled on their houses, vehicles, driveways, and at the bottom of their swimming pools. Excessive dust within the home was also listed as a concern. Participants cited the nearby power plant as the source of the soot and dust; however, participants did note that soot and dust problems improved after the nearby power plant converted from using coal to natural gas. Several participants also discussed seeing a chemical film that was described as a "glue-type substance" that covered houses, vehicles, and children's outdoor toys. This substance was believed to come from the chemical company that borders the neighborhood. Participants expressed that their efforts to clean their houses, vehicles, driveways, swimming pools, and children's toys to remove all of these substances were futile - the substances quickly redeposited after cleaning. In another 
example of the problem of pollutant deposits, one 59-year-old female participant recounted a recent experience with an unknown substance that had deposited on her sidewalk:

"[T]here's like these big yellow blotches that were on [the sidewalk]. You had to take a scrub brush and bleach them. Scrub them off and stuff. I mean, there's different things you have to do more than you would someplace else just because you live where you live."

Two-thirds of participants $(66.7 \%, \mathrm{n}=10)$ expressed concerns over the health effects related to the neighborhood's air pollution problems. As one 58-year-old male participant explained, "[We] get the fallout from any of these plants depending on which way the wind is blowing. It's just too much exposure to things the human body shouldn't be exposed to." Another male participant (age 62) shared, "I believe [the health problems] ha[ve] to do with what we're breathing out there. See, it's a silent killer. You don't see it." One male participant (age 69) summarized what several others expressed by saying, "You're afraid to take a deep breath around here."

\subsubsection{Odor Concerns. When talking about air pollution, the presence of strong} odors in the neighborhood was also discussed by participants. Participants described how pungent odors were emitted from the landfill during the time it was operational and for years after. One 60-year-old male participant described the landfill's odor as a "bad...strange smell" like "something you...never smelled before in your life." Today, participants say that most odors come from the chemical, plastic, and rubber manufacturers to the north of the neighborhood. Terms used to describe these odors 
included "rotten eggs," "Kool-Aid," "menthol," "sickeningly sweet," "burnt brakes," and "rubber." Participants noted that the odors vary depending on the time of day, day of the week (i.e. weekday versus weekend), season, and wind direction. Several participants also went on to explain how these odors have affected them, with one 51-year-old female participant explaining that the odors "gag" her when she walks outdoors in the morning and make her "sick to [her] stomach after a while." Three participants $(20.0 \%)$ shared that they frequently experience headaches as a result of smelling these odors.

1.3.3 Water Pollution. Over $70 \%$ of participants $(73.3 \%, \mathrm{n}=11)$ mentioned water pollution when describing the neighborhood's environmental problems. Several of the participants who lived in the neighborhood during the time that the landfill was operational or shortly after it closed, recalled concerns about groundwater contamination caused by the landfill waste. Many homes in the neighborhood used well water during this time, and private wells were tested because of contamination concerns. One 59-yearold male participant who grew up in the neighborhood recalled his family's experience with well water testing during this time: "We were lucky...We were far enough away from the dump that our well hadn't gotten contaminated. We were one of the lucky ones." Two participants shared concerns that drinking well water may have contributed to their, their family members', or their neighbors' health problems.

Numerous participants also discussed waste releases made by the neighboring industries into the creek that runs through the neighborhood or into the river that borders the neighborhood. Several participants mentioned a release that had occurred a couple of months before interviews were conducted, during which a neighboring chemical 
company had released a substance that was described as being "fluorescent green" in color into a creek that runs through the neighborhood. Community members were later told that the substance was paint. One 24-year-old female participant who lives along the creek expressed dissatisfaction with how the creek was cleaned following the release. She described her experience as this:

"They first got that water pumped out. That paint. Then they was cleaning and trimming up over [the creek]. Then they was like, 'Okay. It's enough.' They were supposed to clean it, but all that I saw them do was chop some stuff down and move it up on the bank up further up. Which that's not cleaning. Cleaning's taking that away and removing it so that it's clear."

1.3.4 Noise Pollution. One-third $(\mathrm{n}=5)$ of participants mentioned loud noises that could be heard in the neighborhood and were believed to come from the nearby industries. Two participants described one of the noises as a "high-pitched" sound coming from the direction of the power plant. One of these participants (male, age 60) expanded on the description of the sound:

"[H]ave you heard when someone's [using] an air compressor? When somebody's done with an air compressor, and they pull that little pin out and let that air out, it's just a real high-pitched [noise]. That's what it sounds like...It's very, very loud. I mean, if you're dead asleep, that will wake you up."

1.3.5 Exposures During Childhood. The seven participants who grew up in the neighborhood recalled many unique exposure experiences from their childhood, 
particularly experiences related to play. One 69-year-old male participant explained that when he was growing up, there were no parks near the neighborhood, so children "found their own [parks]." One example of a "park" where neighborhood children would go to play was the landfill site. Participants who grew up in the neighborhood when the landfill was still operational (1948-1975) recalled frequently visiting and playing on the landfill. They also discussed coming into contact with waste during these visits. One 62-year-old male participant recalled walking through waste that he described as a "green" "slime" or "gel," while another male participant (age 60) remembered seeing and playing with what he described as rubber that was coming out of the ground at the site. Participants also discussed how they would occasionally remove items such as cigarettes and soft drinks from the landfill. In the years since the landfill's closure, participants commented that the landfill site has continued to be used for recreational activities, such as playing paintball.

In addition to the landfill, participants described ways in which releases from nearby industries affected the play places that existed within their neighborhood. Some participants recalled swimming in the Ohio River, which runs along the west side of the neighborhood. The riverfront that runs along the neighborhood is downstream from several chemical, plastic, and rubber manufacturers, and two older participants recalled pollution in the river after waste was discharged from these plants. One 60 -year-old male participant recounted a time when he was swimming in the river and substances that he described as "hot" and "gooey" were released into the river from the plant that borders the neighborhood on its north side. Another participant (male, age 69) recalled that he and other children would get out of the river when they saw "foam floating down" it or when the water "turned colors." The same participant shared, "It's a wonder we're still 
alive. [The nearby plants] had some very toxic stuff in [the river]." Yet another male participant (age 62) commented that, "Everybody that was involved with us going over [to the river] has got some type of cancer and died or is in bad health."

In addition to pollution at the landfill site and in the river, some participants recalled being unable to play in the snow in their own yards as children because the snow "had black soot on top of it" due to the ash from the nearby coal-burning power plant. One 62-year-old male participant recalled his mother telling him not to eat the snow when he was a child due to the presence of the soot.

\subsection{Community Health and Well-Being}

Thirteen of the fifteen interview participants (86.7\%) felt that environmental exposures impacted the community's health. Most $(80.0 \%, \mathrm{n}=12)$ participants recalled

family members and community members that passed away in the neighborhood. About half of participants felt members of their community both past and present had more health problems than you would find in other neighborhoods. One 53-year-old male participant summarized the thoughts of many by describing the area as a "dying neighborhood."

A variety of health conditions that participants, participants' family members, and community members have experienced were discussed. Cancer was reported as a community health concern by $73.3 \%$ of participants. Numerous specific cancer types were reported; however, lung cancer, brain cancer, bone cancer, and throat cancer were the most frequently reported types. The most frequently reported non-cancer health conditions of concern included respiratory problems (reported by $53.3 \%$ of participants), 
allergies (46.7\%), joint and disc diseases (40.0\%), cardiovascular disease (26.7\%), diabetes (20.0\%), and mental health disorders (20.0\%). Digestive system diseases, sleep disorders, seizure disorders, fertility problems, memory problems, and high cholesterol were less frequently reported conditions. Symptoms that participants reported experiencing in the neighborhood included headaches, skin irritation and dryness, sinus problems, and eye burning.

In addition to the health effects that many participants attributed to the environmental exposures, some participants explained ways in which living in the neighborhood affected their well-being. Participants shared that they felt immense regret for purchasing their homes. Some participants expressed that they were unaware of the landfill and at least one of the chemical companies (the one that directly borders the neighborhood) when they purchased their house. Several participants who did not grow up in the neighborhood and purchased their houses after the landfill was listed as an EPA Superfund site explained that their house's proximity to the site was not disclosed at the time of purchase. As one 58-year-old male participant said, “They don't say nothing about what's down here until after [you] buy your house and then they let the other neighbors tell [you]." Furthermore, three participants shared that they believed that the chemical company that borders the neighborhood was actually a dairy plant at the time that they purchased their house. They thought this because at one point the plant was operated by a company that also had a food division, and the logo on the sign at the plant was the same as the logo on the food products with which they were familiar. As one 59year-old female participant explained, "We all assumed that they were a dairy products plant that was over processing ice cream and, come to find out, they're processing 
formaldehyde." The same participant has a child who grew up in the neighborhood and the child has experienced a variety of chronic health conditions. The participant openly expressed guilt for moving her family into the neighborhood and raising her child there, even though she was unaware of the community's environmental concerns when she purchased her home.

More than half $(53.3 \%, \mathrm{n}=8)$ of participants expressed unease and distrust of the industries based on past exposure experiences and the lack of communication that followed. Participants commented that the surrounding industries rarely reach out to the community after pollutants are unintentionally released or incidents such as explosions occur. If the companies do reach out, participants reported that it is often well after the event occurred. Two participants, a 62-year-old male and a 45-year-old female, recounted that even after a major event in which emergency alarms sounded and community members were told to stay inside, close their windows, and turn off their air conditioners, there was no additional communication with community members to explain what had happened.

Numerous participants described other ways in which the neighborhood's environmental pollution problems impacted their lives. Several of the participants who had children and grandchildren who lived outside of the neighborhood expressed that they did not want their children or grandchildren spending time in the neighborhood because of its environmental pollution problems. One 62-year-old male participant expressed the thoughts of many by saying, "You don't want to live here. You don't want to bring your family, you don't want to bring your kids down here. You don't want them growing up here." Another 53-year-old male participant expressed that his daughter 
limits the amount of time that her children (his grandchildren) are allowed to spend with him in the neighborhood because of the pollution. He said that his daughter was "paranoi[d] about letting the kids come around...because of the chemicals and all the things we found that's in the air."

Four participants (26.7\%) reported that they would not pass their homes down to their children for reasons related to the pollution. One 58-year old male participant expressed that this was his choice by saying, "I told my wife, we're not going to leave this house to the kids. I don't want them living here.” Another 53-year old male participant shared that it was his daughter who was not interested in inheriting his home due to environmental concerns, stating, "She would sell it to the first person that come and give her a price. She'd probably sell it and get rid of it. That's how much she don't like [the neighborhood]."

Several participants also explained that they did not want to sell their homes even if they could get a fair price because selling the home would mean another family would move in and potentially face the same experiences that they had, causing them guilt. As one 53-year-old male participant said, "I don't know if I could put somebody in here. You know, I'd have to tell them the truth, and then if I told 'em the truth, they wouldn't want to stay here."

Six participants $(40.0 \%)$ shared that they had long fought for the health and wellbeing of the community, but after decades of fighting, several participants expressed feelings of powerlessness, hopelessness, and defeat. One community member (male, age 53) who used to participate in community activism efforts explained why he quit by stating, "You just get frustrated. Nobody's hearing you. You're out there hollering... and 
nobody's hearing you." Another community member (male, age 62) communicated feelings of hopelessness by saying, "[A]fter a while you quit getting your hopes up. [The surrounding industries] [a]re going to do what they're going to do anyway...Y You feel helpless."

\subsection{Interview Conclusions and Next Steps}

Information shared during these interviews informed the research team of the diverse ways in which community members have been impacted by the neighborhood's proximity to industry and industrial waste facilities. Participants detailed the types of pollution that they came into contact with while at home and in their neighborhood, including air pollution, strong odors, water pollution, and noise pollution, and alerted the study team to the ways in which community members may come into contact with the landfill site and releases made by nearby industries, especially during childhood. These details, along with the specific health concerns shared, were particularly important when developing the health and exposure questionnaire used in the next phase of the study.

Perhaps the most unexpected interview findings were those related to the wellbeing of interview participants. Many participants went beyond the questions asked during the interview in an attempt to further explain the ways in which living in the neighborhood has affected their lives, including impacts to mental health and quality of life. These stories enhanced the research team's understanding of the numerous ways in which living near industry and industrial waste facilities can impact the lives of residents.

These interview findings were presented to community members during a meeting held in October of 2017. Meeting attendants expanded upon and clarified the exposure 
concerns and health conditions shared during the interviews. Information shared during the interviews and the community meeting was then incorporated into the health and exposure assessment questionnaire that was designed for the Riverside Gardens community for use in the second phase of the study.

\section{Results for Specific Aim 3: To assess and compare the prevalence of self-reported health conditions in Riverside Gardens.}

3.1 Results for Subaim 3A: To compare self-reported chronic disease prevalence between Riverside Gardens residents and local, state, and national prevalence, as available, using data from representative surveys.

Demographics for the 83 participants who completed the full version of the Riverside Gardens health and exposure assessment questionnaire are shown in Table 14. The population was evenly divided by gender ( $50.6 \%$ female), and the median age of participants was 61 years (IQR: 16). The majority of participants were white (84.3\%) and non-Hispanic (95.2\%). Most (84.1\%) had at least a high school diploma or GED, and a little more than one-third (34.1\%) had some form of postsecondary education. Of those who reported their annual household income (86.8\%), half of participants reported earning less than $\$ 25,000$ annually before taxes. Almost all (92.8\%) had some form of health care coverage. When asked how they would rate their health, half of participants selected 'poor' or 'fair' $(50.0 \%)$, followed by 'good' (35.4\%), and 'very good' or 'excellent' (14.6\%). The median number of years that participants reported living in the 
neighborhood was 29 (IQR: 41), and 41.0\% reported living in multiple houses in the neighborhood.

Table 14. Participant Demographics

\begin{tabular}{|c|c|}
\hline & n (\%) \\
\hline Total & $83(100.0 \%)$ \\
\hline \multicolumn{2}{|l|}{ Gender } \\
\hline Male & $41(49.4 \%)$ \\
\hline Female & $42(50.6 \%)$ \\
\hline \multicolumn{2}{|l|}{ Age } \\
\hline Mean (SD) & $58.4(14.7)$ \\
\hline Median (IQR) & $61(16)$ \\
\hline \multicolumn{2}{|l|}{ Race } \\
\hline White & $70(84.3 \%)$ \\
\hline Black & $4(4.8 \%)$ \\
\hline Asian & $1(1.2 \%)$ \\
\hline American Indian or Alaskan Native & $0(0.0 \%)$ \\
\hline Biracial & $8(9.6 \%)$ \\
\hline \multicolumn{2}{|l|}{ Ethnicity } \\
\hline Hispanic & $4(4.8 \%)$ \\
\hline Non-Hispanic & $79(95.2 \%)$ \\
\hline \multicolumn{2}{|l|}{ Highest Level of Education ${ }^{1}$} \\
\hline Less than High School Diploma & $13(15.9 \%)$ \\
\hline High School Diploma/GED & $41(50.0 \%)$ \\
\hline Postsecondary Education & $28(34.1 \%)$ \\
\hline \multicolumn{2}{|l|}{ Annual Household Income } \\
\hline$<\$ 25,000$ & $36(43.4 \%)$ \\
\hline$\geq \$ 25,000$ & $36(43.4 \%)$ \\
\hline Declined to Say & $11(13.3 \%)$ \\
\hline \multicolumn{2}{|l|}{ Health Care Coverage } \\
\hline Yes & $77(92.8 \%)$ \\
\hline No & $5(6.0 \%)$ \\
\hline Don’t Know & $1(1.2 \%)$ \\
\hline \multicolumn{2}{|l|}{ Personal Health Rating $^{1}$} \\
\hline Excellent/Very Good & $12(14.6 \%)$ \\
\hline Good & $29(35.4 \%)$ \\
\hline Fair/Poor & $41(50.0 \%)$ \\
\hline \multicolumn{2}{|c|}{ Number of Years Lived in Neighborhood } \\
\hline Mean (SD) & $33.1(22.1)$ \\
\hline Median (IQR) & $29(41)$ \\
\hline \multicolumn{2}{|c|}{ Number of Houses in Riverside Gardens } \\
\hline 1 & $49(59.0 \%)$ \\
\hline 2 or 3 & $23(27.7 \%)$ \\
\hline 4 or more & $11(13.3 \%)$ \\
\hline
\end{tabular}


As previously mentioned, participants reported being diagnosed with 65 noncancer diseases. These diseases, their crude prevalence estimates, and counts are shown by disease category in Table 15 . 
Table 15. Crude Prevalence of Disease for Non-Cancer Outcomes ${ }^{1}$

\begin{tabular}{|c|c|c|c|c|c|}
\hline \multirow{2}{*}{ Disease by Category } & \multicolumn{2}{|c|}{ Crude Prevalence } & \multirow{2}{*}{ Disease by Category } & \multicolumn{2}{|c|}{ Crude Prevalence } \\
\hline & $\%$ & (n) & & $\%$ & (n) \\
\hline Blood and Blood-Forming Organs & 15.7 & 13 & Endocrine, Nutritional, and & & \\
\hline Anemia & 14.5 & 12 & Metabolic Diseases & 41.0 & 34 \\
\hline Leukopenia & 2.4 & 2 & Adrenal gland disorder & 1.2 & 1 \\
\hline Circulatory System & $\mathbf{5 7 . 8}$ & 48 & Hypercholesterolemia $^{2}$ & 32.5 & 27 \\
\hline Aneurysm & 6.0 & 5 & Thyroid disorder ${ }^{2}$ & 12.0 & 10 \\
\hline Angina/angina pectoris ${ }^{2}$ & 1.2 & 1 & Type 1 diabetes $^{2}$ & 1.2 & 1 \\
\hline Bradycardia & 1.2 & 1 & Type 2 diabetes $^{2}$ & 18.1 & 15 \\
\hline Cardiac arrhythmia & 6.0 & 5 & Eye and Adnexa & 21.7 & 18 \\
\hline Congestive heart failure $^{2}$ & 6.0 & 5 & Cataracts $^{2}$ & 19.3 & 16 \\
\hline Coronary heart disease ${ }^{2}$ & 3.6 & 3 & Glaucoma $^{2}$ & 4.8 & 4 \\
\hline Hypertension $^{2}$ & 50.6 & 42 & Macular degeneration $^{2}$ & 1.2 & 1 \\
\hline Myocardial infarction ${ }^{2}$ & 7.2 & 6 & Retinal disorder & 1.2 & 1 \\
\hline Raynaud's phenomenon & 2.4 & 2 & Genitourinary System & 10.8 & 9 \\
\hline Stroke $^{2}$ & 10.8 & 9 & Endometriosis $^{3}$ & 16.7 & 7 \\
\hline Tachycardia & 3.6 & 3 & Infertility & 1.2 & 1 \\
\hline Digestive System & 37.4 & 31 & Kidney disease ${ }^{2}$ & 2.4 & 2 \\
\hline Crohn's disease ${ }^{2}$ & 3.6 & 3 & Mental, Behavioral, \& & & \\
\hline Gallbladder disease & 16.9 & 14 & Neurodevelopmental Disorders & 31.3 & 26 \\
\hline Gastroesophageal reflux disease & 21.7 & 18 & Anxiety disorder ${ }^{2}$ & 18.1 & 15 \\
\hline Liver disease & 3.6 & 3 & $\mathrm{ADD} / \mathrm{ADHD}^{2}$ & 4.8 & 4 \\
\hline Ulcerative colitis ${ }^{2}$ & 3.6 & 3 & Bipolar disorder $^{2}$ & 9.6 & 8 \\
\hline Ulcers (stomach, duodenal, or & & & Depressive disorder ${ }^{2}$ & 24.1 & 20 \\
\hline peptic) $)^{2}$ & 9.6 & 8 & Obsessive-compulsive disorder & 4.8 & 4 \\
\hline Ear and Mastoid Process & 14.5 & 12 & Panic disorder ${ }^{2}$ & 10.8 & 9 \\
\hline Hearing loss & 14.5 & 12 & Schizophrenia & 2.4 & 2 \\
\hline Vertigo & 1.2 & 1 & & & \\
\hline
\end{tabular}


Table 15. Crude Prevalence of Disease for Non-Cancer Outcomes (continued) ${ }^{1}$

\begin{tabular}{|c|c|c|c|c|c|}
\hline \multirow{2}{*}{ Disease by Category } & \multicolumn{2}{|c|}{ Crude Prevalence } & \multirow{2}{*}{ Disease by Category } & \multicolumn{2}{|c|}{ Crude Prevalence } \\
\hline & & (n) & & $\%$ & (n) \\
\hline Musculoskeletal System and & 578 & 48 & Nervous System & 28.9 & 24 \\
\hline Connective Tissue & $5 / .8$ & 48 & Benign essential tremors & 1.2 & 1 \\
\hline Arthritis (not rheumatoid) ${ }^{2}$ & 41.0 & 34 & Epilepsy/seizure disorder ${ }^{2}$ & 2.4 & 2 \\
\hline Bulging disc & 1.2 & 1 & Migraines & 10.8 & 9 \\
\hline Degenerative disc disease & 15.7 & 13 & Narcolepsy $^{2}$ & 1.2 & 1 \\
\hline Fibromyalgia $^{2}$ & 2.4 & 2 & Peripheral neuropathy/neuritis & 4.8 & 4 \\
\hline Gout $^{2}$ & 1.2 & 1 & Reflex sympathetic dystrophy & & \\
\hline Herniated disc & 13.3 & 11 & syndrome & 3.6 & 3 \\
\hline Osteoarthritis $^{2}$ & 13.3 & 11 & Sleep disorder ${ }^{2}$ & 19.3 & 16 \\
\hline Osteopenia & 1.2 & 1 & Respiratory System & 31.3 & 26 \\
\hline Osteoporosis ${ }^{2}$ & 6.0 & 5 & Asthma $^{2}$ & 19.3 & 16 \\
\hline Rheumatoid arthritis $^{2}$ & 7.2 & 6 & Chronic bronchitis $^{2}$ & 13.3 & 11 \\
\hline Scoliosis & 6.0 & 5 & $\mathrm{COPD}^{2}$ & 15.7 & 13 \\
\hline & & & Emphysema ${ }^{2}$ & 6.0 & 5 \\
\hline & & & Skin and Subcutaneous Tissue & 9.6 & 8 \\
\hline & & & Lupus $^{2}$ & 3.6 & 3 \\
\hline & & & Psoriasis $^{2}$ & 6.0 & 5 \\
\hline & & & Psoriatic arthritis $^{2}$ & 2.4 & 2 \\
\hline
\end{tabular}

${ }^{1}$ A person may be represented multiple times within a disease category and across disease categories.

${ }^{2}$ Comparison data at the local, state, and/or national level are available.

${ }^{3}$ Out of females $(\mathrm{n}=42)$ 
Comparison data at the local, state, and/or national level were available for 38 of the 65 diseases. These comparisons are shown in Tables 16-25. More than one-fourth (28.1\%) of the crude prevalence estimates have RSEs greater than $30 \%$ and less than or equal to $50 \%$, indicating that these estimates are unstable and should be interpreted with caution. An additional $28.1 \%$ of crude prevalence estimates have RSEs that are greater than $50 \%$, indicating that these estimates are unreliable. The low precision of many of the prevalence estimates among the Riverside Gardens sample made it difficult to identify significant differences in prevalence estimates when compared to representative survey data. 
Table 16. Crude and Age-Adjusted Prevalence of Circulatory System Diseases in Riverside Gardens, Louisville/Jefferson County,

Kentucky, and the United States ${ }^{1,2}$

\begin{tabular}{|c|c|c|c|c|c|}
\hline $\begin{array}{l}\text { Diseases of the } \\
\text { Circulatory System }\end{array}$ & $\begin{array}{c}\text { Riverside } \\
\text { Gardens }^{3} \\
\%(95 \% \text { CI }) \\
\end{array}$ & $\begin{array}{c}\text { Louisville/ } \\
\text { Jefferson County } \\
\text { BRFSS } 2017^{3} \\
\%(95 \% \text { CI }) \\
\end{array}$ & $\begin{array}{l}\text { BRFSS } 2017^{3} \\
\mathbf{\%}(\mathbf{9 5} \% \mathbf{C I}) \\
\end{array}$ & $\begin{array}{c}\text { National } \\
\text { NHANES } \\
2015-2016^{3} \\
\% \text { (95\% CI) } \\
\end{array}$ & $\begin{array}{l}\text { NHIS } 2017^{3} \\
\% \text { (95\% CI) }\end{array}$ \\
\hline \multicolumn{6}{|l|}{ Angina/Angina pectoris } \\
\hline Crude Prevalence & $1.2(0.0-3.6)^{5}$ & - & - & $2.0(1.5-2.5)$ & $1.8(1.6-2.0)$ \\
\hline Age-Adjusted Prevalence & $0.6(0.0-2.2)^{5}$ & - & - & $1.8(1.3-2.2)$ & $1.6(1.4-1.8)$ \\
\hline \multicolumn{6}{|c|}{ Coronary heart/Coronary artery disease } \\
\hline Crude Prevalence & $3.6(0.0-7.6)^{5}$ & - & - & $3.5(2.7-4.3)$ & $4.4(4.1-4.7)$ \\
\hline Age-Adjusted Prevalence & $1.7(0.0-4.5)^{5}$ & - & - & $3.0(2.4-3.6)$ & $3.8(3.6-4.1)$ \\
\hline \multicolumn{6}{|c|}{ Angina or Coronary heart disease } \\
\hline Crude Prevalence & $4.8(0.2-9.4)^{4}$ & $5.4(3.9-6.9)$ & $6.2(5.5-7.0)$ & $4.7(3.8-5.6)$ & $5.1(4.8-5.4)$ \\
\hline Age-Adjusted Prevalence & $2.3(0.0-5.5)^{5}$ & $4.7(3.4-6.0)$ & $5.4(4.7-6.1)$ & $4.1(3.6-4.8)$ & $4.5(4.2-4.7)$ \\
\hline \multicolumn{6}{|l|}{ Congestive heart failure } \\
\hline Crude Prevalence & $6.0(0.9-11.1)^{4}$ & - & - & $2.5(2.0-2.9)$ & - \\
\hline Age-Adjusted Prevalence & $3.0(0.0-6.7)^{5}$ & - & - & $2.1(1.8-2.5)$ & - \\
\hline \multicolumn{6}{|l|}{ Myocardial infarction } \\
\hline Crude Prevalence & $7.2(1.7-12.8)^{4}$ & $5.5(3.9-7.1)$ & $6.5(5.8-7.3)$ & $3.4(2.7-4.0)$ & $3.1(2.8-3.3)$ \\
\hline Age-Adjusted Prevalence & $3.8(0.0-7.9)^{5}$ & $4.7(3.4-6.1)$ & $5.7(5.0-6.3)$ & $2.9(2.4-3.4)$ & $2.7(2.5-2.9)$ \\
\hline \multicolumn{6}{|l|}{ Hypertension } \\
\hline Crude Prevalence & $50.6(39.8-61.4)$ & $34.6(30.8-38.4)$ & $39.4(37.7-41.0)$ & $31.5(29.0-33.9)$ & $30.6(29.9-31.4)$ \\
\hline Age-Adjusted Prevalence & $39.9(29.4-50.5)$ & $31.5(28.2-34.8)$ & $36.1(34.6-37.6)$ & $29.0(26.9-31.1)$ & $28.0(27.4-28.7)$ \\
\hline \multicolumn{6}{|l|}{ Stroke } \\
\hline Crude Prevalence & $10.8(4.2-17.6)^{4}$ & $4.9(3.1-6.6)$ & $4.7(4.0-5.4)$ & $2.7(2.3-3.2)$ & $3.1(2.9-3.4)$ \\
\hline Age-Adjusted Prevalence & $6.1(1.0-11.3)^{4}$ & $4.2(2.7-5.7)$ & $4.2(3.5-4.8)$ & $2.4(2.0-2.8)$ & $2.8(2.6-3.0)$ \\
\hline
\end{tabular}

${ }^{1}$ A person may be represented in more than one disease category.

${ }^{2}$ Estimates are age-adjusted to the projected 2000 U.S. population using three age groups: 18-44, 45-64, and 65 and over.

${ }^{3}$ In separate questions, respondents were asked if they had ever been told by a doctor or other health professional that they had angina/angina pectoris (RG,

NHANES, NHIS), coronary heart disease (RG, NHANES, NHIS), angina or coronary heart disease (BRFSS), congestive heart failure (RG, NHANES), a heart attack also called a myocardial infarction, high blood pressure or hypertension, or a stroke (RG, BRFSS, NHANES, NHIS). Responses regarding angina and coronary heart disease in RG, NHANES, and NHIS were combined for comparison across all surveys.

${ }^{4} \mathrm{RSE}$ greater than $30 \%$ and less than or equal to $50 \%$.

${ }^{5}$ RSE greater than $50 \%$. 
Table 17. Crude and Age-Adjusted Prevalence of Digestive System Diseases in Riverside Gardens and the United States ${ }^{1,2}$

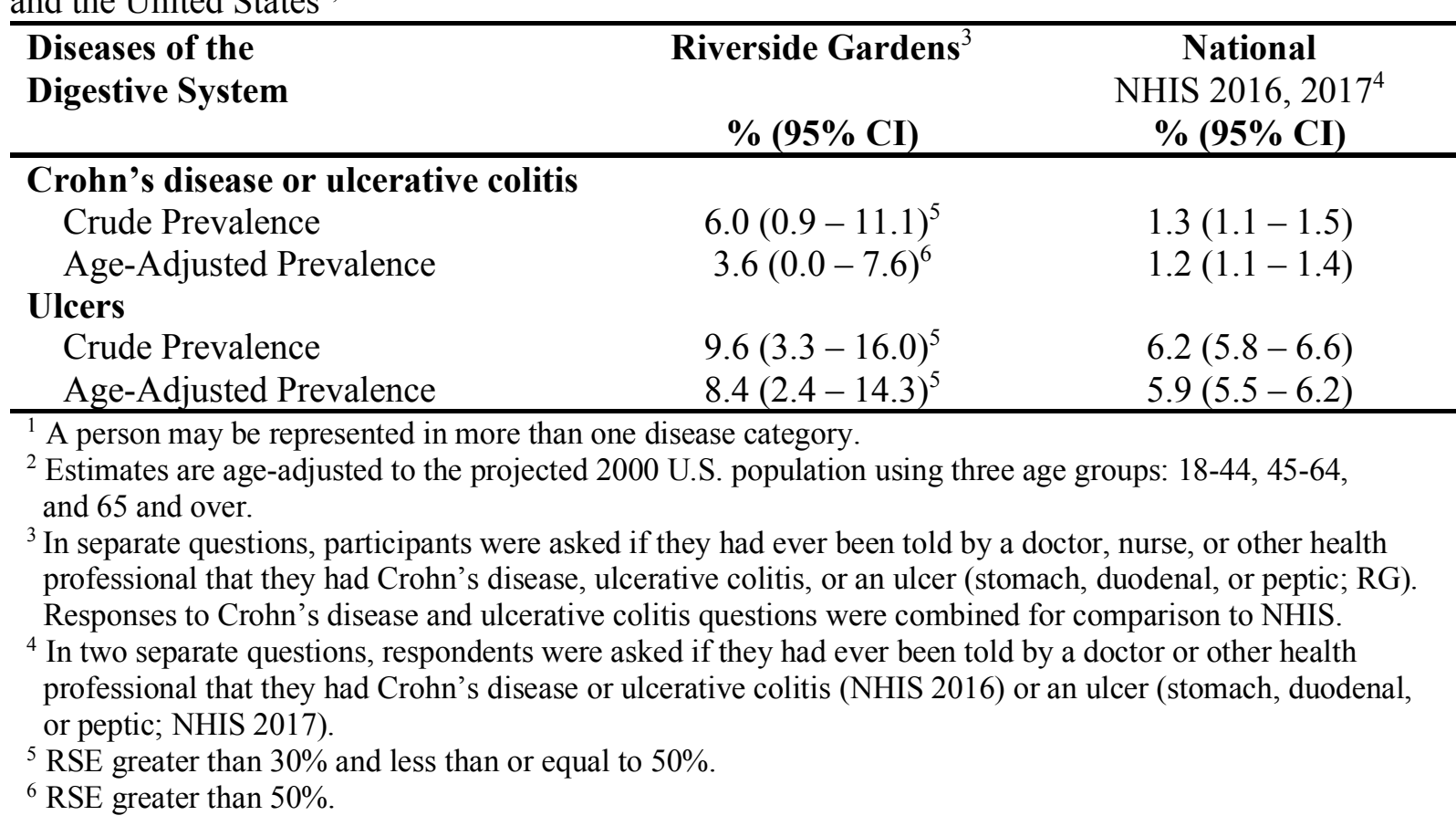


Table 18. Crude and Age-Adjusted Prevalence of Endocrine, Nutritional, and Metabolic Diseases in Riverside Gardens,

Louisville/Jefferson County, Kentucky, and the United States ${ }^{1,2}$

\begin{tabular}{|c|c|c|c|c|c|}
\hline $\begin{array}{l}\text { Endocrine, Nutritional, } \\
\text { and Metabolic Diseases }\end{array}$ & $\begin{array}{c}\text { Riverside } \\
\text { Gardens }^{3} \\
\%(95 \% \text { CI }) \\
\end{array}$ & $\begin{array}{c}\text { Louisville/ } \\
\text { Jefferson County } \\
\text { BRFSS } 2017^{4} \\
\%(95 \% \text { CI }) \\
\end{array}$ & $\begin{array}{c}\text { Kentucky } \\
\text { BRFSS } 2017^{4} \\
\%(95 \% \text { CI) } \\
\end{array}$ & $\begin{array}{c}\text { National } \\
\text { NHANES } \\
2015-2016^{4} \\
\%(\mathbf{9 5 \%} \text { CI) } \\
\end{array}$ & $\begin{array}{c}\text { National } \\
\text { NHIS } 2017^{4} \\
\% \text { (95\% CI) } \\
\end{array}$ \\
\hline \multicolumn{6}{|l|}{ Diabetes } \\
\hline Crude Prevalence & $18.1(9.8-26.4)$ & $12.9(11.8-13.9)$ & $12.9(11.8-13.9)$ & $10.7(9.2-12.3)$ & $9.3(8.9-9.8)$ \\
\hline Age-Adjusted Prevalence & $12.9(5.7-20.2)$ & $11.3(10.4-12.3)$ & $11.3(10.4-12.3)$ & $9.7(8.3-11.1)$ & $8.5(8.1-8.8)$ \\
\hline \multicolumn{6}{|l|}{ Hypercholesterolemia } \\
\hline Crude Prevalence & $32.5(22.5-42.6)$ & $35.4(31.3-39.5)$ & $38.1(36.3-39.9)$ & $32.5(30.0-35.0)$ & $28.7(27.9-29.6)$ \\
\hline Age-Adjusted Prevalence & $17.9(9.7-26.2)$ & $31.8(27.9-35.7)$ & $33.7(31.9-35.4)$ & $29.9(28.1-31.7)$ & $26.4(25.7-27.1)$ \\
\hline \multicolumn{6}{|l|}{ Thyroid disorder } \\
\hline Crude Prevalence & $12.0(5.1-19.1)$ & - & - & $12.1(10.2-14.0)$ & - \\
\hline Age-Adjusted Prevalence & $6.7(1.3-12.0)^{5}$ & - & - & $11.1(9.6-12.6)$ & - \\
\hline
\end{tabular}

${ }^{1}$ A person may be represented in more than one disease category.

${ }^{2}$ Estimates are age-adjusted to the projected 2000 U.S. population using three age groups: $18-44,45-64$, and 65 and over.

$\bullet \quad{ }^{3}$ In separate questions, respondents were asked if they had ever been told by a doctor or other health professional that they had type 1 diabetes, type 2

diabetes, high cholesterol/hypercholesterolemia, or a thyroid problem. Responses to type 1 and type 2 diabetes questions were combined for comparison to other surveys.

${ }^{4}$ In separate questions, respondents were asked if they had ever been told by a doctor or other health professional that they had diabetes (or sugar diabetes

in NHANES and NHIS questionnaires; pregnancy-related diabetes, prediabetes, and borderline diabetes were excluded), high cholesterol, or a thyroid problem (NHANES only).

${ }^{5}$ RSE greater than $30 \%$ and less than or equal to $50 \%$. 
Table 19. Crude and Age-Adjusted Prevalence of Diseases of the Eye in Riverside Gardens and the United States ${ }^{1,2}$

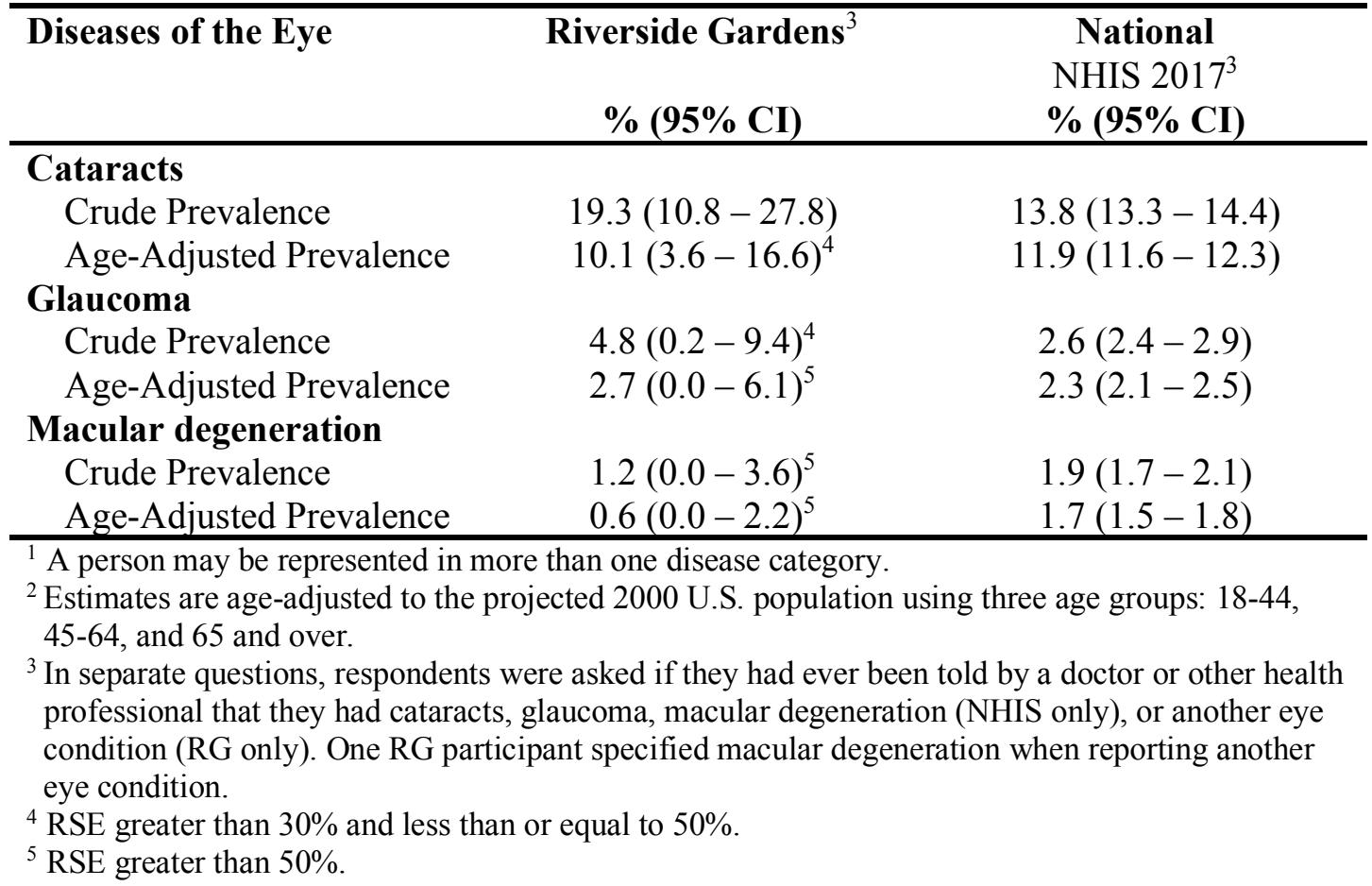

Table 20. Crude and Age-Adjusted Prevalence of Diseases of the Genitourinary System in Riverside Gardens, Louisville/Jefferson County, and Kentucky ${ }^{1,2}$

\begin{tabular}{llcc}
\hline $\begin{array}{l}\text { Diseases of the } \\
\text { Genitourinary System }\end{array}$ & $\begin{array}{l}\text { Riverside } \\
\text { Gardens }^{3}\end{array}$ & $\begin{array}{c}\text { Louisville/ } \\
\text { Jefferson } \\
\text { County } \\
\text { BRFSS 2017 } \\
\text { \% (95\% CI) }\end{array}$ & $\begin{array}{c}\text { Kentucky } \\
\text { BRFSS } 2017^{3} \\
\text { (95\% CI) }\end{array}$ \\
\hline $\begin{array}{l}\text { Kidney disease } \\
\text { Crude Prevalence }\end{array}$ & $2.4(0.0-5.7)^{4}$ & $4.1(2.3-5.9)$ & $4.0(3.3-4.6)$ \\
$\quad$ Age-Adjusted Prevalence & $1.5(0.0-4.2)^{4}$ & $3.7(1.9-5.5)$ & $3.6(3.0-4.2)$ \\
\hline
\end{tabular}

${ }^{1}$ A person may be represented in more than one disease category.

${ }^{2}$ Estimates are age-adjusted to the projected 2000 U.S. population using three age groups: 18-44, 4564, and 65 and over.

${ }^{3}$ Respondents were asked if they had ever been told by a doctor or other health professional that they had kidney disease.

${ }^{4}$ RSE greater than $50 \%$. 
Table 21. Crude and Age-Adjusted Prevalence of Mental, Behavioral, and Neurodevelopmental Disorders in Riverside Gardens, Louisville/Jefferson County, Kentucky, and the United States ${ }^{1,2}$

\begin{tabular}{|c|c|c|c|c|}
\hline $\begin{array}{l}\text { Mental, Behavioral, and } \\
\text { Neurodevelopmental } \\
\text { Disorders }\end{array}$ & $\begin{array}{c}\text { Riverside } \\
\text { Gardens }^{3,4} \\
\text { \% (95\% CI) } \\
\end{array}$ & $\begin{array}{c}\text { Louisville/ } \\
\text { Jefferson County } \\
\text { BRFSS } 2017^{4} \\
\% \text { (95\% CI) } \\
\end{array}$ & $\begin{array}{l}\text { BRFSS } 2017^{4} \\
\%(\mathbf{9 5 \%} \text { CI) } \\
\end{array}$ & $\begin{array}{c}\text { NCS-R }{ }^{5} \\
\%(\mathbf{9 5 \%} \mathbf{C I}) \\
\end{array}$ \\
\hline \multicolumn{5}{|l|}{ Anxiety disorder } \\
\hline Crude Prevalence & $18.1(9.8-26.4)$ & - & - & $27.2(26.0-28.5)$ \\
\hline Age-Adjusted Prevalence & $19.8(11.2-28.3)$ & - & - & $27.1(25.8-28.4)$ \\
\hline \multicolumn{5}{|l|}{ ADD/ADHD } \\
\hline Crude Prevalence & $4.8(0.2-9.4)^{6}$ & - & - & $4.0(3.5-4.6)$ \\
\hline Age-Adjusted Prevalence & $9.1(2.9-15.3)^{6}$ & - & - & $4.0(3.4-4.6)$ \\
\hline \multicolumn{5}{|l|}{ Bipolar disorder } \\
\hline Crude Prevalence & $9.6(3.3-16.0)^{6}$ & - & - & $2.1(1.7-2.4)$ \\
\hline Age-Adjusted Prevalence & $12.2(5.1-19.2)$ & - & - & $2.1(1.7-2.4)$ \\
\hline \multicolumn{5}{|l|}{ Depressive disorder } \\
\hline Crude Prevalence & $24.1(14.9-33.3)$ & $21.9(18.3-25.4)$ & $24.3(22.8-25.9)$ & $19.5(18.5-20.6)$ \\
\hline Age-Adjusted Prevalence & $20.2(11.6-28.8)$ & $21.6(18.0-25.3)$ & $24.3(22.7-25.9)$ & $19.4(18.3-20.4)$ \\
\hline \multicolumn{5}{|l|}{ Panic disorder } \\
\hline Crude Prevalence & $10.8(4.2-17.5)^{6}$ & - & - & $4.7(4.2-5.2)$ \\
\hline Age-Adjusted Prevalence & $12.7(5.6-19.9)$ & - & - & $4.7(4.2-5.1)$ \\
\hline
\end{tabular}

\footnotetext{
${ }^{1}$ A person may be represented in more than one disorder category.

${ }^{2}$ Estimates are age-adjusted to the projected 2000 U.S. population using three age groups: 18-44, 45-64, and 65 and over.

${ }^{3}$ In separate questions, respondents were asked if they had ever been told by a doctor or other health professional that they had anxiety disorder (any type), ADHD or ADD, bipolar disorder, or panic disorder.

${ }^{4}$ In a single question, respondents were asked if they had ever been told by a doctor or other health professional that they had a depressive disorder, including depression, major depression, dysthymia, or minor depression.

${ }^{5}$ Respondents met DSM-IV criteria for an anxiety disorder (including generalized anxiety disorder, separation anxiety disorder, post-traumatic stress disorder, social phobia, or a specific phobia), ADD/ADHD, bipolar disorder (bipolar I or II), depressive disorder (major depressive episode or dysthymia), or panic disorder.

${ }^{6} \mathrm{RSE}$ greater than $30 \%$ and less than or equal to $50 \%$.
} 
Table 22. Crude and Age-Adjusted Prevalence of Diseases of the Musculoskeletal System and Connective Tissue in Riverside Gardens, Louisville/Jefferson County, Kentucky, and the United States ${ }^{1,2}$

\begin{tabular}{|c|c|c|c|c|c|}
\hline $\begin{array}{l}\text { Diseases of the } \\
\text { Musculoskeletal System } \\
\text { and Connective Tissue }\end{array}$ & $\begin{array}{c}\text { Riverside } \\
\text { Gardens }^{3,4} \\
\text { \% (95\% CI) } \\
\end{array}$ & $\begin{array}{c}\text { Louisville/ } \\
\text { Jefferson County } \\
\text { BRFSS } 2017^{5} \\
\% \text { (95\% CI) } \\
\end{array}$ & $\begin{array}{l}\text { BRFSS } 2017^{5} \\
\text { \% }(\mathbf{9 5 \%} \mathbf{C I}) \\
\end{array}$ & $\begin{array}{l}\text { NHANES } \\
\text { \% (95\% CI) }\end{array}$ & $\begin{array}{l}\text { NHIS } 2017^{5} \\
\%(\mathbf{9 5 \%} \mathbf{C I}) \\
\end{array}$ \\
\hline \multicolumn{6}{|c|}{ Arthritis (including lupus and fibromyalgia) } \\
\hline Crude Prevalence & $48.2(37.4-58.9)$ & $26.5(23.1-29.8)$ & $32.4(30.8-33.9)$ & - & $23.8(23.0-24.5)$ \\
\hline Age-Adjusted Prevalence & $39.0(28.5-49.5)$ & $23.6(20.8-26.5)$ & $29.6(28.1-31.0)$ & - & $21.5(20.9-22.1)$ \\
\hline \multicolumn{6}{|l|}{ Arthritis } \\
\hline Crude Prevalence & $47.0(36.3-57.7)$ & - & - & $28.1(26.0-30.3)$ & - \\
\hline Age-Adjusted Prevalence & $38.4(28.0-48.9)$ & - & - & $25.0(23.4-26.5)$ & - \\
\hline \multicolumn{6}{|l|}{ Osteoporosis $^{7}$} \\
\hline Crude Prevalence & $6.9(1.5-12.4)^{8}$ & - & - & $8.3(6.6-10.1)$ & - \\
\hline Age-Adjusted Prevalence & $4.9(0.3-9.6)^{8}$ & - & - & $8.1(6.4-9.8)$ & - \\
\hline
\end{tabular}

${ }^{1}$ A person may be represented in more than one disease category.

${ }^{2}$ Estimates for arthritis are age-adjusted to the projected 2000 U.S. population using three age groups: 18-44, 45-64, and 65 and over. Estimates for

osteoporosis are age-adjusted to the projected 2000 U.S. population using the following three age groups: 40-49, 50-64, and 65 and over.

${ }^{3}$ In separate questions, respondents were asked if they had ever been told by a doctor or other health professional that they had arthritis (not

rheumatoid), osteoarthritis, psoriatic arthritis, rheumatoid arthritis, gout, lupus, or fibromyalgia. These variables were combined for comparison to other datasets.

${ }^{4}$ Respondents were asked if they had ever been told by a doctor or other health professional that they had osteoporosis (RG) or osteoporosis/brittle bones (NHANES 2013-2014).

${ }^{5}$ In a single question, respondents were asked if they had ever been told by a doctor or other health professional that they had some form of arthritis, rheumatoid arthritis, gout, lupus, or fibromyalgia.

${ }^{6}$ In separate questions, respondents were asked if they had ever been told by a doctor or other health professional that they had arthritis or gout (NHANES 2015-2016). These variables were combined for comparison.

${ }^{7}$ Only includes those 40 years and older.

${ }^{8}$ RSE greater than $30 \%$ and less than or equal to $50 \%$. 
Table 23. Crude and Age-Adjusted Prevalence of Diseases of the Nervous System in Riverside Gardens and the United States ${ }^{1,2}$

\begin{tabular}{|c|c|c|c|}
\hline $\begin{array}{l}\text { Diseases of the } \\
\text { Nervous System }\end{array}$ & Riverside Gardens $^{3,4}$ & $\begin{array}{c}\text { National } \\
\text { NHANES } \\
2013-2014^{3} \\
\text { \% (95\% CI) }\end{array}$ & $\begin{array}{c}\text { National } \\
\text { NHIS } 2017^{4} \\
\%(\mathbf{9 5 \%} \mathbf{C I})\end{array}$ \\
\hline \multicolumn{4}{|l|}{ Epilepsy/seizure disorder } \\
\hline Crude Prevalence & $2.4(0.0-5.7)^{5}$ & - & $1.9(1.7-2.1)$ \\
\hline Age-Adjusted Prevalence & $1.5(0.0-4.2)^{5}$ & - & $1.9(1.7-2.2)$ \\
\hline \multicolumn{4}{|l|}{ Sleep disorder } \\
\hline Crude Prevalence & $19.3(10.8-27.8)$ & $12.7(10.9-14.6)$ & - \\
\hline Age-Adjusted Prevalence & $17.9(9.7-26.2)$ & $12.2(9.8-14.6)$ & - \\
\hline \multicolumn{4}{|c|}{$\begin{array}{l}{ }^{1} \text { A person may be represented in more than one disease category. } \\
{ }^{2} \text { Estimates are age-adjusted to the projected } 2000 \text { U.S. population using three age groups: } 18-44,45-64 \text {, and } 65 \text { and over } \\
{ }^{3} \text { In a single question, respondents were asked if they had ever been told by a doctor or other health professional that they } \\
\text { had a sleep disorder (RG, NHANES). RG respondents were also asked about narcolepsy, a type of sleep disorder. RG } \\
\text { responses to sleep disorder and narcolepsy were combined for comparison to NHANES. } \\
{ }^{4} \text { In a single question, respondents were asked if they had ever been told by a doctor or other health professional that they } \\
\text { had a seizure disorder or epilepsy. }\end{array}$} \\
\hline
\end{tabular}


Table 24. Crude and Age-Adjusted ${ }^{1}$ Prevalence of Disease of the Respiratory System in Riverside Gardens,

Louisville/Jefferson County, Kentucky, and the United States ${ }^{1,2}$

\begin{tabular}{|c|c|c|c|c|c|}
\hline $\begin{array}{l}\text { Diseases of the } \\
\text { Respiratory System }\end{array}$ & $\begin{array}{l}\text { Riverside } \\
\text { Gardens }^{3} \\
\%(95 \% \text { CI }) \\
\end{array}$ & $\begin{array}{c}\text { Louisville/ } \\
\text { Jefferson County } \\
\text { BRFSS } 2017^{3} \\
\%(95 \% \text { CI }) \\
\end{array}$ & $\begin{array}{l}\text { BRFSS } 2017^{3} \\
\% \text { (95\% CI) }\end{array}$ & $\begin{array}{c}\text { National } \\
\text { NHANES } \\
2015-2016^{3} \\
\% \mathbf{( 9 5 \% ~ C I )} \\
\end{array}$ & $\begin{array}{l}\text { NHIS } 2017^{3} \\
\%(\mathbf{9 5 \%} \text { CI) } \\
\end{array}$ \\
\hline \multicolumn{6}{|l|}{ Asthma } \\
\hline Crude Prevalence & $19.3(10.8-27.8)$ & $16.5(13.3-19.7)$ & $15.5(14.2-16.8)$ & $16.0(15.2-16.8)$ & $13.4(12.0-14.0)$ \\
\hline Age-Adjusted Prevalence & $23.4(14.3-32.5)$ & $16.8(13.3-20.3)$ & $15.6(14.2-17.0)$ & $16.2(15.3-17.0)$ & $13.6(13.0-14.2)$ \\
\hline \multicolumn{6}{|l|}{ Chronic bronchitis } \\
\hline Crude Prevalence & $13.3(6.0-20.6)$ & - & - & $5.7(4.5-6.9)$ & - \\
\hline Age-Adjusted Prevalence & $8.2(2.3-14.2)^{4}$ & - & - & $5.3(4.2-6.4)$ & - \\
\hline \multicolumn{6}{|l|}{ COPD } \\
\hline Crude Prevalence & $15.7(7.8-23.5)$ & - & - & $3.1(2.1-4.1)$ & $3.4(3.1-3.7)$ \\
\hline Age-Adjusted Prevalence & $9.2(3.0-15.4)^{4}$ & - & - & $2.7(1.8-3.5)$ & $3.0(2.7-3.2)$ \\
\hline \multicolumn{6}{|l|}{ Emphysema } \\
\hline Crude Prevalence & $6.0(0.9-11.1)^{4}$ & - & - & $1.8(1.2-2.3)$ & $1.4(1.2-1.6)$ \\
\hline Age-Adjusted Prevalence & $3.6(0.0-7.7)^{5}$ & - & - & $1.5(1.1-2.0)$ & $1.2(1.1-1.4)$ \\
\hline \multicolumn{6}{|c|}{ Chronic bronchitis, COPD, or emphysema } \\
\hline Crude Prevalence & $21.7(12.8-30.6)$ & $10.9(8.3-13.4)$ & $12.2(11.1-13.3)$ & $7.9(6.5-9.2)$ & - \\
\hline Age-Adjusted Prevalence & $12.8(5.6-20.0)$ & $9.8(7.4-12.2)$ & $11.2(10.1-12.3)$ & $7.2(6.0-8.4)$ & - \\
\hline
\end{tabular}

Age-Adjusted Prevalence $12.8(5.6-20.0) \quad 9.8(7.4$

${ }^{2}$ Estimates are age-adjusted to the projected 2000 U.S. population using three age groups: 18-44, 45-64, and 65 and over.

${ }^{3}$ In separate questions, respondents were asked if they had ever been told by a doctor or other health professional that they had asthma (RG, BRFSS, NHANES, NHIS); COPD, emphysema, or chronic bronchitis (BRFSS); chronic bronchitis (RG, NHANES); COPD (RG, NHANES, NHIS); or emphysema (RG, NHANES, NHIS). The RG and NHANES variables for chronic bronchitis, COPD, and emphysema were combined for

comparison to other surveys.

${ }^{4} \mathrm{RSE}$ greater than $30 \%$ and less than or equal to $50 \%$.

${ }^{5} \mathrm{RSE}$ greater than $50 \%$. 
Table 25. Crude and Age-Adjusted Prevalence of Skin and Subcutaneous Diseases in Riverside Gardens and the United States ${ }^{1}$

\begin{tabular}{|c|c|c|}
\hline $\begin{array}{l}\text { Skin and Subcutaneous } \\
\text { Diseases }\end{array}$ & $\begin{array}{c}\text { Riverside Gardens }^{2} \\
\text { \% (95\% CI) }\end{array}$ & $\begin{array}{c}\text { National } \\
\text { NHANES 2013-2014 } \\
\text { \% (95\% CI) }\end{array}$ \\
\hline \multicolumn{3}{|l|}{ Psoriasis } \\
\hline Crude Prev & $6.0(0.9-11.1)^{3}$ & $3.5(2.4-4.6)$ \\
\hline Age-Adjusted Prevalence & $3.2(0.0-7.0)^{4}$ & $3.0(1.7-4.2)$ \\
\hline \multicolumn{3}{|c|}{$\begin{array}{l}1 \text { Estimates are age-adjusted to the projected } 2000 \text { U.S. population using three age groups: } 18-44 \text {, } \\
45-64 \text {, and } 65 \text { and over. } \\
2 \text { In a single question, respondents were asked if they had ever been told by a doctor or other health } \\
\text { professional that they had psoriasis. } \\
3 \text { RSE greater than } 30 \% \text { and less than or equal to } 50 \% \text {. } \\
{ }^{4} \text { RSE greater than } 50 \% \text {. }\end{array}$} \\
\hline
\end{tabular}

Statistically significant prevalence differences between Riverside Gardens estimates and local, state, or national estimates were, however, observed for 9 diseases or disease groupings. These prevalence differences and their 95\% CIs are presented in Table 26. 
Table 26. Significant Differences in Disease Prevalence Estimates between Riverside Gardens and Louisville/Jefferson County, Kentucky, and the United States ${ }^{1}$

\begin{tabular}{|c|c|c|c|c|c|}
\hline Disease $^{2}$ & $\begin{array}{c}\text { RG vs } \\
\text { Louisville/Jeff Co. } \\
\text { BRFSS } 2017 \\
\text { Prev. Diff. }^{3} \\
\text { (95\% CI) } \\
\end{array}$ & $\begin{array}{c}\text { RG vs Kentucky } \\
\text { BRFSS } 2017 \\
\text { Prev. Diff. }^{3} \\
\text { (95\% CI) }^{9} \\
\end{array}$ & $\begin{array}{c}\text { RG vs National } \\
\text { NHANES } \\
2015-2016 \\
\text { Prev. Diff. }^{3} \\
\text { (95\% CI) }^{\text {(95\% }} \\
\end{array}$ & $\begin{array}{c}\text { RG vs National } \\
\text { NHIS } 2017 \\
\text { Prev. Diff. }^{3} \\
\text { (95\% CI) }^{\text {(95\% }}\end{array}$ & $\begin{array}{c}\text { NCS-R } \\
\text { Prev. Diff. }^{3} \\
\text { (95\% CI) }\end{array}$ \\
\hline \multicolumn{6}{|l|}{ Arthritis } \\
\hline Crude Prevalence & - & - & $18.9(8.0-29.8)$ & - & - \\
\hline Age-Adjusted Prevalence ${ }^{4}$ & - & - & $13.4(2.8-24.0)$ & - & - \\
\hline \multicolumn{6}{|c|}{ Arthritis (including lupus and fibromyalgia) } \\
\hline Crude Prevalence & $21.7(10.4-33.0)$ & $15.8(4.9-26.7)$ & - & $24.4(13.6-35.2)$ & - \\
\hline Age-Adjusted Prevalence ${ }^{4}$ & $15.4(4.5-26.3)$ & - & - & $17.5(7.0-28.0)$ & - \\
\hline \multicolumn{6}{|l|}{ Bipolar disorder } \\
\hline Crude Prevalence & - & - & - & - & $7.5(1.1-13.9)$ \\
\hline Age-Adjusted Prevalence ${ }^{4}$ & - & - & - & - & $10.1(3.1-17.1)$ \\
\hline \multicolumn{6}{|l|}{ COPD } \\
\hline Crude Prevalence & - & - & $12.6(4.7-20.5)$ & $12.3(4.5-20.1)$ & - \\
\hline \multicolumn{6}{|c|}{ Chronic bronchitis, COPD, or emphysema } \\
\hline Crude Prevalence & - & - & $13.8(4.8-22.8)$ & - & - \\
\hline \multicolumn{6}{|l|}{ Hypercholesterolemia } \\
\hline Age-Adjusted Prevalence ${ }^{4}$ & $-13.9(-23.0--4.8)$ & $-15.8(-24.2--7.4)$ & $-12(-20.4--3.6)$ & - & - \\
\hline \multicolumn{6}{|l|}{ Hypertension } \\
\hline Crude Prevalence & $16.0(4.7-27.3)$ & - & $19.1(8.1-30.1)$ & $20(9.2-30.8)$ & - \\
\hline Age-Adjusted Prevalence ${ }^{4}$ & - & - & - & $11.9(1.3-22.5)$ & - \\
\hline \multicolumn{6}{|l|}{ Panic disorder } \\
\hline Age-Adjusted Prevalence ${ }^{4}$ & - & - & - & - & $8.0(0.8-15.2)$ \\
\hline \multicolumn{6}{|l|}{ Stroke } \\
\hline Crude Prevalence & - & - & $8.1(1.4-14.8)$ & $7.7(1.0-14.4)$ & - \\
\hline
\end{tabular}

${ }^{1}$ A person may be represented in more than one disease category.

${ }^{2}$ Notes on survey items and variable mergers related to disease definitions are available in Tables 16-25.

${ }^{3}$ Prev. Diff.=Prevalence Difference (Prevalence in Riverside Gardens - Prevalence in Comparison Group).

${ }^{4}$ Estimates are age-adjusted to the projected 2000 U.S. population using three age groups: 18-44, 45-64, and 65 and over. 
Crude and age-adjusted comparisons to local, state, and national prevalence estimates showed a significantly higher prevalence of arthritis among Riverside Gardens residents. The prevalence differences ranged between 15.4 and 24.4 across crude and age-adjusted differences and all comparisons.

The prevalence estimates for two disorders in the mental, behavioral, and neurodevelopmental category were significantly higher among Riverside Gardens residents when compared to national data. The age-adjusted prevalence difference for bipolar disorder was 10.1 (95\% CI: $3.1-17.1)$ and the age-adjusted prevalence difference for panic disorder was 8.0 (95\% CI: $0.8-15.2)$.

The crude prevalence differences for COPD and the chronic bronchitis, COPD, or emphysema disease grouping were statistically significant in comparisons between Riverside Gardens estimates and national estimates; however, there were no significant differences at the local or state level, or among age-adjusted prevalence comparisons.

The prevalence estimates of two circulatory system diseases, hypertension and stroke, were found to exceed local and national estimates. Only the crude prevalence estimate for hypertension exceeded the local estimate (prevalence difference: 16.0; 95\% CI $4.7-27.3$ ), and only one age-adjusted prevalence difference, the difference in estimates for hypertension between Riverside Gardens and NHIS 2017, was significant (prevalence difference: 11.9; 95\% CI: $1.3-22.5$ ). All other significant prevalence differences for hypertension and stroke involved crude comparisons between Riverside Gardens and NHANES 2015-2016 and NHIS 2017 data. The prevalence difference for hypertension between Riverside Gardens estimates and national estimates was 19.1 for the comparison to NHANES 2015-2016 data (95\% CI: $8.1-30.1)$ and 20.0 for the 
comparison to NHIS 2017 data (95\% CI: 9.2 - 30.8). For stroke, the difference was 8.1 when compared to NHANES 2015-2016 (95\% CI: $1.4-14.8)$ and 7.7 when compared to NHIS 2017 (95\% CI: $1.0-14.4)$.

The prevalence of only one disease was found to be significantly lower among Riverside Gardens residents compared to prevalence estimates at the local, state, and national level: hypercholesterolemia. The age-adjusted prevalence difference was significant when compared to the local, state, and one of the national age-adjusted estimates (prevalence difference range: $-12--15.8$ ).

3.2 Results for Subaim 3B: To compare self-reported cancer prevalence between Riverside Gardens residents and local, state, and national cancer prevalence using representative survey data.

Eleven participants (13.3\%) reported being diagnosed with cancer, and 11 different cancer sites were reported (see Table 27). Eight participants (9.6\%) reported non-skin cancer sites. No more than two participants reported being diagnosed with cancer at the same site (excluding non-melanoma skin cancer), and almost half of the cancer sites ( 5 of 11$)$ were only reported by one participant. 
Table 27. Crude Prevalence of Reported Cancer Sites ${ }^{1}$

\begin{tabular}{lcc}
\hline \multirow{2}{*}{ Cancer Site } & \multicolumn{2}{c}{ Crude Prevalence } \\
& \% & (n) \\
\hline All sites (including skin cancer) & $\mathbf{1 3 . 3}$ & $\mathbf{1 1}$ \\
All sites (excluding skin cancer) & $\mathbf{9 . 6}$ & $\mathbf{8}$ \\
Bladder & 1.2 & 1 \\
Breast $^{2}$ & 4.8 & 2 \\
Cervix $^{2}$ & 2.4 & 1 \\
Colon and rectum & 2.4 & 2 \\
Lung & 1.2 & 1 \\
Ovary $^{2}$ & 2.4 & 1 \\
Prostate & 4.9 & 2 \\
Skin - melanoma & 2.4 & 2 \\
Skin - non-melanoma & 3.6 & 3 \\
Thyroid & 2.4 & 2 \\
Uterus $^{2}$ & 2.4 & 1 \\
\hline
\end{tabular}

${ }^{1}$ A person may be represented multiple times across specific cancer sites.

${ }^{2}$ Out of females $(n=42)$

${ }^{3}$ Out of males $(\mathrm{n}=41)$

Crude and age-adjusted comparisons for the overall prevalence of cancer are shown in Table 28. Two versions of an all-cancer site variable were used: one including skin cancer and one excluding skin cancer. The crude and age-adjusted prevalence of cancer at any site, either including or excluding skin cancer, did not significantly differ between Riverside Gardens estimates and local, state, or national estimates. 


\section{Results for Specific Aim 4: To evaluate the relationship between environmental exposure histories and self-reported health conditions among residents of Riverside}

\section{Gardens.}

4.1 Results for Subaim 4A: To assess if residents with higher exposure scores are more likely to report histories of disease diagnoses within defined categories (e.g., circulatory system diseases, respiratory system diseases, etc.).

The most frequently reported disease diagnoses belong to the circulatory system $(57.8 \%, \mathrm{n}=48)$; musculoskeletal system or connective tissue $(57.8 \%, \mathrm{n}=48)$; and endocrine, nutritional, and metabolic disease $(41.0 \%, \mathrm{n}=34)$ groups. About one-third of participants reported digestive system disease diagnoses $(37.4 \%, \mathrm{n}=31)$; mental, behavioral, and neurodevelopmental disorder diagnoses $(31.3 \%, \mathrm{n}=26)$; and respiratory system disease diagnoses $(31.3 \%, \mathrm{n}=26)$, and a little more than one-quarter of participants reported nervous system disease diagnoses $(28.9 \%, n=24)$. Diseases of the blood and blood-forming organs $(15.7 \%, \mathrm{n}=13)$, ear and mastoid process $(14.5 \%, \mathrm{n}=12)$, eye $(21.7 \%, n=18)$, genitourinary system $(10.8 \%, n=9)$, and skin subcutaneous tissue $(9.6 \%, n=8)$, as well as cancer $(13.3 \%, n=11)$, were less frequently reported.

Demographic characteristics, potential covariates, and the exposure score were assessed by each disease category. Results tables are displayed here for disease categories that were associated with the continuous exposure score at $P \leq .20$ (Tables 31, 33, 34, 36, 38, and 41), and in Appendix C for disease categories that were not associated with the exposure score (Tables 29, 30, 32, 35, 37, 39, and 40). Additional tables in which the individual exposure score components were assessed by each disease category are included in Appendix C (Tables 42 - 54). 
Table 31. Potential Covariates and Exposure Score by Circulatory System Disease

\begin{tabular}{|c|c|c|c|c|}
\hline & \multirow{2}{*}{$\begin{array}{l}\text { Total } \\
\text { N (\%) }\end{array}$} & \multicolumn{2}{|c|}{$\begin{array}{c}\text { Diagnosed with } \\
\text { Circulatory System Disease }\end{array}$} & \multirow[t]{2}{*}{$P$ value } \\
\hline & & No n(\%) & Yes n(\%) & \\
\hline Total & $83(100.0 \%)$ & $35(42.2 \%)$ & $48(57.8 \%)$ & \\
\hline Gender & & & & .90 \\
\hline Male & $41(49.4 \%)$ & $17(41.5 \%)$ & $24(58.5 \%)$ & \\
\hline Female & $42(50.6 \%)$ & $18(42.9 \%)$ & $24(57.1 \%)$ & \\
\hline Age (in years) & & & & $<.001^{2}$ \\
\hline Median (IQR) & $61(16)$ & $55(20)$ & $64.5(13.5)$ & \\
\hline Mean (SD) & $58.4(14.7)$ & $52.2(14.3)$ & $62.9(13.5)$ & \\
\hline Race & & & & .12 \\
\hline White & $70(84.3 \%)$ & $27(38.6 \%)$ & $43(61.4 \%)$ & \\
\hline Other Race & $13(15.7 \%)$ & $8(61.5 \%)$ & $5(38.5 \%)$ & \\
\hline $\mathbf{B M I}^{1}$ & & & & .95 \\
\hline Normal & $22(27.2 \%)$ & $9(40.9 \%)$ & $13(59.1 \%)$ & \\
\hline Overweight & $31(38.3 \%)$ & $12(38.7 \%)$ & $19(61.3 \%)$ & \\
\hline Obese & $28(34.6 \%)$ & $12(42.9 \%)$ & $16(57.1 \%)$ & \\
\hline Personal Tobacco Use ${ }^{1}$ & & & & .52 \\
\hline Never User & $32(39.0 \%)$ & $12(37.5 \%)$ & $20(62.5 \%)$ & \\
\hline Former User & $25(30.5 \%)$ & $10(40.0 \%)$ & $15(60.0 \%)$ & \\
\hline Current User & $25(30.5 \%)$ & $13(52.0 \%)$ & $12(48.0 \%)$ & \\
\hline Occupational Exposure ${ }^{1}$ & & & & .16 \\
\hline No & $41(53.3 \%)$ & $14(34.2 \%)$ & $27(65.9 \%)$ & \\
\hline Yes & $36(46.8 \%)$ & $18(50.0 \%)$ & $18(50.0 \%)$ & \\
\hline Exposure Score & & & & $.07^{2}$ \\
\hline Median (IQR) & $3(3)$ & $2(2)$ & $3(4)$ & \\
\hline Mean (SD) & $2.9(1.9)$ & $2.4(1.8)$ & $3.3(2.0)$ & \\
\hline
\end{tabular}

${ }^{1}$ Missing data for BMI $(n=2)$, personal tobacco use $(n=1)$, and occupational exposure $(n=6)$

${ }^{2}$ Wilcoxon Rank Sum $P$ value 
Table 33. Potential Covariates and Exposure Score by Ear and Mastoid Process Disease

\begin{tabular}{|c|c|c|c|c|}
\hline & \multirow{2}{*}{$\begin{array}{l}\text { Total } \\
\text { N (\%) }\end{array}$} & \multicolumn{2}{|c|}{$\begin{array}{c}\text { Diagnosed with } \\
\text { Ear Disease }\end{array}$} & \multirow[t]{2}{*}{$P$ value } \\
\hline & & No n(\%) & Yes n $(\%)$ & \\
\hline Total & $83(100.0 \%)$ & $71(85.5 \%)$ & $12(14.5 \%)$ & \\
\hline Gender & & & & .50 \\
\hline Male & $41(49.4 \%)$ & $34(82.9 \%)$ & $7(17.1 \%)$ & \\
\hline Female & $42(50.6 \%)$ & $37(88.1 \%)$ & $5(11.9 \%)$ & \\
\hline Age (in years) & & & & $.002^{2}$ \\
\hline Median (IQR) & $61(16)$ & $60(15)$ & $71.5(17)$ & \\
\hline Mean (SD) & $58.4(14.7)$ & $56.4(14.2)$ & $69.8(13.0)$ & \\
\hline Race & & & & $.68^{3}$ \\
\hline White & $70(84.3 \%)$ & $59(84.3 \%)$ & $11(15.7 \%)$ & \\
\hline Other Race & $13(15.7 \%)$ & $12(92.3 \%)$ & $1(7.7 \%)$ & \\
\hline BMI $^{1}$ & & & & $.79^{3}$ \\
\hline Normal & $22(27.2 \%)$ & $18(81.8 \%)$ & $4(18.2 \%)$ & \\
\hline Overweight & $31(38.3 \%)$ & $26(83.9 \%)$ & $5(16.1 \%)$ & \\
\hline Obese & $28(34.6 \%)$ & $25(89.3 \%)$ & $3(10.7 \%)$ & \\
\hline Personal Tobacco Use ${ }^{1}$ & & & & $.12^{3}$ \\
\hline Never User & $32(39.0 \%)$ & $27(84.4 \%)$ & $5(15.6 \%)$ & \\
\hline Former User & $25(30.5 \%)$ & $19(76.0 \%)$ & $6(24.0 \%)$ & \\
\hline Current User & $25(30.5 \%)$ & $24(96.0 \%)$ & $1(4.0 \%)$ & \\
\hline Occupational Exposure ${ }^{1}$ & & & & .81 \\
\hline No & $41(53.3 \%)$ & $35(85.4 \%)$ & $6(14.6 \%)$ & \\
\hline Yes & $36(46.8 \%)$ & $30(83.3 \%)$ & $6(16.7 \%)$ & \\
\hline Exposure Score & & & & $.15^{2}$ \\
\hline Median (IQR) & $3(3)$ & $3(3)$ & $3(3.5)$ & \\
\hline Mean (SD) & $2.9(1.9)$ & $2.8(1.9)$ & $3.7(1.9)$ & \\
\hline
\end{tabular}

${ }^{1}$ Missing data for BMI $(n=2)$, personal tobacco use $(n=1)$, and occupational exposure $(n=6)$

${ }^{2}$ Wilcoxon Rank Sum $P$ value

${ }^{3}$ Fisher's exact $P$ value calculated due to low expected cell counts 
Table 34. Potential Covariates and Exposure Score by Endocrine, Nutritional, and Metabolic Diseases

\begin{tabular}{|c|c|c|c|c|}
\hline & \multirow{2}{*}{$\begin{array}{l}\text { Total } \\
\text { N (\%) }\end{array}$} & \multicolumn{2}{|c|}{$\begin{array}{c}\text { Diagnosed with } \\
\text { Endocrine, Nutritional, } \\
\text { and Metabolic Disease }\end{array}$} & \multirow[t]{2}{*}{$P$ value } \\
\hline & & No n(\%) & Yes n(\%) & \\
\hline Total & $83(100.0 \%)$ & $49(59.0 \%)$ & $34(41.0 \%)$ & \\
\hline Gender & & & & .72 \\
\hline Male & $41(49.4 \%)$ & $25(61.0 \%)$ & $16(39.0 \%)$ & \\
\hline Female & $42(50.6 \%)$ & $24(57.1 \%)$ & $18(42.9 \%)$ & \\
\hline Age (in years) & & & & $.003^{2}$ \\
\hline Median (IQR) & $61(16)$ & $56(24)$ & $64.5(10)$ & \\
\hline Mean (SD) & $58.4(14.7)$ & $54.6(16.7)$ & $63.9(9.0)$ & \\
\hline Race & & & & .42 \\
\hline White & $70(84.3 \%)$ & $40(57.1 \%)$ & $30(42.9 \%)$ & \\
\hline Other Race & $13(15.7 \%)$ & $9(69.2 \%)$ & $4(30.8 \%)$ & \\
\hline BMI $^{1}$ & & & & .41 \\
\hline Normal & $22(27.2 \%)$ & $15(68.2 \%)$ & $7(31.8 \%)$ & \\
\hline Overweight & $31(38.3 \%)$ & $19(61.3 \%)$ & $12(38.7 \%)$ & \\
\hline Obese & $28(34.6 \%)$ & $14(50.0 \%)$ & $14(50.0 \%)$ & \\
\hline Personal Tobacco Use ${ }^{1}$ & & & & .05 \\
\hline Never User & $32(39.0 \%)$ & $16(50.0 \%)$ & $16(50.0 \%)$ & \\
\hline Former User & $25(30.5 \%)$ & $13(52.0 \%)$ & $12(48.0 \%)$ & \\
\hline Current User & $25(30.5 \%)$ & $20(80.0 \%)$ & $5(20.0 \%)$ & \\
\hline Occupational Exposure $^{1}$ & & & & .49 \\
\hline No & $41(53.3 \%)$ & $23(56.1 \%)$ & $18(43.9 \%)$ & \\
\hline Yes & $36(46.8 \%)$ & $23(63.9 \%)$ & $13(36.1 \%)$ & \\
\hline Exposure Score & & & & $.06^{2}$ \\
\hline Median (IQR) & $3(3)$ & $2(3)$ & $4(4)$ & \\
\hline Mean (SD) & $2.9(1.9)$ & $2.6(1.8)$ & $3.4(2.0)$ & \\
\hline
\end{tabular}

${ }^{1}$ Missing data for BMI $(\mathrm{n}=2)$, personal tobacco use $(\mathrm{n}=1)$, and occupational exposure $(\mathrm{n}=6)$

${ }^{2}$ Wilcoxon Rank Sum $P$ value 
Table 36. Potential Covariates and Exposure Score by Genitourinary System Disease

\begin{tabular}{|c|c|c|c|c|}
\hline & \multirow{2}{*}{$\begin{array}{l}\text { Total } \\
\text { N (\%) }\end{array}$} & \multicolumn{2}{|c|}{$\begin{array}{c}\text { Diagnosed with } \\
\text { Genitourinary System Disease }\end{array}$} & \multirow[t]{2}{*}{$P$ value } \\
\hline & & No n(\%) & Yes n $(\%)$ & \\
\hline Total & $83(100.0 \%)$ & $74(89.2 \%)$ & $9(10.8 \%)$ & \\
\hline Gender & & & & $.002^{3}$ \\
\hline Male & $41(49.4 \%)$ & $41(100.0 \%)$ & $0(0.0 \%)$ & \\
\hline Female & $42(50.6 \%)$ & $33(78.6 \%)$ & $9(21.4 \%)$ & \\
\hline Age (in years) & & & & $.22^{2}$ \\
\hline Median (IQR) & $61(16)$ & $60.5(14)$ & $64(11)$ & \\
\hline Mean (SD) & $58.4(14.7)$ & $57.6(14.6)$ & $64.9(14.8)$ & \\
\hline Race & & & & $1.00^{3}$ \\
\hline White & $70(84.3 \%)$ & $62(88.6 \%)$ & $8(11.4 \%)$ & \\
\hline Other Race & $13(15.7 \%)$ & $12(92.3 \%)$ & $1(7.7 \%)$ & \\
\hline BMI $^{1}$ & & & & $.18^{3}$ \\
\hline Normal & $22(27.2 \%)$ & $18(81.8 \%)$ & $4(18.2 \%)$ & \\
\hline Overweight & $31(38.3 \%)$ & $30(96.8 \%)$ & $1(3.2 \%)$ & \\
\hline Obese & $28(34.6 \%)$ & $24(85.7 \%)$ & $4(14.3 \%)$ & \\
\hline Personal Tobacco Use ${ }^{1}$ & & & & $.03^{3}$ \\
\hline Never User & $32(39.0 \%)$ & $25(78.1 \%)$ & $7(21.9 \%)$ & \\
\hline Former User & $25(30.5 \%)$ & $23(92.0 \%)$ & $2(8.0 \%)$ & \\
\hline Current User & $25(30.5 \%)$ & $25(100.0 \%)$ & $0(0.0 \%)$ & \\
\hline Occupational Exposure ${ }^{1}$ & & & & $.16^{3}$ \\
\hline No & $41(53.3 \%)$ & $34(82.9 \%)$ & $7(17.1 \%)$ & \\
\hline Yes & $36(46.8 \%)$ & $34(94.4 \%)$ & $2(5.6 \%)$ & \\
\hline Exposure Score & & & & $.09^{2}$ \\
\hline Median (IQR) & $3(3)$ & $3(3)$ & $5(4)$ & \\
\hline Mean (SD) & $2.9(1.9)$ & $2.8(1.9)$ & $4.0(2.1)$ & \\
\hline
\end{tabular}

${ }^{1}$ Missing data for BMI $(\mathrm{n}=2)$, personal tobacco use $(\mathrm{n}=1)$, and occupational exposure $(\mathrm{n}=6)$

${ }^{2}$ Wilcoxon Rank Sum $P$ value

${ }^{3}$ Fisher's exact $P$ value calculated due to low expected cell counts 
Table 38. Potential Covariates and Exposure Score by Musculoskeletal System and Connective Tissue Diseases

\begin{tabular}{|c|c|c|c|c|}
\hline & Total & $\begin{array}{r}\text { Diagno } \\
\text { Musculoskele } \\
\text { Connective }\end{array}$ & $\begin{array}{l}\text { I with } \\
\text { System and } \\
\text { sue Disease }\end{array}$ & $P$ value \\
\hline & N (\%) & No n(\%) & Yes n(\%) & \\
\hline Total & $83(100.0 \%)$ & $35(42.2 \%)$ & $48(57.8 \%)$ & \\
\hline Gender & & & & .23 \\
\hline Male & $41(49.4 \%)$ & $20(48.8 \%)$ & $21(51.2 \%)$ & \\
\hline Female & $42(50.6 \%)$ & $15(35.7 \%)$ & $27(64.3 \%)$ & \\
\hline Age (in years) & & & & $.002^{2}$ \\
\hline Median (IQR) & $61(16)$ & $55(23)$ & $63.5(13.5)$ & \\
\hline Mean (SD) & $58.4(14.7)$ & $52.8(15.9)$ & $62.5(12.5)$ & \\
\hline Race & & & & $.35^{3}$ \\
\hline White & $70(84.3 \%)$ & $28(40.0 \%)$ & $42(60.0 \%)$ & \\
\hline Other Race & $13(15.7 \%)$ & $7(53.9 \%)$ & $6(46.2 \%)$ & \\
\hline $\mathbf{B M I}^{1}$ & & & & .40 \\
\hline Normal & $22(27.2 \%)$ & $12(54.6 \%)$ & $10(45.5 \%)$ & \\
\hline Overweight & $31(38.3 \%)$ & $13(41.9 \%)$ & $18(58.1 \%)$ & \\
\hline Obese & $28(34.6 \%)$ & $10(35.7 \%)$ & $18(64.3 \%)$ & \\
\hline Personal Tobacco Use ${ }^{1}$ & & & & .72 \\
\hline Never User & $32(39.0 \%)$ & $12(37.5 \%)$ & $20(62.5 \%)$ & \\
\hline Former User & $25(30.5 \%)$ & $12(48.0 \%)$ & $13(52.0 \%)$ & \\
\hline Current User & $25(30.5 \%)$ & $11(44.0 \%)$ & $14(56.0 \%)$ & \\
\hline Occupational Exposure $^{1}$ & & & & .79 \\
\hline No & $41(53.3 \%)$ & $17(41.5 \%)$ & $24(58.5 \%)$ & \\
\hline Yes & $36(46.8 \%)$ & $16(44.4 \%)$ & $20(55.6 \%)$ & \\
\hline Exposure Score & & & & $.01^{2}$ \\
\hline Median (IQR) & $3(3)$ & $2(3)$ & $3(3)$ & \\
\hline Mean (SD) & $2.9(1.9)$ & $2.3(1.9)$ & $3.4(1.9)$ & \\
\hline
\end{tabular}


Table 41. Potential Covariates and Exposure Score by Skin and Subcutaneous Diseases

\begin{tabular}{|c|c|c|c|c|}
\hline & \multirow{2}{*}{$\begin{array}{c}\text { Total } \\
\text { N (\%) } \\
\end{array}$} & \multicolumn{2}{|c|}{$\begin{array}{l}\text { Diagnosed with } \\
\text { Skin Disease }\end{array}$} & \multirow[t]{2}{*}{$P$ value } \\
\hline & & No $n(\%)$ & Yes n $(\%)$ & \\
\hline Total & $83(100.0 \%)$ & $75(90.4 \%)$ & $8(9.6 \%)$ & \\
\hline Gender & & & & $.71^{3}$ \\
\hline Male & $41(49.4 \%)$ & $38(92.7 \%)$ & $3(7.3 \%)$ & \\
\hline Female & $42(50.6 \%)$ & $37(88.1 \%)$ & $5(11.9 \%)$ & \\
\hline Age (in years) & & & & $.10^{2}$ \\
\hline Median (IQR) & $61(16)$ & $60(14)$ & $66(11.5)$ & \\
\hline Mean (SD) & $58.4(14.7)$ & $57.6(15.0)$ & $65.8(9.1)$ & \\
\hline Race & & & & $1.00^{3}$ \\
\hline White & $70(84.3 \%)$ & $63(90.0 \%)$ & $7(10.0 \%)$ & \\
\hline Other Race & $13(15.7 \%)$ & $12(92.3 \%)$ & $1(7.7 \%)$ & \\
\hline BMI $^{1}$ & & & & $.52^{3}$ \\
\hline Normal & $22(27.2 \%)$ & $21(95.5 \%)$ & $1(4.6 \%)$ & \\
\hline Overweight & $31(38.3 \%)$ & $28(90.3 \%)$ & $3(9.7 \%)$ & \\
\hline Obese & $28(34.6 \%)$ & $24(85.7 \%)$ & $4(14.3 \%)$ & \\
\hline Personal Tobacco Use ${ }^{1}$ & & & & .37 \\
\hline Never User & $32(39.0 \%)$ & $30(93.8 \%)$ & $2(6.3 \%)$ & \\
\hline Former User & $25(30.5 \%)$ & $21(84.0 \%)$ & $4(16.0 \%)$ & \\
\hline Current User & $25(30.5 \%)$ & $24(96.0 \%)$ & $1(4.0 \%)$ & \\
\hline Occupational Exposure ${ }^{1}$ & & & & $1.00^{3}$ \\
\hline No & $41(53.3 \%)$ & $37(90.2 \%)$ & $4(9.8 \%)$ & \\
\hline Yes & $36(46.8 \%)$ & $33(91.7 \%)$ & $3(8.3 \%)$ & \\
\hline Exposure Score & & & & $.10^{2}$ \\
\hline Median (IQR) & $3(3)$ & $3(3)$ & $4.5(4)$ & \\
\hline Mean (SD) & $2.9(1.9)$ & $2.8(1.9)$ & $4.1(2.3)$ & \\
\hline
\end{tabular}

The median exposure score was 3 out of a possible 7 with an IQR of 3. Exposure scores significantly differed between those who had and had not been diagnosed with musculoskeletal system or connective tissue diseases $(P=.01)$. Exposure scores also differed between circulatory system; ear and mastoid process; endocrine, nutritional, or metabolic; genitourinary system; and skin or subcutaneous tissue disease diagnoses groups at a more liberal significance value $(P \leq .20)$. 
Gender only significantly differed by the genitourinary system disease category $(P=.002)$. Those who were diagnosed with circulatory system; ear or mastoid process; endocrine, nutritional, or metabolic; and musculoskeletal system or connective tissue diseases were found to be significantly older than those who were not diagnosed with diseases in these groups at $P<.05$, while those with skin or subcutaneous diseases were found to be significantly older than those without a disease of this type at $P=.10$. Race was only related to one disease group, circulatory system diseases, at a liberal $P$ value threshold $(P=.12)$.

BMI did not differ by disease status in most categories; however, BMI did differ between genitourinary system disease diagnoses at $P<.20$. Personal tobacco use status significantly differed by whether participants had been diagnosed with an endocrine, nutritional, or metabolic or genitourinary system diseases at $P<.05$, and by ear or mastoid process diagnoses at $P \leq .20$. Occupational exposure history was related to circulatory system and genitourinary system diagnoses at $P \leq .20$.

The relationships between potential covariates and the exposure score are assessed in Table 55. Age was significantly, but moderately, correlated with the exposure score (Spearman correlation coefficient: $0.23 ; P=.04$ ). BMI and personal tobacco use are also significantly related to the exposure score at a more liberal $P$ value $(P \leq .20)$. These variables were assessed as potential confounders in the relationship between the exposure score and disease categories during logistic regression modeling. 
Table 55. Potential Covariates by Exposure Score

\begin{tabular}{|c|c|c|c|}
\hline & \multicolumn{2}{|c|}{ Exposure Score } & \multirow{2}{*}{$\begin{array}{c}\text { Wilcoxon } \\
\text { Rank Sum } \\
P \text { value }\end{array}$} \\
\hline & Median (IQR) & Mean (SD) & \\
\hline Total & $3(3)$ & $2.9(1.9)$ & \\
\hline Gender & & & .90 \\
\hline Male & $3(4)$ & $3.0(2.2)$ & \\
\hline Female & $3(3)$ & $2.8(1.7)$ & \\
\hline Age (in years) & & & $.04^{3}$ \\
\hline Correlation Coefficient & 0.23 & - & \\
\hline Race & & & .91 \\
\hline White & $3(3)$ & $2.9(1.9)$ & \\
\hline Other Race & $2(3)$ & $2.9(2.2)$ & \\
\hline BMI ${ }^{1}$ & & & $.13^{2}$ \\
\hline Normal & $3(2)$ & $3.3(1.8)$ & \\
\hline Overweight & $2(3)$ & $2.3(1.8)$ & \\
\hline Obese & $3(3.5)$ & $3.2(2.1)$ & \\
\hline Personal Tobacco Use ${ }^{1}$ & & & $.05^{2}$ \\
\hline Never User & $3(4)$ & $3.0(2.1)$ & \\
\hline Former User & $4(3)$ & $3.5(2.1)$ & \\
\hline Current User & $2(2)$ & $2.1(1.3)$ & \\
\hline Occupational Exposure ${ }^{1}$ & & & .34 \\
\hline No & $3(3)$ & $2.7(1.7)$ & \\
\hline Yes & $3(3.5)$ & $3.3(2.2)$ & \\
\hline
\end{tabular}

Table 56 shows the results of the unadjusted binary logistic regression analyses with disease group diagnoses as the outcome variable and continuous exposure score as the exposure variable. Only the musculoskeletal system and connective tissue disease group was significantly related with the exposure score at $P<.05$. 
Table 56. Unadjusted Binary Logistic Regression Models Predicting Disease Group Diagnoses

\begin{tabular}{|c|c|c|c|}
\hline Model & OR & 95\% CI & $P$ value \\
\hline \multicolumn{4}{|c|}{ Blood and Blood-Forming Organs Disease } \\
\hline Exposure Score & 1.11 & $0.82-1.50$ & .51 \\
\hline \multicolumn{4}{|l|}{ Cancer } \\
\hline Exposure Score & 1.12 & $0.81-1.55$ & .50 \\
\hline \multicolumn{4}{|c|}{ Circulatory System Disease } \\
\hline Exposure Score & 1.26 & $0.99-1.60$ & .06 \\
\hline \multicolumn{4}{|c|}{ Digestive System Disease } \\
\hline Exposure Score & 1.06 & $0.84-1.33$ & 64 \\
\hline \multicolumn{4}{|c|}{ Ear and Mastoid Process Disease } \\
\hline Exposure Score & 1.26 & $0.92-1.73$ & .15 \\
\hline \multicolumn{4}{|c|}{ Endocrine, Nutritional, and } \\
\hline \multicolumn{4}{|c|}{ Metabolic Disease } \\
\hline Exposure Score & 1.27 & $1.00-1.60$ & .05 \\
\hline \multicolumn{4}{|c|}{ Eye and Adnexa Disease } \\
\hline Exposure Score & 1.03 & $0.79-1.35$ & .81 \\
\hline \multicolumn{4}{|c|}{ Genitourinary System Disease } \\
\hline Exposure Score & 1.38 & $0.96-1.99$ & .08 \\
\hline \multicolumn{4}{|c|}{ Mental, Behavioral, and } \\
\hline \multicolumn{4}{|c|}{ Neurodevelopmental Disorder } \\
\hline Exposure Score & 0.99 & $0.78-1.26$ & .95 \\
\hline \multicolumn{4}{|c|}{ Musculoskeletal System and } \\
\hline \multicolumn{4}{|c|}{ Connective Tissue Disease } \\
\hline Exposure Score & 1.39 & $1.08-1.78$ & .01 \\
\hline \multicolumn{4}{|c|}{ Nervous System Disease } \\
\hline Exposure Score & 1.18 & $0.92-1.50$ & .20 \\
\hline \multicolumn{4}{|c|}{ Respiratory System Disease } \\
\hline Exposure Score & 1.01 & $0.79-1.29$ & .95 \\
\hline \multicolumn{4}{|c|}{ Skin and Subcutaneous Tissue Disease } \\
\hline Exposure Score & 1.43 & $0.97-2.10$ & .07 \\
\hline
\end{tabular}

Final adjusted ORs, 95\% CIs, and $P$ values are reported for the relationship between exposure score and each dichotomized disease group in Table 57. After considering potential covariates for inclusion in models, no covariates were included in the final versions of the cancer; digestive system; genitourinary system; mental, behavioral, and developmental; or the skin and subcutaneous tissue disease models due to the lack of statistical significance of the considered covariates as well as their lack of 
significant improvement to model fit. All other disease models included at least one covariate.

The exposure score was significant at $P<.05$ in one of the final adjusted disease group models: the musculoskeletal system and connective tissue disease group model. For each one-unit increase in the exposure score, the odds of reporting a musculoskeletal system or connective tissue disease diagnosis increased by $32 \%$, after controlling for age (AOR: 1.32; 95\% CI $1.01-1.72$ ).

Age was statistically significant and was included in five of the final disease group diagnoses models: circulatory system model; ear and mastoid process model; endocrine, nutritional, and metabolic disease model; eye and adnexa model; and musculoskeletal system and connective tissue model; as age increased, the odds of being diagnosed with a disease in one of these groups also increased. Additionally, personal tobacco use status was included in the final respiratory system disease model. 
Table 57. Adjusted Binary Logistic Regression Models Predicting Disease Group Diagnoses

\begin{tabular}{|c|c|c|c|}
\hline Model & AOR & 95\% CI & $P$ value \\
\hline \multicolumn{4}{|l|}{ Blood and Blood-Forming Organs Disease } \\
\hline Exposure Score & $1.11^{1}$ & $0.82-1.50$ & .51 \\
\hline \multicolumn{4}{|l|}{ Cancer } \\
\hline Exposure Score & $1.12^{1}$ & $0.81-1.55$ & .50 \\
\hline \multicolumn{4}{|l|}{ Circulatory System Disease } \\
\hline Exposure Score & 1.18 & $0.92-1.52$ & .20 \\
\hline Age & 1.05 & $1.02-1.09$ & .01 \\
\hline \multicolumn{4}{|l|}{ Digestive System Disease } \\
\hline Exposure Score & $1.06^{1}$ & $0.84-1.33$ & .64 \\
\hline \multicolumn{4}{|l|}{ Ear and Mastoid Process Disease } \\
\hline Exposure Score & 1.17 & $0.84-1.64$ & .36 \\
\hline Age & 1.10 & $1.03-1.17$ & .008 \\
\hline \multicolumn{4}{|c|}{ Endocrine, Nutritional, and Metabolic Disease } \\
\hline Exposure Score & 1.19 & $0.94-1.52$ & .16 \\
\hline Age & 1.05 & $1.01-1.09$ & .02 \\
\hline \multicolumn{4}{|l|}{ Eye and Adnexa Disease } \\
\hline Exposure Score & 0.89 & $0.65-1.22$ & .96 \\
\hline Age & 1.15 & $1.07-1.24$ & $<.001$ \\
\hline \multicolumn{4}{|l|}{ Genitourinary System Disease } \\
\hline Exposure Score & $1.38^{1}$ & $0.96-1.99$ & .08 \\
\hline \multicolumn{4}{|l|}{ Mental, Behavioral, and } \\
\hline \multicolumn{4}{|l|}{ Neurodevelopmental Disorder } \\
\hline Exposure Score & $0.99^{1}$ & $0.78-1.26$ & .95 \\
\hline \multicolumn{4}{|l|}{ Musculoskeletal System and } \\
\hline \multicolumn{4}{|l|}{ Connective Tissue Disease } \\
\hline Exposure Score & 1.32 & $1.01-1.72$ & .04 \\
\hline Age & 1.04 & $1.01-1.08$ & .01 \\
\hline \multicolumn{4}{|l|}{ Nervous System Disease } \\
\hline Exposure Score & $1.18^{1}$ & $0.92-1.50$ & .20 \\
\hline \multicolumn{4}{|l|}{ Respiratory System Disease } \\
\hline Exposure Score & 1.12 & $0.85-1.47$ & .43 \\
\hline Tobacco Use (Former vs Never User) & 1.61 & $0.46-5.64$ & .46 \\
\hline Tobacco Use (Current vs Never User) & 5.28 & $1.54-18.12$ & .008 \\
\hline \multicolumn{4}{|l|}{ Skin and Subcutaneous Tissue Disease } \\
\hline Exposure Score & $1.43^{1}$ & $0.97-2.10$ & .07 \\
\hline
\end{tabular}

${ }^{1} \mathrm{OR}$; no covariates were included in the final model.

Next, demographic characteristics, potential covariates, and the exposure score were assessed by the categorized number of chronic diseases reported $(0-2,3-7$, and $\geq 8$; see Table 58). Due to the significant relationship between age and the number of diseases 
reported, as well as the significant relationship between age and the exposure score (see Table 55), age was assessed for possible confounding in the association between the exposure score and the number of chronic diseases reported.

Table 58. Potential Covariates and Exposure Score by Number of Chronic Diseases Reported

\begin{tabular}{|c|c|c|c|c|c|}
\hline & \multirow{2}{*}{$\begin{array}{c}\text { Total } \\
\text { N (\%) }\end{array}$} & \multicolumn{3}{|c|}{ Number of Diseases Reported } & \multirow{2}{*}{$\begin{array}{c}P \\
\text { value }\end{array}$} \\
\hline & & $0-2 \mathrm{n}(\%)$ & 3-7 n(\%) & $\geq 8 \mathrm{n}(\%)$ & \\
\hline Total & $83(100.0 \%)$ & $27(32.5 \%)$ & $29(34.9 \%)$ & $27(32.5 \%)$ & \multirow{4}{*}{.03} \\
\hline \multicolumn{5}{|l|}{ Gender } & \\
\hline Male & $41(49.4 \%)$ & $19(46.3 \%)$ & $11(26.8 \%)$ & $11(26.8 \%)$ & \\
\hline Female & $42(50.6 \%)$ & $8(19.1 \%)$ & $18(42.9 \%)$ & $16(38.1 \%)$ & \\
\hline \multicolumn{5}{|l|}{ Age (in years) } & \multirow[t]{3}{*}{$.004^{2}$} \\
\hline Median (IQR) & $61(16)$ & $55(21)$ & $63(15)$ & $63(16)$ & \\
\hline Mean (SD) & $58.4(14.7)$ & $50.7(14.8)$ & $60.8(13.5)$ & $63.4(13.2)$ & \\
\hline \multicolumn{5}{|l|}{ Race } & \multirow[t]{3}{*}{$.48^{3}$} \\
\hline White & $70(84.3 \%)$ & $21(30.0 \%)$ & $26(37.1 \%)$ & $23(32.9 \%)$ & \\
\hline Other Race & $13(15.7 \%)$ & $6(46.2 \%)$ & $3(23.1 \%)$ & $4(30.8 \%)$ & \\
\hline \multicolumn{5}{|l|}{ BMI ${ }^{1}$} & \multirow[t]{4}{*}{.83} \\
\hline Normal & $22(27.2 \%)$ & $5(22.7 \%)$ & $8(36.4 \%)$ & $9(40.9 \%)$ & \\
\hline Overweight & $31(38.3 \%)$ & $11(35.5 \%)$ & $10(32.3 \%)$ & $10(32.3 \%)$ & \\
\hline Obese & $28(34.6 \%)$ & $9(32.1 \%)$ & $11(39.3 \%)$ & $8(28.6 \%)$ & \\
\hline \multicolumn{5}{|c|}{ Personal Tobacco Use ${ }^{1}$} & \multirow[t]{4}{*}{.70} \\
\hline Never User & $32(39.0 \%)$ & $10(31.3 \%)$ & $13(40.6 \%)$ & $9(28.1 \%)$ & \\
\hline Former User & $25(30.5 \%)$ & $10(40.0 \%)$ & $6(24.0 \%)$ & $9(36.0 \%)$ & \\
\hline Current User & $25(30.5 \%)$ & $7(28.0 \%)$ & $10(40.0 \%)$ & $8(32.0 \%)$ & \\
\hline \multicolumn{5}{|c|}{ Occupational Exposure ${ }^{1}$} & \multirow[t]{3}{*}{.11} \\
\hline No & $41(53.3 \%)$ & $9(22.0 \%)$ & $17(41.5 \%)$ & $15(36.6 \%)$ & \\
\hline Yes & $36(46.8 \%)$ & $16(44.4 \%)$ & $10(27.8 \%)$ & $10(27.8 \%)$ & \\
\hline \multicolumn{5}{|l|}{ Exposure Score } & \multirow[t]{3}{*}{$.12^{2}$} \\
\hline Median (IQR) & $3(3)$ & $2(3)$ & $2(3)$ & $4(3)$ & \\
\hline Mean (SD) & $2.9(1.9)$ & $2.6(1.9)$ & $2.6(1.9)$ & $3.6(1.9)$ & \\
\hline
\end{tabular}

Table 59 shows the results of the unadjusted and adjusted multinomial logistic regression analyses assessing the association between the exposure score and the number of chronic diseases reported (3-7 vs. 0-2 and $\geq 8$ vs. $0-2$ ). The exposure score was not 
significantly related to the number of chronic diseases reported in any comparison, before or after adjustment for age.

Table 59. The Crude and Adjusted Associations between Exposure Score and Number of Chronic Diseases Reported

\begin{tabular}{|c|c|c|c|c|c|c|c|c|c|}
\hline \multirow[b]{3}{*}{ Unadjusted Model } & \multirow{2}{*}{$\frac{0-2}{N}$} & \multicolumn{4}{|c|}{$3-7$} & \multicolumn{4}{|c|}{$\geq 8$} \\
\hline & & $\mathbf{N}$ & OR & \multicolumn{2}{|c|}{$(95 \%$ CI $)$} & $\mathbf{N}$ & OR & \multicolumn{2}{|c|}{$(95 \% \mathrm{CI})$} \\
\hline & & & & & & & & & \\
\hline Exposure Score & 27 & 29 & 1.00 & $(0.75$ & 1.33) & 27 & 1.30 & $(0.98$ & 1.73) \\
\hline Adjusted Model & $\mathbf{N}$ & $\mathbf{N}$ & AOR & \multicolumn{2}{|c|}{$(95 \% \mathrm{CI})$} & $\mathbf{N}$ & AOR & \multicolumn{2}{|c|}{$(95 \%$ CI) } \\
\hline Exposure Score & 27 & 29 & 0.93 & $(0.69$ & 1.26) & 27 & 1.19 & $(0.88$ & 1.61) \\
\hline Age & & & 1.05 & $(1.01$ & 1.10) & & 1.06 & (1.02 & 1.11) \\
\hline
\end{tabular}

4.2 Results for Subaim 4B: To assess if residents of Riverside Gardens with home locations in closer proximity to sources of pollution, including the Lees Lane Landfill, Rubbertown, and $L G \& E$, are more likely to report frequently (i.e. daily or weekly) experiencing groups of symptoms (e.g., respiratory symptoms, neurological symptoms, etc.) while in the neighborhood and in their homes.

Slightly more than half of participants reported experiencing bone and muscle symptoms $(57.8 \%, \mathrm{n}=48)$, neurological symptoms $(56.6 \%, \mathrm{n}=47)$, and respiratory symptoms $(50.6 \%, \mathrm{n}=42)$ daily or weekly while in the neighborhood, while more than one-third of participants reported experiencing eye symptoms $(34.9 \%, \mathrm{n}=29)$, gastrointestinal symptoms $(36.1 \%, \mathrm{n}=30)$, and skin symptoms $(37.3 \%, \mathrm{n}=31)$ daily or weekly. About one-quarter of participants $(28.9 \%, \mathrm{n}=24)$ reported experiencing mood symptoms daily or weekly. 
Demographic characteristics, potential covariates, and the exposure variable (home's location in the neighborhood; interior/exterior) were assessed by each symptom group's dichotomized frequency (daily or weekly/monthly or less). These results are displayed in Tables $60-66$ in Appendix C.

Home location was not significantly related to the reported frequency of any of the symptom groups at $P<.05$, and demographic characteristics and potential covariates did not significantly differ by home location. The relationships between potential covariates and home location are shown in Table 67 in Appendix C.

Unadjusted ORs, 95\% CIs, and $P$ values are reported for the relationship between home location and each symptom group's dichotomized frequency in Table 68. As previously stated, home location was not significantly related to the reported frequency of any of the symptom groups. 
Table 68. Unadjusted Binary Logistic Regression Models Predicting Daily or Weekly Symptom Frequency

\begin{tabular}{|c|c|c|c|}
\hline Model & $\mathbf{O R}$ & $95 \% \mathrm{CI}$ & $P$ value \\
\hline \multicolumn{4}{|l|}{ Bone and Muscle Symptoms } \\
\hline $\begin{array}{l}\text { Home's Location in Neighborhood } \\
\text { (Exterior vs Interior) }\end{array}$ & 1.37 & $0.56-3.38$ & .50 \\
\hline \multicolumn{4}{|l|}{ Eye Symptoms } \\
\hline $\begin{array}{l}\text { Home's Location in Neighborhood } \\
\text { (Exterior vs Interior) }\end{array}$ & 0.77 & $0.30-1.96$ & .58 \\
\hline \multicolumn{4}{|l|}{ Gastrointestinal Symptoms } \\
\hline $\begin{array}{l}\text { Home's Location in Neighborhood } \\
\text { (Exterior vs Interior) }\end{array}$ & 1.34 & $0.55-3.42$ & .50 \\
\hline \multicolumn{4}{|l|}{ Mood Symptoms } \\
\hline $\begin{array}{l}\text { Home's Location in Neighborhood } \\
\text { (Exterior vs Interior) }\end{array}$ & 1.20 & $0.46-3.16$ & .71 \\
\hline \multicolumn{4}{|l|}{ Neurological Symptoms } \\
\hline $\begin{array}{l}\text { Home's Location in Neighborhood } \\
\text { (Exterior vs Interior) }\end{array}$ & 1.20 & $0.49-2.94$ & .69 \\
\hline \multicolumn{4}{|l|}{ Respiratory Symptoms } \\
\hline $\begin{array}{l}\text { Home's Location in Neighborhood } \\
\text { (Exterior vs Interior) }\end{array}$ & 1.78 & $0.73-4.36$ & .21 \\
\hline \multicolumn{4}{|l|}{ Skin Symptoms } \\
\hline $\begin{array}{l}\text { Home's Location in Neighborhood } \\
\text { (Exterior vs Interior) }\end{array}$ & 1.01 & $0.41-2.52$ & .98 \\
\hline
\end{tabular}

Potential covariates were considered for inclusion in adjusted models based on the results of the analyses presented in Tables $60-67$. No potential confounders were identified using a liberal $P$ value threshold of .20; therefore, the unadjusted models presented in Table 68 are the final models. 


\section{DISCUSSION}

This study explored the health and exposure histories of residents of Riverside Gardens, a neighborhood that is bordered on three sides by industry and industrial waste, using a two-part, community-based, mixed-methods, cross-sectional epidemiologic design. For years, residents expressed concerns of elevated rates of cancer and other health conditions within the community. ${ }^{2-5}$ This dissertation study is the first documented attempt to collect health and exposure histories from Riverside Gardens residents. While the quantitative findings presented in this dissertation are based on a small sample size, elevated prevalence estimates for several diseases were identified. Additionally, the likelihood of reporting a musculoskeletal system or connective tissue disease was significantly higher with increasing levels of exposure as measured by the exposure score.

\section{Summary of Results}

\subsection{Individual Interviews and Qualitative Analysis}

Themes in three main areas arose during thematic analysis: community history and transformation, environmental exposure experiences, and health and well-being. Many participants detailed ways in which the neighborhood has changed over time, including a decline in the sense of community, prevalence of homeownership, and property values. The results of these interviews are supported by other studies that have

shown a decline in property values in neighborhoods surrounding Superfund sites. ${ }^{250-252}$ 
While information about the community's history and transformation was not utilized when creating the health and exposure assessment questionnaire, it did alert the study team to some of the participant recruitment obstacles that were ultimately faced during the second phase of the study. Additionally, the research team gained a better understanding of other ways in which community members were impacted by the neighborhood's proximity to industry and industrial waste facilities (i.e., the decline in property values).

Participants also discussed ways in which living near a hazardous waste landfill, a power plant, and chemical, rubber, and plastic manufacturers impacted their daily lives. Specifically, air pollution, strong odors, and water pollution were discussed. Unique exposures to environmental pollutants during childhood were also described. These details provided information on the ways in which community members may be exposed to environmental pollutants, which contributed to the development of questionnaire items in the Neighborhood Exposures and Outdoor Activities In and Around the Neighborhood sections (see Appendix B), and to the development of the exposure score.

When asked to detail specific health concerns during interviews, cancer, respiratory problems, allergies, joint and disc diseases, cardiovascular disease, diabetes, and mental health disorders were most frequently reported. Headaches, skin irritation and dryness, sinus problems, and eye burning were listed as symptoms of concern. These reports contributed to the health conditions and symptoms included in the Personal Health History section of the questionnaire.

Along with health effects, interview participants shared stories about how living in the neighborhood has affected their well-being. Regret for purchasing a home in the 
neighborhood, distrust of the surrounding industries, the negative impacts that living in the neighborhood has had on family life, feeling stuck in the neighborhood, and feelings of powerlessness, hopelessness, and defeat were expressed. These findings are supported by past research studies and observations that have documented feelings of powerlessness

and psychological distress among residents living near toxic waste sites..$^{253-255}$ Similar to the information shared concerning the neighborhood's history and transformation, these details were not used to create questionnaire items. However, understanding the wellbeing of the community is essential to understanding the health of the community, and by sharing these feelings, interview participants enhanced the research team's understanding of the numerous ways in which living in the Riverside Gardens neighborhood has impacted the lives of residents.

After qualitative data were analyzed, these results were presented at a community meeting and a discussion between community members and researchers took place to refine specific health and exposure concerns for inclusion in the health and exposure assessment questionnaire.

\subsection{Comparisons of Prevalence Estimates to Local, State, and National Data}

Specific Aim 3 sought to assess and compare the prevalence of self-reported health conditions in Riverside Gardens as reported on the health and exposure assessment questionnaire. Participants reported diagnoses of 65 non-cancer diseases and 11 sites of cancer. Comparisons involving 38 of the 65 non-cancer diseases and all-site cancer were made to local, state, and national data. 
Many (28.1\%) of the prevalence estimates involving Riverside Gardens data had RSEs between $30 \%$ and $50 \%$ and, therefore, are considered unstable estimates. Another 28.1\% had RSEs greater than 50\% and are considered unreliable. The low frequencies of many individual diseases reported as well as the small size of the study sample contributed to the number of estimates with high RSEs and a lack of statistical power when comparing data. While some diseases had higher prevalence estimates than local, state, or national data, even after age adjustment (e.g., asthma), the imprecision of the estimate led to the inability to detect a significant difference.

Significant differences in disease prevalence estimates were detected for arthritis (with definitions excluding and including lupus and fibromyalgia), bipolar disorder, respiratory diseases (COPD alone or any of the following: COPD, chronic bronchitis, or emphysema), hypercholesterolemia, hypertension, panic disorder, and stroke. All prevalence estimates but that of hypercholesterolemia were higher among Riverside Gardens residents. Interestingly, the majority of the diseases for which an excess prevalence estimate was found belong to disease groups that were most frequently reported during interviews (respiratory problems, joint and disc diseases, cardiovascular disease, and mental health disorders).

The crude prevalence difference for COPD between Riverside Gardens data and national data was 12.6 (95\% CI: 4.7-20.5) when compared to NHANES 2015-2016 and 12.3 (95\% CI: 4.5-20.1) when compared to NHIS 2017. When COPD, chronic bronchitis, or emphysema were considered, the crude prevalence difference between Riverside Gardens and NHANES 2015-2016 was 13.8 (95\% CI: 4.8-22.8). Respiratory outcomes and breathing difficulties may result from exposure to contaminants from many 
of industries or industrial waste facilities surrounding Riverside Gardens, ${ }^{134,143-147}$ and exposure to airborne particulate matter such as fly ash from the neighboring power plant has been linked to respiratory conditions including COPD. ${ }^{156}$ Respiratory symptoms and disorders have also been frequently reported in other human health studies of those exposed to hazardous waste sites and industrially-contaminated areas. ${ }^{178,180,183,185,188}$ However, it is important to note that prevalence estimates for COPD and chronic bronchitis, COPD, or emphysema were not adjusted for smoking status, the leading risk factor for COPD and emphysema. ${ }^{256}$ Additionally, while these estimates exceeded national estimates, they did not exceed local or state estimates. Smoking rates in Kentucky are among the highest in the nation, ${ }^{257}$ so it is possible that the prevalence difference between Riverside Gardens estimates and national estimates may be attenuated and/or the significant difference may dissolve if adjusted for smoking status.

The prevalence of bipolar disorder and panic disorder could not be compared on the local or state level due to the lack of comparison data; however, the prevalence of both disorders among Riverside Gardens residents significantly exceeded national estimates (crude difference for bipolar disorder: 7.4, 95\% CI: 1.1-13.9; age-adjusted difference for bipolar disorder: 10.1, 95\% CI: 3.1-17.1; age-adjusted difference for panic disorder: 8.0, 95\% CI: 0.8-15.2). Psychological symptoms have been frequently reported in many health studies of individuals living near hazardous waste sites. ${ }^{179,180,182-184,187}$ Furthermore, exposure to neurotoxins, including those that have been detected at the landfill site, can be found in coal ash, and are released by several nearby companies, may result in changes in behavior and other neurobehavioral impacts. ${ }^{147,175}$ In particular, increasing blood lead levels have been associated with increased odds of panic disorder ${ }^{258}$ 
and elevated median blood lead levels have been observed in patients with bipolar disorder. ${ }^{259}$ Early life exposure to PCE - which has been released by a nearby chemical company, has been detected in samples collected from sites between the landfill site and Riverside Gardens, and is a known contaminant of the site of a former neighboring chemical company - has also been associated with bipolar disorder. ${ }^{260,261}$

Crude and age-adjusted prevalence estimates for hypertension and stroke among Riverside Gardens residents exceeded all local, state, and national crude and age-adjusted estimates; however, only some of the estimates significantly differed. The crude prevalence estimates for hypertension and stroke significantly exceeded estimates from national datasets (hypertension prevalence difference: 19.1, 95\% CI: 8.1-30.1 and 20.0, 95\% CI: 9.2-30.8; stroke prevalence difference: $8.1,95 \%$ CI $1.4-14.8$ and $7.7,95 \%$ CI 1.0-14.4; comparison to NHANES 2015-2016 and NHIS 2017, respectively). Additionally, the prevalence estimate for hypertension was significantly higher in Riverside Gardens in one of the age-adjusted comparisons to national data (NHIS 2017; prevalence difference; $11.9,95 \%$ CI: 1.3-22.5) and in the crude comparison to local data (BRFSS-KY 2017; prevalence difference: 16.0, 95\% CI: 4.7-27.3). Exposures to metal pollutants such as arsenic, lead, and possibly cadmium, all of which have been identified at the Lees Lane Landfill and may be found in coal ash, as well as exposure to particulate matter, are associated with stroke and hypertension. ${ }^{162}$ Moreover, a study by Shcherbatykh et al. (2005) found increased hospitalization rates for stroke in areas near persistent organic pollutant (POPs) sites (rate ratio: $1.15,95 \%$ CI: 1.05-1.26). ${ }^{262}$ POPs include PCBs, dioxins, and chlorinated pesticides, chemicals that have been detected at 
the landfill site and have been released from the neighboring power plant. Exposure to certain POPs has also been associated with hypertension. ${ }^{263}$

Finally, the prevalence difference in arthritis (including and excluding lupus and fibromyalgia) was significant in many crude and age-adjusted local, state, and national comparisons. The prevalence difference ranged between 13.4-17.5 for age-adjusted comparisons and 15.8-24.4 for crude estimates. Many contaminants released by industries and present at hazardous and industrial waste sites are thought to be associated with the development or severity of arthritis, lupus, fibromyalgia, and gout. ${ }^{264-269}$ These contaminants include particulate matter, POPs, heavy metals, and TCE. The hypothesized biological mechanisms for the relationship between these contaminants and arthritis, lupus, fibromyalgia, and gout vary based on the specific contaminant and exposure. One possibility involving arthritis (excluding rheumatoid arthritis), the condition within this group that was most frequently reported by Riverside Gardens residents, is that lead, a heavy metal that is known to affect bone and is present at the landfill and other nearby industrial sites, may also affect cartilage. ${ }^{269}$ Arthritis was not, however, found to be a health outcome of concern during the literature review of studies assessing the health of communities near hazardous waste and other industrially-contaminated sites.

\subsection{Relationship between Exposure Score and Disease Categories}

Participants had a median exposure score of 3 out of a possible 7 (IQR: 3 ). The most frequently reported disease diagnoses belonged to the circulatory system, musculoskeletal system or connective tissue, and endocrine, nutritional, and metabolic disease groups (prevalence range: 41.0-57.8\%). 
The exposure score used in Specific Aim 4 was significantly related to musculoskeletal system and connective tissue diseases. In both unadjusted logistic regression models and models adjusted for age, those with higher exposure scores were more likely to report being diagnosed with a musculoskeletal system or connective tissue disease (OR: 1.39, 95\% CI: 1.08-1.78; AOR: 1.32, 95\% CI: 1.01-1.72).

This provides additional support for the hypothesis that exposure to contaminants from the industries and industrial waste sites surrounding Riverside Gardens may be associated with the development of the related conditions found to be higher in prevalence than comparison data.

\subsection{Relationship between Home's Location and Symptom Frequency}

About $40 \%$ of participants lived within the exterior zone of the neighborhood, meaning that they live closer to industry and industrial waste sites. When asked to report symptoms experienced in the neighborhood and the frequency with which these symptoms were experienced, the most common groups were bone and muscle, neurological, and respiratory symptoms; more than half of participants reported that they experienced these daily or weekly (reported by $50.6 \%-57.8 \%$ of participants). Although, when assessed by participants' home location, those who lived closer to industry and industrial waste sites were not significantly more likely to report experiencing symptoms daily or weekly than those who lived farther from these sites.

Despite the lack of difference by home location, residents of Riverside Gardens may still experience these symptoms more frequently than residents of other neighborhoods. Perhaps a more interesting comparison would have been the difference in 
reported symptom group frequency between Riverside Gardens community members and residents of a neighborhood not surrounded by industry and industrial waste. Several studies that have evaluated self-reported symptoms within communities that surround hazardous waste sites have utilized control populations in order to compare the prevalence of symptoms, and significant differences have been observed. ${ }^{178,180,181,270}$ Data on the frequency of symptoms are not available in datasets such as BRFSS, NHANES, and NHIS; therefore, the only way to have compared symptom frequency data would have been through administering the questionnaire to a control population, which, unfortunately, was outside the scope of this study.

\section{Study Limitations}

This study has several limitations that should be considered when interpreting its results. First, only 83 participants completed the full version of the health and exposure assessment questionnaire (the focus of this dissertation). Using ACS 2016 data, it is estimated that 560 adults live in the neighborhood. ${ }^{1}$ Based on this population estimate, the participation rate for the full version of the questionnaire was $14.8 \%$. However, this estimate does not take length of residency or the diagnosis of cognitive illnesses into account, two of the eligibility requirements for the second phase of the study. Therefore, the estimated participation rate is an underestimation of the true participation rate of eligible participants. This small sample size led to imprecise prevalence estimates for diseases reported by participants, as well as underpowered comparisons to local, state, and national data. 
Next, a limitation related to the low participation rate is that the study sample may not be representative of all adults who live in the Riverside Gardens neighborhood due to observed differences in demographic characteristics. When compared to ACS 2016 block group estimates, those who completed the full version of the questionnaire for this study were older (median age 61 years vs. 50-54 years $\left.{ }^{21}\right)$, more educated $(84.1 \%$ with high school diploma or GED vs. $75.8 \%{ }^{22}$ ), and reported lower annual household incomes (median $\$ 27,500$ vs. $\$ 33,750^{23}$ ). Additionally, the disease prevalence estimates for these individuals may not be representative of adults in the community. For instance, community members who had more disease diagnoses to report and/or those who felt that they were more exposed to pollution may have been more likely to complete the health and exposure assessment questionnaire than those who did not, resulting in a selection bias. This bias may have inflated both the disease prevalence estimates within the community and the average exposure score; it also may have biased odds ratios away from the null.

\subsection{Recruitment Challenges}

Recruitment for this study was challenging for many reasons. First, the community has had negative past experiences with researchers and government bodies. Much of the research that has been conducted with the community in the past was "mosquito research" (i.e. where researchers collect data and then leave the community, never returning to share the study's findings). These experiences have made some community members hesitant to invest their time in subsequent research projects and work with researchers again. Additionally, many community members have expressed 
concern over the fact that government bodies like the EPA have conducted studies without informing the community of the results. In fact, some community members have had their homes sampled and report never having received the findings.

Furthermore, some community members were disinclined to respond to questions regarding their health and exposure histories because they felt that they had already reported this information multiple times. This is due to lawsuits that have involved the neighborhood. In the past, when the community has taken legal action against the companies that surround the neighborhood, legal teams representing the community have requested health and exposure information from community members to help build their case. Many community members recalled providing their health and exposure histories to these individuals (some thinking that these individuals were researchers), but there seems to be a misunderstanding over why this information was collected and how it was used. Those who thought that their health and exposure histories were collected by legal teams for the purpose of research have expressed frustration that they were being asked to provide this information again during this study.

Another recruitment challenge involved rumors that this study was sponsored by one of the nearby industries or that it was related to a lawsuit were also circulating throughout the neighborhood during the time that recruitment was underway. Both of these rumors made community members hesitant to participate.

Finally, many homes in the neighborhood have privacy fences that enclose the entire property. Study team members would not approach these homes due to safety concerns, which prevented the study team from speaking directly with these residents 
about the study. While flyers were left along fence gates at these homes, they may have blown away before they were seen by residents.

Each of these challenges posed barriers to successfully enrolling all eligible adults who had lived in Riverside Gardens for at least one year to participate in the study, obtaining a representative sample of adult community members, and attaining a sample size with sufficient power to detect a significant difference in disease prevalence when compared to other datasets. However, the study attempted to tackle these challenges by engaging the community from the beginning and employing a variety of methods to dispel rumors, inform community members about the study, and recruit participants.

\subsection{Limitations of Study Design}

The next limitation of this study relates to its design. This is a cross-sectional study, and while the prevalence estimates of disease are reported, the temporal relationship between exposure and disease cannot be assessed. Additionally, no environmental or biological samples were collected. Exposure variables and the prevalence of health conditions were both obtained through self-report, which is subject to bias.

Some of the exposure variables that made up the exposure score may have been subject to recall bias. For example, many participants moved out of the neighborhood at least once before moving into their current home. If participants incorrectly reported the length of time that they lived inside and outside of the neighborhood, they may have been miscategorized when the proportion of life variable was created. Other exposure variables, including participating in activities on or near the landfill site, swimming in the 
Ohio River, and eating plants or animals grown or captured in the neighborhood, did not consider the frequency with which these activities occurred, meaning that participants who infrequently participated in these activities were categorized the same as others who participated in these activities more often. These variables were also subject to recall bias - participants may not have recalled taking part in these activities, particularly if they did so during childhood. Taken together, there may have been a random misclassification of exposure in regression analyses involving the exposure score, which could have biased the odds ratios toward the null.

Because exposure and health histories were based on self-report and were not verified, it is also possible that participants may have over-reported their exposure histories, health histories, or both, resulting in information bias. Assessing the prevalence of health conditions without consulting medical records to confirm disease diagnoses may also be viewed as a limitation due to potential recall bias. However, a high level of agreement between self-reported health conditions and medical record reports has been documented by numerous studies involving adult, including older adult, populations. ${ }^{271-}$ ${ }^{278}$ Additionally, the prevalence estimates of the majority of diseases reported by Riverside Gardens residents were similar to local, state, and national estimates, which limits the concern that overreporting may have been an issue in this study. Moreover, prevalence comparisons were made to survey data that also relied on self-report.

Next, while reference data were available for more than half of the diseases reported by participants, many individual diseases could not be compared due to the lack of local, state, and national data. Some of the diseases that could not be compared were of interest to the community, and questions related to elevated prevalence estimates of these 
conditions remain unanswered. Had the questionnaire been administered to a comparison population (i.e., a demographically similar population from an area not surrounded by industry and industrial waste), more individual disease comparisons may have been possible.

Additionally, community members with cognitive illnesses such as dementia or Alzheimer's disease were excluded due to the study's reliance on self-report; therefore, the prevalence of such conditions among adults within the neighborhood could not be assessed or compared to other populations.

Finally, the prevalence estimates presented in this study only provide a snapshot of the diseases that the current adult residents of Riverside Gardens reported. Data were not collected regarding the health conditions of former residents or the deceased. Thus, conclusions about the prevalence of disease among these populations cannot be drawn.

\section{Study Strengths}

Despite its limitations, this study has many strengths. First, this study employed a community-based design. Feedback from community members played a role in the development and review of the data collection instruments employed in this study, and community members assisted the study team with participant recruitment. Research has shown that this study design increases participation and enhances the relevance of the research to the community. ${ }^{279-283}$

Holding community meetings, conducting individual interviews, and walking around the community to talk with residents allowed the research team to become familiar with the health and environmental concerns of the community, as well as 
provided the opportunity to build trust with the community, prior to developing and distributing the health and exposure assessment questionnaire. These efforts may have increased participant recruitment and the study's relevance to the community.

\subsection{Strengths of the Health and Exposure Assessment Questionnaire}

The health and exposure assessment questionnaire that was used in this study was an additional study strength. It was developed specifically for adults of the Riverside Gardens community, and the questionnaire items were blended from multiple sources. Health and exposure items presented by the community were included but were asked in ways that were consistent with the phrasing of representative validated surveys when possible. Health conditions and symptoms that are related to exposure to contaminants released by nearby industries and detected at nearby waste sites were also included. Other questions related to participant demographics and potential covariates were added; these questions were taken from representative surveys and other validated instruments. The result was a questionnaire that collected information of relevance to both community members and researchers that was also designed to allow direct comparison to other representative datasets.

\subsection{Recruitment Strengths}

This study employed the use of multiple recruitment methods to increase participation. Flyers were distributed door-to-door to all homes in the neighborhood on numerous occasions throughout all phases of the study to notify residents of the study and study-related community meetings. The research team also knocked on doors in an 
attempt to introduce the study to community members and assess their eligibility. Doorto-door efforts took place on weekdays and weekends, during the daytime and in the evening, in an attempt to reach residents when they were at home. Community members also volunteered to assist the study team with foot recruitment efforts, occasionally helping the study team to reach homes that could not have been approached otherwise. Logs of attempts to reach residents were kept to ensure that an adequate number of attempts were made to reach residents. At a minimum, every home in the neighborhood received 8 flyers and 3 home visits (unless residents had already participated) related to the distribution of the health and exposure assessment questionnaire between July and October of 2018.

Additionally, letters were mailed to residents twice during the health and exposure assessment phase of the study to dispel rumors, invite community members to study meetings, and recruit participants. The research team also attended community-sponsored events and meetings for recruitment purposes. While participation in the study was low, numerous attempts were made to ensure that all community members knew about the study.

\subsection{Ease of Participation}

Many efforts were made to increase the ease of participating in the study. Questionnaire packets could be delivered to and picked up from the homes of interested residents. Additionally, events were held in the neighborhood and at a nearby restaurant to give participants the opportunity to complete questionnaires. The questionnaire took most participants about 30 minutes or less to complete, but the majority of participants 
opted to keep the questionnaire and fill it out over the course of a week. Reminder calls, texts, and emails were used to check in on participants who were completing questionnaires and to schedule collection times that worked well for participants. Removing barriers to participation by conducting the study in the community was an important step in obtaining a more representative sample of the community.

\subsection{Representation of Homes}

Despite the study's limited sample size, those who completed the full version of the questionnaire represented $25.4 \%$ of the potentially eligible homes in the neighborhood (excluding homes with those who were determined to be ineligible and unoccupied homes). This is a conservative estimate that assumes that all of the individuals that the study team did not make direct contact with were eligible to participate in the study. Almost $40.0 \%$ of these homes were located in the exterior neighborhood zone (closest to industry and industrial waste facilities) and $61.4 \%$ were in the interior of the neighborhood.

\subsection{Reporting Results to Community}

A final strength of this study is that its results will be shared with community members. A community meeting will be held after this dissertation has been formally submitted for the fulfillment of the degree to discuss the study's findings. All community members, including those who did not participate, will be invited to attend. Not only is this an important step due to the community-based design of this study, but it is particularly important given that community members have complained about not 
receiving the results of previous research projects in the area. Reporting the results back to the community is another way to build trust and strengthen the relationship between researchers and Riverside Gardens community members.

\section{Conclusion}

Living in close proximity to industry and industrial waste sites may negatively impact the health and well-being of community members. Many long-term residents of Riverside Gardens requested that a formal health study take place in the neighborhood to assess concerns about the contaminants that surround it and how they may impact the health of the community. This was the first documented attempt to do so, and the findings of this study suggest that the prevalence estimates of certain musculoskeletal, respiratory, circulatory, and mental health conditions among adults in Riverside Gardens significantly exceed local, state, and national estimates. However, additional research is needed to assess the relationship between timing and exposure to environmental contaminants and disease outcomes in the community. Specifically, future studies should attempt to quantify exposure to contaminants by collecting biological samples from residents and environmental samples, including soil, water, and air, from their homes. Furthermore, studies assessing the health conditions of children in the neighborhood should be conducted, as the health experiences of children may differ from those of adults. These steps would enable researchers to better answer the long-standing questions held by community members and could also provide justification for action that could improve the community's environment for current and future residents. 


\section{REFERENCES}

1. U.S. Census Bureau. American Community Survey, 2016 American Community Survey 5-Year Estimates, Table B01003; generated by Lindsay Tompkins using American FactFinder. http://factfinder.census.gov/. Accessed January 29, 2018.

2. Peterson E. Riverside Gardens: A former resort community besieged by pollution. $89.3 \mathrm{WFPL}$. January 18, 2013. http://wfpl.org/riverside-gardens-former-resortcommunity-besieged-pollution/. Accessed February 23, 2016.

3. Bruggers J. Toxic Lees Lane dump gets two EPA public meetings. CourierJournal. May 21, 2014. http://www.courier-journal.com/story/watchdogearth/2014/05/21/epa-meetings-on-lees-lane-landfill/9371533/. Accessed February 23, 2016.

4. Peterson E. Southwest Louisville residents still concerned about long-dormant landfill. 89.3 WFPL. January 21, 2013. http://wfpl.org/southwest-louisvilleresidents-still-concerned-about-long-dormant-landfill/. Accessed February 23, 2016.

5. Meador J. Not in my backyard: Residents express outrage over proposed LG\&E ash pond. LEO Weekly. June 2, 2010. https://www.leoweekly.com/2010/06/notin-my-backyard-2/. Accessed February 1, 2016.

6. Voskuhl J. Lees Lane site is filled with history. Courier-Journal. July 1, 1987:Neighborhoods-South End: 1.

7. Kleber JE. The Encylopedia of Louisville. Lexington, Kentucky: The University Press of Kentucky; 2001.

8. Advertisement for Riverside Gardens. Courier-Journal. May 30, 1926:1.

9. Holt D. The rocky road back from paradise lost. Courier-Journal \& Times. March 1, 1970:D1.

10. Sprague P. Waters left Churchill Downs slowed, but not stopped. CourierJournal. January 21/22, 1987:Neighborhoods-South End: 4.

11. Resource Applications Incorporated. Review of the Response Actions at the Lees Lane Landfill Site Louisville, Kentucky. 1993.

12. Roy F. Weston Inc. Five-Year Review Final Report: Lees Lane Landfill site Louisville, Jefferson County, Kentucky. 1998. 
13. U.S. Army Corps of Engineers. Superfund Five Year Review Report Lee's Lane Landfill Louisville, Jefferson County, KY. 2003.

14. U.S. Army Corps of Engineers. Fourth Five-Year Review Report for Lee's Lane Landfill Louisville Jefferson County, Kentucky. 2008.

15. United States Environmental Protection Agency. Fifth Five-Year Review Report for Lee's Lane Landfill. 2013.

16. United States Environmental Protection Agency, Office of Emergency and Remedial Response. Superfund Enforcement Decision Document: Lees Lane Landfill, KY. 1986.

17. Metro Parks. Louisville Loop Strategic Plan. 2011. https://louisvilleky.gov/government/louisville-loop/history-loop. Accessed February 8, 2018.

18. Metro Parks. Louisville Loop: Riverside Gardens Path Riverside Gardens Trailhead. https://louisvilleky.gov/government/louisville-loop/louisville-loopriverside-gardens-path-riverside-gardens-trailhead. Accessed February 8, 2018.

19. U.S. Census Bureau. American Community Survey, 2016 American Community Survey 5-Year Estimates, Table B03002; generated by Lindsay Tompkins using American FactFinder. http://factfinder.census.gov/. Accessed January 29, 2018.

20. U.S. Census Bureau. American Community Survey, 2016 American Community Survey 5-Year Estimates, Table B16004; generated by Lindsay Tompkins using American FactFinder. http://factfinder.census.gov/. Accessed January 29, 2018.

21. U.S. Census Bureau. American Community Survey, 2016 American Community Survey 5-Year Estimates, Table B01001; generated by Lindsay Tompkins using American FactFinder. http://factfinder.census.gov/. Accessed January 29, 2018.

22. U.S. Census Bureau. American Community Survey, 2016 American Community Survey 5-Year Estimates, Table B15003; generated by Lindsay Tompkins using American FactFinder. http://factfinder.census.gov/. Accessed January 29, 2018.

23. U.S. Census Bureau. American Community Survey, 2016 American Community Survey 5-Year Estimates, Table B19013; generated by Lindsay Tompkins using American FactFinder. http://factfinder.census.gov/. Accessed January 29, 2018.

24. U.S. Census Bureau. American Community Survey, 2016 American Community Survey 5-Year Estimates, Table GCT1901; generated by Lindsay Tompkins using American FactFinder. http://factfinder.census.gov/. Accessed January 29, 2018.

25. U.S. Census Bureau. American Community Survey, 2016 American Community Survey 5-Year Estimates, Table GCT1901; generated by Lindsay Tompkins using American FactFinder. http://factfinder.census.gov/. Accessed January 29, 2018. 
26. U.S. Census Bureau. American Community Survey, 2016 American Community Survey 5-Year Estimates, Table C24010; generated by Lindsay Tompkins using American FactFinder. http://factfinder.census.gov/. Accessed January 29, 2018.

27. U.S. Census Bureau. American Community Survey, 2016 American Community Survey 5-Year Estimates, Table B25003; generated by Lindsay Tompkins using American FactFinder. http://factfinder.census.gov/. Accessed February 27, 2018.

28. Barnett RA. Environmental Issues: Louisville, KY. Kentucky Institute for the Environment and Sustainable Development. 2011.

29. Coleman P. Rubbertown Helps Whip Japs; Builds Louisville's Future. CourierJournal. March 26, 1944.

30. American Synthetic Rubber Company. ASRC History. americansyntheticrubberco.com/about-us/our-history/. Accessed February 10, 2018 .

31. Louisville Gas \& Electric. History of Cane Run Plant. https://lge-ku.com/canerun/history. Accessed November 3, 2018.

32. United States Environmental Protection Agency. Sixth Five-Year Review Report for Lee's Lane Landfill Superfund Site Jefferson County, Kentucky. 2018.

33. United States Environmental Protection Agency. Superfund Record of Decision: Lee's Lane Landfill. 1986.

34. Plan Commission files suit agains landfill. Courier-Journal. July 29, 1971:A12.

35. Northern R. Riverside Gardens residents finally win dump fight, but 'system' is still puzzle. Courier-Journal. July 24, 1972:B1.

36. Melnykovych A. Louisville chemical plants have reduced spills, leaks. CourierJournal. May 27, 1997:1, 5.

37. Bruggers J. Rubbertown spill turns creek bright yellow. Courier-Journal. March 8, 2017. https://www.courierjournal.com/story/tech/science/environment/2017/03/08/rubbertown-spill-turnscreek-bright-yellow/98912970/. Accessed February 9, 2018.

38. WDRB.com. Fire at Rubbertown chemical plant sends black smoke into the air. September 5, 2018. http://www.wdrb.com/story/39033663/fire-at-rubbertownchemical-plant-send-black-smoke-into-the-air. Accessed September 5, 2018.

39. Voskuhl J. Borden neighbors fear fatal explosion left toxic fallout. CourierJournal. August 7, 1985:B1. 
40. Humphrey et al v. Hexion Specialty Chemicals, Inc. June 7, 2006 (Kentucky Western District Court 2007).

41. Centlivre A. Something rotten in the state of Rubbertown. WAVE 3 News. March 20, 2018. http://www.wave3.com/story/37770272/something-rotten-in-the-stateof-rubbertown. Accessed March 25, 2018.

42. Bruggers J. Something smells. It's Louisville's neighborhoods, and the poorer ones don't get relief. Courier-Journal. March 15, 2018. https://www.courierjournal.com/story/tech/science/environment/2018/03/15/louisville-odorcomplaints-stinky-neighborhoods/346322002/. Accessed March 25, 2018.

43. Bruggers J. Preliminary air tests find hazardous chemicals. Courier-Journal. June 30, 2000:1, 6 .

44. Pike B. Group doing health survey near Rubbertown. Courier-Journal. March 24, 1999:B2.

45. Cox B. Riverside Gardens area must wait for air relief. Courier-Journal. March 13, 1974:B11.

46. Peterson E. LG\&E agrees to pay $\$ 113,000$ for coal ash, odor violations at Cane Run plant. 89.3 WFPL. November 13, 2013; https://wfpl.org/lge-agrees-pay113000-coal-ash-odor-violations-cane-run-plant/. Accessed February 13, 2018.

47. Bruggers J. New Cane Run fine assessed on LG\&E. Courier-Journal. July 22, 2014. https:/www.courier-journal.com/story/watchdog-earth/2014/07/22/canerun-odors/13008123/. Accessed February 7, 2018.

48. Zierold KM, Sears CG. Community views about the health and exposure of children living near a coal ash storage site. J Community Health. 2015;40(2):357363.

49. Agency for Toxic Substances and Disease Registry. Site Review and Update: Lees Lane Landfill Louisville, Jefferson County, Kentucky. 1993.

50. United States Environmental Protection Agency. Lee's Lane Landfill Superfund Site, Louisville, Jefferson County, Kentucky (written communication, recipient: Goodrich Corporation). 2014.

51. US District Court for the Western District of Kentucky. United States of America, Plaintiff, v. Ben Hardy, et al., Defendants. 1996.

52. Joseph Schmidt of the Kentucky Department for Natural Resources and Environmental Protection, Bureau of Environmental Protection, Division of Waste Management. Lee's Lane Landfill Groundwater Data (written communication, recipient: R.A. Wentworth of Louisville Gas \& Electric).1981. 
53. Environmental Protection Agency Hazardous Ranking System. Vol 40 CFR $\S$ 300. 1990.

54. United States Environmental Protection Agency. Superfund Remedial Investigation/Feasibility Study (Site Characterization).

https://www.epa.gov/superfund/superfund-remedial-investigationfeasibilitystudy-site-characterization. Accessed February 17, 2018.

55. United States Environmental Protection Agency. Regional Screening Levels (RSLs). https://www.epa.gov/risk/regional-screening-levels-rsls. Accessed April $6,2018$.

56. United States Environmental Protection Agency, Office of Emergency and Remedial Response. Soil Screening Guidance: Fact Sheet. 1996.

57. Lee's Lane Landfill Group and The Louisville and Jefferson County Metropolitan Sewer District. Conceptual Site Model: Lee's Lane Landfill Site, Louisville, KY. 2016.

58. Kentucky Division of Waste Management. Lees Lane Landfill Sampling Report April 1, 2013 Sampling Event. 2013.

59. Agency for Toxic Substances and Disease Registry, U.S. Department of Health and Human Services, Division of Community Health Investigations. Letter Health Consultation: Review of Soil Gas Data Collected in 2013, Lee's Lane Landfill Site, Louisville, Jefferson County, Kentucky. 2014.

60. United States Environmental Protection Agency. Superfund: Five Year Reviews. https://www.epa.gov/superfund/superfund-five-year-reviews. Accessed February 20, 2018.

61. United States Environmental Protection Agency. Public Health Assessment Guidance Manual (2005 Update). Chapter 6: Exposure Evaluation: Evaluating Exposure Pathways. 2005.

https://www.atsdr.cdc.gov/hac/phamanual/ch6.html\#6.1. Accessed February 2, 2019 .

62. MacDonald S, Fineman H. Illegal wastes reported at controversial landfill. Courier-Journal. March 26, 1975:A:1, 6.

63. McDonough R. Riverside Gardens: Despite county's promises, debris still covers 8 Putnam Avenue lots. Courier-Journal. November 27, 1980:NeighborhoodSouthwest: 9.

64. Melnykovych A. Leaky drums to stay put pending tests of contents. CourierJournal. October 12, 1991:A12. 
65. United States Environmental Protection Agency. RCRAInfo Facility Information. Putnam Avenue Drum Site. Handler ID: KYD985092105.

https://ofmpub.epa.gov/enviro/rcrainfoquery_3.facility_information?pgm_sys_id= KYD985092105. Accessed November 1, 2018.

66. Pike B. Lees Lane Landfill cleaned up. Courier-Journal. January 27, 1988:Neighborhoods-City: 2.

67. Ellis L. Plan to vent gas at Lee's Lane landfill has its skeptics. Courier-Journal. July 27, 1979:B1.

68. Council RCA. Rubbertown's Early Years.

http://www.rubbertowncac.org/history.htm. Accessed January 29, 2018.

69. United States Environmental Protection Agency. TRI Facility Report: Hexion Inc (40216BRDNN6200C), Facility Information.

https://www3.epa.gov/enviro/facts/tri/effacilities/\#/Facility/40216BRDNN6200C/HEXION\%20INC). Accessed January $31,2018$.

70. United States Environmental Protection Agency. TRI Facility Report: Hexion Inc (40216BRDNN6200C), Releases of TRI Chemicals to the Environment.

https://www3.epa.gov/enviro/facts/tri/ef-

facilities/\#/Release/40216BRDNN6200C. Accessed January 31, 2018.

71. United States Environmental Protection Agency. Toxics Release Inventory (TRI) Program: Learn about the Toxics Release Inventory. https:/www.epa.gov/toxicsrelease-inventory-tri-program/learn-about-toxics-release-inventory. Accessed January 31, 2018.

72. Environmental Geology. Remedial Investigation Work Plan: Atkemix Ten Inc., Louisville, Kentucky. 1989.

73. United States Environmental Protection Agency, RCRA Info. Facility Information: Atkemix Ten Inc.

https://oaspub.epa.gov/enviro/rcrainfoquery_3.facility_information?pgm_sys_id= KYD006372197. Accessed February 16, 2018.

74. United States Environmental Protection Agency. Categories of Hazardous Waste Generators. https:/www.epa.gov/hwgenerators/categories-hazardous-wastegenerators. Accessed February 16, 2018.

75. United States Environmental Protection Agency. RCRA Showcase Pilot, Region 4, Phased Approach to Site Remediation Expedites Progress Toward Environmental Indicators and Final Remediation, Atkemix Ten Inc. Facility Louisville, Kentucky. https://archive.epa.gov/epawaste/hazard/web/pdf/r4_atkem.pdf. 
76. United States Environmental Protection Agency. BR Facility Summary Report: Atkemix Ten Inc. 2001.

https://oaspub.epa.gov/enviro/brs_report_v2.get_data?hand_id=KYD006372197 \&rep_year $=2001 \&$ naic_code $=\&$ naic_code_desc $=\&$ yvalue $=2001 \&$ mopt $=0 \& \mathrm{mmo}$ $\mathrm{pt}=\&$ wst_search $=0 \&$ keyword $1=\&$ keyword $2=\&$ keyword $3=\&$ rvalue $1=\&$ rvalue $2=$ \&rvalue $3=\&$ cvalue $1=\&$ cvalue $2=\&$ cvalue $3=$. Accessed February 16, 2018.

77. United States Environmental Protection Agency. BR Facility Summary Report: Atkemix Ten Inc. 2003. https://oaspub.epa.gov/enviro/brs_report_v2.get_data?hand_id=KYD006372197 \&rep_year $=2003 \&$ naic_code $=\&$ naic_code_desc $=\& y$ value $=2003 \&$ mopt $=0 \& \mathrm{mmo}$ $\mathrm{pt}=\&$ wst_search $=0 \&$ keyword $1=\&$ keyword $2=\&$ keyword $3=\&$ rvalue $1=\&$ rvalue $2=$ \&rvalue $3=\&$ cvalue $1=\&$ cvalue2 $=\&$ cvalue $3=$. Accessed February 16, 2018.

78. United States Environmental Protection Agency. BR Facility Summary Report: Atkemix Ten Inc. 2005. https://oaspub.epa.gov/enviro/brs_report_v2.get_data?hand_id=KYD006372197 \&rep_year $=2005 \&$ naic_code $=\&$ naic_code_desc $=\& y v a l u e=2005 \& \mathrm{mopt}=0 \& \mathrm{mmo}$ $\mathrm{pt}=\&$ wst_search $=0 \&$ keyword $1=\&$ keyword $2=\&$ keyword $3=\&$ rvalue $1=\&$ rvalue $2=$ \&rvalue $3=\&$ cvalue $1=\&$ cvalue $2=\&$ cvalue $3=$. Accessed February 16, 2018.

79. United States Environmental Protection Agency. BR Facility Summary Report: Atkemix Ten Inc. 2007. https://oaspub.epa.gov/enviro/brs_report_v2.get_data?hand_id=KYD006372197 \&rep_year $=2007 \&$ naic_code $=\&$ naic_code_desc $=\& y v a l u e=2007 \&$ mopt $=0 \& \mathrm{mmo}$ $\mathrm{pt}=\&$ wst_search $=0 \&$ keyword $1=\&$ keyword $2=\&$ keyword $3=\&$ rvalue $1=\&$ rvalue $2=$ \&rvalue $3=\&$ cvalue $1=\&$ cvalue $2=\&$ cvalue $3=$. Accessed February 16, 2018.

80. United States Environmental Protection Agency. BR Facility Summary Report: Atkemix Ten Inc. 2009. https://oaspub.epa.gov/enviro/brs_report_v2.get_data?hand_id=KYD006372197 $\&$ rep_year $=2009 \&$ naic_code $=\&$ naic_code_desc $=\& y v a l u e=2009 \& \mathrm{mopt}=0 \& \mathrm{mmo}$ $\mathrm{pt}=\&$ wst_search $=0 \&$ keyword $1=\&$ keyword $2=\&$ keyword $3=\&$ rvalue $1=\&$ rvalue $2=$ \&rvalue $3=\&$ cvalue $1=\&$ cvalue $2=\&$ cvalue $3=$. Accessed February 16, 2018.

81. United States Environmental Protection Agency. BR Facility Summary Report: Atkemix Ten Inc. 2011.

https://oaspub.epa.gov/enviro/brs_report_v2.get_data?hand_id=KYD006372197 $\&$ rep_year $=2011 \&$ naic_code $=\&$ naic_code_desc $=\& y v a l u e=2011 \&$ mopt $=0 \& \mathrm{mmo}$ $\mathrm{pt}=\&$ wst_search $=0 \&$ keyword $1=\&$ keyword $2=\&$ keyword $3=\&$ rvalue $1=\&$ rvalue $2=$ \&rvalue $3=\&$ cvalue $1=\&$ cvalue2 $=\&$ cvalue $3=$. Accessed February 16, 2018.

82. United States Environmental Protection Agency. BR Facility Summary Report: Atkemix Ten Inc. 2013. https://oaspub.epa.gov/enviro/brs_report_v2.get_data?hand_id=KYD006372197 \&rep_year $=2013 \&$ naic_code $=\&$ naic_code_desc $=\& y$ value $=2013 \&$ mopt $=0 \& \mathrm{mmo}$ 
$\mathrm{pt}=\&$ wst_search $=0 \&$ keyword $1=\&$ keyword $2=\&$ keyword $3=\&$ rvalue $1=\&$ rvalue $2=$ \&rvalue $3=\&$ cvalue $1=\&$ cvalue $=\&$ cvalue $3=$. Accessed February 16, 2018.

83. United States Environmental Protection Agency. BR Facility Summary Report: Atkemix Ten Inc. 2015. https://oaspub.epa.gov/enviro/brs_report_v2.get_data?hand_id=KYD006372197 $\&$ rep_year $=2015 \&$ naic_code $=\&$ naic_code_desc $=\& y$ value $=2015 \& \mathrm{mopt}=0 \& \mathrm{mmo}$ $\mathrm{pt}=\&$ wst $\mathrm{search}=0 \&$ keyword $1=\&$ keyword $2=\&$ keyword $3=\&$ rvalue $1=\&$ rvalue $2=$ \&rvalue $3=\&$ cvalue $1=\&$ cvalue $2=\&$ cvalue $3=$. Accessed February 16, 2018.

84. United States Environmental Protection Agency. TRI Facility Report: Superior Solvents \& Chemicals (40216SPRRS4211B), Facility Information. https://www3.epa.gov/enviro/facts/tri/ef-facilities/\#/Facility/40216SPRRS4211B. Accessed January 31, 2018.

85. United States Environmental Protection Agency. TRI Facility Report: Superior Solvents \& Chemicals (40216SPRRS4211B), Releases of TRI Chemicals to the Environment. https://www3.epa.gov/enviro/facts/tri/effacilities/\#/Release/40216SPRRS4211B. Accessed January 31, 2018.

86. United States Environmental Protection Agency. TRI Facility Report: MPLX Terminals LLC - Louisville Kramers KY Terminal (40216LSVLL3920K), Facility Information. https://www3.epa.gov/enviro/facts/tri/effacilities/\#/Facility/40216LSVLL3920K. Accessed January 31, 2018.

87. United States Environmental Protection Agency. TRI Facility Report: MPLX Terminals LLC - Louisville Kramers KY Terminal (40216LSVLL3920K), Releases of TRI Chemicals to the Environment. https://www3.epa.gov/enviro/facts/tri/ef-facilities/\#/Release/40216LSVLL3920K. Accessed January 31, 2018.

88. United States Environmental Protection Agency. TRI Facility Report: American Synthetic Rubber Co (40216MRCNS4500C), Releases of TRI Chemicals to the Environment. https://www3.epa.gov/enviro/facts/tri/effacilities/\#/Release/40216MRCNS4500C. Accessed January 31, 2018.

89. United States Environmental Protection Agency. TRI Facility Report: Arkema Inc Louisville Plant (40216LFTCH4350C), Facility Information. https://www3.epa.gov/enviro/facts/tri/ef-facilities/\#/Facility/40216LFTCH4350C. Accessed January 31, 2018.

90. Karman JR. Arkema scaling back plans for West Louisville plant. Louisville Business First, 2005. https://www.bizjournals.com/louisville/stories/2005/12/12/daily33.html. Accessed February 12, 2018.

91. United States Environmental Protection Agency. TRI Facility Report: Arkema Inc Louisville Plant (40216LFTCH4350C), Releases of TRI Chemicals to the 
Environment. https://www3.epa.gov/enviro/facts/tri/ef-

facilities/\#/Release/40216LFTCH4350C. Accessed January 31, 2018.

92. United States Environmental Protection Agency. TRI Facility Report: Rohm \& Haas Louisville Plant (40216RHMND4300C), Facility Information. https://www3.epa.gov/enviro/facts/tri/effacilities/\#/Facility/40216RHMND4300C. Accessed January 31, 2018.

93. United States Environmental Protection Agency. Envirofacts Report: Rohm \& Haas Louisville Plant. https://oaspub.epa.gov/enviro/tris_control_v2.tris_print?tris_id=40216RHMND43 00C\&pPrev=1. Accessed January 31, 2018.

94. United States Environmental Protection Agency. TRI Facility Report: Chemours Louisville Plant (40216DPNTL4200C), Facility Information.

https://www3.epa.gov/enviro/facts/tri/ef-facilities/\#/Facility/40216DPNTL4200C. Accessed January 31, 2018.

95. United States Environmental Protection Agency. TRI Facility Report: Chemours Louisville Plant (40216DPNTL4200C), . https://www3.epa.gov/enviro/facts/tri/ef-facilities/\#/Release/40216DPNTL4200C. Accessed January 31, 2018.

96. McConnell R. Residents seek change from industrial zoning. Courier-Journal. December 9, 1971:C1.

97. Northern R. An industrial area out of the ordinary. Courier-Journal. September 23, 1971:C1.

98. Riverside Gardens zoning hearing scheduled today. Courier-Journal:B14.

99. Bruggers J. Explosions rocked DuPont plant 50 years ago. Courier-Journal. August 25, 2015. https://www.courier-journal.com/story/tech/science/watchdogearth/2015/08/25/explosions-rocked-dupont-plant-50-years-ago/32347111/. Accessed February 12, 2018.

100. Rossano AT. The Joint City, County, State and Federal Study of Air Pollution in Louisville. J Air Pollut Control Assoc. 1956;6(3):176-181.

101. Bruggers J. Louisville slaps chemical plant with big fine, saying failures caused too much pollution. Courier-Journal. March 14, 2018. https://www.courierjournal.com/story/tech/science/environment/2018/03/14/hexion-chemical-plantfine-louisville/424915002/. Accessed July 25, 2018.

102. Bruggers J. Sixty years of coal burning ends at LG\&E plant. Courier-Journal. July 6, 2015.

103. E.On U.S. Jefferson County Coal Ash Storage Facility Update. 
104. Adnams KE, Stellato AP, Harris WA. Assessment of Dam Safety Coal Combustion Surface Impoundments (Task 3) Final Report: Cane Run Power Station. 2010.

105. Louisville Gas \& Electric Company. CCR Fugitive Dust Control Plan - Cane Run Generating Station. 2015.

106. Louisville Gas \& Electric. Closing and capping our ash ponds and other impoundments. https://lge-ku.com/environment/land-and-water-quality/cap-andclosing. Accessed November 3, 2018.

107. Herron DE. Notification of Closure: Ash Pond. October 30, 2017. https://ccr.lgeku.com/CR/ATB/CPCC. Accessed January 31, 2018.

108. United States Environmental Protection Agency. Fact sheet: Coal combstion residuals (CCR) surface impoundments with high hazard potential ratings. 2009. EPA Publication No. EPA530-F-09-006.

109. Hazardous and Solid Waste Management System. Disposal of Coal Combustion Residuals from Electric Utilities. 80 CFR Parts 257 and 261. 2015.

110. Adriano DC, Page AL, Elseewi AA, Chang AC, Straughan I. Utilization and disposal of fly ash and other coal residues in terrestrial ecosystems: A review. $J$ Environ Qual. 1980;9(3):333-344.

111. Brown $\mathrm{P}$, Jones $\mathrm{T}$, BeruBe $\mathrm{K}$. The internal microstructure and fibrous mineralogy of fly ash from coal-burning power stations. Environ Pollut. 2011;159(12):33243333.

112. el-Mogazi D, Lisk DJ, Weinstein LH. A review of physical, chemical, and biological properties of fly ash and effects on agricultural ecosystems. Sci Total Environ. 1988;74:1-37.

113. Roy WR, Thiery RG, Schuller RM, Suloway JJ. Coal fly ash: a review of the literature and proposed classification system with emphasis on environmental impacts. Illinois State Geological Survey Environmental Geology Notes, No. 96. Champaign, IL: Illinois State Geological Survey; 1981.

114. Roper AR, Stabin MG, Delapp RC, Kosson DS. Analysis of naturally-occurring radionuclides in coal combustion fly ash, gypsum, and scrubber residue samples. Health Phys. 2013;104(3):264-269.

115. Tang D, Li TY, Liu JJ, et al. Effects of prenatal exposure to coal-burning pollutants on children's development in China. Environ Health Perspect. 2008;116(5):674-679.

116. American Coal Ash Association. Coal ash recycling reaches record 56 percent amid shifting production and use patterns. 2017. https://www.acaa- 
usa.org/Portals/9/Files/PDFs/News-Release-Coal-Ash-Production-and-Use2016.pdf.

117. Patra KC, Rautray TR, Tripathy BB, Nayak P. Elemental analysis of coal and coal ASH by PIXE technique. Appl Radiat Isot. 2012;70(4):612-616.

118. World Health Organization Europe. Heath risks of particulate matter from longrange transboundary air pollution. Copenhagen, Denmark: WHO; 2006.

119. United States Environmental Protection Agency. Frequent questions about the Coal Ash Disposal Rule. 2017. https://www.epa.gov/coalash/frequent-questionsabout-coal-ash-disposal-rule. Accessed February 27, 2018.

120. Sonka J. Washing away the gray. Leo Weekly. August 17, 2011. https://www.leoweekly.com/2011/08/washing-away-the-gray/. Accessed February $11,2018$.

121. Oberdorster G, Oberdorster E, Oberdorster J. Nanotoxicology: An emerging discipline evolving from studies of ultrafine particles. Environ Health Perspect. 2005;113(7):823-839.

122. Spencer LLS, Drake LD. Hydrogeology of an alkaline fly ash landfill in eastern Iowa. Groundwater. 1987;25(5):519-526.

123. United States Environmental Protection Agency. TRI Facility Report: Louisville Gas \& Electric Co - Cane Run Station (40216LSVLL5252C), Releases of TRI Chemicals to the Environment. https:/www3.epa.gov/enviro/facts/tri/effacilities/\#/Release/40216LSVLL5252C. Accessed January 31, 2018.

124. International Agency for Research on Cancer. IARC Monographs on the Evaluation of Carcinogenic Risks to Humans, Volume 100C. Arsenic, Metals, Fibres and Dust. Lyon, France: IARC; 2012.

125. International Agency for Research on Cancer. IARC Monographs on the Evaluation of Carcinogenic Risks to Humans, Volume 100F. Chemical Agents and Related Occupations. Lyon, France: IARC; 2012.

126. International Agency for Research on Cancer. IARC Monographs on the Evaluation of Carcinogenic Risks to Humans, Volume 107. Polychlorinated Biphenyls and Polybrominated Biphenyls. Lyon, France: IARC; 2016.

127. International Agency for Research on Cancer. IARC Monographs on the Evaluation of Carcinogenic Risks to Humans, Volume 106. Trichloroethylene, Tetrachloroethylene, and Some Other Chlorinated Agents. Lyon, France: IARC; 2014.

128. IARC: Outdoor air pollution a leading environmental cause of cancer deaths [press release]. 2013. 
129. National Toxicology Program, Department of Health and Human Services, Public Health Service, National Toxicology Program. Report on Carcinogens, Fourteenth Edition. 2016.

130. New Jersey Department of Health and Senior Services. Hazardous Susbtance Fact Sheet: Benzo(b)fluoranthene. 2001.

131. New Jersey Department of Health and Senior Services. Hazardous Substance Fact Sheet: Benzo(k)fluoranthene. 2002.

132. Agency for Toxic Substances and Disease Registry, U.S. Department of Health and Human Services, Public Health Service. Toxicological profile for carbon tetrachloride. Atlanta, GA: ATSDR; 2005.

133. Agency for Toxic Substances and Disease Registry, U.S. Department of Health and Human Services, Public Health Service. Toxicological profile for chloroform. Atlanta, GA: ATSDR; 1997.

134. Agency for Toxic Substances and Disease Registry, U.S. Department of Health and Human Services, Public Health Service. Toxicological profile for acrylonitrile. Atlanta, GA: ATSDR; 1999.

135. International Agency for Research on Cancer. IARC Monographs on the Evaluation of Carcinogenic Risks to Humans, Volume 101. Some Chemicals Present in Industrial and Consumer Products, Food and Drinking-water. Lyon, France: IARC; 2013.

136. International Agency for Research on Cancer. IARC Monographs on the Evaluation of Carcinogenic Risks to Humans, Volume 77. Some Industrial Chemicals. Lyon, France: IARC; 2000.

137. International Agency for Research on Cancer. IARC Monographs on the Evaluation of Carcinogenic Risks to Humans, Volume 73. Some Chemicals that Cause Tumours of the Kidney or Urinary Bladder in Rodents and Some Other Substances. Lyon, France: IARC; 1999.

138. Agency for Toxic Substances and Disease Registry, U.S. Department of Health and Human Services, Public Health Service. Toxicological profile for lead. Atlanta, GA: ATSDR; 2007.

139. International Agency for Research on Cancer. IARC Monographs on the Evaluation of Carcinogenic Risks to Humans, Volume 87. Inorganic and Organic Lead Compounds. Lyon, France: IARC; 2006.

140. International Agency for Research on Cancer. IARC Monographs on the Evaluation of Carcinogenic Risks to Humans, Volume 71. Re-evaluation of Some Organic Chemicals, Hydrazine and Hydrogen Peroxide. Lyon, France: IARC; 1999. 
141. International Agency for Research on Cancer. IARC Monographs on the Evaluation of Carcinogenic Risks to Humans, Volume 82. Some Traditional Herbal Medicines, Some Myotoxins, Naphthalene and Styrene. Lyon, France: IARC; 2002.

142. International Agency for Research on Cancer. IARC Monographs on the Evaluation of Carcinogenic Risks to Humans, Volume 97. 1,3-Butadiene, Ethylene Oxide and Vinyl Halides (Vinyl Fluoride, Vinyl Chloride and Vinyl Bromide). Lyon, France: IARC; 2008.

143. Agency for Toxic Substances and Disease Registry, U.S. Department of Health and Human Services, Public Health Service. Toxicological profile for chromium. Atlanta, GA: ATSDR; 2012.

144. Agency for Toxic Substances and Disease Registry, U.S. Department of Health and Human Services, Public Health Service. Toxicological profile for ammonia. Atlanta, GA: ATSDR; 2004.

145. Agency for Toxic Substances and Disease Registry, U.S. Department of Health and Human Services, Public Health Service. Toxicological profile for formaldehyde. Atlanta, GA: ATSDR; 2015.

146. Pope CA, 3rd. Epidemiology of fine particulate air pollution and human health: biologic mechanisms and who's at risk? Environ Health Perspect. 2000;108 Suppl 4(Suppl 4):713-723.

147. Gottlieb B, Gilbert SG, Evans LG. Coal Ash: The toxic threat to our health and environment. A Report from Physicians for Social Responsibility and Earthjustice. 2010.

148. Agency for Toxic Substances and Disease Registry, U.S. Department of Health and Human Services, Public Health Service. Toxicological profile for 1,3butadiene. Atlanta, GA: ATSDR; 2009.

149. Agency for Toxic Substances and Disease Registry, U.S. Department of Health and Human Services, Public Health Service. Toxicological profile for dichlorobenzenes. Atlanta, GA: ATSDR; 2006.

150. Agency for Toxic Substances and Disease Registry, U.S. Department of Health and Human Services, Public Health Service. Toxicological profile for benzene. Atlanta, GA: ATSDR; 2007.

151. Agency for Toxic Substances and Disease Registry, U.S. Department of Health and Human Services, Public Health Service. Toxicological profile for arsenic. Atlanta, GA: ATSDR; 2007. 
152. Agency for Toxic Substances and Disease Registry, U.S. Department of Health and Human Services, Public Health Service. Toxicological profile for xylene. Atlanta, GA: ATSDR; 2007.

153. Agency for Toxic Substances and Disease Registry, U.S. Department of Health and Human Services, Public Health Service. Toxicological profile for 2-butanone. Atlanta, GA: ATSDR; 1995.

154. Agency for Toxic Substances and Disease Registry, U.S. Department of Health and Human Services, Public Health Service. Toxicological profile for methyl tertbutyl ether. Atlanta, GA: ATSDR; 1997.

155. Agency for Toxic Substances and Disease Registry, U.S. Department of Health and Human Services, Public Health Service. Toxicological profile for sodium hydroxide. Atlanta, GA: ATSDR; 2002.

156. Schikowski T, Sugiri D, Ranft U, et al. Long-term air pollution exposure and living close to busy roads are associated with COPD in women. Respir Res. 2005;6:152.

157. Agency for Toxic Substances and Disease Registry, U.S. Department of Health and Human Services, Public Health Service. Toxicological profile for barium. Atlanta, GA: ATSDR; 2013.

158. Agency for Toxic Substances and Disease Registry, U.S. Department of Health and Human Services, Public Health Service. Toxicological profile for thallium. Atlanta, GA: ATSDR; 2013.

159. Agency for Toxic Substances and Disease Registry, U.S. Department of Health and Human Services, Public Health Service. Toxicological profile for trichloroethylene (TCE). Atlanta, GA: ATSDR; 2016.

160. Agency for Toxic Substances and Disease Registry, U.S. Department of Health and Human Services, Public Health Service. Toxicological profile for 1,2dichloroethane. Atlanta, GA: ATSDR; 2001.

161. Agency for Toxic Substances and Disease Registry, U.S. Department of Health and Human Services, Public Health Service. Toxicological profile for vinyl chloride. Atlanta, GA: ATSDR; 2006.

162. Cosselman KE, Navas-Acien A, Kaufman JD. Environmental factors in cardiovascular disease. Nat Rev Cardiol. 2015;12(11):627-642.

163. Brook RD, Rajagopalan S, Pope CA, 3rd, et al. Particulate matter air pollution and cardiovascular disease: An update to the scientific statement from the American Heart Association. Circulation. 2010;121(21):2331-2378. 
164. Agency for Toxic Substances and Disease Registry, U.S. Department of Health and Human Services, Public Health Service. Toxicological profile for naphthalene, 1-methylnapthalene, and 2-methylnapthalene. Atlanta, GA: ATSDR; 2005.

165. Agency for Toxic Substances and Disease Registry, U.S. Department of Health and Human Services, Public Health Service. Toxicological profile for cadmium. Atlanta, GA: ATSDR; 2012.

166. Agency for Toxic Substances and Disease Registry, U.S. Department of Health and Human Services, Public Health Service. Toxicological profile for mercury. Atlanta, GA: ATSDR; 1999.

167. Agency for Toxic Substances and Disease Registry, U.S. Department of Health and Human Services, Public Health Service. Toxicological profile for tetrachloroethylene (PERC). Atlanta, GA: ATSDR; 2014.

168. Agency for Toxic Substances and Disease Registry, U.S. Department of Health and Human Services, Public Health Service. Public Health Statement Aldrin and Dieldrin. 2002.

169. Agency for Toxic Substances and Disease Registry, U.S. Department of Health and Human Services, Public Health Service. Toxicological profile for phenol. Atlanta, GA: ATSDR; 2008.

170. Agency for Toxic Substances and Disease Registry, U.S. Department of Health and Human Services, Public Health Service. Toxicological profile for acetone. Atlanta, GA: ATSDR; 1994.

171. Agency for Toxic Substances and Disease Registry, U.S. Department of Health and Human Services, Public Health Service. Toxicological profile for n-hexane. Atlanta, GA: ATSDR; 1999.

172. Agency for Toxic Substances and Disease Registry, U.S. Department of Health and Human Services, Public Health Service. Toxicological profile for manganese. Atlanta, GA: ATSDR; 2012.

173. United States Environmental Protection Agency. TRI Facility Report: Hexion Inc (40216BRDNN6200C), Chemicals and Associated Health Effects. https://www3.epa.gov/enviro/facts/tri/effacilities/\#/Chemical/40216BRDNN6200C. Accessed January 31, 2018.

174. Zanobetti A, Redline S, Schwartz J, et al. Associations of PM10 with sleep and sleep-disordered breathing in adults from seven U.S. urban areas. Am J Respir Crit Care Med. 2010;182(6):819-825. 
175. Tyler CR, Allan AM. The effects of arsenic exposure on neurological and cognitive dysfunction in human and rodent studies: A review. Curr Environ Health Rep. 2014;1(2):132-147.

176. Agency for Toxic Substances and Disease Registry, U.S. Department of Health and Human Services, Public Health Service. Toxicological profile for polychlorinated biphenyls (PCBs). Atlanta, GA: ATSDR; 2014.

177. Integrated Risk Information System, National Center for Environmental Assessment, Office of Research and Development, U.S. Environmental Protection Agency. Toxicological review of benzo(a)pyrene. Washington, DC: IRIS; 2017.

178. Baker DB, Greenland S, Mendlein J, Harmon P. A health study of two communities near the Stringfellow Waste Disposal site. Arch Environ Health. 1988;43(5):325-334.

179. Dayal H, Gupta S, Trieff N, Maierson D, Reich D. Symptom clusters in a community with chronic exposure to chemicals in two superfund sites. Arch Environ Health. 1995;50(2):108-111.

180. Lipscomb JA, Goldman LR, Satin KP, Smith DF, Vance WA, Neutra RR. A follow-up study of the community near the McColl waste disposal site. Environ Health Perspect. 1991;94:15-24.

181. Logue JN, Fox JM. Residential health study of families living near the Drake Chemical Superfund site in Lock Haven, Pennsylvania. Arch Environ Health. 1986;41(4):222-228.

182. Miller MS, McGeehin MA. Reported health outcomes among residents living adjacent to a hazardous waste site, Harris County, Texas, 1992. Toxicol Ind Health. 1997;13(2-3):311-319.

183. Hertzman C, Hayes M, Singer J, Highland J. Upper Ottawa street landfill site health study. Environ Health Perspect. 1987;75:173-195.

184. Dunne MP, Burnett P, Lawton J, Raphael B. The health effects of chemical waste in an urban community. Med J Aust. 1990;152(11):592-597.

185. Najem GR, Strunck T, Feuerman M. Health effects of a Superfund hazardous chemical waste disposal site. Am J Prev Med. 1994;10(3):151-155.

186. Byers VS, Levin AS, Ozonoff DM, Baldwin RW. Association between clinical symptoms and lymphocyte abnormalities in a population with chronic domestic exposure to industrial solvent-contaminated domestic water supply and a high incidence of leukaemia. Cancer Immunol Immunother. 1988;27(1):77-81. 
187. Paigen B, Goldman LR, Highland J, Magnant MM, Steegman AT. Prevalence of Health Problems in Children Living Near Love Canal. Hazardous Waste \& Hazardous Materials. 1985;2(1):23-43.

188. Ozonoff D, Colten ME, Cupples A, et al. Health problems reported by residents of a neighborhood contaminated by a hazardous waste facility. Am J Ind Med. 1987;11(5):581-597.

189. Carpenter DO, Shen Y, Nguyen T, Le L, Lininger LL. Incidence of endocrine disease among residents of New York areas of concern. Environ Health Perspect. 2001;109 Suppl 6:845-851.

190. Kihal-Talantikite W, Zmirou-Navier D, Padilla C, Deguen S. Systematic literature review of reproductive outcome associated with residential proximity to polluted sites. Int J Health Geogr. 2017;16(1):20.

191. Fazzo L, Minichilli F, Santoro M, et al. Hazardous waste and health impact: a systematic review of the scientific literature. Environ Health. 2017;16(1):107.

192. New York State Department of Public Health. Love Canal: A Special Report to the Governor and Legislature. 1981.

193. University of Buffalo. Love Canal Chronologies: The Niagara Gazette Love Canal Chronology, 1894 - May 1980.

https://library.buffalo.edu/archives/lovecanal/about/chronologies.html. Accessed April 7, 2018.

194. Engelhaupt E. Happy birthday, Love Canal. Environ Sci Technol. 2008;42(22):8179-8186.

195. Division of Environmental Health Assessment, Center for Environmental Health, New York State Department of Health. Love Canal Follow-Up Health Study. 2008.

196. Heath CW, Nadel MR, Zack MM, Chen ATL, Bender MA, Preston RJ. Cytogenetic Findings in Persons Living Near the Love Canal. JAMA. 1984;251(11):1437-1440.

197. Vianna NJ, Polan AK. Incidence of Low Birth Weight Among Love Canal Residents. Science. 1984;226:1217-1219.

198. Goldman LR, Paigen B, Magnant MM, Highland JH. Low Birth Weight, Prematurity and Birth Defects in Children Living Near the Hazardous Waste Site, Love Canal. Hazardous Waste \& Hazardous Materials. 1985;2(2):209-223.

199. Austin AA, Fitzgerald EF, Pantea CI, et al. Reproductive outcomes among former Love Canal residents, Niagara Falls, New York. Environ Res. 2011;111(5):693701. 
200. Gensburg LJ, Pantea C, Fitzgerald E, Stark A, Hwang SA, Kim N. Mortality among former Love Canal residents. Environ Health Perspect. 2009;117(2):209216.

201. Gensburg LJ, Pantea C, Kielb C, Fitzgerald E, Stark A, Kim N. Cancer incidence among former Love Canal residents. Environ Health Perspect. 2009;117(8):12651271.

202. Maslia ML, Reyes JJ, Gillig RE, Sautner JB, Fagliano JA, Aral MM. Public health partnerships addressing childhood cancer investigations: case study of Toms River, Dover Township, New Jersey, USA. Int J Hyg Environ Health. 2005;208(1-2):45-54.

203. Hazardous Site Health Evaluation Program, Consumer and Environmental Health Services, Division of Epidemiology, Environmental and Occupational Health New Jersey Department of Health and Senior Services. Public Health Assessment: Ciba-Geigy Corporation CERCLIS Number: NJD001502517. 2001.

204. United States Environmental Protection Agency. Fourth Five-Year Review Report for Ciba-Geigy Chemical Corporation Superfund Site, Ocean County, New Jersey. 2018.

205. Mikle J. Toms River cancer cluster: Will environmental rollbacks bring back 'toxic' town? Asbury Park Press 2018; https://www.app.com/story/news/local/land-environment/2018/08/14/toms-rivercancer-cluster-environmental-rollbacks-ciba-geigy/619144002/. Accessed October 25, 2018.

206. United States Environmental Protection Agency. Superfund Site: Reich Farms Pleasant Plains, NJ, Cleanup Activities. 2018; https://cumulis.epa.gov/supercpad/SiteProfiles/index.cfm?fuseaction=second.Clea nup\&id=0200662\#bkground. Accessed October 29, 2018.

207. United States Environmental Protection Agency. Fourth Five-Year Review Report for the Reich Farm Superfund Site, Ocean County, NJ. 2018.

208. New Jersey Department of Health and Senior Services and the Agency for Toxic Substances and Disease Registry. Dover Township Childhood Cancer Investigation: Public Health Response Progress Report. 2001.

209. Hazardous Site Health Evaluation Program, Consumer and Environmental Health Service, Division of Epidemiology, Environmental and Occupational Health, The New Jersey Department of Health and Senior Services. Public Health Assessment: Dover Township Municipal Landfill CERCLIS Number: NJD980771570 and the Silverton Private Well Contamination Investigation CERCLIS Number: NJD981877780 Dover Township, Ocean County, New Jersey. 2001. 
210. New Jersey Department of Health and the Agency for Toxic Substances and Disease Registry. Dover Township Childhood Cancer Investigation Public Health Response Plan. 1996.

211. Division of Environmental and Occupational Health Services, Consumer and Environmental Health Services. Childhood cancer incidence health consultation: A review and analysis of cancer registry data, 1979-1995 for Dover Township (Ocean County), New Jersey. 1997.

212. Division of Epidemiology, Environmental and Occupational Health, New Jersey Department of Health and Senior Services. Case-control Study of Childhood Cancers in Dover Township (Ocean County), New Jersey Volume II: Final Technical Report. 2003.

213. United States Environmental Protection Agency. Chemours Pompton Lakes Works Site, Pompton Lakes, NJ. 2018; https://www.epa.gov/nj/chemourspompton-lakes-works-site-pompton-lakes-nj. Accessed October 12, 2018.

214. New Jersey Department of Health. Health Consultation: Community Health Profile, DuPont Pompton Lakes Works Site, Pompton Lakes, Passaic County, New Jersey, EPA Facility ID: NJD980771604. 2014.

215. New Jersey Department of Health and Senior Services. Health Consultation: Analysis of cancer incidence in the Pompton Lakes neighborhood impacted by the DuPont groundwater contamination, Pompton Lakes, Passaic County, New Jersey, EPA Facility ID: NJD980771604. 2009.

216. Environmental and Occupational Health Surveillance Program Consumer, Environmental and Occupational Health Service, Division of Epidemiology, Environmental and Occupational Health, New Jersey Department of Health. Health Consultation: Synthesis Report of a Community Health Profile and Household Health Survey, Pompton Lakes, New Jersey. 2014.

217. New Jersey Department of Health. Health Consultation: Report of a Household Health Sruvey Groundwater Contamination Area, Pompton Lakes, New Jersey. 2014.

218. O’Neill JM. Like Christie, Murphy's DEP says no to Superfund for Pompton Lakes cleanup. North Jersey. June 3, 2018. https://www.northjersey.com/story/news/2018/06/03/dep-opposes-superfundcleanup-dupont-pollution-pompton-lakes/665156002/. Accessed October 23, 2018

219. Riggiola L. DuPont Pompton Lakes Works Contaminated Sites/Neighborhoods, Pompton Lakes, New Jersey. March 16, 2012. https://iavi.rti.org/attachments/WorkshopsAndConferences/05_Riggiola_CCPL_I ssues_Pres_final_3-16-12.pd. Accessed April 1, 2018. 
220. O'Neill JM. Like Christie, Murphy's DEP says no to Superfund for Pompton Lakes cleanup. June 3, 2018.

https://www.northjersey.com/story/news/2018/06/03/dep-opposes-superfundcleanup-dupont-pollution-pompton-lakes/665156002/. Accessed February 2, 2019.

221. Patton MQ. Qualitative Evaluation and Research Methods. 3rd ed. Thousand Oaks, CA: Sage; 2002.

222. Braun V, Clarke V. Using thematic analysis in psychology. Qual Res Psychol. 2006;3(2):77-101.

223. Friese S, Soratto J, Pires D. Carrying out a computer-aided thematic content analysis with ATLAS.ti. Göttingen, Germany; 2018.

224. United States Environmental Protection Agency. Superfund Records Collections. https://www.epa.gov/superfund/search-superfund-documents. Accessed February $16,2018$.

225. United States Environmental Protection Agency. Toxics Release Inventory (TRI) Program. 2016. https://www.epa.gov/toxics-release-inventory-tri-program. Accessed January 31, 2018.

226. United States Environmental Protection Agency. Biennial Report Summary. https://rcrainfo.epa.gov/rcrainfoweb/action/modules/br/summary/view. Accessed February 16, 2018.

227. Louisville Gas \& Electric. CCR Rule Compliance Data and Information. https://ccr.lge-ku.com/. Accessed February 10, 2018.

228. United States Environmental Protection Agency. Toxics Release Inventory (TRI) Program: TRI-Listed Chemicals. 2018. https://www.epa.gov/toxics-releaseinventory-tri-program/tri-listed-chemicals. Accessed July 6, 2018.

229. Stantec Consulting Services Inc. Notification of Closure: Ash Pond. 2017. https://ccr.lge-ku.com/CR/ATB/CPCC. Accessed January 31, 2018.

230. Stantec Consulting Services Inc. Notification of Intent to Close - Inactive CCR Unit. 2016. https://ccr.lge-ku.com/CR/ATB/CPCC. Accessed January 31, 2018.

231. Louisville Gas \& Electric Company. Annual CCR Fugitive Dust Control Report Cane Run Generating Station. 2017.

232. Louisville Gas \& Electric Company. Annual CCR Fugitive Dust Control Plan Cane Run Generating Station. 2016.

233. Hollenbach expected at Riverside meeting. Courier-Journal. March 17, 1970:B3. 
234. Kentucky Cancer Registry. Age-Adjusted Cancer Incidence Rates in Kentucky. https://www.cancer-rates.info/ky/. Accessed May 8, 2018.

235. Centers for Disease Control and Prevention. Behavioral Risk Factor Surveillance System (BRFSS): 2016 BRFSS Survey Data and Documentation. 2017. https://www.cdc.gov/brfss/annual_data/annual_2016.html. Accessed February 22, 2018.

236. Centers for Disease Control and Prevention, National Center for Health Statistics. National Health and Nutrition Examination Survey (NHANES) 2015-2016 Survey Questionnaires. https://wwwn.cdc.gov/nchs/nhanes/ContinuousNhanes/questionnaires.aspx?Begin Year=2015. Accessed February 22, 2018.

237. Centers for Disease Control and Prevention, National Center for Health Statistics. National Health Interview Survey: 2016 Data Release. 2017. https://www.cdc.gov/nchs/nhis/nhis_2016_data_release.htm. Accessed February 22, 2018.

238. Substance Abuse and Mental Health Services Administration (SAMHSA), U.S. Department of Health and Human Services. Population Data / NSDUH. 2016. https://www.samhsa.gov/data/population-data-nsduh.

239. Institute for Social Research, University of Michigan. The Health and Retirement Study. http://hrsonline.isr.umich.edu/. Accessed February 26, 2018.

240. Centers for Disease Control and Prevention, National Center for Health Statistics. National Survey of Family Growth. https://www.cdc.gov/nchs/nsfg/index.htm. Accessed March 2, 2018.

241. Harvard Medical School. National Comorbidity Survey (NCS). https://www.hcp.med.harvard.edu/ncs/index.php. Accessed March 1, 2018.

242. National Sleep Foundation. Sleep Health Index. https://sleepfoundation.org/howamerica-sleeps. Accessed March 5, 2018.

243. Agency for Toxic Substances and Disease Registry. Exposure History Form. https://www.atsdr.cdc.gov/csem/exphistory/docs/CSEMExposHist-26-29.pdf. Accessed February 16, 2018.

244. OpenStreetMap. https://www.openstreetmap.org/. Accessed January 12, 2019.

245. Klein RJ, Schoenborn CA. Age adjustment using the 2000 projected U.S. population. Healthy People 2010 statistical notes, no 20. Hyattsville, MD: U.S. Department of Health and Human Services, Centers for Disease Control and Prevention, National Center for Health Statistics; 2001. 
246. Klein RJ, Proctor SE, Boudreault MA, Turczyn KM. Healthy People 2010 criteria for data suppression, no 24. Hyattsville, MD: US Department of Health and Human Services, Centers for Disease Control and Prevention, National Center for Health Statistics; 2002.

247. National Center for Health Statistics. International Statistical Classification of Diseases and Related Health Problems, 10th Revision, Clinical Modification. 2019. https://www.cdc.gov/nchs/icd/icd10cm.htm. Accessed January 31, 2019.

248. Hosmer DW, Lemeshow S. Applied Logistic Regression. 2nd ed. New York: John Wiley \& Sons; 2000.

249. Jewell NP. Statistics for Epidemiology. Boca Raton, Florida: CRC Press; 2004.

250. Kiel KA, Williams M. The impact of Superfund sites on local property values: Are all sites the same? J Urban Econ. 2007;61(1):170-192.

251. Reichert AK, Small M, Mohanty S. The impact of landfills on residential property values. J Real Estate Res. 1992;7(3):297-314.

252. Deaton B, Hoehn J. The effect of hazardous waste sites on property values in zones of high industrial activity: A hedonic approach. American Agricultural Economics Association (AAEA) Annual Meeting; 2002; Long Beach, CA, USA.

253. Gibbs L. Community response to an emergency situation: Psychological destruction and the Love Canal. Am J Community Psychol. 1983;11(2):116-125.

254. Matthies E, Höger R, Guski R. Living on Polluted Soil: Determinants of Stress Symptoms. Environ Behav. 2000;32(2):270-286.

255. Downey L, Van Willigen M. Environmental Stressors: The Mental Health Impacts of Living Near Industrial Activity\&quot;17. J Health Soc Behav. 2005;46(3):289-305.

256. U.S. Department of Health and Human Services. The Health Consequences of Smoking-50 Years of Progress: A Report of the Surgeon General. Atlanta: U.S. Deparment of Health and Human Services, Centers for Disease Control and Prevention, National Center for Chronic Disease Prevention and Health Promotion, Office on Smoking and Health; 2014.

257. Centers for Disease Control and Prevention. State Tobacco Activities Tracking and Evaluation (STATE) System: Current Cigarette Use Among Adults (Behavior Risk Factor Surveillance System) 2017. 2018. https://www.cdc.gov/statesystem/cigaretteuseadult.html. Accessed February 27, 2019. 
258. Bouchard MF, Bellinger DC, Weuve J, et al. Blood lead levels and major depressive disorder, panic disorder, and generalized anxiety disorder in US young adults. Archives of general psychiatry. 2009;66(12):1313-1319.

259. Gonzalez-Estecha M, Trasobares EM, Tajima K, et al. Trace elements in bipolar disorder. J Trace Elem Med Biol. 2011;25 Suppl 1:S78-83.

260. Aschengrau A, Weinberg JM, Janulewicz PA, et al. Occurrence of mental illness following prenatal and early childhood exposure to tetrachloroethylene (PCE)contaminated drinking water: A retrospective cohort study. Environ Health. 2012;11:2.

261. Aschengrau A, Janulewicz PA, White RF, et al. Long-term neurotoxic effects of early-life exposure to tetrachloroethylene-contaminated drinking water. Ann Glob Health. 2016;82(1):169-179.

262. Shcherbatykh I, Huang X, Lessner L, Carpenter DO. Hazardous waste sites and stroke in New York State. Environ Health. 2005;4:18.

263. Park SH, Lim JE, Park H, Jee SH. Body burden of persistent organic pollutants on hypertension: a meta-analysis. Environ Sci Pollut Res Int. 2016;23(14):1428414293.

264. Bernatsky S, Smargiassi A, Barnabe C, et al. Fine particulate air pollution and systemic autoimmune rheumatic disease in two Canadian provinces. Environ Res. 2016;146:85-91.

265. Bernatsky S, Smargiassi A, Johnson M, et al. Fine particulate air pollution, nitrogen dioxide, and systemic autoimmune rheumatic disease in Calgary, Alberta. Environ Res. 2015;140:474-478.

266. Kilburn KH, Warshaw RH. Prevalence of symptoms of systemic lupus erythematosus (SLE) and of fluorescent antinuclear antibodies associated with chronic exposure to trichloroethylene and other chemicals in well water. Environ Res. 1992;57(1):1-9.

267. Lee D-H, Steffes M, Jacobs DR. Positive associations of serum concentration of polychlorinated biphenyls or organochlorine pesticides with self-reported arthritis, especially rheumatoid type, in women. Environ Health Perspect. 2007;115(6):883-888.

268. Mahmood NMA. Relationship between serum levels of some trace elements, disease duration and severity in patients with knee osteoarthritis. Pharmacol Pharm. 2015;6:489-495.

269. Nelson AE, Shi XA, Schwartz TA, et al. Whole blood lead levels are associated with radiographic and symptomatic knee osteoarthritis: a cross-sectional analysis 
in the Johnston County Osteoarthritis Project. Arthritis research \& therapy. 2011;13(2):R37-R37.

270. Logue JN, Stroman RM, Reid D, Hayes CW, Sivarajah K. Investigation of potential health effects associated with well water chemical contamination in Londonderry Township, Pennsylvania, U.S.A. Arch Environ Health. 1985;40(3):155-160.

271. Bush TL, Miller SR, Golden AL, Hale WE. Self-report and medical record report agreement of selected medical conditions in the elderly. Am J Public Health. 1989;79(11):1554-1556.

272. Haapanen N, Miilunpalo S, Pasanen M, Oja P, Vuori I. Agreement between questionnaire data and medical records of chronic diseases in middle-aged and elderly Finnish men and women. Am J Epidemiol. 1997;145(8):762-769.

273. Kriegsman DM, Penninx BW, van Eijk JT, Boeke AJ, Deeg DJ. Self-reports and general practitioner information on the presence of chronic diseases in community dwelling elderly. A study on the accuracy of patients' self-reports and on determinants of inaccuracy. J Clin Epidemiol. 1996;49(12):1407-1417.

274. Ye F, Moon DH, Carpenter WR, et al. Comparison of patient report and medical records of comorbidities: Results from a population-based cohort of patients with prostate cancer. JAMA Oncol. 2017;3(8):1035-1042.

275. De-loyde KJ, Harrison JD, Durcinoska I, Shepherd HL, Solomon MJ, Young JM. Which information source is best? Concordance between patient report, clinician report and medical records of patient co-morbidity and adjuvant therapy health information. J Eval Clin Pract. 2015;21(2):339-346.

276. Kilbourne AM, Schumacher K, Frayne SM, et al. Physical health conditions among a population-based cohort of Vietnam-era women veterans: Agreement between self-report and medical records. J Womens Health. 2017;26(11):12441251.

277. Mukerji SS, Duffy SA, Fowler KE, Khan M, Ronis DL, Terrell JE. Comorbidities in head and neck cancer: agreement between self-report and chart review. Otolaryngol Head Neck Surg. 2007;136(4):536-542.

278. Skinner KM, Miller DR, Lincoln E, Lee A, Kazis LE. Concordance between respondent self-reports and medical records for chronic conditions: experience from the Veterans Health Study. J Ambul Care Manage. 2005;28(2):102-110.

279. Brown P. The role of the evaluator in comprehensive community initiatives. Connell JP, Kubisch AC, Schorr LB, Weiss CH, eds. New Approaches to Evaluating Community Initiatives. Washington, DC: Aspen; 1995. 
280. Schulz AJ, Parker EA, Israel BA, Becker AB, Maciak BJ, Hollis R. Conducting a participatory community-based survey for a community health intervention on Detroit's east side. J Public Health Manag Pract. 1998;4(2):10-24.

281. Israel BA, Schulz AJ, Parker EA, Becker AB. Review of community-based research: assessing partnership approaches to improve public health. Annu Rev Public Health. 1998;19:173-202.

282. Tajik M, Minkler M. Environmental justice research and action: A case study in political economy and community-academic collaboration. Int $Q$ Community Health Educ. 2006;26(3):213-231.

283. Bach M, Jordan S, Hartung S, Santos-Hovener C, Wright MT. Participatory epidemiology: The contribution of participatory research to epidemiology. Emerg Themes Epidemiol. 2017;14:2. 
APPENDIX A: INTERVIEW GUIDE 
UofL Institutional Review Boards IRB NUMBER: 16.0843

IRB APPROVAL DATE: 10/31/2016

Interview Guide

RIVERSIDE GARDENS COMMUNITY HEALTH ASSESSMENT

\section{INTRODUCTION}

To begin, we would like to thank you for your participation in this interview. The purpose of our talk is to learn more about your experience as a member of the Riverside Gardens community. This interview, along with other community member interviews, will help to guide us in the creation of a detailed health questionnaire that will later be given to all members of the Riverside Gardens community.

During our talk, we will ask you about when you moved to Riverside Gardens, the community's history, the health of the community, exposures experienced by you and your neighbors, and your and your neighbors' health. We will tape record this interview so that we may review your responses again; however, your name will not be saved in connection with the tape recording. If you prefer, you can pick a name that is different from your name and use it throughout our talk. After our talk is over, we will transcribe the talk from the tape recorder so that we can make sure your answers are used in developing the health questionnaire. Your name will not be used. The only paper that has your name and the tape recording number will be in a locked filing cabinet in our locked offices.

We would like to remind you that all of the information you provide in this interview will be kept confidential. Your participation in this interview is voluntary. If you wish to stop at any point in time, please let us know and all of the information you have provided will be destroyed. Do you have any questions about our talk today? 


\section{DEMOGRAPHICS}

1) What is your age?

2) How long have you lived in Riverside Gardens?

3) How old were you when you moved to Riverside Gardens?

4) Describe where you live in the community.

5) Have you moved in and out of the neighborhood or lived here the whole time?

6) Have you lived in more than one home within Riverside Gardens? If so, how many?

7) What type of work do you do or have you done in the past?

\section{COMMUNITY HISTORY}

1) Think back to when you first moved to the neighborhood. How has your house changed since then?

2) How has the neighborhood changed since then?

3) Describe how you think the neighborhood's environmental problems have changed since you moved here.

Prompt: If participant seems unsure, ask about air pollution, smells, landfill changes, etc.

4) What can you share about the history of the Riverside Gardens neighborhood?

\section{HEALTH OF COMMUNITY}

1) What do you think about the overall health of your neighborhood?

2) Can you recall a time when you felt that your neighborhood was affected by the surrounding industries?

3) How has your neighborhood been affected by the industries?

Page 2 of 4 


\section{EXPOSURES EXPERIENCED BY INDIVIDUAL AND NEIGHBORS}

1) What, if anything, do you feel that you have been exposed to since moving to Riverside Gardens?

Prompt: If participant seems unsure, ask about environmental problems and exposures.

2) What, if anything, do you think your neighbors may have been exposed to while living in Riverside Gardens?

\section{HEALTH OF INDIVIDUAL AND NEIGHBORHOOD}

1) Describe the health of your neighbors during the time that you have lived in Riverside Gardens.

2) How would you describe YOUR health during the time you have lived in Riverside Gardens?

3) Describe any long-lasting health issues you have experienced since moving to the neighborhood.

Prompt: If participant seems unsure, provide a simple example like asthma or cancer.

4) Do any of your family members have the same health problems? If so, who?

5) Describe any short-term illnesses have you experienced while living here.

Prompt: If participant seems unsure, provide a simple example like coughing.

\section{FINAL QUESTIONS}

1) Is there anything else that you would like to share about your community, the health of your community, or your own personal exposure or health experiences? 
UofL Institutional Review Boards

IRB NUMBER: 16.0843

IRB APPROVAL DATE: 10/31/2016

\section{THANK YOU!}

Thank you for your time today. We know that sharing personal details concerning exposures and health conditions can be difficult and uncomfortable. We appreciate the time that you have spent informing us of your community and your exposures and health since moving to Riverside Gardens. Your responses and the responses of other community members will be used to guide us in developing a detailed health questionnaire that will be given to all members of the Riverside Gardens community. We are appreciative of the time that you have taken to share your feelings and experiences with us today!

Do you have any final questions? Thank you.

Page 4 of 4 
APPENDIX B: HEALTH AND EXPOSURE ASSESSMENT QUESTIONNAIRE 
Participant ID:

\section{Riverside Gardens Community Health and Exposure Assessment}

All answers to questions contained in this questionnaire are strictly confidential.

\section{DEMOGRAPHIC INFORMATION}

The following questions concern your education, race/ethnicity, household members, employment, and health care coverage.

What is your highest level of education? Fill in one circle.

O Never Attended School/Kindergarten Only

O Some/All Elementary School

Some/All Junior High/Middle School

O Some High School

High School Diploma or GED

Trade School after High School

Some Junior College

Junior College/Associate's Degree

- Some College

- College Graduate/Bachelor's Degree

O Some Graduate School

Completed Graduate School

What is your racial and ethnic background? Check all that apply.

$\square$ White/Caucasian

$\square$ Black/African American

$\square$ Hispanic/Latino

$\square$ Asian

$\square$ American Indian or Alaskan Native

$\square$ Native Hawaiian or Other Pacific Islander

$\square$ Other Specify:

What is your marital status? Fill in one circle.
Single
O Partnered
Married
Separated
Divorced
Widowed

Including yourself, how many people live in your home?

How many adults (18 and older) live in your home?

How many children (under age 18) live in your home? 
Are you currently...? Fill in one circle.
Employed for wages
O Self-employed
Out of work for 1 year or more
O Out of work for less than 1 year
- A Homemaker
O A Student
Retired
Unable to work

Did you receive any disability pension (not including Social Security benefits) in the last year? Fill in one circle.

O Yes.

O No.
What is your annual household income before taxes? Please include income from sources such as wages, salaries, Social Security or retirement benefits, help from similar populations. Fill in once circle.
O $\$ 1-\$ 4,999$
O $\$ 5,000-\$ 9,999$
O $\$ 10,000-\$ 14,999$
O $\$ 15,000-\$ 19,999$
○ $\$ 20,000-\$ 24,999$
O $\$ 25,000-\$ 29,999$
- $\$ 30,000-\$ 34,999$

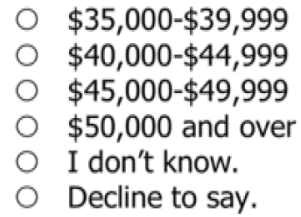
relatives, and so forth. Your income level is needed so that we can compare your health information against

Do you have any kind of health care coverage, including health insurance; prepaid plans such as HMOs; government plans such as Medicare, Medicaid, or Indian Health Service; or military health care such as TRICARE or Veterans Affairs health benefits? Fill in one circle.

Y Yes.

No.

I don't know. 


\section{PERSONAL HEALTH HISTORY}

The following questions concern your general health.

\section{How tall are you?}

feet

inches

In general, how would you rate your health? Fill in one circle.
Excellent
V Very good
O Good
O Fair

\section{Your Diagnosed Medical Conditions}

Has a doctor, nurse, or other health professional ever told you that you have any of the following medical conditions? Check all medical conditions that apply and provide the year you were diagnosed. Please also indicate if a biological family member has been diagnosed with this condition and the family member's relation to you.

Medical conditions are separated by where they affect your body.

\section{Medical Condition}

\section{Blood Conditions}

Anemia

(low red blood cell count)

Leukopenia

(low white blood cell count)

Sickle cell anemia

\section{Cardiovascular (Heart and Blood Vessel) Conditions}

Aneurysm

Angina or angina pectoris

Bradycardia

(slow heart rate)

Cardiac arrhythmia

(abnormal heart rhythm)

Congestive heart failure

Coronary heart disease (CHD) or

Coronary artery disease (CAD)

Heart attack / Myocardial infarction

High Blood Pressure / Hypertension

High cholesterol / Hypercholesterolemia

Tachycardia

(fast heart rate)

\section{Yes, I have} been diagnosed with this condition. (check box)
Were any of your biological family members diagnosed with this condition?

If so, please list the biological family members diagnosed (e.g., mother, brother, daughter, etc.). If you are unsure if another family member was diagnosed, please write, "I don't know." were you diagnosed?
Ibs.

Poor 


\section{Your Diagnosed Medical Conditions (continued)}

Has a doctor, nurse, or other health professional ever told you that you have any of the following medical conditions? Check all medical conditions that apply and provide the year you were diagnosed. Please also indicate if a biological family member has been diagnosed with this condition and the family member's relation to you.

Medical conditions are separated by where they affect your body.

\begin{tabular}{|l|c|c|}
\hline Medical Condition & $\begin{array}{c}\text { Yes, I have } \\
\text { been } \\
\text { diagnosed } \\
\text { with this } \\
\text { condition. } \\
\text { (check box) }\end{array}$ & $\begin{array}{c}\text { What year } \\
\text { were you } \\
\text { diagnosed? }\end{array}$ \\
\hline
\end{tabular}

Were any of your biological family members diagnosed with this condition? If so, please list the biological family members diagnosed (e.g., mother, brother, daughter, etc.). If you are unsure if another family member was diagnosed, please write, "I don't know."

Digestive (Esophagus, Stomach, Small and Large Intestine, Liver, Gallbladder) System Conditions

Crohn's disease

$$
\square
$$

Gallbladder disease

Specify Type (e.g., gallstones):

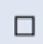

Gastroesophageal reflux disease (GERD)

Jaundice

Liver disease

Specify Type:

Ulcerative colitis

Ulcers

(stomach, duodenal, or peptic ulcer)

Endocrine (Hormone) System and Immune System Conditions

Allergies

HIV/AIDS

Lupus

Thyroid problem

Specify Type:

Type I Diabetes or "Juvenile Diabetes"

Type II Diabetes or "Adult Onset Diabetes"

\section{$\square$}

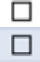

Mental Health Conditions

Anxiety disorder (any type)

Attention-deficit/hyperactivity

disorder (ADHD) or Attention-deficit

disorder (ADD)

Bipolar Disorder

Depressive Disorder (including depression,

major depression, dysthymia, or minor

depression)

Obsessive-compulsive disorder (OCD)

Panic disorder

Schizophrenia

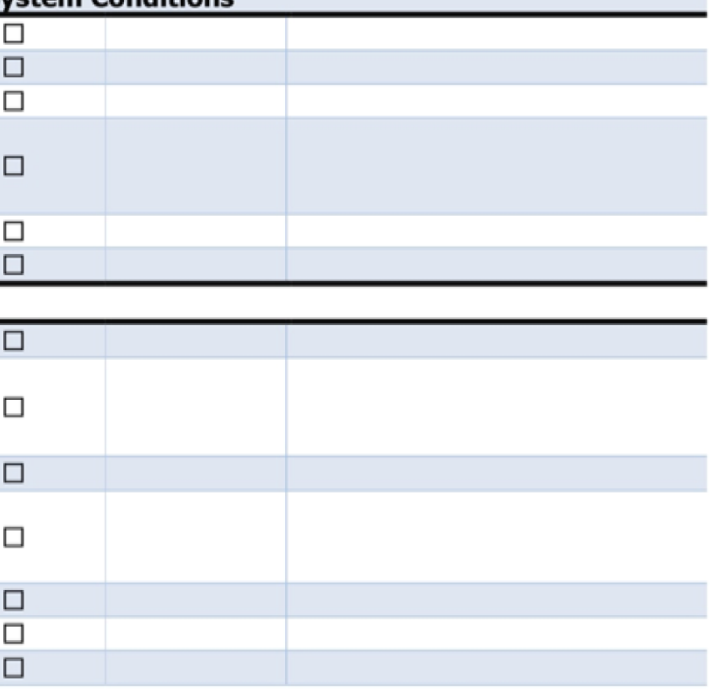




\section{Your Diagnosed Medical Conditions (continued)}

Has a doctor, nurse, or other health professional ever told you that you have any of the following medical conditions? Check all medical conditions that apply and provide the year you were diagnosed. Please also indicate if a biological family member has been diagnosed with this condition and the family member's relation to you.

Medical conditions are separated by where they affect your body.

\begin{tabular}{|l|c|c|}
\hline Medical Condition & $\begin{array}{c}\text { Yes, I have } \\
\text { been } \\
\text { diagnosed } \\
\text { with this }\end{array}$ & $\begin{array}{c}\text { What year } \\
\text { were you } \\
\text { diagnosed? }\end{array}$ \\
\hline $\begin{array}{c}\text { condition. } \\
\text { (check box) }\end{array}$ & \\
\hline
\end{tabular}

Were any of your biological family members diagnosed with this condition? If so, please list the biological family members diagnosed (e.g., mother, brother, daughter, etc.). If you are unsure if another family member was Nervous System (Brain, Nerve, and Spinal Cord) Conditions

Alzheimer's Disease

Amyotrophic lateral sclerosis (ALS)

Central nervous system (brain and spinal cord) disease

Specify Type:

Dementia

\section{Epilepsy}

Migraines

Multiple Sclerosis (MS)

Narcolepsy

Parkinson's disease

Peripheral neuropathy or peripheral

neuritis

Seizure disorder

Sleep disorder

(sleep apnea, insomnia, etc.)

Stroke

Reproductive System Conditions

Endometriosis

Fertility problems

Specify Type:

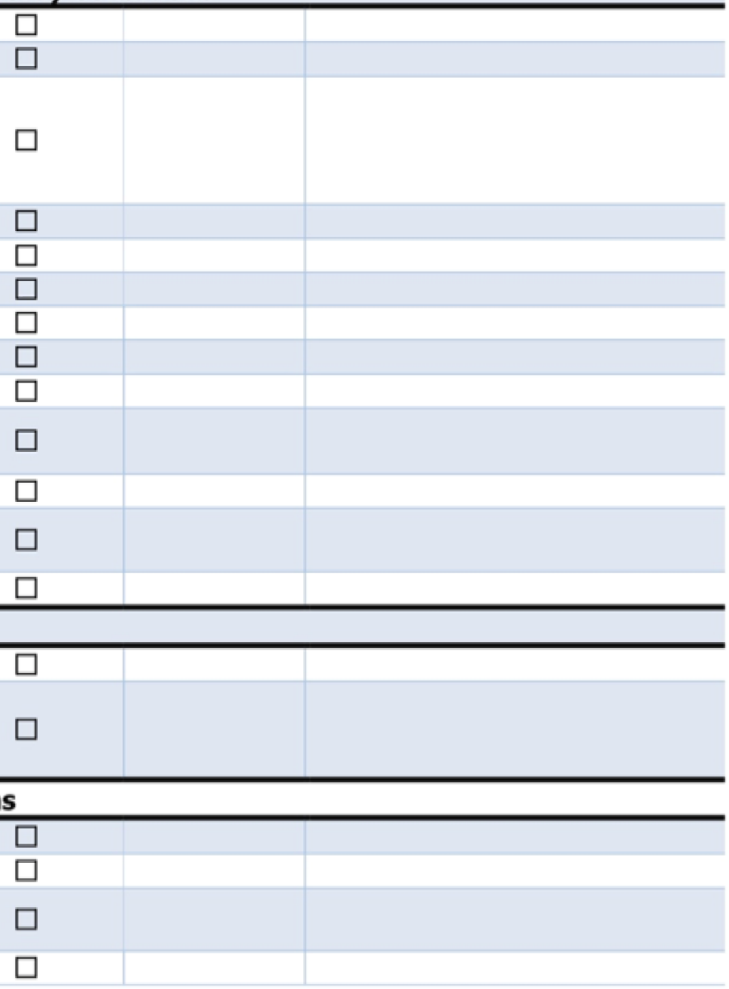

Respiratory (Windpipe and Lung) Conditions

Asthma

Chronic bronchitis

Chronic obstructive pulmonary disease

(COPD; lung disease)

Emphysema 


\section{Your Diagnosed Medical Conditions (continued)}

Has a doctor, nurse, or other health professional ever told you that you have any of the following medical conditions? Check all medical conditions that apply and provide the year you were diagnosed. Please also indicate if a biological family member has been diagnosed with this condition and the family member's relation to you.

Medical conditions are separated by where they affect your body.

\begin{tabular}{|l|c|c|}
\hline Medical Condition & $\begin{array}{c}\text { Yes, I have } \\
\text { been } \\
\text { diagnosed } \\
\text { with this } \\
\text { condition. } \\
\text { (check box) }\end{array}$ & $\begin{array}{c}\text { What year } \\
\text { were you } \\
\text { diagnosed? }\end{array}$ \\
\hline
\end{tabular}

Were any of your biological family members diagnosed with this condition? If so, please list the biological family members diagnosed (e.g., mother, brother, daughter, etc.). If you are unsure if another family member was diagnosed, please write, "I don't know."

Sensory Organ (Eye and Ear) Conditions

Cataracts

Eye condition

Specify Type:

Glaucoma

Hearing loss

Specify Type:

\begin{tabular}{l|l|l|}
\hline Skeletal (Bone and Joint) Conditions & & \\
\hline Arthritis & $\square$ & \\
(not rheumatoid) & & \\
\hline Back condition & $\square$ & \\
\hline Specify Type: & $\square$ \\
\hline Degenerative disc disease & $\square$ \\
\hline Gout & $\square$ \\
\hline Herniated disc & $\square$ \\
\hline Osteoarthritis & $\square$ \\
\hline Osteoporosis & $\square$ \\
\hline Psoriatic Arthritis & \\
\hline Rheumatoid Arthritis & $\square$ \\
\hline Other Conditions & $\square$ \\
\hline Autism Spectrum Disorder & $\square$ \\
\hline Fibromyalgia & $\square$ \\
\hline Kidney disease & $\square$ \\
\hline Psoriasis & \\
\hline Reflex Sympathetic Dystrophy Syndrome & \\
\hline (RSD) & & \\
\hline
\end{tabular}




\section{Your Cancer History}

Has a doctor, nurse, or other health professional ever told you that you have any of the following types of cancer? Check all that apply and provide the year you were diagnosed. If your cancer spread to other locations, check only where your cancer originated. Also indicate if a biological family member has been diagnosed with the same cancer type.

O I have never been diagnosed with cancer. Proceed to next page, "Other Diagnosed Medical Conditions."

\begin{tabular}{|c|c|c|c|}
\hline Cancer Type & $\begin{array}{l}\text { Yes, I have } \\
\text { been } \\
\text { diagnosed } \\
\text { with this } \\
\text { type of } \\
\text { cancer. } \\
\text { (check box) } \\
\end{array}$ & $\begin{array}{l}\text { What year } \\
\text { were you } \\
\text { diagnosed? }\end{array}$ & $\begin{array}{l}\text { Were any of your biological } \\
\text { family members diagnosed } \\
\text { with this type of cancer? } \\
\text { If so, please list the biological family } \\
\text { members diagnosed (e.g., mother, } \\
\text { brother, daughter, etc.). If you are } \\
\text { unsure if another family member was } \\
\text { diagnosed, please write, "I don't know." }\end{array}$ \\
\hline Bladder Cancer & $\square$ & & \\
\hline Bone or Joint Cancer & $\square$ & & \\
\hline Brain Cancer & $\square$ & & \\
\hline Breast Cancer & $\square$ & & \\
\hline Cervical (cervix) Cancer & $\square$ & & \\
\hline Colon \& Rectal Cancer & $\square$ & & \\
\hline $\begin{array}{l}\text { Colon Cancer } \\
\text { (not including rectum) }\end{array}$ & $\square$ & & \\
\hline Esophageal (esophagus) Cancer & $\square$ & & \\
\hline Kidney Cancer & $\square$ & & \\
\hline Laryngeal (larynx/windpipe) Cancer & $\square$ & & \\
\hline $\begin{array}{l}\text { Leukemia } \\
\text { Provide specific type: }\end{array}$ & $\square$ & & \\
\hline Liver Cancer & $\square$ & & \\
\hline Lung Cancer & $\square$ & & \\
\hline Melanoma & $\square$ & & \\
\hline Myeloma & $\square$ & & \\
\hline Non-Hodgkin Lymphoma & $\square$ & & \\
\hline Ovarian (ovary) Cancer & $\square$ & & \\
\hline Pancreatic (pancreas) Cancer & $\square$ & & \\
\hline Pharyngeal (throat) Cancer & $\square$ & & \\
\hline Prostate Cancer & $\square$ & & \\
\hline Rectal Cancer (not colon) & $\square$ & & \\
\hline Skin Cancer (not melanoma) & $\square$ & & \\
\hline Stomach Cancer & $\bar{\square}$ & & \\
\hline Testicular (testicle) Cancer & $\square$ & & \\
\hline Thyroid Cancer & $\square$ & & \\
\hline $\begin{array}{l}\text { Uterine Cancer } \\
\text { Specify type: }\end{array}$ & $\square$ & & \\
\hline Vulvar Cancer & $\square$ & & \\
\hline $\begin{array}{l}\text { Other } \\
\text { Specify type: }\end{array}$ & $\square$ & & \\
\hline $\begin{array}{l}\text { Other } \\
\text { Specify type: }\end{array}$ & $\square$ & & \\
\hline
\end{tabular}




\section{Other Diagnosed Medical Conditions}

Has a doctor, nurse, or other health professional ever told you that you have any medical conditions that were not listed in the previous sections?

Yes. Please describe the condition and provide the year you were diagnosed in the space below.

No.

I don't know.

\section{Undiagnosed Medical Conditions}

Have you experienced any other medical conditions that have not been diagnosed by a doctor, nurse, or other health professional?

Yes. Please describe the condition and the year you began experiencing this condition in the space below.

No.

I don't know. 


\section{Symptoms Experienced at Home and in Neighborhood}

During the time you have lived in Riverside Gardens or the Huff Lane area, have you experienced any of the following symptoms? If so, how frequently do you experience them and when did they begin? Respond to both questions for all symptoms that apply to you.

\begin{tabular}{|c|c|c|c|c|c|c|}
\hline \multirow[b]{2}{*}{ Symptom } & \multicolumn{5}{|c|}{$\begin{array}{l}\text { How Frequently Do You Experience This Symptom? } \\
\text { (Check box to respond. Specify the frequency if 'other.') }\end{array}$} & \multirow{2}{*}{$\begin{array}{c}\text { When Did } \\
\text { Symptom } \\
\text { Begin? } \\
\text { (List Month } \\
\text { and Year) }\end{array}$} \\
\hline & Daily & Weekly & Monthly & $\begin{array}{c}\text { Seasonally } \\
\text { (certain periods } \\
\text { of year) }\end{array}$ & $\begin{array}{l}\text { Other } \\
\text { (Specify) }\end{array}$ & \\
\hline \multicolumn{7}{|l|}{ Bone and Muscle Symptoms } \\
\hline Back pain & $\square$ & $\square$ & $\square$ & $\square$ & & \\
\hline Lack of muscle coordination & $\square$ & $\square$ & $\square$ & $\square$ & & \\
\hline Muscle cramps & $\square$ & $\square$ & $\square$ & $\square$ & & \\
\hline Muscle weakness & $\square$ & $\square$ & $\square$ & $\square$ & & \\
\hline \multicolumn{7}{|l|}{ Brain and Nerve Symptoms } \\
\hline Confusion & $\square$ & $\square$ & $\square$ & $\square$ & & \\
\hline Dizziness & $\square$ & $\square$ & $\square$ & $\square$ & & \\
\hline Drowsiness & $\square$ & $\square$ & $\square$ & $\square$ & & \\
\hline $\begin{array}{l}\text { Feeling of "pins and needles" } \\
\text { on hands or feet }\end{array}$ & $\square$ & $\square$ & $\square$ & $\square$ & & \\
\hline Headaches & $\square$ & $\square$ & $\square$ & $\square$ & & \\
\hline Memory loss & $\square$ & $\square$ & $\square$ & $\square$ & & \\
\hline Numbness in hands or feet & $\square$ & $\square$ & $\square$ & $\square$ & & \\
\hline Rapid heart rate at rest & $\square$ & $\square$ & $\square$ & $\square$ & & \\
\hline Tired or fatigued & $\square$ & $\square$ & $\square$ & $\square$ & & \\
\hline Tremors & $\square$ & $\square$ & $\square$ & $\square$ & & \\
\hline Trouble concentrating & $\square$ & $\square$ & $\square$ & $\square$ & & \\
\hline Trouble with balance & $\square$ & $\square$ & $\square$ & $\square$ & & \\
\hline \multicolumn{7}{|l|}{ Eye Symptoms } \\
\hline Blurred vision & $\square$ & $\square$ & $\square$ & $\square$ & & \\
\hline Eye burning & $\square$ & $\square$ & $\square$ & $\square$ & & \\
\hline Eye watering & $\square$ & $\square$ & $\square$ & $\square$ & & \\
\hline \multicolumn{7}{|l|}{ Digestive System Symptoms } \\
\hline Diarrhea & $\square$ & $\square$ & $\square$ & $\square$ & & \\
\hline Heartburn & $\square$ & $\square$ & $\square$ & $\square$ & & \\
\hline Nausea & $\square$ & $\square$ & $\square$ & $\square$ & & \\
\hline Stomach discomfort & $\square$ & $\square$ & $\square$ & $\square$ & & \\
\hline \multicolumn{7}{|l|}{ Mood Symptoms } \\
\hline Anxiety & $\square$ & $\square$ & $\square$ & $\square$ & & \\
\hline Depression & $\square$ & $\square$ & $\square$ & $\square$ & & \\
\hline \multicolumn{7}{|l|}{ Respiratory Symptoms } \\
\hline Cough & $\square$ & $\square$ & $\square$ & $\square$ & & \\
\hline Shortness of breath & $\square$ & $\square$ & $\square$ & $\square$ & & \\
\hline Sinus problems & $\square$ & $\square$ & $\square$ & $\square$ & & \\
\hline Sore throat & $\square$ & $\square$ & $\square$ & $\square$ & & \\
\hline Wheezing & $\square$ & $\square$ & $\square$ & $\square$ & & \\
\hline
\end{tabular}




\section{Symptoms Experienced at Home and in Neighborhood (continued)}

During the time you have lived in Riverside Gardens or the Huff Lane area, have you experienced any of the following symptoms? If so, how frequently do you experience them and when did they begin? Respond to both questions for all symptoms that apply to you.

\begin{tabular}{|c|c|c|c|c|c|c|}
\hline \multirow[b]{2}{*}{ Symptom } & \multicolumn{5}{|c|}{$\begin{array}{l}\text { How Frequently Do You Experience This Symptom? } \\
\text { (Check box to respond. Specify the frequency if 'other.') }\end{array}$} & \multirow{2}{*}{$\begin{array}{l}\text { When Did } \\
\text { Symptom } \\
\text { Begin? } \\
\text { (List Month } \\
\text { and Year) }\end{array}$} \\
\hline & Daily & Weekly & Monthly & $\begin{array}{c}\text { Seasonally } \\
\text { (certain periods } \\
\text { of year) }\end{array}$ & Other (Specify) & \\
\hline \multicolumn{7}{|l|}{ Skin Symptoms } \\
\hline Boils & $\square$ & $\square$ & $\square$ & $\square$ & & \\
\hline $\begin{array}{l}\text { Corns or warts on hands, } \\
\text { feet, chest, back, or } \\
\text { abdomen }\end{array}$ & $\square$ & $\square$ & $\square$ & $\square$ & & \\
\hline Darkening of skin & $\square$ & $\square$ & $\square$ & $\square$ & & \\
\hline Skin dryness & $\square$ & $\square$ & $\square$ & $\square$ & & \\
\hline Skin itchiness & $\square$ & $\square$ & $\square$ & $\square$ & & \\
\hline Skin ulcers & $\square$ & $\square$ & $\square$ & $\square$ & & \\
\hline Rashes & $\square$ & $\square$ & $\square$ & $\square$ & & \\
\hline \multicolumn{7}{|l|}{ Other Symptoms } \\
\hline $\begin{array}{l}\text { Other } \\
\text { Specify: }\end{array}$ & $\square$ & $\square$ & $\square$ & $\square$ & & \\
\hline $\begin{array}{l}\text { Other } \\
\text { Specify: }\end{array}$ & $\square$ & $\square$ & $\square$ & $\square$ & & \\
\hline $\begin{array}{l}\text { Other } \\
\text { Speciff: }\end{array}$ & $\square$ & $\square$ & $\square$ & $\square$ & & \\
\hline
\end{tabular}




\section{Medication Use}

The following questions concern the medications that you take. Please retrieve any medications that you take, including vitamins, in order to answer the following questions.

Are you currently taking medications prescribed to you by a doctor or other health professional?

Yes. Specify the name, frequency, dose, and how long you have taken this medication in the space below.

No.

I don't know.

Do you take vitamins (e.g. multivitamin, vitamin D, biotin, etc.) daily?

Yes. Specify the name, frequency, dose, and how long you have taken this vitamin in the space below.

No.

I don't know.

Do you take any other over-the-counter medications (e.g. aspirin, Zantac, etc.) daily?

Y Yes. Specify the name, frequency, dose, and how long you have taken this medication in the space below.

No.

I don't know. 


\section{ENVIRONMENTAL EXPOSURE HISTORY}

The following questions concern things you have been exposed to during your life.

\section{Employment History}

Please tell us about the types of jobs that you have held in your life starting with your current or most recent job. Include job title, employer and/or industry type, job location (in-home or outside the home), a brief description of your job tasks, and the length of time that you held each position.

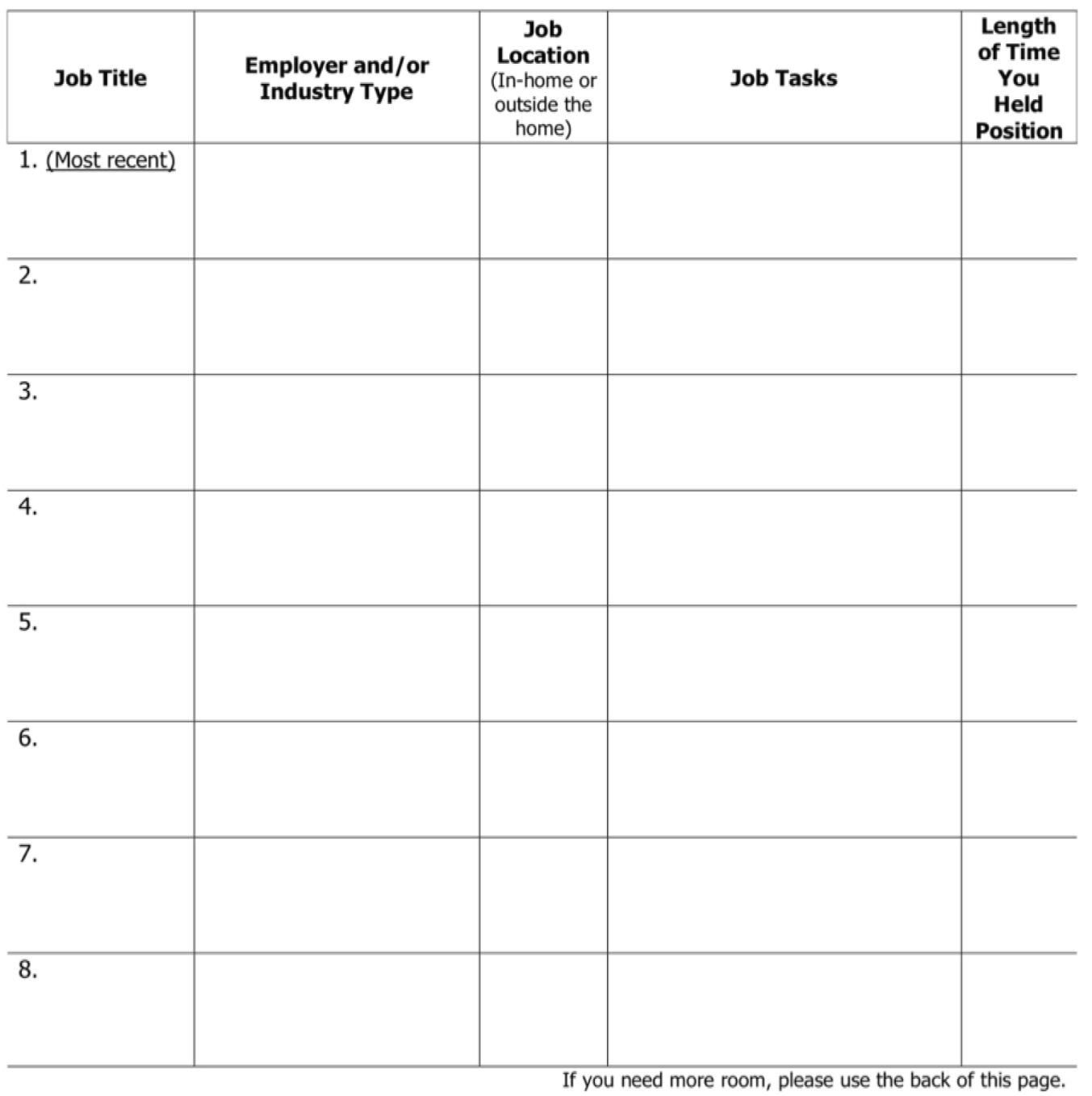




\section{Employment History (continued)}

Have you ever held a job where you handled, worked around, or were otherwise exposed to any of the following? Fill in one response for each type of exposure.

\begin{tabular}{|c|c|}
\hline $\begin{array}{l}\text { Chemicals } \\
\text { Yes. }\end{array}$ & If yes, during which job(s) are/were you exposed? \\
\hline $\begin{array}{l}\text { questions to the right.) } \\
\text { No. }\end{array}$ & What types of chemicals are/were you exposed to? \\
\hline
\end{tabular}

What does/did your job entail?

Do/did you use personal protective equipment (such as gloves, masks, or respirators)? O Yes. O No. O I don't know.

Metals

If yes, during which job(s) are/were you exposed?

Y Yes.

(If yes, answer the

questions to the right.) What types of metals are/were you exposed to?

No.

I don't know.

What does/did your job entail?

Do/did you use personal protective equipment (such as gloves, masks, or respirators)? O Yes. O No. O I don't know.

Hazardous waste If yes, during which job(s) are/were you exposed?

$O$ Yes.

(If yes, answer the

questions to the right.) What types of hazardous waste are/were you exposed to?

No.

I don't know.

What does/did your job entail?

Do/did you use personal protective equipment (such as gloves, masks, or respirators)? O Yes. O No. O I don't know.

Dust or fibers

If yes, during which job(s) are/were you exposed?

Yes.

(If yes, answer the

questions to the right.) What types of dust or fibers are/were you exposed to?

No.

I don't know.

What does/did your job entail?

Do/did you use personal protective equipment (such as gloves, masks, or respirators)? O Yes. O No. O I don't know. 


\begin{tabular}{|c|c|}
\hline & Employment History (continued) \\
\hline $\begin{array}{l}\text { Have you ever held a } j \\
\text { any of the following? }\end{array}$ & $\begin{array}{l}\text { b where you handled, worked around, or were otherwise exposed to } \\
\text { ill in one response for each type of exposure. }\end{array}$ \\
\hline Fumes (such as & If yes, during which job(s) are/were you exposed? \\
\hline $\begin{array}{l}\text { Yes. } \\
\text { (If yes, answer the } \\
\text { questions to the right.) }\end{array}$ & What types of fumes are/were you exposed to? \\
\hline $\begin{array}{l}\text { No. } \\
\text { I don't know. }\end{array}$ & What does/did your job entail? \\
\hline & $\begin{array}{l}\text { Do/did you use personal protective equipment (such as gloves, masks, or } \\
\text { respirators)? O Yes. O No. O I don't know. }\end{array}$ \\
\hline Radiation & If yes, during which job(s) are/were you exposed? \\
\hline No. & What types of radiation are/were you exposed to? \\
\hline & What does/did your job entail? \\
\hline & $\begin{array}{l}\text { Do/did you use personal protective equipment (such as lead aprons)? } \\
\text { Yes. } \bigcirc \text { No. O I don't know. }\end{array}$ \\
\hline Biologic agents & If yes, during which job(s) are/were you exposed? \\
\hline questions to the right.) & What types of biologic agents are/were you exposed to? \\
\hline & What does/did your job entail? \\
\hline & $\begin{array}{l}\text { Do/did you use personal protective equipment (such as gloves, masks, or } \\
\text { respirators)? } \bigcirc \text { Yes. } \bigcirc \text { No. O I don't know. }\end{array}$ \\
\hline Loud noise or & If yes, during which job(s) are/were you exposed? \\
\hline $\begin{array}{l}\text { (If yes, answer the } \\
\text { questions to the right.) }\end{array}$ & What types of loud noises or vibrations are/were you exposed to? \\
\hline $\begin{array}{l}\text { No. } \\
\text { I don't know. }\end{array}$ & What does/did your job entail? \\
\hline & Do/did you use personal protective equipment (such as hearing protectors)? \\
\hline & $\bigcirc$ Yes. $\bigcirc$ No. I don't know. \\
\hline
\end{tabular}




\section{Address History in Riverside Gardens}

Please list the address for every home in which you have ever lived in Riverside Gardens or the Huff Lane area. Additionally, please provide the date range for the length of time you lived in each.

If you lived in the same home during multiple periods of your life, please list separate date ranges for each time you lived in the home (see example). Please provide as much detail as possible.

\begin{tabular}{l|l|l}
\multicolumn{1}{c|}{\begin{tabular}{c}
\multicolumn{1}{c}{ Riverside Gardens / Huff Lane Area } \\
Addresses
\end{tabular}} & \multicolumn{1}{|c}{$\begin{array}{c}\text { Month and Year } \\
\text { You Moved In }\end{array}$} & $\begin{array}{l}\text { Month and Year } \\
\text { You Moved Out }\end{array}$ \\
\hline $\begin{array}{l}\text { Example: } \\
100 \text { Lees Lane }\end{array}$ & $\begin{array}{l}\text { Example: } \\
\text { November 1968 }\end{array}$ & $\begin{array}{l}\text { Example: } \\
\text { March 1979 }\end{array}$ \\
\hline $\begin{array}{l}\text { Example: } \\
100 \text { Lees Lane }\end{array}$ & $\begin{array}{l}\text { Example: } \\
\text { August 1990 }\end{array}$ & $\begin{array}{l}\text { Example: } \\
\text { Currently live in home. }\end{array}$ \\
\hline & & \\
\hline & & \\
\hline & & \\
\hline
\end{tabular}




\section{Address History Outside Riverside Gardens}

Please list the addresses or areas where you lived that were outside of Riverside Gardens/Huff Lane area.

I have only lived in Riverside Gardens or the Huff Lane area. If so, proceed to the next page, "Neighborhood Exposures."

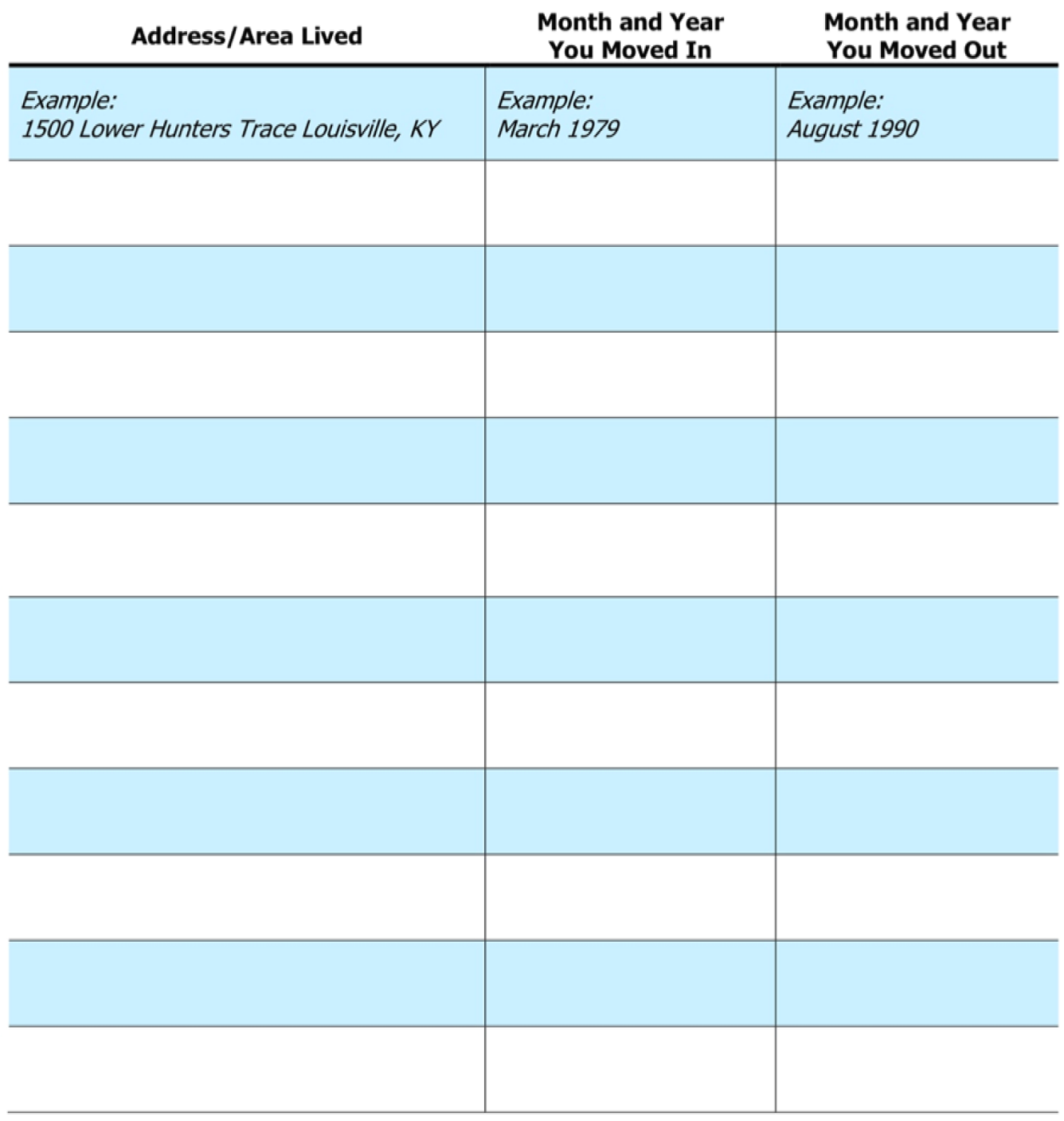




\section{Neighborhood Exposures}

Do you think the physical environment (air, water, soil) in your neighborhood has gotten better, worse, or stayed the same during the time you lived in the neighborhood? Select only one.

$\bigcirc$ Gotten better $\bigcirc$ Gotten worse $\quad$ Stayed the same I don't know.

Do you think you are exposed to environmental pollution (e.g., air pollution, water pollution, etc.) in your neighborhood? Select only one.

Yes. Describe what you think you are exposed to in the space below.

No.

I don't know.

Which of the following do you think contribute to pollution in your neighborhood? For each of the following, fill in the appropriate circle to indicate if it contributes to pollution, does not contribute to pollution, or if you are unsure.

Lees Lane Landfill

Coal ash landfill

Coal ash pond

Chemical companies

Companies in Rubbertown

Other

Specify:

\section{Contributes to} Pollution

\section{O}

0

0

O

O
Does Not Contribute to Pollution

$\begin{array}{ll}0 & 0 \\ 0 & 0 \\ 0 & 0 \\ 0 & 0 \\ 0 & 0 \\ 0 & 0\end{array}$




\section{Neighborhood Exposures (continued)}

Are there specific companies that you think pollute your neighborhood? Select only one.

Yes. List the specific companies and the ways you think they pollute your neighborhood in the space below.

No.

I don't know.

Do you think that you are exposed to any specific chemicals in your neighborhood?

Yes. List the specific chemicals in the space below.

No.

I don't know.

Why do you think that you are being exposed to environmental pollution in your neighborhood? Check all that apply.

$\square$ You see residue/dust/a film/sticky substance on your house.

$\square$ You have had vapor and/or water tests on your home with abnormal findings.

$\square$ You experience physical changes when you are in the neighborhood (e.g., cough or skin irritation). $\square$ You smell a particular odor when you are in your neighborhood.

$\square$ You have seen changes in your pets (e.g. fur color changes).

$\square$ Something else Specify:

$\square$ I do not think that I am being exposed to environmental pollution in my neighborhood. 


\section{Neighborhood Exposures (continued)}

If you have seen anything in your neighborhood's environment that makes you feel like you are being exposed to pollution, how would you describe what you see? Does it look like...? Check all that apply.
$\square$ White ash
$\square$ Black soot
$\square$ Black film
$\square$ Green slime
$\square$ Orange smoke

$\square$ Purple goo

$\square$ Dust

$\square$ Something else Specify:

$\square$ I have not seen anything in my neighborhood that makes me feel like I am exposed to pollution.

Where do you see the things that you described in the last question? Check all that apply.

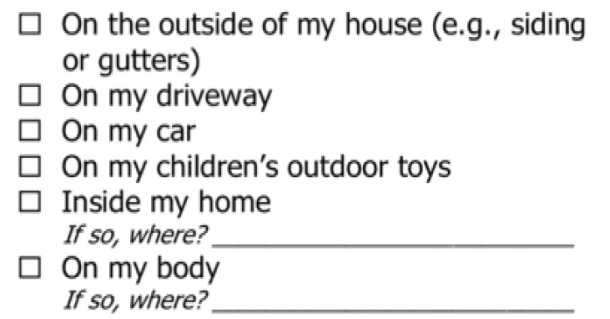

$\square$ In my swimming pool

$\square$ On outdoor plants

$\square$ Somewhere else Specify:

$\square$ I have not seen anything in my neighborhood that makes me feel like I am exposed to pollution.

Some of your neighbors have mentioned frequently smelling unusual odors in the neighborhood. If you have smelled any of these odors, how would you describe them? Do they smell like...? Check all that apply.
$\square$ Wires burning
$\square$ A strong, sweet smell
$\square$ Kool-Aid
$\square$ Brakes burning
$\square$ Rotten eggs
$\square$ Burnt rubber
$\square$ Menthol
$\square$ Cherry cough drops

$\square$ Antifreeze

$\square$ Fingernail polish

$\square$ Blood orange or other citrus

$\square$ Melted plastic

$\square$ Beans cooking

$\square$ Something else Specify:

$\square$ I have not smelled any unique odors while in the neighborhood.

During the time you have lived in Riverside Gardens, have you ever used well water? Select only one.

Yes. What was that home's address?

Years that you used well water: (please provide range of years)

No.

I don't know. 
Have you had any encounters with environmental pollution from the Lees Lane Landfill since it closed (e.g., seeing barrels of waste in the landfill, having your house measured by the EPA for pollutants, etc.)? Select only one.

Yes. Describe your experiences in the space below.

No.

I don't know.

What is your biggest environmental concern about your neighborhood? Describe in the space below.

I do not have any environmental concerns about my neighborhood.

I don't know. 


\section{Outdoor Activities In and Around Neighborhood}

Which of the following outdoor activities do you or have you ever participated in in the Riverside Gardens/Huff Lane area? Check all that apply.

$\square$ Running

Where do you run?

$\square$ Walking

Where do you walk?

$\square$ Bicycling

Where do you bike?

$\square$ Swimming

Where do you swim?

$\square$ Organized sports (baseball, soccer, etc.)

Where do you play?

$\square$ Paintball

Where do you play? $\square$ Gardening

Do you eat anything that you grow? $\bigcirc$ Yes $\bigcirc$ No

$\square$ Hunting

Where do you hunt?

Do you eat what you hunt? $\mathrm{O}$ Yes $\mathrm{O}$ No

$\square$ Fishing

Where do you fish?

Do you eat what you catch? $\bigcirc$ Yes $\bigcirc$ No

$\square$ Other

Specify:

$\square$ I have not participated in any of these activities in the Riverside Gardens/Huff Lane area.

\section{About how many hours per week do you spend outdoors in your neighborhood?}

hours per week

Have you visited and/or participated in activities on or near the site of the closed Lees Lane Landfill? (Note: The Lees Lane Landfill closed in 1975.) For example, have you gone on walks near the site or used the bike path?

Yes. Describe the visits and/or activities using the space below.

No.

I don't know. 


\section{Outdoor Activities In and Around Neighborhood (continued)}

Did you live in the neighborhood during the time the landfill was open (1948-1975)?

Yes. Please describe how living near the landfill impacted your life.

No. Proceed to next section, "Childhood in Riverside Gardens."

I don't know.

Did you ever go in or near the landfill when it was open (1948-1975)?

Yes. Describe what you did in or near the landfill using the space below.

No. Proceed to next section, "Childhood in Riverside Gardens."

I don't know. 


\section{Outdoor Activities In and Around Neighborhood (continued)}

Did you ever remove items from the landfill when it was open (1948-1975)?

Yes. Describe the types of items you removed using the space below.

No.

I don't know.

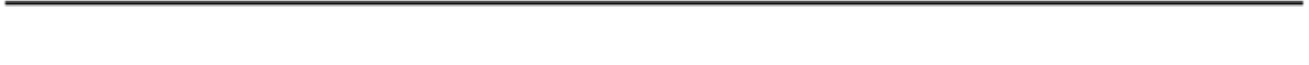




\section{Childhood in Riverside Gardens}

Did you live in Riverside Gardens or the Huff Lane area when you were under the age of 18 ?

Yes.

No. Proceed to next section, "Tobacco and Alcohol Use."

I don't know.

Where did you play in the Riverside Gardens/Huff Lane area when you were growing up (less than 18)? Check all that apply.

$\square$ In/near landfill when open

$\square$ On/near landfill when closed

$\square$ In the creek that runs through the neighborhood $\square$ Riverside Gardens Park

$\square$ In your yard

$\square$ In the Ohio River behind neighborhood $\square$ Along the floodwall

$\square$ At your neighbor's house

$\square$ Somewhere else Specify:

Do you recall anything unusual from when you were growing up (less than 18) about the environmental condition of your neighborhood (e.g., black soot on snow)?

Yes. Describe what you recall using the space below.

No.

I don't know. 


\section{Childhood in Riverside Gardens (continued)}

Which of the following were open/operating near the neighborhood when you lived there as a child (less than 18)? Fill in circle to indicate if each of the following were open/operating, closed, or if you are unsure.

\begin{tabular}{l|c|c|c} 
& Open/Operating & $\begin{array}{c}\text { Not Open/ } \\
\text { Not Operating }\end{array}$ & Unsure \\
\hline Lees Lane Landfill & 0 & 0 & 0 \\
\hline Coal-burning power plant & 0 & 0 & 0 \\
\hline Coal ash pond & 0 & 0 & 0 \\
\hline Coal ash landfill & 0 & 0 & 0 \\
\hline Chemical companies & 0 & 0 & 0 \\
\hline Companies in Rubbertown & 0 & 0 & 0 \\
\hline $\begin{array}{l}\text { Other } \\
\text { Specify: }\end{array}$ & 0 & 0 & 0 \\
\hline
\end{tabular}

Can you recall the names of any of the chemical companies operating near the neighborhood when you were a child (less than 18)?

Yes, I can recall their names. Provide their names in the space below.

No, I cannot recall their names.

I don't remember chemical companies operating near the neighborhood when I was a child.

Do you think your health was affected by any of the Rubbertown companies when you were a child (less than 18)?

Yes. Provide the names of the plants and how you think they affected you in the space below.

No.

I don't know. 


\section{Childhood in Riverside Gardens (continued)}

Do you think your health was affected by the Lees Lane Landfill when you were a child (less than 18)?

Yes. Provide information on how you think you were affected in the space below.

No.

I don't know.

Do you think your health was affected by the coal-burning power plant when you were a child (less than 18)?

Yes. Provide information on how you think you were affected in the space below.

No.

I don't know.

Not applicable. The coal-burning power plant was not operating when I was a child.

Do you remember coal ash being a problem in the neighborhood when you were a child (less than 18)?
- Yes.
O No.
I don't know. 


\section{Tobacco and Alcohol Use}

CIGARETTES

Have you smoked at least 100 cigarettes (approximately 5 packs) in your entire life?

$\bigcirc$ Yes.

No. Proceed to section below, "Cigars \& Cigarillos."

I don't know.

Do you now smoke cigarettes every day, some days, or not at all?
Every day
Some days
Not at all
I don't know.

If you no longer smoke cigarettes, how long has it been since you quit?

(fill in number) days / weeks / months / years (circle one)

During the last $\mathbf{3 0}$ days, on how many days did you smoke cigarettes? days

\section{CIGARS \& CIGARILLOS}

Have you ever smoked a regular cigar, cigarillo, or little filtered cigar even one time?

Y Yes.

No. Proceed to section below, "Smokeless Tobacco."

I don't know.

During the past $\mathbf{3 0}$ days, on how many days did you smoke a regular cigar, cigarillo, or little filtered cigar?

days

\section{SMOKELESS TOBACCO}

Smokeless tobacco products are placed in the mouth or nose and can include chewing tobacco, snuff, dip, snus, or dissolvable tobacco.

Have you ever used smokeless tobacco products even one time?

Y Yes.

No. Proceed to next page ("Electronic Cigarettes").

I don't know.

During the past $\mathbf{3 0}$ days, on how many days did you use smokeless tobacco? days 


\begin{tabular}{l} 
Tobacco and Alcohol Use (continued) \\
\hline ELECTRONIC CIGARETTES \\
\hline The next question is about electronic cigarettes or e-cigarettes. You may also know them as vape- \\
pens, hookah-pens, e-hookahs, or e-vaporizers. Some look like cigarettes, and others look like pens \\
or small pipes. These are battery-powered, usually contain liquid nicotine, and produce vapor instead \\
of smoke. \\
Have you ever used an electronic cigarette (e-cigarette) even one time? \\
Yes. \\
No. Proceed to section below, "Household Tobacco Use." \\
I don't know. \\
During the past 30 days, on how many days did you use e-cigarettes? \\
HOUSEHOLD TOBACCO USE
\end{tabular}

Not including yourself, has anyone in your home used any of the following products? You only need to answer the second question (on past 30-day use) if you answered "Yes" to the first question (on ever using the product).

\begin{tabular}{l|l|l|l} 
Product & $\begin{array}{l}\text { Has anyone in your home ever } \\
\text { used this product? }\end{array}$ & $\begin{array}{l}\text { Has anyone in your home used } \\
\text { this product in the past 30 days? }\end{array}$ \\
\hline Cigarettes & $\bigcirc$ Yes. O No. O I don't know. & $\bigcirc$ Yes. O No. O I don't know. \\
$\begin{array}{l}\text { Electronic cigarettes } \\
\text { or Vape pens }\end{array}$ & O Yes. O No. O I don't know. & O Yes. O No. O I don't know. \\
Cigars & $\bigcirc$ Yes. $\bigcirc$ No. $\bigcirc$ I don't know. & $\bigcirc$ Yes. O No. O I don't know.
\end{tabular}

\section{ALCOHOL USE}

For this section, alcoholic beverages include liquor (such as whiskey or gin), beer, wine, wine coolers, and any other type of alcoholic beverages. A drink is considered 12 ounces of beer, a 5 ounce glass of wine, or one and a half ounces of liquor.

In your entire life, have you had at least 12 drinks of any type of alcoholic beverage?

Yes.

No. Proceed to next page.

I don't know.

In any one year, have you had at least 12 drinks of any type of alcoholic beverage?

0 Yes.

O No.

I don't know.

In the past 12 months, how many days per week, month, or year did you drink any type of alcoholic beverage?

(fill in number) days per week / month / year (circle one)

In the past 12 months, on those days that you drank alcoholic beverages, on the average, how many drinks did you have?

(fill in number) drinks per day 


\section{End of Questionnaire}

You have now reached the end of the questionnaire. Is there anything we did not ask that you think we should know?

\section{Thank you!}

Thank you for answering the questions in this questionnaire.

The information you provided will help us to assess if Riverside Gardens residents have more health problems than other people in the county, Kentucky, and in the U.S. The results of this health assessment will be shared with you and your neighbors as soon as they are available.

Please notify us if your contact information changes before the results are distributed. We will use the contact information you have provided to reach you when the results are ready to be distributed.

If you have any questions, please contact us.

Lindsay Tompkins, MS

Co-Investigator

(502) 548-6511

lindsay.koloff@louisville.edu
Kristina Zierold, PhD

Co-Investigator

(502) 216-9673

kristina.zierold@louisville.edu
Stephanie Boone, PhD

Principal Investigator

(502) 852-2257

stephanie.boone@louisville.edu 
APPENDIX C: SUPPLEMENTAL TABLES

Table 9. Participant Demographics by Questionnaire Version

\begin{tabular}{|c|c|c|c|c|}
\hline & $\begin{array}{c}\text { Full } \\
\text { Sample } \\
\text { N (\%) } \\
\end{array}$ & $\begin{array}{c}\text { Completed } \\
\text { Full Version } \\
\text { of } \\
\text { Questionnaire } \\
\text { n (\%) } \\
\end{array}$ & $\begin{array}{c}\text { Completed } \\
\text { Short Version } \\
\text { of } \\
\text { Questionnaire } \\
\text { n (\%) } \\
\end{array}$ & $\begin{array}{c}P \\
\text { value }\end{array}$ \\
\hline Total & $131(100.0 \%)$ & $83(63.4 \%)$ & $48(36.6 \%)$ & \\
\hline Gender & & & & .53 \\
\hline Male & $62(47.3 \%)$ & $41(49.4 \%)$ & $21(43.8 \%)$ & \\
\hline Female & $69(52.7 \%)$ & $42(50.6 \%)$ & $27(56.2 \%)$ & \\
\hline Age & & & & $<.001^{1}$ \\
\hline Mean (SD) & $54.8(16.3)$ & $58.4(14.7)$ & $48.5(17.2)$ & \\
\hline Median (IQR) & $57(25)$ & $61(16)$ & $48(28.5)$ & \\
\hline Race & & & & $.40^{2}$ \\
\hline White & $113(86.3 \%)$ & $70(84.3 \%)$ & $43(89.6 \%)$ & \\
\hline Black & $8(6.1 \%)$ & $4(4.8 \%)$ & $4(8.3 \%)$ & \\
\hline Asian & $1(0.8 \%)$ & $1(1.2 \%)$ & $0(0.0 \%)$ & \\
\hline $\begin{array}{l}\text { American Indian or } \\
\text { Alaskan Native }\end{array}$ & $1(0.8 \%)$ & $0(0.0 \%)$ & $1(2.1 \%)$ & \\
\hline Biracial & $8(6.1 \%)$ & $8(9.6 \%)$ & $0(0.0 \%)$ & \\
\hline Ethnicity & & & & $.71^{3}$ \\
\hline Hispanic & $7(5.3 \%)$ & $4(4.8 \%)$ & $3(6.2 \%)$ & \\
\hline Non-Hispanic & $124(94.7 \%)$ & $79(95.2 \%)$ & $45(93.8 \%)$ & \\
\hline Health Care Coverage & & & & $.06^{3}$ \\
\hline Yes & $116(88.5 \%)$ & $77(92.8 \%)$ & $39(81.3 \%)$ & \\
\hline No & $10(7.6 \%)$ & $5(6.0 \%)$ & $5(10.4 \%)$ & \\
\hline $\begin{array}{l}\text { I Don't Know/ } \\
\text { No Response }\end{array}$ & $5(3.8 \%)$ & $1(1.2 \%)$ & $4(8.3 \%)$ & \\
\hline Years in Neighborhood & & & & $<.001^{1}$ \\
\hline Mean (SD) & $27.8(21.1)$ & $33.1(22.1)$ & $18.6(15.5)$ & \\
\hline Median (IQR) & $26(34)$ & $29(41)$ & $16(23.5)$ & \\
\hline
\end{tabular}


Table 10. Disease Category Prevalence by Questionnaire Version

\begin{tabular}{|c|c|c|c|c|}
\hline \multirow[b]{2}{*}{ Disease Category } & \multicolumn{4}{|c|}{$\begin{array}{c}\text { Questionnaire } \\
\text { Version Completed }\end{array}$} \\
\hline & $\begin{array}{c}\text { Full } \\
\text { Sample } \\
\mathrm{N}=\mathbf{1 3 1}\end{array}$ & $\begin{array}{c}\text { Full } \\
\text { Version } \\
\mathbf{n}=\mathbf{8 3} \\
\end{array}$ & $\begin{array}{c}\text { Short } \\
\text { Version } \\
\mathbf{n}=48 \\
\end{array}$ & $\begin{array}{c}P \\
\text { value }\end{array}$ \\
\hline & $\%(\mathrm{~N})$ & $\%(n)$ & $\%(\mathrm{n})$ & \\
\hline $\begin{array}{l}\text { Blood and Blood-Forming } \\
\text { Organs }\end{array}$ & $14.5 \%(19)$ & $15.7 \%(13)$ & $12.5 \%(6)$ & .62 \\
\hline Cancer (any site) & $13.0 \%(17)$ & $13.3 \%(11)$ & $12.5 \%(6)$ & .90 \\
\hline Circulatory System & $49.6 \%(65)$ & $57.8 \%(48)$ & $35.4 \%(17)$ & .01 \\
\hline Digestive System & $35.1 \%(46)$ & $37.4 \%(31)$ & $31.3 \%(15)$ & .48 \\
\hline Ear and Mastoid Process & $11.5 \%(15)$ & $14.5 \%(12)$ & $6.3 \%(3)$ & .16 \\
\hline $\begin{array}{l}\text { Endocrine, Nutritional, } \\
\text { and Metabolic Diseases }\end{array}$ & $42.0 \%(55)$ & $41.0 \%(34)$ & $43.8 \%(21)$ & .76 \\
\hline Eye and Adnexa & $18.3 \%(24)$ & $21.7 \%(18)$ & $10.4 \%(5)$ & .10 \\
\hline Genitourinary System & $12.2 \%(16)$ & $10.8 \%(9)$ & $14.6 \%(7)$ & .53 \\
\hline $\begin{array}{l}\text { Mental, Behavioral, and } \\
\text { Neurodevelopmental } \\
\text { Disorders }\end{array}$ & $31.3 \%(41)$ & $31.3 \%(26)$ & $31.3 \%(15)$ & .99 \\
\hline $\begin{array}{l}\text { Musculoskeletal System } \\
\text { and Connective Tissue }\end{array}$ & $52.7 \%(69)$ & $57.8 \%(48)$ & $43.8 \%(21)$ & .12 \\
\hline Nervous System & $31.3 \%(41)$ & $28.9 \%(24)$ & $35.4 \%(17)$ & .44 \\
\hline Respiratory System & $26.0 \%(34)$ & $31.3 \%(26)$ & $16.7 \%(8)$ & .07 \\
\hline $\begin{array}{l}\text { Skin and Subcutaneous } \\
\text { Tissue }\end{array}$ & $11.5 \%(15)$ & $9.6 \%(8)$ & $14.6 \%(7)$ & .39 \\
\hline
\end{tabular}


Table 12. Associations Between Exposure Score Variables

\begin{tabular}{|c|c|c|c|c|c|c|c|}
\hline Variables & 1 & 2 & 3 & 4 & 5 & 6 & 7 \\
\hline 1. Lived in neighborhood for at least $50.0 \%$ of life & - & & & & & & \\
\hline 2. Lived in neighborhood during childhood & $0.63 * *$ & - & & & & & \\
\hline 3. Lived in an exterior neighborhood zone & 0.03 & 0.03 & - & & & & \\
\hline 4. Participated in activities in or around the landfill & 0.10 & $0.38 * *$ & 0.07 & - & & & \\
\hline 5. Consumed plants grown/animals captured in neighborhood & 0.01 & $0.26^{*}$ & 0.08 & 0.14 & - & & \\
\hline 6. Swam in the Ohio River & 0.21 & $0.49 * *$ & 0.01 & $0.45^{* *}$ & $0.30 * *$ & - & \\
\hline 7. Used well water in neighborhood & $0.49 * *$ & $0.55^{* *}$ & 0.01 & 0.09 & 0.15 & $0.21 * *$ & - \\
\hline
\end{tabular}

Notes: Phi coefficients are reported. ${ }^{*} P<.05 * * P<.01$ 
Table 29. Potential Covariates and Exposure Score by Diseases of the Blood and Blood-Forming Organs

\begin{tabular}{|c|c|c|c|c|}
\hline & \multirow{2}{*}{$\begin{array}{c}\text { Total } \\
\text { N (\%) }\end{array}$} & \multicolumn{2}{|c|}{$\begin{array}{l}\text { Diagnosed with } \\
\text { Blood Disease }\end{array}$} & \multirow[t]{2}{*}{$P$ value } \\
\hline & & No n(\%) & Yes n(\%) & \\
\hline Total & $83(100.0 \%)$ & $70(84.3 \%)$ & $13(15.7 \%)$ & \\
\hline Gender & & & & .01 \\
\hline Male & $41(49.4 \%)$ & $39(95.1 \%)$ & $2(4.9 \%)$ & \\
\hline Female & $42(50.6 \%)$ & $31(73.8 \%)$ & $11(26.2 \%)$ & \\
\hline Age (in years) & & & & $.28^{2}$ \\
\hline Median (IQR) & $61(16)$ & $61(15)$ & $57(19)$ & \\
\hline Mean (SD) & $58.4(14.7)$ & $59.0(15.1)$ & $54.8(12.6)$ & \\
\hline Race & & & & $.42^{3}$ \\
\hline White & $70(84.3 \%)$ & $60(85.7 \%)$ & $10(14.3 \%)$ & \\
\hline Other Race & $13(15.7 \%)$ & $10(76.9 \%)$ & $3(23.1 \%)$ & \\
\hline BMI $^{1}$ & & & & $.21^{3}$ \\
\hline Normal & $22(27.2 \%)$ & $20(90.9 \%)$ & $2(9.1 \%)$ & \\
\hline Overweight & $31(38.3 \%)$ & $23(74.2 \%)$ & $8(25.8 \%)$ & \\
\hline Obese & $28(34.6 \%)$ & $25(89.3 \%)$ & $3(10.7 \%)$ & \\
\hline Personal Tobacco Use ${ }^{1}$ & & & & $.59^{3}$ \\
\hline Never User & $32(39.0 \%)$ & $25(78.1 \%)$ & $7(21.9 \%)$ & \\
\hline Former User & $25(30.5 \%)$ & $22(88.0 \%)$ & $3(12.0 \%)$ & \\
\hline Current User & $25(30.5 \%)$ & $22(88.0 \%)$ & $3(12.0 \%)$ & \\
\hline Occupational Exposure ${ }^{1}$ & & & & .81 \\
\hline No & $41(53.3 \%)$ & $35(85.4 \%)$ & $6(14.6 \%)$ & \\
\hline Yes & $36(46.8 \%)$ & $30(83.3 \%)$ & $6(16.7 \%)$ & \\
\hline Exposure Category & & & & $.50^{2}$ \\
\hline Median (IQR) & $3(3)$ & $2.5(3)$ & $3(2)$ & \\
\hline Mean (SD) & $2.9(1.9)$ & $2.8(1.9)$ & $3.2(2.1)$ & \\
\hline
\end{tabular}


Table 30. Potential Covariates and Exposure Score by Cancer Diagnosis

\begin{tabular}{|c|c|c|c|c|}
\hline & \multirow{2}{*}{$\begin{array}{c}\text { Total } \\
\text { N (\%) }\end{array}$} & \multicolumn{2}{|c|}{ Diagnosed with Cancer } & \multirow[t]{2}{*}{$P$ value } \\
\hline & & No n(\%) & Yes n(\%) & \\
\hline Total & $83(100.0 \%)$ & $72(86.8 \%)$ & $11(13.3 \%)$ & \\
\hline Gender & & & & .78 \\
\hline Male & $41(49.4 \%)$ & $36(87.8 \%)$ & $5(12.2 \%)$ & \\
\hline Female & $42(50.6 \%)$ & $36(85.7 \%)$ & $6(14.3 \%)$ & \\
\hline Age (in years) & & & & $.12^{2}$ \\
\hline Median (IQR) & $61(16)$ & $60(16)$ & $65(13)$ & \\
\hline Mean (SD) & $58.4(14.7)$ & $57.3(14.9)$ & $65.3(11.7)$ & \\
\hline Race & & & & $1.00^{3}$ \\
\hline White & $70(84.3 \%)$ & $12(92.3 \%)$ & $1(7.7 \%)$ & \\
\hline Other Race & $13(15.7 \%)$ & $60(85.7 \%)$ & $10(14.3 \%)$ & \\
\hline BMI $^{1}$ & & & & $.08^{3}$ \\
\hline Normal & $22(27.2 \%)$ & $18(81.8 \%)$ & $4(18.2 \%)$ & \\
\hline Overweight & $31(38.3 \%)$ & $30(96.8 \%)$ & $1(3.2 \%)$ & \\
\hline Obese & $28(34.6 \%)$ & $22(78.6 \%)$ & $6(21.4 \%)$ & \\
\hline Personal Tobacco Use ${ }^{1}$ & & & & $.28^{3}$ \\
\hline Never User & $32(39.0 \%)$ & $26(81.3 \%)$ & $6(18.8 \%)$ & \\
\hline Former User & $25(30.5 \%)$ & $21(84.0 \%)$ & $4(16.0 \%)$ & \\
\hline Current User & $25(30.5 \%)$ & $24(96.0 \%)$ & $1(4.0 \%)$ & \\
\hline Occupational Exposure $^{1}$ & & & & $.75^{3}$ \\
\hline No & $41(53.3 \%)$ & $36(87.8 \%)$ & $5(12.2 \%)$ & \\
\hline Yes & $36(46.8 \%)$ & $30(83.3 \%)$ & $6(16.7 \%)$ & \\
\hline Exposure Score & & & & $.53^{2}$ \\
\hline Median (IQR) & $3(3)$ & $3(3)$ & $4(5)$ & \\
\hline Mean (SD) & $2.9(1.9)$ & $2.8(1.9)$ & $3.3(2.2)$ & \\
\hline
\end{tabular}

${ }^{1}$ Missing data for BMI $(\mathrm{n}=2)$, personal tobacco use $(\mathrm{n}=1)$, and occupational exposure $(\mathrm{n}=6)$

${ }^{2}$ Wilcoxon Rank Sum $P$ value

${ }^{3}$ Fisher's exact $P$ value calculated due to low expected cell counts 
Table 32. Potential Covariates and Exposure Score by Digestive System Disease

\begin{tabular}{lcccl}
\hline & Total & \multicolumn{2}{c}{ Diagnosed with } & P value \\
& N (\%) & \multicolumn{2}{c}{ Digestive System Disease } & \\
No n(\%) & Yes n(\%) & \\
\hline Total & $83(100.0 \%)$ & $52(62.7 \%)$ & $31(37.4 \%)$ & \\
Gender & & & & .004 \\
$\quad$ Male & $41(49.4 \%)$ & $32(78.1 \%)$ & $9(22.0 \%)$ & \\
$\quad$ Female & $42(50.6 \%)$ & $20(47.6 \%)$ & $22(52.4 \%)$ & \\
Age (in years) & & & & \\
$\quad$ Median (IQR) & $61(16)$ & $60(14.5)$ & $61(14)$ & $.26^{2}$ \\
$\quad$ Mean (SD) & $58.4(14.7)$ & $56.4(15.0)$ & $61.6(13.9)$ & \\
Race & & & & $1.00^{3}$ \\
$\quad$ White & $70(84.3 \%)$ & $44(62.9 \%)$ & $26(37.1 \%)$ & \\
$\quad$ Other Race & $13(15.7 \%)$ & $8(61.5 \%)$ & $5(38.5 \%)$ & \\
BMI & & & & .87 \\
$\quad$ Normal & $22(27.2 \%)$ & $14(63.6 \%)$ & $8(36.4 \%)$ & \\
$\quad$ Overweight & $31(38.3 \%)$ & $18(58.1 \%)$ & $13(41.9 \%)$ & \\
$\quad$ Obese & $28(34.6 \%)$ & $18(64.3 \%)$ & $10(35.7 \%)$ & \\
Personal Tobacco Use & & & & .08 \\
$\quad$ Never User & $32(39.0 \%)$ & $18(56.3 \%)$ & $14(43.8 \%)$ & \\
$\quad \begin{array}{l}\text { Former User } \\
\quad \text { Current User }\end{array}$ & $25(30.5 \%)$ & $13(52.0 \%)$ & $12(48.0 \%)$ & \\
Occupational Exposure1 & $25(30.5 \%)$ & $20(80.0 \%)$ & $5(20.0 \%)$ & \\
$\quad$ No & $41(53.3 \%)$ & $22(53.7 \%)$ & $19(46.3 \%)$ & \\
$\quad$ Yes & $36(46.8 \%)$ & $27(75.0 \%)$ & $9(25.0 \%)$ & \\
Exposure Score & & & & .64 \\
$\quad$ Median (IQR) & $3(3)$ & $3(3)$ & $3(4)$ & \\
$\quad$ Mean (SD) & $2.9(1.9)$ & $2.8(2.0)$ & $3.0(1.9)$ & \\
\hline
\end{tabular}

\footnotetext{
${ }^{1}$ Missing data for BMI $(\mathrm{n}=2)$, personal tobacco use $(\mathrm{n}=1)$, and occupational exposure $(\mathrm{n}=6)$

${ }^{2}$ Wilcoxon Rank Sum $P$ value

${ }^{3}$ Fisher's exact $P$ value calculated due to low expected cell counts
} 
Table 35. Potential Covariates and Exposure Score by Eye and Adnexa Disease

\begin{tabular}{lcccl}
\hline & Total & Diagnosed with Eye Disease & P value \\
& No (\%) & No no) & Yes n(\%) & \\
\hline Total & $83(100.0 \%)$ & $65(78.3 \%)$ & $18(21.7 \%)$ & \\
Gender & & & & .63 \\
$\quad$ Male & $41(49.4 \%)$ & $33(80.5 \%)$ & $8(19.5 \%)$ & \\
$\quad$ Female & $42(50.6 \%)$ & $32(76.2 \%)$ & $10(23.8 \%)$ & \\
Age (in years) & & & & $<.001^{2}$ \\
$\quad$ Median (IQR) & $61(16)$ & $57(17)$ & $70(14)$ & \\
$\quad$ Mean (SD) & $58.4(14.7)$ & $54.9(14.2)$ & $70.8(8.7)$ & \multirow{2}{*}{$1.00^{3}$} \\
Race & & & & \\
$\quad$ White & $70(84.3 \%)$ & $55(78.6 \%)$ & $15(21.4 \%)$ & \\
$\quad$ Other Race & $13(15.7 \%)$ & $10(76.9 \%)$ & $3(23.1 \%)$ & \\
BMI & & & & $.16^{3}$ \\
$\quad$ Normal & $22(27.2 \%)$ & $15(68.2 \%)$ & $7(31.8 \%)$ & \\
$\quad$ Overweight & $31(38.3 \%)$ & $23(74.2 \%)$ & $8(25.8 \%)$ & \\
$\quad$ Obese & $28(34.6 \%)$ & $25(89.3 \%)$ & $3(10.7 \%)$ & \\
Personal Tobacco Use & & & & \\
$\quad$ Never User & $32(39.0 \%)$ & $22(68.8 \%)$ & $10(31.3 \%)$ & \\
$\quad$ Former User & $25(30.5 \%)$ & $21(84.0 \%)$ & $4(16.0 \%)$ & \\
$\quad$ Current User & $25(30.5 \%)$ & $22(88.0 \%)$ & $3(12.0 \%)$ & \\
Occupational Exposure & & & & .03 \\
$\quad$ No & $41(53.3 \%)$ & $28(68.3 \%)$ & $13(31.7 \%)$ & \\
$\quad$ Yes & $36(46.8 \%)$ & $32(88.9 \%)$ & $4(11.1 \%)$ & \\
Exposure Score & & & & $0.81^{2}$ \\
$\quad$ Median (IQR) & $3(3)$ & $3(3)$ & $2.5(4)$ & \\
$\quad$ Mean (SD) & $2.9(1.9)$ & $2.9(1.9)$ & $3.0(2.0)$ & \\
\hline
\end{tabular}

${ }^{1}$ Missing data for BMI $(\mathrm{n}=2)$, personal tobacco use $(\mathrm{n}=1)$, and occupational exposure $(\mathrm{n}=6)$

${ }^{2}$ Wilcoxon Rank Sum $P$ value

${ }^{3}$ Fisher's exact $P$ value calculated due to low expected cell counts 
Table 37. Potential Covariates and Exposure Score by Mental, Behavioral, and Neurodevelopmental Disorders

\begin{tabular}{|c|c|c|c|c|}
\hline & \multirow{2}{*}{$\begin{array}{l}\text { Total } \\
\text { N (\%) } \\
\end{array}$} & \multicolumn{2}{|c|}{$\begin{array}{c}\text { Diagnosed with Mental, } \\
\text { Behavioral, and } \\
\text { Neurodevelopmental } \\
\text { Disorder }\end{array}$} & \multirow[t]{2}{*}{$P$ value } \\
\hline & & No n(\%) & Yes n(\%) & \\
\hline Total & $83(100.0 \%)$ & $57(68.7 \%)$ & $26(31.3 \%)$ & \\
\hline Gender & & & & .18 \\
\hline Male & $41(49.4 \%)$ & $31(75.6 \%)$ & $10(24.4 \%)$ & \\
\hline Female & $42(50.6 \%)$ & $26(61.9 \%)$ & $16(38.1 \%)$ & \\
\hline Age (in years) & & & & $.63^{2}$ \\
\hline Median (IQR) & $61(16)$ & $61(15)$ & $60.5(15)$ & \\
\hline Mean (SD) & $58.4(14.7)$ & $58.7(15.1)$ & $57.7(14.0)$ & \\
\hline Race & & & & $.53^{3}$ \\
\hline White & $70(84.3 \%)$ & $49(70.0 \%)$ & $21(30.0 \%)$ & \\
\hline Other Race & $13(15.7 \%)$ & $8(61.5 \%)$ & $5(38.5 \%)$ & \\
\hline BMI $^{1}$ & & & & .60 \\
\hline Normal & $22(27.2 \%)$ & $16(72.7 \%)$ & $6(27.3 \%)$ & \\
\hline Overweight & $31(38.3 \%)$ & $19(61.3 \%)$ & $12(38.7 \%)$ & \\
\hline Obese & $28(34.6 \%)$ & $20(71.4 \%)$ & $8(28.6 \%)$ & \\
\hline Personal Tobacco Use ${ }^{1}$ & & & & .07 \\
\hline Never User & $32(39.0 \%)$ & $24(75.0 \%)$ & $8(25.0 \%)$ & \\
\hline Former User & $25(30.5 \%)$ & $20(80.0 \%)$ & $5(20.0 \%)$ & \\
\hline Current User & $25(30.5 \%)$ & $13(52.0 \%)$ & $12(48.0 \%)$ & \\
\hline Occupational Exposure ${ }^{1}$ & & & & .19 \\
\hline No & $41(53.3 \%)$ & $25(61.0 \%)$ & $16(39.0 \%)$ & \\
\hline Yes & $36(46.8 \%)$ & $27(75.0 \%)$ & $9(25.0 \%)$ & \\
\hline Exposure Score & & & & $.96^{2}$ \\
\hline Median (IQR) & $3(3)$ & $3(3)$ & $3(2)$ & \\
\hline Mean (SD) & $2.9(1.9)$ & $2.9(2.0)$ & $2.9(1.8)$ & \\
\hline
\end{tabular}


Table 39. Potential Covariates and Exposure Score by Nervous System Diseases

\begin{tabular}{|c|c|c|c|c|}
\hline & Total & \multicolumn{2}{|c|}{$\begin{array}{c}\text { Diagnosed with } \\
\text { Nervous System Diseases }\end{array}$} & \multirow[t]{2}{*}{$P$ value } \\
\hline & $\mathbf{N}(\%)$ & No n(\%) & Yes n $(\%)$ & \\
\hline Total & $83(100.0 \%)$ & $59(71.1 \%)$ & $24(28.9 \%)$ & \\
\hline Gender & & & & .94 \\
\hline Male & $41(49.4 \%)$ & $29(70.7 \%)$ & $12(29.3 \%)$ & \\
\hline Female & $42(50.6 \%)$ & $30(71.4 \%)$ & $12(28.6 \%)$ & \\
\hline Age (in years) & & & & $.57^{2}$ \\
\hline Median (IQR) & $61(16)$ & $61(17)$ & $60.5(11.5)$ & \\
\hline Mean (SD) & $58.4(14.7)$ & $58.6(15.2)$ & $57.8(13.7)$ & \\
\hline Race & & & & $.75^{3}$ \\
\hline White & $70(84.3 \%)$ & $49(70.0 \%)$ & $21(30.0 \%)$ & \\
\hline Other Race & $13(15.7 \%)$ & $10(76.9 \%)$ & $3(23.1 \%)$ & \\
\hline BMI $^{1}$ & & & & .84 \\
\hline Normal & $22(27.2 \%)$ & $15(68.2 \%)$ & $7(31.8 \%)$ & \\
\hline Overweight & $31(38.3 \%)$ & $23(74.2 \%)$ & $8(25.8 \%)$ & \\
\hline Obese & $28(34.6 \%)$ & $19(67.9 \%)$ & $9(32.1 \%)$ & \\
\hline Personal Tobacco Use ${ }^{1}$ & & & & .50 \\
\hline Never User & $32(39.0 \%)$ & $25(78.1 \%)$ & $7(21.9 \%)$ & \\
\hline Former User & $25(30.5 \%)$ & $18(72.0 \%)$ & $7(28.0 \%)$ & \\
\hline Current User & $25(30.5 \%)$ & $16(64.0 \%)$ & $9(36.0 \%)$ & \\
\hline Occupational Exposure ${ }^{1}$ & & & & .93 \\
\hline No & $41(53.3 \%)$ & $30(73.2 \%)$ & $11(26.8 \%)$ & \\
\hline Yes & $36(46.8 \%)$ & $26(72.2 \%)$ & $10(27.8 \%)$ & \\
\hline Exposure Score & & & & $.21^{2}$ \\
\hline Median (IQR) & $3(3)$ & $2(3)$ & $3(3)$ & \\
\hline Mean (SD) & $2.9(1.9)$ & $2.7(1.9)$ & $3.3(1.9)$ & \\
\hline
\end{tabular}

${ }^{1}$ Missing data for BMI $(n=2)$, personal tobacco use $(n=1)$, and occupational exposure $(n=6)$

${ }^{2}$ Wilcoxon Rank Sum $P$ value

${ }^{3}$ Fisher's exact $P$ value calculated due to low expected cell counts 
Table 40. Potential Covariates and Exposure Score by Respiratory Diseases

\begin{tabular}{|c|c|c|c|c|}
\hline & \multirow{2}{*}{$\begin{array}{l}\text { Total } \\
\text { N (\%) }\end{array}$} & \multicolumn{2}{|c|}{$\begin{array}{c}\text { Diagnosed with } \\
\text { Respiratory Diseases }\end{array}$} & \multirow[t]{2}{*}{$P$ value } \\
\hline & & No n(\%) & Yes n $(\%)$ & \\
\hline Total & $83(100.0 \%)$ & $57(68.7 \%)$ & $26(31.3 \%)$ & \\
\hline Gender & & & & .07 \\
\hline Male & $41(49.4 \%)$ & $32(78.1 \%)$ & $9(21.9 \%)$ & \\
\hline Female & $42(50.6 \%)$ & $25(59.5 \%)$ & $17(40.5 \%)$ & \\
\hline Age (in years) & & & & $.98^{2}$ \\
\hline Median (IQR) & $61(16)$ & $61(15)$ & $59.5(21)$ & \\
\hline Mean (SD) & $58.4(14.7)$ & $57.9(14.6)$ & $59.3(15.2)$ & \\
\hline Race & & & & $.33^{3}$ \\
\hline White & $70(84.3 \%)$ & $50(71.4 \%)$ & $20(28.6 \%)$ & \\
\hline Other Race & $13(15.7 \%)$ & $7(53.9 \%)$ & $6(46.1 \%)$ & \\
\hline BMI $^{1}$ & & & & .58 \\
\hline Normal & $22(27.2 \%)$ & $13(59.1 \%)$ & $9(40.9 \%)$ & \\
\hline Overweight & $31(38.3 \%)$ & $22(71.0 \%)$ & $9(29.0 \%)$ & \\
\hline Obese & $28(34.6 \%)$ & $20(71.4 \%)$ & $8(28.6 \%)$ & \\
\hline Personal Tobacco Use ${ }^{1}$ & & & & .02 \\
\hline Never User & $32(39.0 \%)$ & $26(81.3 \%)$ & $6(18.8 \%)$ & \\
\hline Former User & $25(30.5 \%)$ & $18(72.0 \%)$ & $7(28.0 \%)$ & \\
\hline Current User & $25(30.5 \%)$ & $12(48.0 \%)$ & $13(52.0 \%)$ & \\
\hline Occupational Exposure ${ }^{1}$ & & & & .41 \\
\hline No & $41(53.3 \%)$ & $26(63.4 \%)$ & $15(36.6 \%)$ & \\
\hline Yes & $36(46.8 \%)$ & $26(72.2 \%)$ & $10(27.8 \%)$ & \\
\hline Exposure Score & & & & $.96^{2}$ \\
\hline Median (IQR) & $3(3)$ & $3(3)$ & $2.5(3)$ & \\
\hline Mean (SD) & $2.9(1.9)$ & $2.9(2.0)$ & $2.9(1.9)$ & \\
\hline
\end{tabular}


Table 42. Exposure Variables and Score by Diseases of the Blood and Blood-Forming Organs

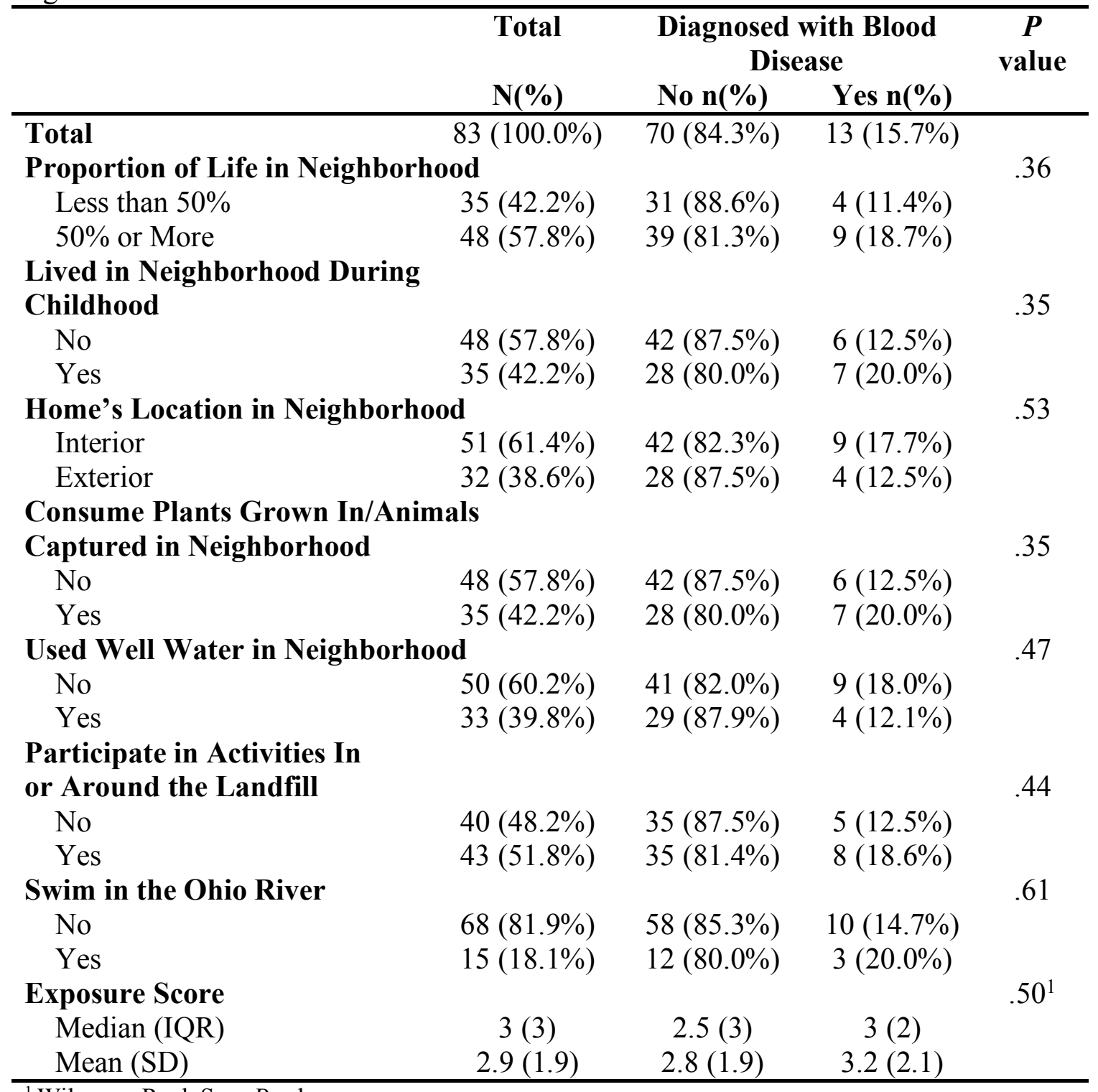

${ }^{1}$ Wilcoxon Rank Sum $P$ value 
Table 43. Exposure Variables and Score by Cancer Diagnosis

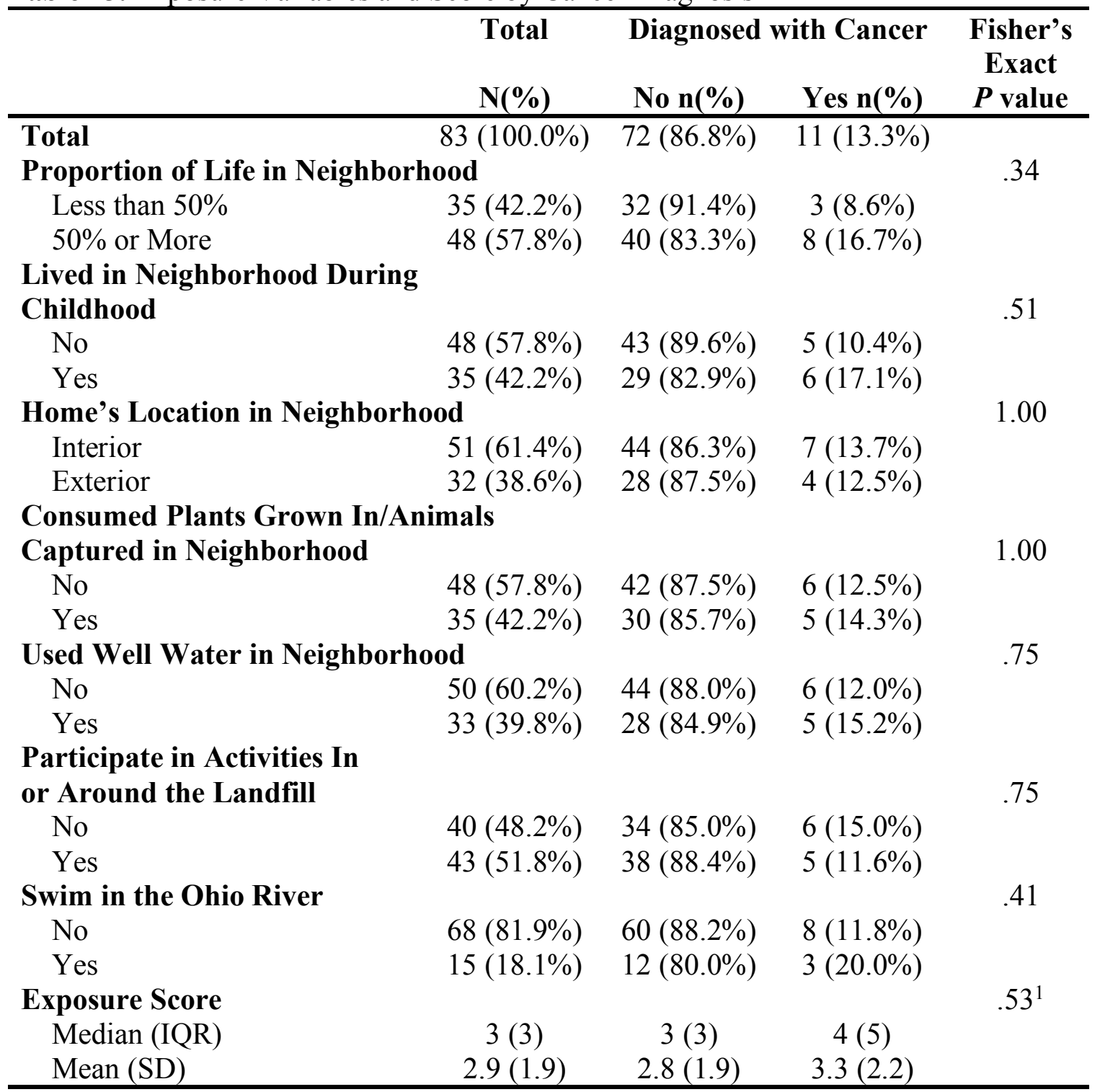

${ }^{1}$ Wilcoxon Rank Sum $P$ value 
Table 44. Exposure Variables and Score by Diseases of the Circulatory System

\begin{tabular}{|c|c|c|c|c|}
\hline & \multirow{2}{*}{$\begin{array}{l}\text { Total } \\
\text { N(\%) }\end{array}$} & \multicolumn{2}{|c|}{$\begin{array}{l}\text { Diagnosed with } \\
\text { Circulatory } \\
\text { System Disease }\end{array}$} & \multirow[t]{2}{*}{$\begin{array}{c}P \\
\text { value }\end{array}$} \\
\hline & & No n $(\%)$ & Yes n(\%) & \\
\hline Total & $83(100.0 \%)$ & $35(42.2 \%)$ & $48(57.8 \%)$ & \\
\hline Proportion of Life in Neighborhoo & & & & .02 \\
\hline Less than $50 \%$ & $35(42.2 \%)$ & $20(57.1 \%)$ & $15(42.9 \%)$ & \\
\hline $50 \%$ or More & $48(57.8 \%)$ & $15(31.3 \%)$ & $33(68.7 \%)$ & \\
\hline Lived in Neighborhood During & & & & \\
\hline Childhood & & & & .03 \\
\hline No & $48(57.8 \%)$ & $25(52.1 \%)$ & $23(47.9 \%)$ & \\
\hline Yes & $35(42.2 \%)$ & $10(28.6 \%)$ & $25(71.4 \%)$ & \\
\hline Home's Location in Neighborhood & & & & .25 \\
\hline Interior & $51(61.4 \%)$ & $19(37.3 \%)$ & $32(62.7 \%)$ & \\
\hline Exterior & $32(38.6 \%)$ & $16(50.0 \%)$ & $16(50.0 \%)$ & \\
\hline Consumed Plants Grown In/Anima & & & & \\
\hline Captured in Neighborhood & & & & .43 \\
\hline No & $48(57.8 \%)$ & $22(45.8 \%)$ & $26(54.2 \%)$ & \\
\hline Yes & $35(42.2 \%)$ & $13(37.1 \%)$ & $22(62.9 \%)$ & \\
\hline Used Well Water in Neighborhood & & & & .08 \\
\hline No & $50(60.2 \%)$ & $25(50.0 \%)$ & $25(50.0 \%)$ & \\
\hline Yes & $33(39.8 \%)$ & $10(30.3 \%)$ & $23(69.7 \%)$ & \\
\hline $\begin{array}{l}\text { Participate in Activities In } \\
\text { or Around the Landfill }\end{array}$ & & & & .61 \\
\hline No & $40(48.2 \%)$ & $18(45.0 \%)$ & $22(55.0 \%)$ & \\
\hline Yes & $43(51.8 \%)$ & $17(39.5 \%)$ & $26(60.5 \%)$ & \\
\hline Swim in the Ohio River & & & & .18 \\
\hline No & $68(81.9 \%)$ & $31(45.6 \%)$ & $37(54.4 \%)$ & \\
\hline Yes & $15(18.1 \%)$ & $4(26.7 \%)$ & $11(73.3 \%)$ & \\
\hline Exposure Score & & & & $.07^{1}$ \\
\hline Median (IQR) & $3(3)$ & $2(2)$ & $3(4)$ & \\
\hline Mean (SD) & $2.9(1.9)$ & $2.4(1.8)$ & $3.3(2.0)$ & \\
\hline
\end{tabular}

${ }^{1}$ Wilcoxon Rank Sum $P$ value 
Table 45. Exposure Variables and Score by Diseases of the Digestive System

\begin{tabular}{|c|c|c|c|c|}
\hline & \multirow{2}{*}{$\begin{array}{l}\text { Total } \\
\text { N(\%) }\end{array}$} & \multicolumn{2}{|c|}{$\begin{array}{c}\text { Diagnosed with } \\
\text { Digestive Disease }\end{array}$} & \multirow[t]{2}{*}{$\begin{array}{c}P \\
\text { value }\end{array}$} \\
\hline & & No $n(\%)$ & Yes n $(\%)$ & \\
\hline Total & $83(100.0 \%)$ & $52(62.7 \%)$ & $31(37.3 \%)$ & \\
\hline Proportion of Life in Neighborhooc & & & & .06 \\
\hline Less than $50 \%$ & $35(42.2 \%)$ & $26(74.3 \%)$ & $9(25.7 \%)$ & \\
\hline $50 \%$ or More & $48(57.8 \%)$ & $26(54.2 \%)$ & $22(45.8 \%)$ & \\
\hline Lived in Neighborhood During & & & & \\
\hline Childhood & & & & .67 \\
\hline No & $48(57.8 \%)$ & $31(64.6 \%)$ & $17(35.4 \%)$ & \\
\hline Yes & $35(42.2 \%)$ & $21(60.0 \%)$ & $14(40.0 \%)$ & \\
\hline Home's Location in Neighborhood & & & & .66 \\
\hline Interior & $51(61.4 \%)$ & $31(60.8 \%)$ & $20(39.2 \%)$ & \\
\hline Exterior & $32(38.6 \%)$ & $21(65.6 \%)$ & $11(34.4 \%)$ & \\
\hline Consumed Plants Grown In/Anima & & & & \\
\hline Captured in Neighborhood & & & & .97 \\
\hline No & $48(57.8 \%)$ & $30(62.5 \%)$ & $18(37.5 \%)$ & \\
\hline Yes & $35(42.2 \%)$ & $22(62.9 \%)$ & $13(37.1 \%)$ & \\
\hline Used Well Water in Neighborhood & & & & .88 \\
\hline No & $50(60.2 \%)$ & $31(62.0 \%)$ & $19(38.0 \%)$ & \\
\hline Yes & $33(39.8 \%)$ & $21(63.6 \%)$ & $12(36.4 \%)$ & \\
\hline $\begin{array}{l}\text { Participate in Activities In } \\
\text { or Around the Landfill }\end{array}$ & & & & .98 \\
\hline No & $40(48.2 \%)$ & $25(62.5 \%)$ & $15(37.5 \%)$ & \\
\hline Yes & $43(51.8 \%)$ & $27(62.8 \%)$ & $16(37.2 \%)$ & \\
\hline Swim in the Ohio River & & & & .81 \\
\hline No & $68(81.9 \%)$ & $43(63.2 \%)$ & $25(36.8 \%)$ & \\
\hline Yes & $15(18.1 \%)$ & $9(60.0 \%)$ & $6(40.0 \%)$ & \\
\hline Exposure Score & & & & $.64^{1}$ \\
\hline Median (IQR) & $3(3)$ & $3(3)$ & $3(4)$ & \\
\hline Mean (SD) & $2.9(1.9)$ & $2.8(2.0)$ & $3.0(1.9)$ & \\
\hline
\end{tabular}

${ }^{1}$ Wilcoxon Rank Sum $P$ value 
Table 46. Exposure Variables and Score by Diseases of the Ear and Mastoid Process

\begin{tabular}{|c|c|c|c|c|}
\hline & \multirow{2}{*}{$\begin{array}{l}\text { Total } \\
\text { N(\%) } \\
\end{array}$} & \multicolumn{2}{|c|}{$\begin{array}{l}\text { Diagnosed with } \\
\text { Ear Disease }\end{array}$} & \multirow[t]{2}{*}{$\begin{array}{c}P \\
\text { value }\end{array}$} \\
\hline & & No $n(\%)$ & Yes $n(\%)$ & \\
\hline Total & $83(100.0 \%)$ & $71(85.5 \%)$ & $12(14.5 \%)$ & \\
\hline Proportion of Life in Neighborhooc & & & & .19 \\
\hline Less than $50 \%$ & $35(42.2 \%)$ & $32(91.4 \%)$ & $3(8.6 \%)$ & \\
\hline $50 \%$ or More & $48(57.8 \%)$ & $39(81.2 \%)$ & $9(18.8 \%)$ & \\
\hline \multicolumn{5}{|l|}{ Lived in Neighborhood During } \\
\hline Childhood & & & & .55 \\
\hline No & $48(57.8 \%)$ & $42(87.5 \%)$ & $6(12.5 \%)$ & \\
\hline Yes & $35(42.2 \%)$ & $29(82.9 \%)$ & $6(17.1 \%)$ & \\
\hline Home's Location in Neighborhood & & & & .38 \\
\hline Interior & $51(61.4 \%)$ & $45(88.2 \%)$ & $6(11.8 \%)$ & \\
\hline Exterior & $32(38.6 \%)$ & $26(81.3 \%)$ & $6(18.7 \%)$ & \\
\hline \multicolumn{5}{|c|}{ Consumed Plants Grown In/Animals } \\
\hline Captured in Neighborhood & & & & .50 \\
\hline No & $48(57.8 \%)$ & $40(83.3 \%)$ & $8(16.7 \%)$ & \\
\hline Yes & $35(42.2 \%)$ & $31(88.6 \%)$ & $4(11.4 \%)$ & \\
\hline Used Well Water in Neighborhood & & & & $.06^{1}$ \\
\hline No & $50(60.2 \%)$ & $46(92.0 \%)$ & $4(8.0 \%)$ & \\
\hline Yes & $33(39.8 \%)$ & $25(75.8 \%)$ & $8(24.2 \%)$ & \\
\hline $\begin{array}{l}\text { Participate in Activities In } \\
\text { or Around the Landfill }\end{array}$ & & & & .62 \\
\hline No & $40(48.2 \%)$ & $35(87.5 \%)$ & $5(12.5 \%)$ & \\
\hline Yes & $43(51.8 \%)$ & $36(83.7 \%)$ & $7(16.3 \%)$ & \\
\hline Swim in the Ohio River & & & & .14 \\
\hline No & $68(81.9 \%)$ & $60(88.2 \%)$ & $8(11.8 \%)$ & \\
\hline Yes & $15(18.1 \%)$ & $11(73.3 \%)$ & $4(26.7 \%)$ & \\
\hline Exposure Score & & & & $.15^{2}$ \\
\hline Median (IQR) & $3(3)$ & $3(3)$ & $3(3.5)$ & \\
\hline Mean (SD) & $2.9(1.9)$ & $2.8(1.9)$ & $3.7(1.9)$ & \\
\hline
\end{tabular}

${ }^{1}$ Fisher's exact $P$ value calculated due to low expected cell counts

${ }^{2}$ Wilcoxon Rank Sum $P$ value 
Table 47. Exposure Variables and Score by Endocrine, Nutritional, and Metabolic Diseases

\begin{tabular}{|c|c|c|c|c|}
\hline & \multirow{2}{*}{$\begin{array}{l}\text { Total } \\
\text { N(\%) }\end{array}$} & \multicolumn{2}{|c|}{$\begin{array}{c}\text { Diagnosed with } \\
\text { Endocrine, Nutritional, } \\
\text { or Metabolic Disease }\end{array}$} & \multirow[t]{2}{*}{$\begin{array}{c}P \\
\text { value }\end{array}$} \\
\hline & & No n(\%) & Yes $n(\%)$ & \\
\hline Total & $83(100.0 \%)$ & $49(59.0 \%)$ & $34(41.0 \%)$ & \\
\hline \multicolumn{4}{|c|}{ Proportion of Life in Neighborhood } & .02 \\
\hline Less than $50 \%$ & $35(42.2 \%)$ & $26(74.3 \%)$ & $9(25.7 \%)$ & \\
\hline $50 \%$ or More & $48(57.8 \%)$ & $23(47.9 \%)$ & $25(52.1 \%)$ & \\
\hline \multicolumn{5}{|l|}{ Lived in Neighborhood During } \\
\hline Childhood & & & & .04 \\
\hline No & $48(57.8 \%)$ & $33(68.8 \%)$ & $15(31.2 \%)$ & \\
\hline Yes & $35(42.2 \%)$ & $16(45.7 \%)$ & $19(54.3 \%)$ & \\
\hline Home's Location in Neighborhood & & & & .18 \\
\hline Interior & $51(61.4 \%)$ & $33(64.7 \%)$ & $18(35.3 \%)$ & \\
\hline Exterior & $32(38.6 \%)$ & $16(50.0 \%)$ & $16(50.0 \%)$ & \\
\hline \multicolumn{5}{|c|}{ Consumed Plants Grown In/Animals } \\
\hline Captured in Neighborhood & & & & .88 \\
\hline No & $48(57.8 \%)$ & $28(58.3 \%)$ & $20(41.7 \%)$ & \\
\hline Yes & $35(42.2 \%)$ & $21(60.0 \%)$ & $14(40.0 \%)$ & \\
\hline Used Well Water in Neighborhood & & & & .11 \\
\hline No & $50(60.2 \%)$ & $33(66.0 \%)$ & $17(34.0 \%)$ & \\
\hline Yes & $33(39.8 \%)$ & $16(48.5 \%)$ & $17(51.5 \%)$ & \\
\hline $\begin{array}{l}\text { Participate in Activities In } \\
\text { or Around the Landfill }\end{array}$ & & & & .78 \\
\hline No & $40(48.2 \%)$ & $23(57.5 \%)$ & $17(42.5 \%)$ & \\
\hline Yes & $43(51.8 \%)$ & $26(60.5 \%)$ & $17(39.5 \%)$ & \\
\hline Swim in the Ohio River & & & & .28 \\
\hline No & $68(81.9 \%)$ & $42(61.8 \%)$ & $26(38.2 \%)$ & \\
\hline Yes & $15(18.1 \%)$ & $7(46.7 \%)$ & $8(53.3 \%)$ & \\
\hline Exposure Score & & & & $.06^{1}$ \\
\hline Median (IQR) & $3(3)$ & $2(3)$ & $4(4)$ & \\
\hline Mean (SD) & $2.9(1.9)$ & $2.6(1.8)$ & $3.4(2.0)$ & \\
\hline
\end{tabular}

${ }^{1}$ Wilcoxon Rank Sum $P$ value 
Table 48. Exposure Variables and Score by Diseases of the Eye and Adnexa

\begin{tabular}{|c|c|c|c|c|}
\hline & \multirow{2}{*}{$\begin{array}{l}\text { Total } \\
\text { N(\%) }\end{array}$} & \multicolumn{2}{|c|}{$\begin{array}{l}\text { Diagnosed with } \\
\text { Eye Disease }\end{array}$} & \multirow[t]{2}{*}{$\begin{array}{c}P \\
\text { value }\end{array}$} \\
\hline & & No n $(\%)$ & Yes n $(\%)$ & \\
\hline Total & $83(100.0 \%)$ & $65(78.3 \%)$ & $18(21.7 \%)$ & \\
\hline \multicolumn{4}{|c|}{ Proportion of Life in Neighborhood } & .16 \\
\hline Less than $50 \%$ & $35(42.2 \%)$ & $30(85.7 \%)$ & $5(14.3 \%)$ & \\
\hline $50 \%$ or More & $48(57.8 \%)$ & $35(72.9 \%)$ & $13(27.1 \%)$ & \\
\hline \multicolumn{5}{|l|}{ Lived in Neighborhood During } \\
\hline Childhood & & & & .83 \\
\hline No & $48(57.8 \%)$ & $38(79.2 \%)$ & $10(20.8 \%)$ & \\
\hline Yes & $35(42.2 \%)$ & $27(77.1 \%)$ & $8(22.9 \%)$ & \\
\hline Home's Location in Neighborhood & & & & .61 \\
\hline Interior & $51(61.4 \%)$ & $39(76.5 \%)$ & $12(23.5 \%)$ & \\
\hline Exterior & $32(38.6 \%)$ & $26(81.3 \%)$ & $6(18.8 \%)$ & \\
\hline \multicolumn{5}{|c|}{ Consumed Plants Grown In/Animals } \\
\hline Captured in Neighborhood & & & & .39 \\
\hline No & $48(57.8 \%)$ & $36(75.0 \%)$ & $12(25.0 \%)$ & \\
\hline Yes & $35(42.2 \%)$ & $29(82.9 \%)$ & $6(17.1 \%)$ & \\
\hline Used Well Water in Neighborhood & & & & .04 \\
\hline No & $50(60.2 \%)$ & $43(86.0 \%)$ & $7(14.0 \%)$ & \\
\hline Yes & $33(39.8 \%)$ & $22(66.7 \%)$ & $11(33.3 \%)$ & \\
\hline $\begin{array}{l}\text { Participate in Activities In } \\
\text { or Around the Landfill }\end{array}$ & & & & .08 \\
\hline No & $40(48.2 \%)$ & $28(70.0 \%)$ & $12(30.0 \%)$ & \\
\hline Yes & $43(51.8 \%)$ & $37(86.1 \%)$ & $6(14.0 \%)$ & \\
\hline Swim in the Ohio River & & & & $.73^{1}$ \\
\hline No & $68(81.9 \%)$ & $54(79.4 \%)$ & $14(20.6 \%)$ & \\
\hline Yes & $15(18.1 \%)$ & $11(73.3 \%)$ & $4(26.7 \%)$ & \\
\hline Exposure Score & & & & $.81^{2}$ \\
\hline Median (IQR) & $3(3)$ & $3(3)$ & $2.5(4)$ & \\
\hline Mean (SD) & $2.9(1.9)$ & $2.9(1.9)$ & $3.0(2.0)$ & \\
\hline
\end{tabular}

${ }^{1}$ Fisher's exact $P$ value calculated due to low expected cell counts

${ }^{2}$ Wilcoxon Rank Sum $P$ value 
Table 49. Exposure Variables and Score by Diseases of the Genitourinary System

\begin{tabular}{|c|c|c|c|c|}
\hline & \multirow{2}{*}{$\begin{array}{l}\text { Total } \\
\text { N(\%) } \\
\end{array}$} & \multicolumn{2}{|c|}{$\begin{array}{c}\text { Diagnosed with } \\
\text { Genitourinary System }\end{array}$} & \multirow{2}{*}{$\begin{array}{c}\text { Fisher's } \\
\text { Exact } \\
P \text { value } \\
\end{array}$} \\
\hline & & No n $(\%)$ & Yes n $(\%)$ & \\
\hline Total & $83(100.0 \%)$ & $74(86.2 \%)$ & $9(10.8 \%)$ & \\
\hline \multicolumn{4}{|c|}{ Proportion of Life in Neighborhood } & .07 \\
\hline Less than $50 \%$ & $35(42.2 \%)$ & $34(97.1 \%)$ & $1(2.9 \%)$ & \\
\hline $50 \%$ or More & $48(57.8 \%)$ & $40(83.3 \%)$ & $8(16.7 \%)$ & \\
\hline \multicolumn{5}{|l|}{ Lived in Neighborhood During } \\
\hline Childhood & & & & .16 \\
\hline No & $48(57.8 \%)$ & $45(93.8 \%)$ & $3(6.2 \%)$ & \\
\hline Yes & $35(42.2 \%)$ & $29(82.9 \%)$ & $6(17.1 \%)$ & \\
\hline Home's Location in Neighborhooc & & & & .30 \\
\hline Exterior & $32(38.6 \%)$ & $27(84.4 \%)$ & $5(15.6 \%)$ & \\
\hline Interior & $51(61.4 \%)$ & $47(92.2 \%)$ & $4(7.8 \%)$ & \\
\hline \multicolumn{5}{|c|}{ Consumed Plants Grown In/Animals } \\
\hline Captured in Neighborhood & & & & 1.00 \\
\hline No & $48(57.8 \%)$ & $43(89.6 \%)$ & $5(10.4 \%)$ & \\
\hline Yes & $35(42.2 \%)$ & $31(88.6 \%)$ & $4(11.4 \%)$ & \\
\hline Used Well Water in Neighborhooc & & & & .47 \\
\hline No & $50(60.2 \%)$ & $46(92.0 \%)$ & $4(8.0 \%)$ & \\
\hline Yes & $33(39.8 \%)$ & $28(84.9 \%)$ & $5(15.2 \%)$ & \\
\hline $\begin{array}{l}\text { Participate in Activities In } \\
\text { or Around the Landfill }\end{array}$ & & & & 1.00 \\
\hline No & $40(48.2 \%)$ & $36(90.0 \%)$ & $4(10.0 \%)$ & \\
\hline Yes & $43(51.8 \%)$ & $38(88.4 \%)$ & $5(11.6 \%)$ & \\
\hline Swim in the Ohio River & & & & .35 \\
\hline No & $68(81.9 \%)$ & $62(91.2 \%)$ & $6(8.8 \%)$ & \\
\hline Yes & $15(18.1 \%)$ & $12(80.0 \%)$ & $3(20.0 \%)$ & \\
\hline Exposure Score & & & & $.09^{1}$ \\
\hline Median (IQR) & $3(3)$ & $3(3)$ & $5(4)$ & \\
\hline Mean (SD) & $2.9(1.9)$ & $2.8(1.9)$ & $4.0(2.1)$ & \\
\hline
\end{tabular}

${ }^{1}$ Wilcoxon Rank Sum $P$ value 
Table 50. Exposure Variables and Score by Mental, Behavioral, and Neurodevelopmental Disorders

\begin{tabular}{|c|c|c|c|c|}
\hline & \multirow{2}{*}{$\begin{array}{l}\text { Total } \\
\mathbf{N}(\%) \\
\end{array}$} & \multicolumn{2}{|c|}{$\begin{array}{c}\text { Diagnosed with Mental, } \\
\text { Behavioral, or } \\
\text { Neurodevelopmental } \\
\text { Disease }\end{array}$} & \multirow[t]{2}{*}{$\begin{array}{c}P \\
\text { value }\end{array}$} \\
\hline & & No $n(\%)$ & Yes n(\%) & \\
\hline Total & $83(100.0 \%)$ & $57(68.7 \%)$ & $26(31.3 \%)$ & \\
\hline Proportion of Life in Neighborhoo & & & & .99 \\
\hline Less than $50 \%$ & $35(42.2 \%)$ & $24(68.6 \%)$ & $11(31.4 \%)$ & \\
\hline $50 \%$ or More & $48(57.8 \%)$ & $33(68.8 \%)$ & $15(31.3 \%)$ & \\
\hline \multicolumn{5}{|l|}{ Lived in Neighborhood During } \\
\hline Childhood & & & & .99 \\
\hline No & $48(57.8 \%)$ & $33(68.8 \%)$ & $15(31.2 \%)$ & \\
\hline Yes & $35(42.2 \%)$ & $24(68.6 \%)$ & $11(31.4 \%)$ & \\
\hline Home's Location in Neighborhood & & & & .99 \\
\hline Interior & $51(61.4 \%)$ & $35(68.6 \%)$ & $16(31.4 \%)$ & \\
\hline Exterior & $32(38.6 \%)$ & $22(68.7 \%)$ & $10(31.3 \%)$ & \\
\hline \multicolumn{5}{|c|}{ Consumed Plants Grown In/Animals } \\
\hline Captured in Neighborhood & & & & .35 \\
\hline No & $48(57.8 \%)$ & $31(64.6 \%)$ & $17(35.4 \%)$ & \\
\hline Yes & $35(42.2 \%)$ & $26(74.3 \%)$ & $9(25.7 \%)$ & \\
\hline Used Well Water in Neighborhood & & & & .87 \\
\hline No & $50(60.2 \%)$ & $34(68.0 \%)$ & $16(32.0 \%)$ & \\
\hline Yes & $33(39.8 \%)$ & $23(69.7 \%)$ & $10(30.3 \%)$ & \\
\hline Participate in Activities In & & & & \\
\hline $\begin{array}{l}\text { or Around the Landfill } \\
\text { No }\end{array}$ & $40(48.2 \%)$ & $29(72.5 \%)$ & $11(27.5 \%)$ & .47 \\
\hline Yes & $43(51.8 \%)$ & $28(65.1 \%)$ & $15(34.9 \%)$ & \\
\hline Swim in the Ohio River & & & & $1.00^{1}$ \\
\hline No & $68(81.9 \%)$ & $47(69.1 \%)$ & $21(30.9 \%)$ & \\
\hline Yes & $15(18.1 \%)$ & $10(66.7 \%)$ & $5(33.3 \%)$ & \\
\hline Exposure Score & & & & $.96^{2}$ \\
\hline Median (IQR) & $3(3)$ & $3(3)$ & $3(2)$ & \\
\hline Mean (SD) & $2.9(1.9)$ & $2.9(2.0)$ & $2.9(1.8)$ & \\
\hline
\end{tabular}

${ }^{1}$ Fisher's exact $P$ value calculated due to low expected cell counts

${ }^{2}$ Wilcoxon Rank Sum $P$ value 
Table 51. Exposure Variables and Score by Diseases of the Musculoskeletal System

\begin{tabular}{|c|c|c|c|c|}
\hline & \multirow{2}{*}{$\begin{array}{l}\text { Total } \\
\text { N(\%) }\end{array}$} & \multicolumn{2}{|c|}{$\begin{array}{c}\text { Diagnosed with } \\
\text { Musculoskeletal System } \\
\text { Disease }\end{array}$} & \multirow[t]{2}{*}{$\begin{array}{c}P \\
\text { value }\end{array}$} \\
\hline & & No n(\%) & Yes n(\%) & \\
\hline Total & $83(100.0 \%)$ & $35(42.2 \%)$ & $48(57.8 \%)$ & \\
\hline \multicolumn{4}{|c|}{ Proportion of Life in Neighborhood } & .06 \\
\hline Less than $50 \%$ & $35(42.2 \%)$ & $19(54.3 \%)$ & $16(45.7 \%)$ & \\
\hline $50 \%$ or More & $48(57.8 \%)$ & $16(33.3 \%)$ & $32(66.7 \%)$ & \\
\hline \multicolumn{5}{|l|}{ Lived in Neighborhood During } \\
\hline Childhood & & & & .21 \\
\hline No & $48(57.8 \%)$ & $23(47.9 \%)$ & $25(52.1 \%)$ & \\
\hline Yes & $35(42.2 \%)$ & $12(34.3 \%)$ & $23(65.7 \%)$ & \\
\hline Home's Location in Neighborhood & & & & .01 \\
\hline Interior & $51(61.4 \%)$ & $27(52.9 \%)$ & $24(47.1 \%)$ & \\
\hline Exterior & $32(38.6 \%)$ & $8(25.0 \%)$ & $24(75.0 \%)$ & \\
\hline \multicolumn{5}{|c|}{ Consumed Plants Grown In/Animals } \\
\hline Captured in Neighborhood & & & & .43 \\
\hline No & $48(57.8 \%)$ & $22(45.8 \%)$ & $26(54.2 \%)$ & \\
\hline Yes & $35(42.2 \%)$ & $13(37.1 \%)$ & $22(62.8 \%)$ & \\
\hline Used Well Water in Neighborhood & & & & .03 \\
\hline No & $50(60.2 \%)$ & $26(52.0 \%)$ & $24(48.0 \%)$ & \\
\hline Yes & $33(39.8 \%)$ & $9(27.3 \%)$ & $24(72.7 \%)$ & \\
\hline $\begin{array}{l}\text { Participate in Activities In } \\
\text { or Around the Landfill }\end{array}$ & & & & .61 \\
\hline No & $40(48.2 \%)$ & $18(45.0 \%)$ & $22(55.0 \%)$ & \\
\hline Yes & $43(51.8 \%)$ & $17(39.5 \%)$ & $26(60.5 \%)$ & \\
\hline Swim in the Ohio River & & & & .18 \\
\hline No & $68(81.9 \%)$ & $31(45.6 \%)$ & $37(54.4 \%)$ & \\
\hline Yes & $15(18.1 \%)$ & $4(26.7 \%)$ & $11(73.3 \%)$ & \\
\hline Exposure Score & & & & $.01^{1}$ \\
\hline Median (IQR) & $3(3)$ & $2(3)$ & $3(3)$ & \\
\hline Mean (SD) & $2.9(1.9)$ & $2.3(1.9)$ & $3.4(1.9)$ & \\
\hline
\end{tabular}

${ }^{1}$ Wilcoxon Rank Sum $P$ value 
Table 52. Exposure Variables and Score by Diseases of the Nervous System

\begin{tabular}{|c|c|c|c|c|}
\hline & \multirow{2}{*}{$\begin{array}{l}\text { Total } \\
\text { N(\%) }\end{array}$} & \multicolumn{2}{|c|}{$\begin{array}{c}\text { Diagnosed with Nervous } \\
\text { System Disease }\end{array}$} & \multirow[t]{2}{*}{$\begin{array}{c}P \\
\text { value }\end{array}$} \\
\hline & & No n(\%) & Yes n $(\%)$ & \\
\hline Total & $83(100.0 \%)$ & $59(71.1 \%)$ & $24(28.9 \%)$ & \\
\hline \multicolumn{4}{|c|}{ Proportion of Life in Neighborhood } & .58 \\
\hline Less than $50 \%$ & $35(42.2 \%)$ & $26(74.3 \%)$ & $9(25.7 \%)$ & \\
\hline $50 \%$ or More & $48(57.8 \%)$ & $33(68.8 \%)$ & $15(31.2 \%)$ & \\
\hline \multicolumn{5}{|l|}{ Lived in Neighborhood During } \\
\hline Childhood & & & & .36 \\
\hline No & $48(57.8 \%)$ & $36(75.0 \%)$ & $12(25.0 \%)$ & \\
\hline Yes & $35(42.2 \%)$ & $23(65.7 \%)$ & $12(34.3 \%)$ & \\
\hline Home's Location in Neighborhood & & & & .17 \\
\hline Interior & $51(61.4 \%)$ & $39(76.5 \%)$ & $12(23.5 \%)$ & \\
\hline Exterior & $32(38.6 \%)$ & $20(62.5 \%)$ & $12(37.5 \%)$ & \\
\hline \multicolumn{5}{|c|}{ Consumed Plants Grown In/Animals } \\
\hline Captured in Neighborhood & & & & .95 \\
\hline No & $48(57.8 \%)$ & $34(70.8 \%)$ & $14(29.2 \%)$ & \\
\hline Yes & $35(42.2 \%)$ & $25(71.4 \%)$ & $10(28.6 \%)$ & \\
\hline Used Well Water in Neighborhood & & & & .79 \\
\hline No & $50(60.2 \%)$ & $35(70.0 \%)$ & $15(30.0 \%)$ & \\
\hline Yes & $33(39.8 \%)$ & $24(72.7 \%)$ & $9(27.3 \%)$ & \\
\hline \multicolumn{5}{|l|}{ Participate in Activities In } \\
\hline No & $40(48.2 \%)$ & $32(80.0 \%)$ & $8(20.0 \%)$ & \\
\hline Yes & $43(51.8 \%)$ & $27(62.8 \%)$ & $16(37.2 \%)$ & \\
\hline Swim in the Ohio River & & & & $.35^{1}$ \\
\hline No & $68(81.9 \%)$ & $50(73.5 \%)$ & $18(26.5 \%)$ & \\
\hline Yes & $15(18.1 \%)$ & $9(60.0 \%)$ & $6(40.0 \%)$ & \\
\hline Exposure Score & & & & $.21^{2}$ \\
\hline Median (IQR) & $3(3)$ & $2(3)$ & $3(3)$ & \\
\hline Mean (SD) & $2.9(1.9)$ & $2.7(1.9)$ & $3.3(1.9)$ & \\
\hline
\end{tabular}

${ }^{1}$ Fisher's exact $P$ value calculated due to low expected cell counts

${ }^{2}$ Wilcoxon Rank Sum $P$ value 
Table 53. Exposure Variables and Score by Diseases of the Respiratory System

\begin{tabular}{|c|c|c|c|c|}
\hline & \multirow{2}{*}{$\begin{array}{l}\text { Total } \\
\text { N(\%) }\end{array}$} & \multicolumn{2}{|c|}{$\begin{array}{c}\text { Diagnosed with } \\
\text { Respiratory Disease }\end{array}$} & \multirow[t]{2}{*}{$\begin{array}{c}P \\
\text { value }\end{array}$} \\
\hline & & No n(\%) & Yes n(\%) & \\
\hline Total & $83(100.0 \%)$ & $57(68.7 \%)$ & $26(31.3 \%)$ & \\
\hline \multicolumn{4}{|c|}{ Proportion of Life in Neighborhood } & .16 \\
\hline Less than $50 \%$ & $35(42.2 \%)$ & $27(77.1 \%)$ & $8(22.9 \%)$ & \\
\hline $50 \%$ or More & $48(57.8 \%)$ & $30(62.5 \%)$ & $18(37.5 \%)$ & \\
\hline \multicolumn{5}{|l|}{ Lived in Neighborhood During } \\
\hline Childhood & & & & .66 \\
\hline No & $48(57.8 \%)$ & $32(66.7 \%)$ & $16(33.3 \%)$ & \\
\hline Yes & $35(42.2 \%)$ & $25(71.4 \%)$ & $10(28.6 \%)$ & \\
\hline Home's Location in Neighborhood & & & & .99 \\
\hline Interior & $51(61.4 \%)$ & $35(68.6 \%)$ & $16(31.4 \%)$ & \\
\hline Exterior & $32(38.6 \%)$ & $22(68.8 \%)$ & $10(31.3 \%)$ & \\
\hline \multicolumn{5}{|c|}{ Consumed Plants Grown In/Animals } \\
\hline Captured in Neighborhood & & & & .99 \\
\hline No & $48(57.8 \%)$ & $33(68.8 \%)$ & $15(31.2 \%)$ & \\
\hline Yes & $35(42.2 \%)$ & $24(68.6 \%)$ & $11(31.4 \%)$ & \\
\hline Used Well Water in Neighborhood & & & & .26 \\
\hline No & $50(60.2 \%)$ & $32(64.0 \%)$ & $18(36.0 \%)$ & \\
\hline Yes & $33(39.8 \%)$ & $25(75.8 \%)$ & $8(24.2 \%)$ & \\
\hline Participate in Activities In & & & & \\
\hline or Around the Landfill & & & & .80 \\
\hline No & $40(48.2 \%)$ & $28(70.0 \%)$ & $12(30.0 \%)$ & \\
\hline Yes & $43(51.8 \%)$ & $29(67.4 \%)$ & $14(32.6 \%)$ & \\
\hline Swim in the Ohio River & & & & $.77^{1}$ \\
\hline No & $68(81.9 \%)$ & $46(67.7 \%)$ & $22(32.3 \%)$ & \\
\hline Yes & $15(18.1 \%)$ & $11(73.3 \%)$ & $4(26.7 \%)$ & \\
\hline Exposure Score & & & & $.96^{2}$ \\
\hline Median (IQR) & $3(3)$ & $3(3)$ & $2.5(3)$ & \\
\hline Mean (SD) & $2.9(1.9)$ & $2.9(2.0)$ & $2.9(1.9)$ & \\
\hline
\end{tabular}

${ }^{1}$ Fisher's exact $P$ value calculated due to low expected cell counts

${ }^{2}$ Wilcoxon Rank Sum $P$ value 
Table 54. Exposure Variables and Score by Diseases of the Skin and Subcutaneous Tissue

\begin{tabular}{|c|c|c|c|c|}
\hline & \multirow{2}{*}{$\begin{array}{l}\text { Total } \\
\mathrm{N}(\%)\end{array}$} & \multicolumn{2}{|c|}{$\begin{array}{l}\text { Diagnosed with } \\
\text { Skin Disease }\end{array}$} & \multirow{2}{*}{$\begin{array}{l}\text { Fisher's } \\
\text { Exact } \\
P \text { value }\end{array}$} \\
\hline & & No n(\%) & Yes n(\%) & \\
\hline Total & $83(100.0 \%)$ & $75(90.4 \%)$ & $8(9.6 \%)$ & \\
\hline \multicolumn{4}{|c|}{ Proportion of Life in Neighborhood } & 1.00 \\
\hline Less than $50 \%$ & $35(42.2 \%)$ & $32(91.4 \%)$ & $3(8.6 \%)$ & \\
\hline $50 \%$ or More & $48(57.8 \%)$ & $43(89.6 \%)$ & $5(10.4 \%)$ & \\
\hline \multicolumn{5}{|l|}{ Lived in Neighborhood During } \\
\hline Childhood & & & & .06 \\
\hline No & $48(57.8 \%)$ & $46(95.8 \%)$ & $2(4.2 \%)$ & \\
\hline Yes & $35(42.2 \%)$ & $29(82.9 \%)$ & $6(17.1 \%)$ & \\
\hline Home's Location in Neighborhood & & & & .70 \\
\hline Interior & $51(61.4 \%)$ & $47(92.2 \%)$ & $4(7.8 \%)$ & \\
\hline Exterior & $32(38.6 \%)$ & $28(87.5 \%)$ & $4(12.5 \%)$ & \\
\hline \multicolumn{5}{|c|}{ Consumed Plants Grown In/Animals } \\
\hline Captured in Neighborhood & & & & .72 \\
\hline No & $48(57.8 \%)$ & $44(91.7 \%)$ & $4(8.3 \%)$ & \\
\hline Yes & $35(42.2 \%)$ & $31(88.6 \%)$ & $4(11.4 \%)$ & \\
\hline Used Well Water in Neighborhooc & & & & .26 \\
\hline No & $50(60.2 \%)$ & $47(94.0 \%)$ & $3(6.0 \%)$ & \\
\hline Yes & $33(39.8 \%)$ & $28(84.9 \%)$ & $5(15.2 \%)$ & \\
\hline $\begin{array}{l}\text { Participate in Activities In } \\
\text { or Around the Landfill }\end{array}$ & & & & .71 \\
\hline No & $40(48.2 \%)$ & $37(92.5 \%)$ & $3(7.5 \%)$ & \\
\hline Yes & $43(51.8 \%)$ & $38(88.4 \%)$ & $5(11.6 \%)$ & \\
\hline Swim in the Ohio River & & & & .03 \\
\hline No & $68(81.9 \%)$ & $64(94.1 \%)$ & $4(5.9 \%)$ & \\
\hline Yes & $15(18.1 \%)$ & $11(73.3 \%)$ & $4(26.7 \%)$ & \\
\hline Exposure Score & & & & $.10^{1}$ \\
\hline Median (IQR) & $3(3)$ & $3(3)$ & $4.5(4)$ & \\
\hline Mean (SD) & $2.9(1.9)$ & $2.8(1.9)$ & $4.1(2.3)$ & \\
\hline
\end{tabular}

${ }^{1}$ Wilcoxon Rank Sum $P$ value 
Table 60. Potential Covariates and Home's Location in Neighborhood by Frequency of Reported Bone and Muscle Symptoms

\begin{tabular}{|c|c|c|c|c|}
\hline \multirow[b]{2}{*}{ Variable } & \multicolumn{4}{|c|}{$\begin{array}{l}\text { Reported Bone and Muscle } \\
\text { Symptom Frequency }\end{array}$} \\
\hline & $\begin{array}{l}\text { Total } \\
\text { N (\%) }\end{array}$ & $\begin{array}{c}\text { Monthly } \\
\text { or Less } \\
\text { n (\%) }\end{array}$ & $\begin{array}{c}\text { Daily or } \\
\text { Weekly } \\
\text { n (\%) }\end{array}$ & $P$ value \\
\hline Total & $83(100.0 \%)$ & $35(42.2 \%)$ & $48(57.8 \%)$ & \\
\hline \multicolumn{4}{|l|}{ Gender } & .45 \\
\hline Male & $41(49.4 \%)$ & $19(46.3 \%)$ & $22(53.7 \%)$ & \\
\hline Female & $42(50.6 \%)$ & $16(38.1 \%)$ & $26(61.9 \%)$ & \\
\hline \multicolumn{4}{|l|}{ Age (in years) } & $.26^{2}$ \\
\hline Median (IQR) & $61(16)$ & $60(21)$ & $62(13.5)$ & \\
\hline Mean (SD) & $58.4(14.7)$ & $55.6(16.4)$ & $60.4(13.2)$ & \\
\hline \multicolumn{4}{|l|}{ Race } & .36 \\
\hline White & $70(84.3 \%)$ & $31(44.3 \%)$ & $39(55.7 \%)$ & \\
\hline Other Race & $13(15.7 \%)$ & $4(30.8 \%)$ & $9(69.2 \%)$ & \\
\hline \multicolumn{4}{|l|}{ BMI $^{1}$} & .99 \\
\hline Normal & $22(27.2 \%)$ & $9(40.9 \%)$ & $13(59.1 \%)$ & \\
\hline Overweight & $31(38.3 \%)$ & $13(41.9 \%)$ & $18(58.1 \%)$ & \\
\hline Obese & $28(34.6 \%)$ & $12(42.9 \%)$ & $16(57.1 \%)$ & \\
\hline \multicolumn{4}{|c|}{ History of Musculoskeletal Disease } & $<.001$ \\
\hline No & $35(42.2 \%)$ & $26(74.3 \%)$ & $9(25.7 \%)$ & \\
\hline Yes & $48(57.8 \%)$ & $9(18.8 \%)$ & $39(81.3 \%)$ & \\
\hline \multicolumn{4}{|c|}{ Personal Tobacco Use ${ }^{1}$} & .54 \\
\hline Never User & $32(39.0 \%)$ & $16(50.0 \%)$ & $16(50.0 \%)$ & \\
\hline Former User & $25(30.5 \%)$ & $10(40.0 \%)$ & $15(60.0 \%)$ & \\
\hline Current User & $25(30.5 \%)$ & $9(36.0 \%)$ & $16(64.0 \%)$ & \\
\hline \multicolumn{4}{|c|}{ Occupational Exposure 1} & .99 \\
\hline No & $41(53.3 \%)$ & $17(41.5 \%)$ & $24(58.5 \%)$ & \\
\hline Yes & $36(46.8 \%)$ & $15(41.7 \%)$ & $21(58.3 \%)$ & \\
\hline \multicolumn{4}{|c|}{ Time Spent Outdoors (hours per week) ${ }^{1}$} & .008 \\
\hline$<20$ & $33(48.5 \%)$ & $20(60.6 \%)$ & $13(39.4 \%)$ & \\
\hline$\geq 20$ & $35(51.5 \%)$ & $10(28.6 \%)$ & $25(71.4 \%)$ & \\
\hline \multicolumn{4}{|c|}{ Home's Location in Neighborhood } & .50 \\
\hline Interior & $51(61.5 \%)$ & $23(45.1 \%)$ & $28(54.9 \%)$ & \\
\hline Exterior & $32(38.6 \%)$ & $12(37.5 \%)$ & $20(62.5 \%)$ & \\
\hline
\end{tabular}

${ }^{1}$ Missing data for BMI $(\mathrm{n}=2)$, personal tobacco use $(\mathrm{n}=1)$, occupational exposure $(\mathrm{n}=6)$, and time spent outdoors $(\mathrm{n}=15)$

${ }^{2}$ Wilcoxon Rank Sum $P$ value 
Table 61. Potential Covariates and Home's Location in Neighborhood by Frequency of Reported Eye Symptoms

\begin{tabular}{|c|c|c|c|c|c|c|c|}
\hline \multirow[b]{2}{*}{ Variable } & \multicolumn{6}{|c|}{$\begin{array}{c}\text { Reported Eye Symptom } \\
\text { Frequency }\end{array}$} & \multirow[b]{2}{*}{$\begin{array}{c}P \\
\text { value }\end{array}$} \\
\hline & \multicolumn{2}{|c|}{$\begin{array}{l}\text { Total } \\
\text { N (\%) }\end{array}$} & \multicolumn{2}{|c|}{$\begin{array}{c}\text { Monthly or } \\
\text { Less } \\
\text { n (\%) }\end{array}$} & \multicolumn{2}{|c|}{$\begin{array}{c}\text { Daily or } \\
\text { Weekly } \\
\text { n (\%) }\end{array}$} & \\
\hline Total & 83 & $(100.0 \%)$ & 54 & $(65.1 \%)$ & 29 & $(34.9 \%)$ & \\
\hline Gender & & & & & & & .88 \\
\hline Male & 41 & $(49.4 \%)$ & 27 & $(65.9 \%)$ & 14 & $(34.1 \%)$ & \\
\hline Female & 42 & $(50.6 \%)$ & 27 & $(64.3 \%)$ & 15 & $(35.7 \%)$ & \\
\hline Age (in years) & & & & & & & $.74^{2}$ \\
\hline Median (IQR) & 61 & $(16)$ & 61.5 & $(16)$ & 60 & $(12)$ & \\
\hline Mean (SD) & 58.4 & $(14.7)$ & 58.4 & $(15.5)$ & 58.4 & (13.3) & \\
\hline Race & & & & & & & $.76^{3}$ \\
\hline White & 70 & $(84.3 \%)$ & 46 & $(65.7 \%)$ & 24 & $(34.3 \%)$ & \\
\hline Other Race & 13 & $(15.7 \%)$ & 8 & $(61.5 \%)$ & 5 & $(38.5 \%)$ & \\
\hline BMI $^{1}$ & & & & & & & .62 \\
\hline Normal & 22 & $(27.2 \%)$ & 16 & $(72.7 \%)$ & 6 & $(27.3 \%)$ & \\
\hline Overweight & 31 & $(38.3 \%)$ & 19 & $(61.3 \%)$ & 12 & $(38.7 \%)$ & \\
\hline Obese & 28 & $(34.6 \%)$ & 17 & $(60.7 \%)$ & 11 & $(39.3 \%)$ & \\
\hline History of Eye Disease & & & & & & & .87 \\
\hline No & 65 & $(78.3 \%)$ & 42 & $(64.6 \%)$ & 23 & $(35.4 \%)$ & \\
\hline Yes & 18 & $(21.7 \%)$ & 12 & $(66.7 \%)$ & 6 & $(33.3 \%)$ & \\
\hline Personal Tobacco Use ${ }^{1}$ & & & & & & & .20 \\
\hline Never User & 32 & $(39.0 \%)$ & 24 & $(75.0 \%)$ & 8 & $(25.0 \%)$ & \\
\hline Former User & 25 & $(30.5 \%)$ & 16 & $(64.0 \%)$ & 9 & $(36.0 \%)$ & \\
\hline Current User & 25 & $(30.5 \%)$ & 13 & $(52.0 \%)$ & 12 & $(48.0 \%)$ & \\
\hline Occupational Exposure & & & & & & & .97 \\
\hline No & 41 & $(53.2 \%)$ & 26 & $(63.4 \%)$ & 15 & $(36.6 \%)$ & \\
\hline Yes & 36 & $(46.8 \%)$ & 23 & $(63.9 \%)$ & 13 & $(36.1 \%)$ & \\
\hline Time Spent Outdoors ( & hours & per week) & & & & & .19 \\
\hline$<20$ & 33 & $(48.5 \%)$ & 23 & $(69.7 \%)$ & 10 & $(30.3 \%)$ & \\
\hline$\geq 20$ & 35 & $(51.5 \%)$ & 19 & $(54.3 \%)$ & 16 & $(45.7 \%)$ & \\
\hline Home's Location in Ne & ighbo & rhood & & & & & .58 \\
\hline Interior & 51 & $(61.4 \%)$ & 32 & $(62.7 \%)$ & 19 & $(37.3 \%)$ & \\
\hline Exterior & 32 & $(38.6 \%)$ & 22 & $(68.8 \%)$ & 10 & $(31.3 \%)$ & \\
\hline
\end{tabular}

${ }^{1}$ Missing data for BMI $(\mathrm{n}=2)$, tobacco use $(\mathrm{n}=1)$, occupational exposure $(\mathrm{n}=6)$, and time spent outdoors $(\mathrm{n}=15)$

${ }^{2}$ Wilcoxon Rank Sum $P$ value

${ }^{3}$ Fisher's exact $P$ value calculated due to low expected cell counts 
Table 62. Potential Covariates and Home's Location in Neighborhood by Frequency of Reported Gastrointestinal Symptoms

\begin{tabular}{|c|c|c|c|c|c|c|c|}
\hline \multirow[b]{2}{*}{ Variable } & \multicolumn{6}{|c|}{$\begin{array}{c}\text { Reported Gastrointestinal } \\
\text { Symptom Frequency }\end{array}$} & \multirow[b]{2}{*}{$\begin{array}{c}P \\
\text { value }\end{array}$} \\
\hline & \multicolumn{2}{|c|}{$\mathbf{N}(\%)$} & \multicolumn{2}{|c|}{$\begin{array}{c}\text { Monthly or } \\
\text { Less } \\
\text { n (\%) }\end{array}$} & \multicolumn{2}{|c|}{$\begin{array}{c}\text { Daily or } \\
\text { Weekly } \\
\text { n (\%) }\end{array}$} & \\
\hline Total & 83 & $(100.0 \%)$ & 53 & $(63.9 \%)$ & 30 & $(36.1 \%)$ & \\
\hline Gender & & & & & & & .20 \\
\hline Male & 41 & $(49.4 \%)$ & 29 & $(70.7 \%)$ & 12 & $(29.3 \%)$ & \\
\hline Female & 42 & $(50.6 \%)$ & 24 & $(57.1 \%)$ & 18 & $(42.9 \%)$ & \\
\hline Age (in years) & & & & & & & $.15^{2}$ \\
\hline Median (IQR) & 61 & $(16)$ & 60 & $(14)$ & 63.5 & $(14)$ & \\
\hline Mean (SD) & 58.4 & $(14.7)$ & 56.9 & $(15.0)$ & 61 & $(14.1)$ & \\
\hline Race & & & & & & & $1.00^{3}$ \\
\hline White & 70 & $(84.3 \%)$ & 45 & $(64.3 \%)$ & 25 & $(35.7 \%)$ & \\
\hline Other Race & 13 & $(15.7 \%)$ & 8 & $(61.5 \%)$ & 5 & $(38.5 \%)$ & \\
\hline BMI $^{1}$ & & & & & & & .91 \\
\hline Normal & 22 & $(27.2 \%)$ & 13 & $(59.1 \%)$ & 9 & $(40.9 \%)$ & \\
\hline Overweight & 31 & $(38.3 \%)$ & 20 & $(64.5 \%)$ & 11 & $(35.5 \%)$ & \\
\hline Obese & 28 & $(34.6 \%)$ & 18 & $(64.3 \%)$ & 10 & $(35.7 \%)$ & \\
\hline \multicolumn{8}{|c|}{ History of Digestive Disease } \\
\hline No & 52 & $(62.7 \%)$ & 41 & $(78.9 \%)$ & 11 & $(21.2 \%)$ & $<.001$ \\
\hline Yes & 31 & $(37.4 \%)$ & 12 & $(38.7 \%)$ & 19 & $(61.3 \%)$ & \\
\hline Personal Tobacco Use ${ }^{1}$ & & & & & & & .80 \\
\hline Never User & 32 & $(39.0 \%)$ & 19 & $(59.4 \%)$ & 13 & $(40.6 \%)$ & \\
\hline Former User & 25 & $(30.5 \%)$ & 16 & $(64.0 \%)$ & 9 & $(36.0 \%)$ & \\
\hline Current User & 25 & $(30.5 \%)$ & 17 & $(68.0 \%)$ & 8 & $(32.0 \%)$ & \\
\hline Occupational Exposure $^{1}$ & & & & & & & .84 \\
\hline No & 41 & $(53.2 \%)$ & 26 & $(63.4 \%)$ & 15 & $(36.6 \%)$ & \\
\hline Yes & 36 & $(46.8 \%)$ & 22 & $(61.1 \%)$ & 14 & $(38.9 \%)$ & \\
\hline Time Spent Outdoors (h & ours & per week) & & & & & .02 \\
\hline$<20$ & 33 & $(48.5 \%)$ & 27 & $(81.8 \%)$ & 6 & $(18.2 \%)$ & \\
\hline$\geq 20$ & 35 & $(51.5 \%)$ & 19 & $(54.3 \%)$ & 16 & $(45.7 \%)$ & \\
\hline Home's Location in Neig & ghbor & hood & & & & & .50 \\
\hline Interior & 51 & $(61.4 \%)$ & 34 & $(66.7 \%)$ & 17 & $(33.3 \%)$ & \\
\hline Exterior & 32 & $(38.6 \%)$ & 19 & $(59.4 \%)$ & 13 & $(40.6 \%)$ & \\
\hline
\end{tabular}

\footnotetext{
${ }^{1}$ Missing data for BMI $(n=2)$, personal tobacco use $(n=1)$, occupational exposure $(n=6)$, and time spent outdoors $(\mathrm{n}=15)$

${ }^{2}$ Wilcoxon Rank Sum $P$ value

${ }^{3}$ Fisher's exact $P$ value calculated due to low expected cell counts
} 
Table 63. Potential Covariates and Home's Location in Neighborhood by Frequency of Reported Mood Symptoms

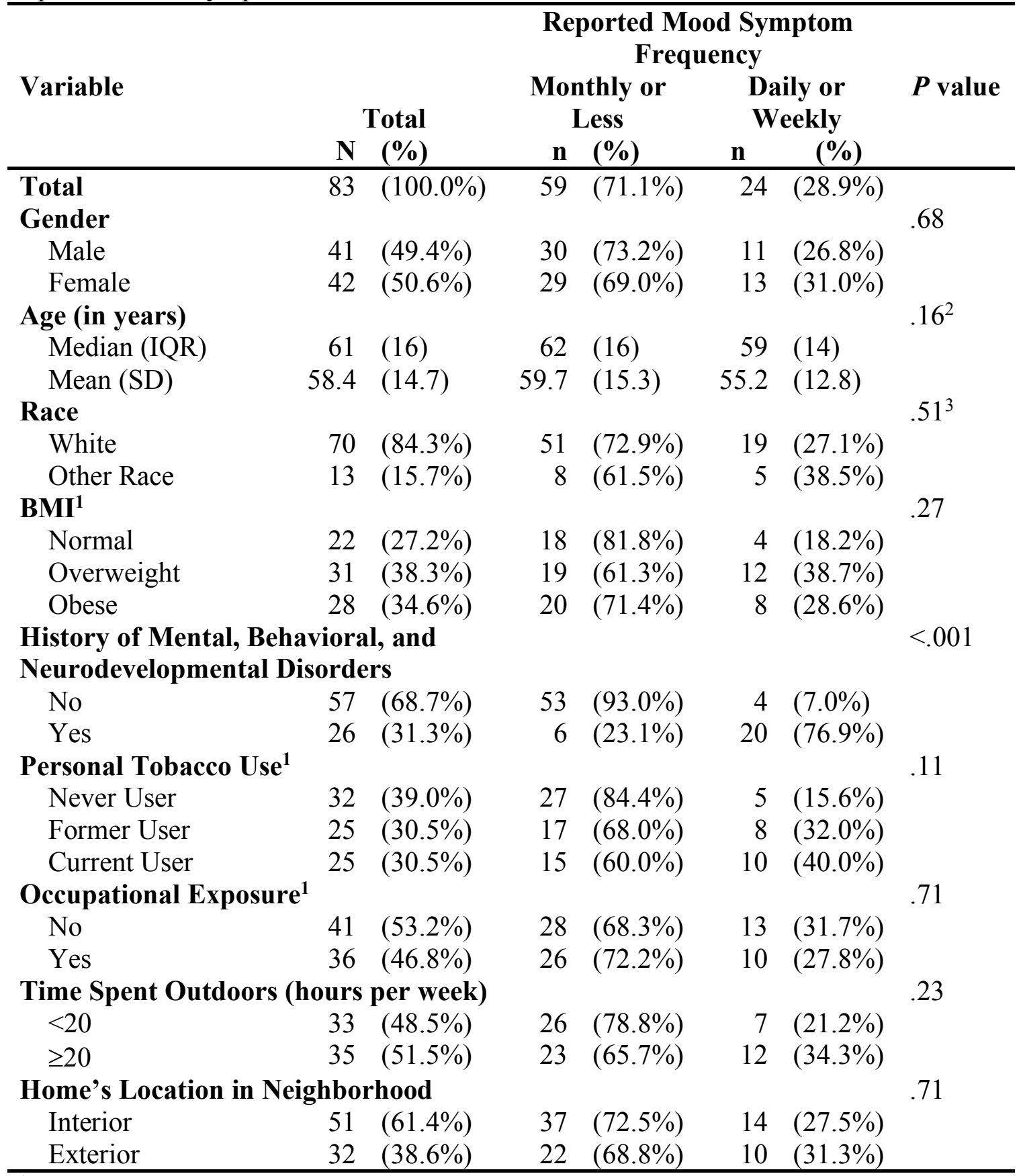

${ }^{1}$ Missing data for BMI ( $\left.\mathrm{n}=2\right)$, personal tobacco use $(\mathrm{n}=1)$, occupational exposure $(\mathrm{n}=6)$, and time spent outdoors $(\mathrm{n}=15)$

${ }^{2}$ Wilcoxon Rank Sum $P$ value

${ }^{3}$ Fisher's exact $P$ value calculated due to low expected cell counts 
Table 64. Potential Covariates and Home's Location in Neighborhood by Frequency of Reported Neurological Symptoms

\begin{tabular}{|c|c|c|c|c|c|c|c|}
\hline \multirow{3}{*}{ Variable } & \multicolumn{7}{|c|}{$\begin{array}{l}\text { Reported Neurological } \\
\text { Symptom Frequency }\end{array}$} \\
\hline & \multicolumn{2}{|c|}{ Total } & \multicolumn{2}{|c|}{ Monthly or } & \multicolumn{2}{|c|}{$\begin{array}{l}\text { Daily or } \\
\text { Weekly }\end{array}$} & \multirow[t]{2}{*}{$P$ value } \\
\hline & $\mathbf{N}$ & $\begin{array}{r}1 \text { otal } \\
(\%)\end{array}$ & n & $(\%)$ & $\mathrm{n}$ & (\%) & \\
\hline Total & 83 & $(100.0 \%)$ & 36 & $(43.4 \%)$ & 47 & $(56.6 \%)$ & \\
\hline Gender & & & & & & & .92 \\
\hline Male & 41 & $(49.4 \%)$ & 18 & $(43.9 \%)$ & 23 & $(56.1 \%)$ & \\
\hline Female & 42 & $(50.6 \%)$ & 18 & $(42.9 \%)$ & 24 & $(57.1 \%)$ & \\
\hline Age (in years) & & & & & & & $.77^{2}$ \\
\hline Median (IQR) & 61 & (16) & 61 & (20) & 61 & (13) & \\
\hline Mean (SD) & 58.4 & (14.7) & 56.9 & $(16.8)$ & 59.5 & $(13.0)$ & \\
\hline Race & & & & & & & .32 \\
\hline White & 70 & $(84.3 \%)$ & 32 & $(45.7 \%)$ & 38 & $(52.3 \%)$ & \\
\hline Other Race & 13 & $(15.7 \%)$ & 4 & $(30.8 \%)$ & 9 & $(69.2 \%)$ & \\
\hline $\mathbf{B M I}^{1}$ & & & & & & & .72 \\
\hline Normal & 22 & $(27.2 \%)$ & 11 & $(50.0 \%)$ & 11 & $(50.0 \%)$ & \\
\hline Overweight & 31 & $(38.3 \%)$ & 12 & $(38.7 \%)$ & 19 & $(61.2 \%)$ & \\
\hline Obese & 28 & $(34.6 \%)$ & 12 & $(42.9 \%)$ & 16 & $(57.1 \%)$ & \\
\hline History of Nerve & tem D & isease & & & & & $<.001$ \\
\hline No & 59 & $(71.1 \%)$ & 34 & $(57.6 \%)$ & 25 & $(42.4 \%)$ & \\
\hline Yes & 24 & $(28.9 \%)$ & 2 & $(8.33 \%)$ & 22 & $(91.7 \%)$ & \\
\hline Personal Tobace & & & & & & & .87 \\
\hline Never User & 32 & $(39.0 \%)$ & 15 & $(46.9 \%)$ & 17 & $(53.1 \%)$ & \\
\hline Former User & 25 & $(30.5 \%)$ & 11 & $(44.0 \%)$ & 14 & $(56.0 \%)$ & \\
\hline Current User & 25 & $(30.5 \%)$ & 10 & $(40.0 \%)$ & 15 & $(60.0 \%)$ & \\
\hline Occupational Ex & & & & & & & .36 \\
\hline No & 41 & $(53.2 \%)$ & 19 & $(46.3 \%)$ & 22 & $(53.7 \%)$ & \\
\hline Yes & 36 & $(46.8 \%)$ & 13 & $(36.1 \%)$ & 23 & $(63.9 \%)$ & \\
\hline Time Spent Out & hours & per week) & & & & & $<.001$ \\
\hline$<20$ & 33 & $(48.5 \%)$ & 20 & $(60.6 \%)$ & 13 & $(39.4 \%)$ & \\
\hline$\geq 20$ & 35 & $(51.5 \%)$ & 7 & $(20.0 \%)$ & 28 & $(80.0 \%)$ & \\
\hline Home's Locatio & ighbo & rhood & & & & & .69 \\
\hline Interior & 51 & $(61.4 \%)$ & 23 & $(45.1 \%)$ & 28 & $(54.9 \%)$ & \\
\hline Exterior & 32 & $(38.6 \%)$ & 13 & $(40.6 \%)$ & 19 & $(59.4 \%)$ & \\
\hline
\end{tabular}

\footnotetext{
${ }^{1}$ Missing data for BMI $(\mathrm{n}=2)$, personal tobacco use $(\mathrm{n}=1)$, occupational exposure $(\mathrm{n}=6)$, and time spent outdoors $(\mathrm{n}=15)$

${ }^{2}$ Wilcoxon Rank Sum $P$ value
} 
Table 65. Potential Covariates and Home's Location in Neighborhood by Frequency of Reported Respiratory Symptoms

\begin{tabular}{|c|c|c|c|c|c|c|c|}
\hline \multirow{3}{*}{ Variable } & \multicolumn{7}{|c|}{$\begin{array}{l}\text { Reported Respiratory } \\
\text { Symptom Frequency }\end{array}$} \\
\hline & \multicolumn{2}{|c|}{ Total } & \multicolumn{2}{|c|}{$\begin{array}{l}\text { Monthly or } \\
\text { Less }\end{array}$} & \multicolumn{2}{|c|}{$\begin{array}{l}\text { Daily or } \\
\text { Weekly }\end{array}$} & \multirow[t]{2}{*}{$\begin{array}{c}P \\
\text { value }\end{array}$} \\
\hline & $\mathbf{N}$ & $(\%)$ & $\mathbf{n}$ & $(\%)$ & n & $(\%)$ & \\
\hline Total & 83 & $(100.0 \%)$ & 41 & $(49.4 \%)$ & 42 & $(50.6 \%)$ & \\
\hline Gender & & & & & & & .10 \\
\hline Male & 41 & $(49.4 \%)$ & 24 & $(58.5 \%)$ & 17 & $(41.5 \%)$ & \\
\hline Female & 42 & $(50.6 \%)$ & 17 & $(40.5 \%)$ & 25 & $(59.5 \%)$ & \\
\hline Age (in years) & & & & & & & $.43^{2}$ \\
\hline Median (IQR) & 61 & $(16)$ & 60 & $(14)$ & 61 & $(14)$ & \\
\hline Mean (SD) & 58.4 & $(14.7)$ & 57.0 & $(15.8)$ & 59.7 & $(13.7)$ & \\
\hline Race & & & & & & & $.80^{3}$ \\
\hline White & 70 & $(84.3 \%)$ & 35 & $(50.0 \%)$ & 35 & $(50.0 \%)$ & \\
\hline Other Race & 13 & $(15.7 \%)$ & 6 & $(46.2 \%)$ & 7 & $(53.8 \%)$ & \\
\hline BMI $^{1}$ & & & & & & & .91 \\
\hline Normal & 22 & $(27.2 \%)$ & 11 & $(50.0 \%)$ & 11 & $(50.0 \%)$ & \\
\hline Overweight & 31 & $(38.3 \%)$ & 14 & $(45.2 \%)$ & 17 & $(54.8 \%)$ & \\
\hline Obese & 28 & $(34.6 \%)$ & 14 & $(50.0 \%)$ & 14 & $(50.0 \%)$ & \\
\hline History of Respi & Diseas & & & & & & .001 \\
\hline No & 57 & $(68.7 \%)$ & 35 & $(61.4 \%)$ & 22 & $(38.6 \%)$ & \\
\hline Yes & 26 & $(31.3 \%)$ & 6 & $(23.1 \%)$ & 20 & $(76.9 \%)$ & \\
\hline Personal Tobacc & & & & & & & .34 \\
\hline Never User & 32 & $(39.0 \%)$ & 19 & $(59.4 \%)$ & 13 & $(40.6 \%)$ & \\
\hline Former User & 25 & $(30.5 \%)$ & 12 & $(48.0 \%)$ & 13 & $(52.0 \%)$ & \\
\hline Current User & 25 & $(30.5 \%)$ & 10 & $(40.0 \%)$ & 15 & $(60.0 \%)$ & \\
\hline Occupational Ex & & & & & & & .44 \\
\hline No & 41 & $(53.2 \%)$ & 18 & $(43.9 \%)$ & 23 & $(56.1 \%)$ & \\
\hline Yes & 36 & $(46.8 \%)$ & 19 & $(52.8 \%)$ & 17 & $(47.2 \%)$ & \\
\hline Time Spent Out & lours & per week) & & & & & .03 \\
\hline$<20$ & 33 & $(48.5 \%)$ & 20 & $(60.6 \%)$ & 13 & $(39.4 \%)$ & \\
\hline$\geq 20$ & 35 & $(51.5 \%)$ & 12 & $(34.3 \%)$ & 23 & $(65.7 \%)$ & \\
\hline Home's Locatior & ghbor & hood & & & & & .21 \\
\hline Interior & 51 & $(61.4 \%)$ & 28 & $(54.9 \%)$ & 23 & $(45.1 \%)$ & \\
\hline Exterior & 32 & $(38.6 \%)$ & 13 & $(40.6 \%)$ & 19 & $(59.4 \%)$ & \\
\hline
\end{tabular}

\footnotetext{
${ }^{1}$ Missing data for BMI $(\mathrm{n}=2)$, personal tobacco use $(\mathrm{n}=1)$, occupational exposure $(\mathrm{n}=6)$, and time spent outdoors $(\mathrm{n}=15)$

${ }^{2}$ Wilcoxon Rank Sum $P$ value

${ }^{3}$ Fisher's exact $P$ value calculated due to low expected cell counts
} 
Table 66. Potential Covariates and Home's Location in Neighborhood by Frequency of Reported Skin Symptoms

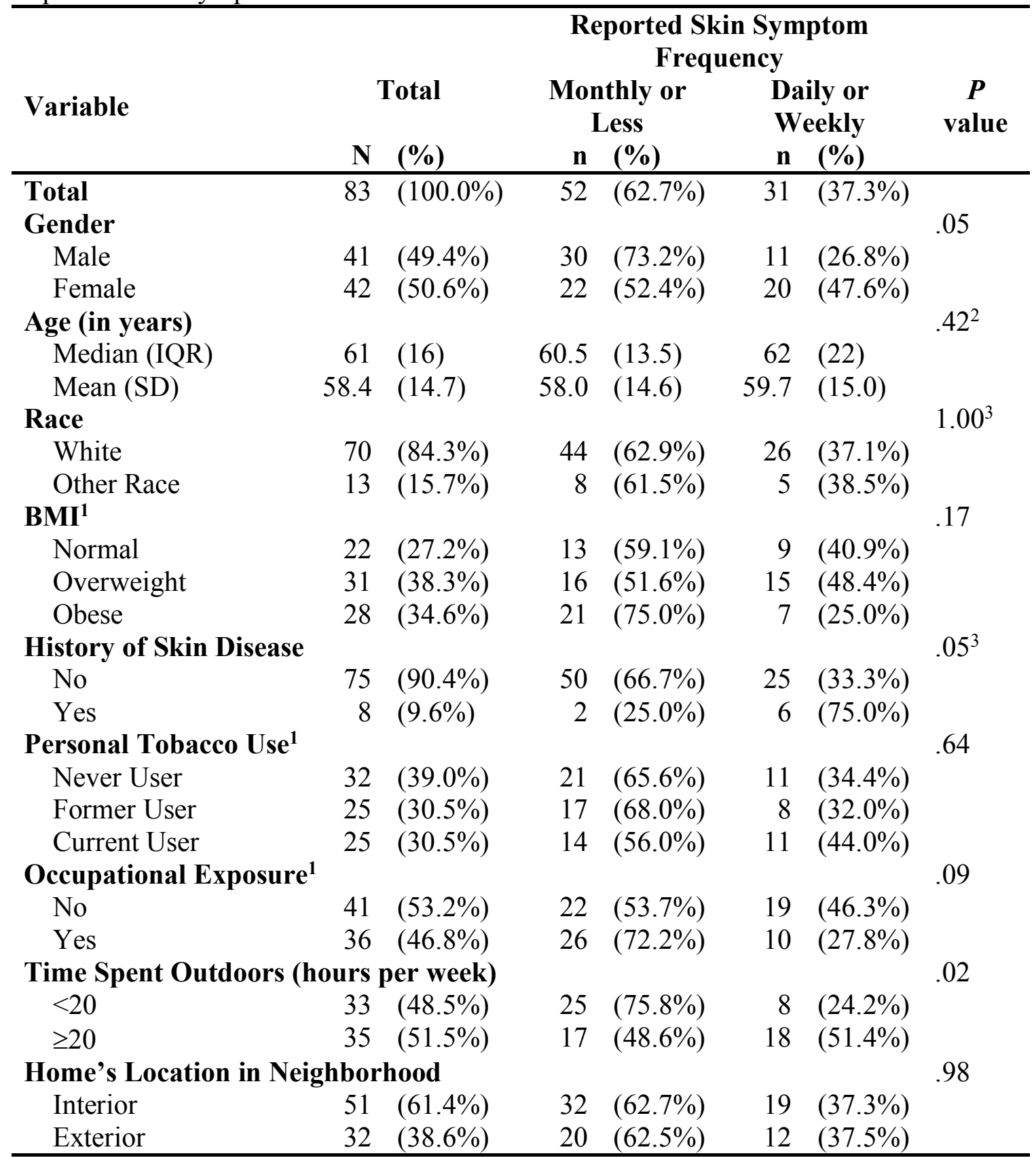

\footnotetext{
${ }^{1}$ Missing data for BMI $(n=2)$, personal tobacco use $(n=1)$, occupational exposure $(n=6)$, and time spent outdoors $(\mathrm{n}=15)$

${ }^{2}$ Wilcoxon Rank Sum $P$ value

${ }^{3}$ Fisher's exact $P$ value calculated due to low expected cell counts
} 
Table 67. Potential Covariates by Home's Location in Neighborhood

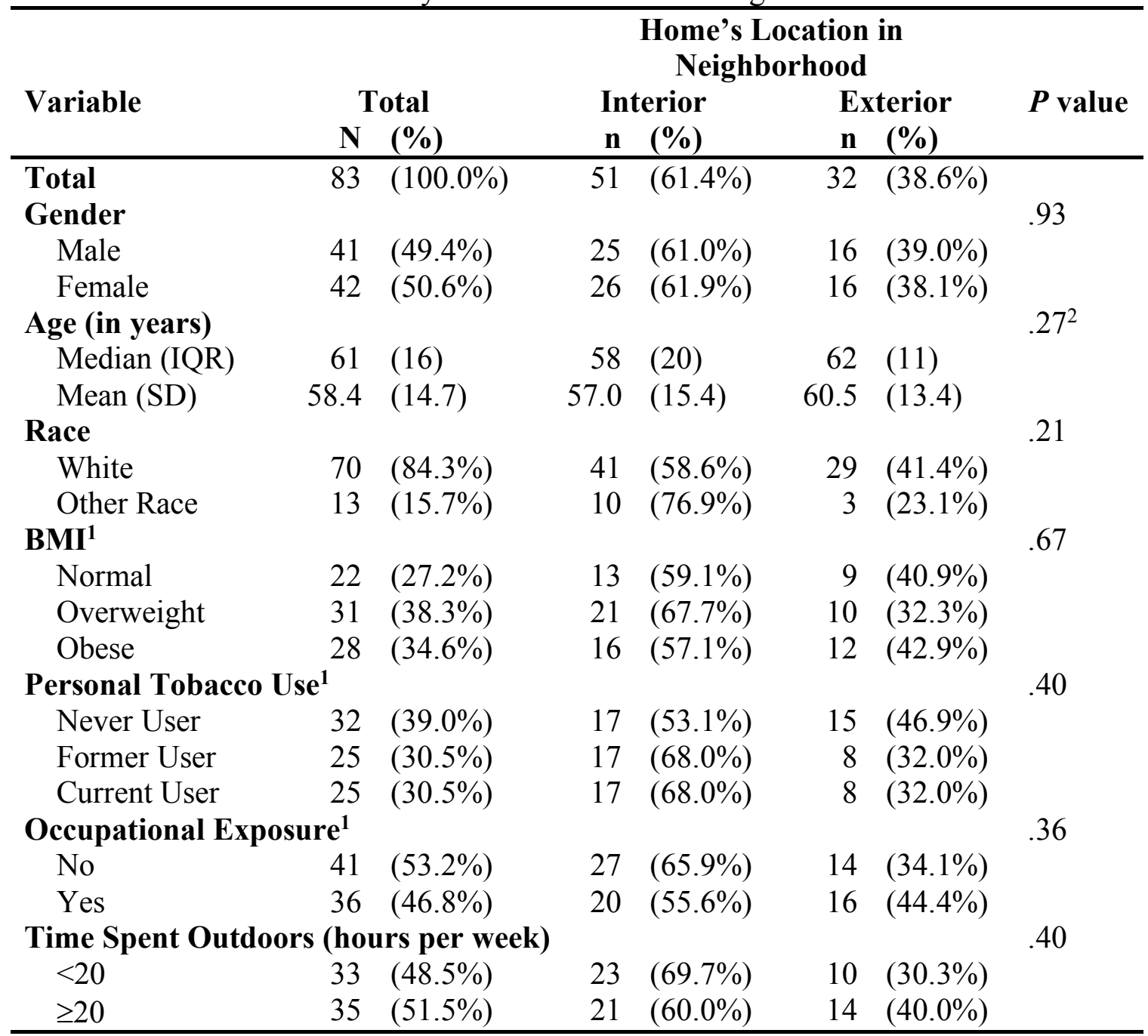

${ }^{1}$ Missing data for BMI $(n=2)$, personal tobacco use $(n=1)$, occupational exposure $(n=6)$, and time spent outdoors $(\mathrm{n}=15)$

${ }^{2}$ Wilcoxon Rank Sum $P$ value 


\author{
CURRICULUM VITAE \\ Lindsay Koloff Tompkins \\ lindsay.koloff@louisville.edu
}

\title{
EDUCATION
}

2019 Ph.D., Public Health Sciences, Concentration in Epidemiology

School of Public Health and Information Sciences, University of Louisville, Louisville, KY

Dissertation: Evaluation of the Health and Exposure Histories of a Community Surrounded by Industry and Industrial Waste: A Mixed Methods Approach

2016 M.S., Epidemiology

School of Public Health and Information Sciences, University of Louisville, Louisville, KY

Thesis: Memory and Fine Motor Skill Test Performance Among Children Living Near Coal Ash Storage Sites

2012 B.S., Psychology

University of North Carolina, Chapel Hill, NC

\section{AWARDS, FELLOWSHIPS, AND GRANTS}

2017 University Fellowship, University of Louisville

2017 David J. Sencer Scholarship, Epidemic Intelligence Service Alumni Association

2017 School of Public Health and Information Sciences Travel Scholarship, University of Louisville

2017 Graduate Student Council Graduate Research Fund, University of Louisville

2016 University Fellowship, University of Louisville 


\section{RESEARCH EXPERIENCE}

Nov 2017 - Present

Nov 2017 - Present

Aug 2016 - Present

\author{
Graduate Research Assistant \\ University of Louisville Superfund Research Center \\ (ULSRC) \\ Research Translation Core \\ University of Louisville, Louisville, KY \\ Description: Responsibilities include working with fellow \\ researchers as well as community members to translate \\ ULSRC-related research findings using novel methods.
}

\section{Graduate Research Assistant}

Green Heart Louisville Community Engagement Core University of Louisville, Louisville, KY

Description: Responsibilities include recruiting participants (co-leader for recruitment); developing questionnaire items; collecting qualitative data, quantitative data, and biological specimens; and analyzing data. Additional tasks include building ongoing relationships with members of the South Louisville [study area] community and developing methods to engage community members in the study.

\section{Co-Investigator}

Riverside Gardens Community Health Assessment University of Louisville, School of Public Health and Information Sciences, Department of Epidemiology and Population Health, Louisville, KY

Description: Responsibilities include securing grant funding for research; obtaining Institutional Review Board (IRB, Human Subjects) approval for the research study; creating all study materials; developing a comprehensive health and exposure history questionnaire; recruiting participants using shoe-leather methods; collecting, entering, and analyzing data; and translating research findings to community members. 
Mar 2016 - Present

Aug 2015 - Present

May 2015 - Aug 2015

Aug 2008 - May 2012
Graduate Research Assistant

American Heart Association Tobacco Regulation and Addiction Center (A-TRAC)

Project 3 - Perception of Tobacco Use in Vulnerable Populations

University of Louisville, Department of Communication, Louisville, KY

Description: Responsibilities include recruiting and consenting participants; collecting lift and air samples, survey information, and biological specimens; preparing samples for analysis; and entering, managing, and analyzing data for a large community-based cross-sectional environmental epidemiology study involving children and adults.

\section{Graduate Research Assistant}

Coal Ash and Neurobehavioral Symptoms in

Children Aged 6-14 Years Old

University of Louisville, School of Public Health and

Information Sciences, Department of Epidemiology and Population Health, Louisville, KY

Description: Responsibilities included questionnaire development for use in qualitative and quantitative research studies evaluating the perceptions and communication surrounding tobacco use. Additionally, I was responsible for data entry and the analysis of both quantitative and qualitative data concerning tobacco use perceptions and communication among Appalachian youth.

\section{Epidemiology Intern}

ExxonMobil Biomedical Sciences, Inc., Clinton, NJ

Description: Responsibilities included obtaining, entering, and managing data for a large-scale meta-analysis project; conducting literature reviews to aid in updating company occupational exposure limits; and assisting in the development of future research projects.

\section{Student Intern}

Cirrus Pharmaceuticals, Morrisville, NC Description: Responsibilities involved aiding senior scientists in the research and development of pharmaceutical products. Specific tasks included performing and documenting laboratory experiments while following test methods and company standard operating procedures, reviewing scientific data, overseeing lab 
cleanliness and safety, calibrating laboratory equipment, and maintaining meticulous records of sponsor samples.

\section{HEALTHCARE EXPERIENCE}

May 2012 - May 2015

Sept $2011-$ Dec 2011

Jan 2009 - May 2009

\section{SERVICE ACTIVITIES}

Jan 2019 - Present

Apr 2018

Apr 2018

\section{Emergency Room Technician}

Norton Children's Medical Center (formerly Kosair

Children's Medical Center), Louisville, KY

Description: Job duties included providing care to pediatric patients in an emergency room setting. Specific activities included collecting vital signs, drawing blood, applying splints, obtaining electrocardiographs, testing blood glucose, and assisting with laceration repairs.

\section{Group Therapy Volunteer}

Central Regional Hospital, Butner, NC

Description: Assisted with adult and geriatric group therapy sessions at North Carolina's largest psychiatric hospital.

\section{Student Aid}

University of North Carolina Hospitals, Anesthesiology Department, Chapel Hill, NC

Description: Job duties included assisting in the recruitment of anesthesiology residents, maintaining a budget for department events, creating PowerPoints and other materials for hospital functions, handling and organizing patient information, and performing secretarial duties as needed.

\section{Ad Hoc Reviewer}

Health Behavior Research

\section{Volunteer}

University of Louisville Community Knowledge Exchange:

VOC Facts

Description: Participated in a community conversation between University of Louisville health scientists and community stakeholders concerning the health impacts of volatile organic compounds (VOCs).

Volunteer

University of Louisville South Louisville Health Clinic 
Sept 2017

Nov 2016 - Present

Aug 2016

May 2015 - Mar 2016
Description: Volunteered at a free health clinic in South Louisville. Responsibilities included health clinic set-up, helping community members navigate the health clinic, and educating community members on the services offered by the University of Louisville as well as research studies for which they may be eligible.

\section{Volunteer}

Community Assessment for Public Health Emergency

Response (CASPER), Green River District Health

Department, Owensboro, Kentucky

Description: Participated in a three-day CASPER designed to assess the needs of the seven counties served by the Green River District Health Department. Responsibilities included applying appropriate sampling methods, maintaining records of selected homes, and collecting survey data.

\section{Certification}

Kentucky Public Health Assistance and Support Team (KPHAST)

Description: Completed a certification course provided by the Kentucky Department for Public Health and am now on a volunteer list to respond to public health emergencies and assist with special projects at local and state levels. The course included an overview of FEMA Incident Command System structure and basic applied epidemiologic methods.

\section{Volunteer}

University of Louisville's Kentucky Cancer Prevention (KCP) Program

Description: Helped to run the KCP booth and the Kentucky State Fair. The booth provides free cancer screenings and distributes educational information to fair attendees. Volunteers were responsible for registering patients, administering surveys, and distributing educational materials.

\section{Treasurer}

Kentucky Public Health Association, University of Louisville Chapter

Description: Responsible for budget management and collection of membership dues. Additional responsibilities included planning and organizing service events and professional development courses for members. 
May 2011 - Apr 2012

\title{
President
}

Operation Building Courage, University of North Carolina Description: Responsible for overseeing a large service club partnered with UNC Hospitals and the Family Violence Prevention Center of Orange County whose mission was to build courage in the hearts and minds of children in need. Example responsibilities included planning fundraising events, identifying children in need, planning volunteer opportunities, forming partnerships with local businesses, and budget management.

Sept 2009 - Apr 2011

\author{
Executive Board Member \\ Operation Building Courage, University of North Carolina \\ Description: Responsible for budget management and \\ forming partnerships with local businesses. Additionally, I \\ organized the process of making and delivering \\ personalized stuffed animals to the children we served. I \\ also led the expansion this service club to the Family \\ Violence Prevention Center of Orange County.
}

\section{RELATED PROFESSIONAL SKILLS}

Proficient in multiple statistical software programs, including SAS and SPSS Familiar with ArcGIS and its public health applications

Experience with REDCap, including building new projects and entering and managing data

Kentucky Public Health Assistance and Support Team (K-PHAST) certified Kentucky Board of Nursing Certified Nurse Aide (Apr 2012 - Apr 2018)

\section{PEER-REVIEWED PUBLISHED MANUSCRIPTS}

Ma JZ, Hart JL, Walker KL, Giachello AL, Groom A, Landry RL, Tompkins LK, Vu TT, Mattingly DT, Sears CG, Kesh A, Hall ME, Robertson RM, Payne TJ. Perceived health risks of electronic nicotine delivery systems (ENDS) users: The role of cigarette smoking status. Addictive Behaviors. 2018. DOI:

https://doi.org/10.1016/j.addbeh.2018.10.044.

Glover LM, Ma JZ, Kesh A, Tompkins LK, Hart JL, Mattingly DT, Walker K, Robertson RM, Payne T, Sims M. The social patterning of electronic nicotine delivery system use among US adults. Preventive Medicine. 2018;116:27-31. DOI: https://doi.org/10.1016/j.ypmed.2018.08.038.

Hart JL, Walker KL, Sears CG, Tompkins LK, Lee AS, Mattingly DT, Groom A, Landry R, Giachello AL, Payne TJ, Kesh A, Siu A, Smith C, Robertson RM. The 'state' 
of tobacco: Perceptions of tobacco among Appalachian youth in Kentucky. Tobacco Prevention and Cessation. 2018;4(January). DOI: https://doi.org/10.18332/tpc/81857.

Tompkins LK, Sears CG, Hart JL, Walker KL, Lee AS, Bhatnagar A. "If you are old enough to die for your country, you should be able to get a pinch of snuff": Views of Tobacco 21 among Appalachian youth. Journal of Applied Research on Children. 2017;8(2). Available at: http://digitalcommons.library.tmc.edu/childrenatrisk/vol8/iss2/2.

\section{PEER-REVIEWED PUBLISHED ABSTRACTS}

Mattingly DT, Tompkins LK, Sears CG, Walker KL, Hart JL. Youth tobacco users perceive less e-cig harm. Circulation. 2018;137:AP087.

Vu TT, Hart J, Walker K, Landry R, Groom A, Sears C, Tompkins L, Mattingly D, Kesh A, Giachello A, Payne TJ. Age differences in patterns of use, health knowledge, perception, and intention to quit among current e-cigarette users. Circulation. 2018;137:AP103.

Tompkins LK, Sears CG, Walker KL, Hart JL. Factors associated with e-cigarette use in Appalachian youth. Circulation. 2017;136:A17328.

\section{PEER-REVIEWED PRESENTATIONS}

Tompkins LK, Pfeiffer J, Wood L, Zachary A, Walker KL, Hart JL. Translating research for community members: Learning partnerships and change mechanisms. Oral presentation at: Southern States Communication Association $89^{\text {th }}$ Annual Meeting; April 3-7, 2019; Montgomery, AL, USA.

Tompkins LK, Sears CG, Lee AS, Smith C, Siu A, Pfeiffer J, Wood L, Zachary A, Walker KL, Hart JL. Engaging communities, engaging change: rural middle and high school youth and tobacco products. Oral presentation at: Southern States Communication Association $89^{\text {th }}$ Annual Meeting; April 3-7, 2019; Montgomery, AL, USA.

Walker KL, Tompkins LK, Hart JL. Environmental communication crossroads:

Connecting primary and secondary school students with tertiary students for instructional translation. Oral presentation at: Southern States Communication Association 89 ${ }^{\text {th }}$ Annual Meeting; April 3-7, 2019; Montgomery, AL, USA.

Hart JL, Tompkins LK, Pfeiffer J, Wood L, Zachary A, Carter S, Gilkey D, Mattingly D, Thornsbury A, Walker KL. Growing together: Community engagement and student involvement. Oral presentation at: Southern States Communication Association $89^{\text {th }}$ Annual Meeting; April 3-7, 2019; Montgomery, AL, USA. 
El-Shahawy O, Walker KL, Groom AM, Tompkins LK, Kesh A, Landry R, Pfeiffer J, Payne TJ, Giachello AL, Vu THT, Ma J, Robertson RM, Sherman SE, \& Hart JL. Association of experimentation with tobacco and nicotine-containing products and current tobacco use status among youth in the US: Findings from a national online survey (2017). Poster presented at: Society for Research on Nicotine and Tobacco Annual Meeting; February 20-23, 2019; San Francisco, CA, USA.

Ma JZ, Hart JL, Walker KL, Giachello AL, Groom A, Landry RL, Vu TT, Kesh A, Tompkins LK, Hall ME, Robertson RM, Payne TJ. Perceived health knowledge and risks for cardiovascular disease of tobacco and electronic nicotine delivery systems in an adult national survey. Poster presented at: Society for Research on Nicotine and Tobacco Annual Meeting; February 20-23, 2019; San Francisco, CA, USA.

Tompkins LK, ${ }^{1}$ Walker KL, Hart JL, Bhatnagar A. The Heart of the Matter: Research translation with youth in Louisville. Poster presented at: Superfund Research Program Annual Meeting; November 28-30, 2018; Sacramento, CA, USA.

Hart JL, Heberle L, Walker KL, Tompkins LK, ${ }^{1}$ Wheeler J, Pfeiffer J, Wood L, Gilkey D, Zachary A, Bhatnagar A. UofL Superfund Research Center: Engaging and communicating across disciplinary, professional, and institutional boundaries. Poster presented at: Superfund Research Program Annual Meeting; November 28-30, 2018; Sacramento, CA, USA.

Hart JL, Walker KL, Tompkins LK, Zachary A, Wood L, Mattingly DT, Pfeiffer J. Environmental health: Engaging a community in research, partnership, and practice. Oral presentation at: Kentucky Communication Association Annual Conference; September 14-15, 2018; Prestonsburg, KY, USA.

Mattingly DT, Tompkins LK, Rai J, Sears CG, Walker KL, Hart JL. Tobacco use and communication channel preferences among Appalachian youth. Poster presented at: Society for Epidemiologic Research Annual Meeting; June 19-22, 2018; Baltimore, MD, USA.

Groom A, Vu TH, Landry R, Kesh A, Hart J, Walker K, Sears C, Tompkins L, Mattingly D, Robertson RM, Payne T. Correlates of youth vaping flavor preferences. Poster presented at: NIH Tobacco Regulatory Science Conference; June 18-20, 2018; Bethesda, MD, USA.

Mattingly DT, Tompkins LK, Sears CG, Walker KL, Hart JL. Youth tobacco users perceive less e-cig harm. Poster presented at: American Heart Association EPI Lifestyle Scientific Sessions; March 20-23, 2018; New Orleans, LA, USA. 
Vu TT, Hart J, Walker K, Landry R, Groom A, Sears C, Tompkins L, Mattingly D, Kesh A, Giachello A, Payne TJ. Age differences in patterns of use, health knowledge, perception, and intention to quit among current e-cigarette users. Poster presented at: American Heart Association EPI Lifestyle Scientific Sessions; March 20-23, 2018; New Orleans, LA, USA.

Tompkins LK, ${ }^{1}$ Odoh CN, Zierold KM. The health and exposure histories of one community battling environmental discrimination. Poster presented at: American Academy of Health Behavior Annual Meeting; March 4-7, 2018; Portland, OR, USA.

Tompkins LK, ${ }^{1}$ Sears CG, Walker KL, Mattingly DT, Hart JL. Knowledge of tobaccorelated cardiovascular disease risks: A study of Appalachian youth. Poster presented at: American Academy of Health Behavior Annual Meeting; March 4-7, 2018; Portland, OR, USA.

Hart JL, Walker KL, Sears CG, Tompkins LK, Mattingly DT, Groom A, Landry R, Giachello AL, Payne TJ, Lee AS, Kesh A, Siu A, Smith C, Robertson RM. The "state" of tobacco: Perceptions of tobacco among Appalachian youth in Kentucky. Oral presentation at: Society for Research on Nicotine \& Tobacco Annual Meeting; February 21-24, 2018; Baltimore, MD, USA.

Heberle L, Tompkins LK, ${ }^{1}$ Walker KL, Hart JL. Capacity building for transdisciplinary collaboration. Poster presented at: Superfund Research Program Annual Meeting; December 6-8, 2017; Philadelphia, PA, USA.

Tompkins LK, ${ }^{1}$ Sears CG, Walker KL, Hart JL. Comparison of factors associated with cigarette use and e-cigarette use in a sample of Appalachian youth. Poster presented at: American Heart Association Scientific Sessions; November 11-15, 2017; Anaheim, CA, USA.

Mattingly DT, Tompkins LK, Sears CG, Walker KL, Hart JL. Tobacco use and harm perceptions among Appalachian youth. Poster presented at: NIH Tobacco Regulatory Science Conference; October 23-24, 2017; Bethesda, MD, USA.

Ma JZ, Hart J, Walker K, Giachello A, Groom A, Landry R, Tompkins L, Vu TH, Mattingly D, Sears C, Kesh A, Robertson RM, Payne T. Characterization of current adult ENDS users by cigarette smoking status. Poster presented at: NIH Tobacco Regulatory Science Conference; October 23-24, 2017; Bethesda, MD, USA.

Tompkins LK, ${ }^{1}$ Sears CG, Hart JL, Walker KL, Lee AS, Bhatnagar A. "If you are old enough to die for your country, you should be able to get a pinch of snuff": Views of Tobacco 21 among Appalachian youth. Poster presented at: Vermont Center on Behavior and Health Annual Conference; October 5-6, 2017; Burlington, VT, USA. 
Mattingly DT, Tompkins LK, Sears CG, Walker KL, Hart JL. Tobacco communication, tobacco culture: Celebrating successes and examining shortcomings. Oral presentation at: Kentucky Communication Association Annual Conference; September 15-16, 2017; Carrollton, KY, USA.

Sears L, Tompkins L, Hanchette C, Polivka B, Zierold K. Effects of manganese body burden on fine motor skills in children aged 6-14 years. Oral presentation at: Developmental Neurotoxicology Society Annual Meeting; June 24-28, 2017; Denver, CO, USA.

Tompkins LK, ${ }^{1}$ Sears LL, Hanchette CL, Polivka BJ, Brock GN, Zierold KM. Levels of metals in nails of children living near coal burning plants. Poster presented at: Children's Environmental Health Network Translational Research Conference; April 5-7, 2017; Arlington, VA, USA.

Tompkins LK, ${ }^{1}$ Sears LL, Lorenz DJ, Hanchette CL, Polivka BJ, Brock GN, Zierold KM. Fly ash presence in homes and children's memory and fine motor skill test performance. Poster presented at: American Academy of Health Behavior Annual Scientific Meeting; March 19-22, 2017; Tucson, AZ, USA.

Sears CG, Groom A, Morgan M, Miller C, Robertson RM, Payne TJ, Giachello AL, Hart JL, Walker KL, Tompkins LK, Lee AS, Landry R. Youth tobacco use in vulnerable populations: Family influences. Poster presented at: Society for Research on Nicotine and Tobacco Annual Meeting; March 8-11, 2017; Florence, Italy.

Sears CG, Hart JL, Walker KL, Lee AS, Tompkins LK, Smith C, Siu A, Keith R, Ridner SL. Vape shop employees: Assisting customers, encouraging cessation, promoting community, and supporting regulations. Poster presented at: Society for Research on Nicotine and Tobacco Annual Meeting; March 8-11, 2017; Florence, Italy.

Sears CG, Lee AS, Walker KL, Hart JL, Giachello AL, Payne TJ, Tompkins LK, Groom A, Smith C, Siu A, Landry R, Seals S, Kesh A, Robertson RM. "You can't go anywhere without seeing someone light up a cigarette": Influences on Appalachian youth tobacco views and use. Poster presented at: Society for Research on Nicotine and Tobacco Annual Meeting; March 8-11, 2017; Florence, Italy.

Sears CG, Walker KL, Hart JL, Lee AS, Smith C, Tompkins L, ${ }^{1}$ Siu A, Bhatnagar A, Robertson RM. Perceptions and use of electronic cigarettes among middle and high school students in Appalachia. Oral presentation at: American Heart Association Scientific Sessions; November 13-16, 2016; New Orleans, LA, USA.

Sears CG, Hart JL, Walker KL, Lee AS, Tompkins L, Groom A, Giachello AL, Payne TJ, Kesh A, Robertson RM. "You got a dip in your mouth, you ain't gonna get no sugar." Poster presented at: NIH Tobacco Regulatory Science Conference; November 7-8, 2016; Bethesda, MD, USA. 
Lee AS, Sears CG, Hart JL, Walker KL, Giachello AL, Payne TJ, Groom A, Tompkins L, Smith C, Siu A, Kesh A, Robertson RM. Assessing "the state" of tobacco: Views and experiences of Kentucky youth. Oral presentation at: Kentucky Communication Association Annual Conference; September 16-17, 2016; Bowling Green, KY, USA.

Sears CG, Lee AS, Walker KL, Hart JL, Tompkins L, Smith C, Siu A. To vape or not to vape?: That is the burning question. Oral presentation at: Kentucky Communication Association Annual Conference; September 16-17, 2016; Bowling Green, KY, USA.

Hart JL, Walker KL, Sears CG, Lee AL, Tompkins LK, Smith C, Siu A, Keith R, Ridner, SL. Vape shop employees: Public health advocates? Oral presentation at: NIH Tobacco Regulatory Science Conference; May 16-18, 2016; Bethesda, MD, USA.

${ }^{1}$ Presenter

\section{INVITED TALKS}

Hart JL, Walker KL, Tompkins LK. The "state" of tobacco: Perceptions of tobacco among Appalachian youth in Kentucky. Webinar presented to Kentucky Tobacco Coordinators. May 1, 2018. 